
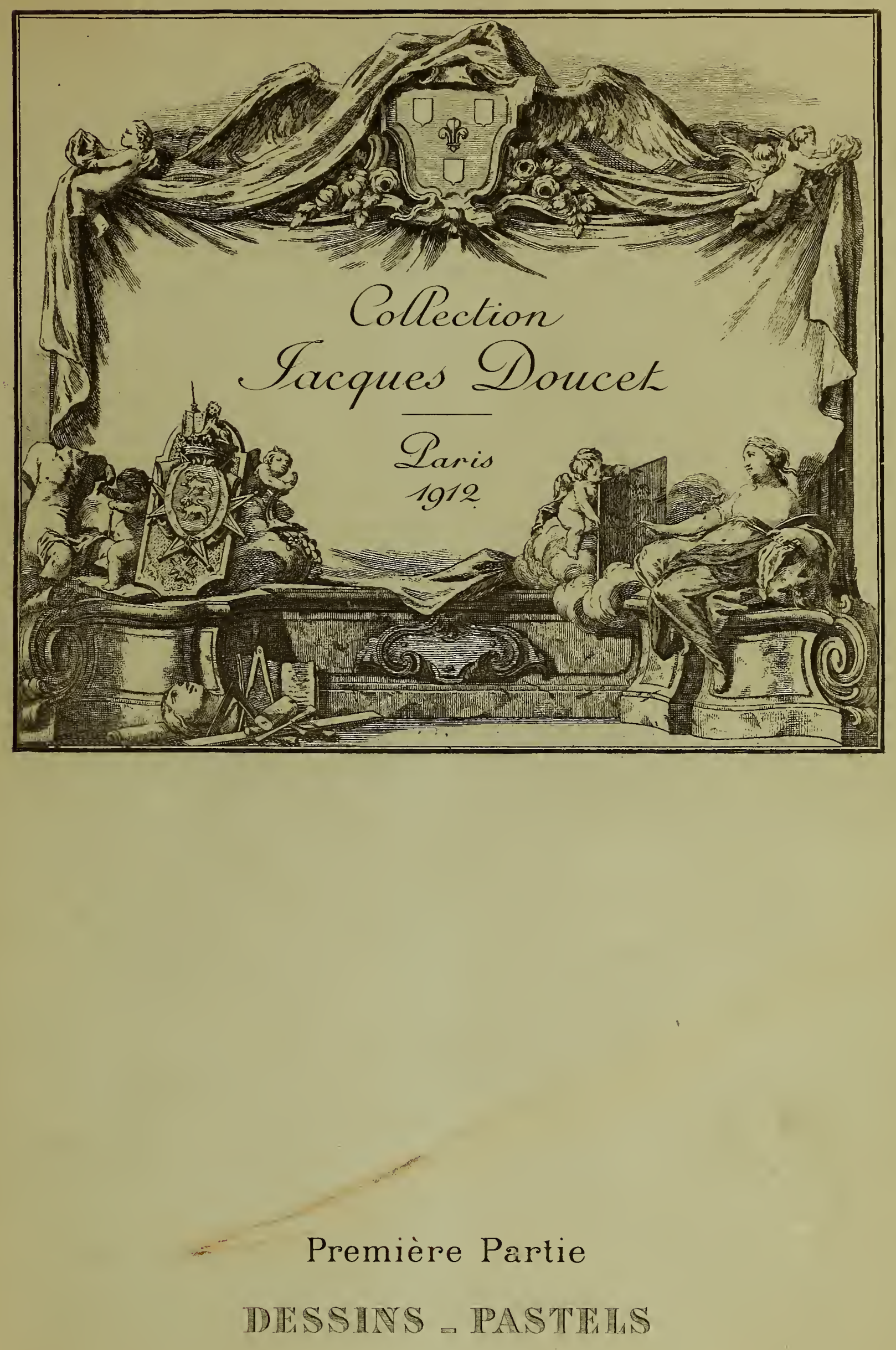







\title{
COLLECTION \\ JACQUES DOUCET
}

\author{
DESSINS, PASTELS \\ SCULPTURES, TABLEAUX \\ MEUBLES ET OBJETS D'ART \\ DU XVIIIE SIÈCLE
}





\section{Collection Jacques Doucet}

ptie 1

CHM

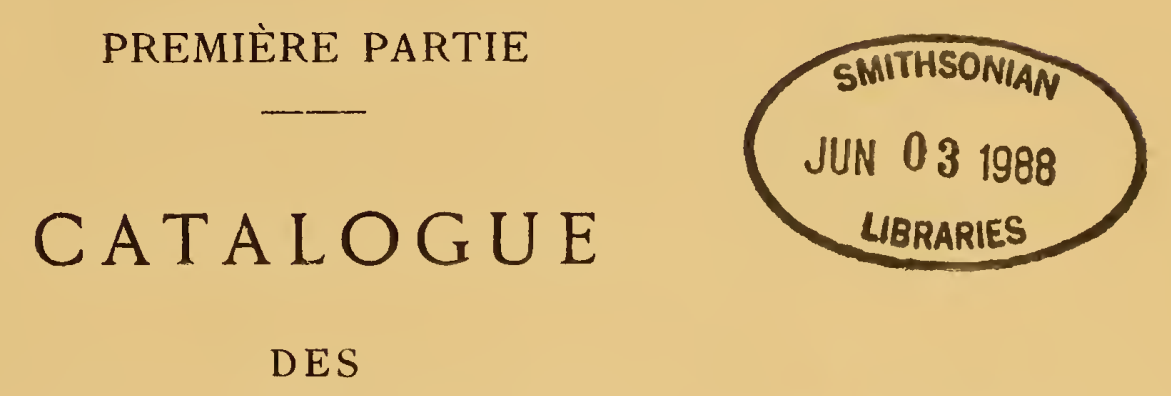

DESSINS \& PASTELS

DU XVIIIE SIÈCLE

dont la a vente aura lieu a paris
GALERIE GEORGES PETIT

8, RUE DE SĖZE, 8

Le Mercredi 5 Juin 1912, à 2 heures

COMMISSAIRES - PRISEURS

Me F. LAIR-DUBREUIL 6 , rue Favart, 6 Me HENRI BAUDOIN Io, rue Grange-Batelière, 10

\section{EXPERTS}

MM. PAULME \& B. LASQUIN FILS

10, rue Chauchat rue Grange-Batelière, II

M. JULES FÉRAL

7 , rue Saint-Georges, 7

M M. MAN NHEIM

7 , rue Saint-Georges, 7

$$
\text { PARIS - I } 9 \text { I } 2
$$





\section{EXPOSITIONS \\ GALERIE GEORGES PETIT, 8, RUE DE SĖZE}

Particulière : Le Lundi 3 Juin IgI2, de 2 heures à 6 heures.

Publique : Le Mardi 4 Juin 1912 , de 2 heures à 6 heures.

\section{ORDRE DES VACATIONS}

Le Mercredi 5 Juin 1912, à 2 heures.

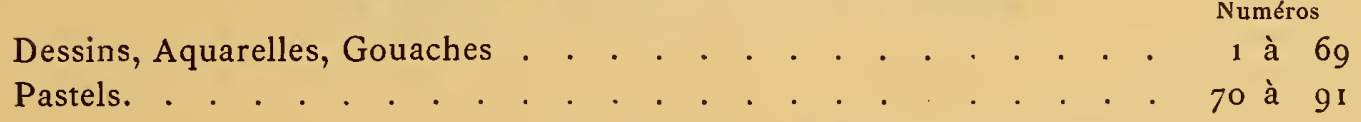

\section{Le Jeudi 6 Juin 1912, à 2 heures.}

Sculptures . . . . . . . . . . . . . . . . . . . . . . 92 à $13 \mathrm{r}$

Tableaux. . . . . . . . . . . . . . . . . . . . . . . 132 à 195

NOTA. - Pour les deux premières vacations, l'ordre numérique ne sera pas suivi.

Le Vendredi 7 Juin 1912, à 2 heures.

Socles. . . . . . . . . . . . . . . . . . . . 348 à 357

Objets variés . . . . . . . . . . . . . . . . . . . . . 225 à 245

Porcelaines de Chine et de Chantilly . . . . . . . . . . . . 196 à 207

Porcelaines, Matières dures et autres montées en bronze . . . . . . 208 à 224

Sièges divers . . . . . . . . . . . . . . . . . . . 273 à 298

\section{Le Samedi 8 Juin 1912, à 2 heures.}

Orfèvrerie et Instruments de mathématiques . . . . . . . . . . 246 à 256 Bronzes d'art et d'ameublement . . . . . . . . . . . . . 257 à 272

Meubles, Paravent en laque de Coromandel. . . . . . . . . . . 304 à 3.39

Sièges et Ameublements couverts en tapisserie . . . . . . . . . . 299 à 303

Tapis et Meubles en tissu de Savonnerie . . . . . . . . . . . . 340 à 344

Tapisseries de Beauvais et Tapis d'Orient. . . . . . . . . . . . 345 à 347

\section{CONDITIONS DE LA VENTE}

La vente sera faite au comptant.

Les acquéreurs paieront dix pour cent en sus des prix d'adjudication. 



\section{Collection Jacques Doucet}

PREMIĖRE PARTIE

\section{CATALOGUE}

DES

\section{DESSINS \& PASTELS \\ DU XVIII ${ }^{\mathrm{E}}$ SIÈCLE}

\section{NOTICES}

\begin{tabular}{|c|c|}
\hline & \\
\hline $\begin{array}{c}\text { É MILE DACIER } \\
\text { Bibliothécaire à la Bibliothèque Nationale } \\
\text { (DEss IN S) }\end{array}$ & $\begin{array}{c}\text { MARCEL NICOLLE } \\
\text { Attaché honoraire des Musées Nationaux } \\
\text { (PASTELS) }\end{array}$ \\
\hline
\end{tabular}
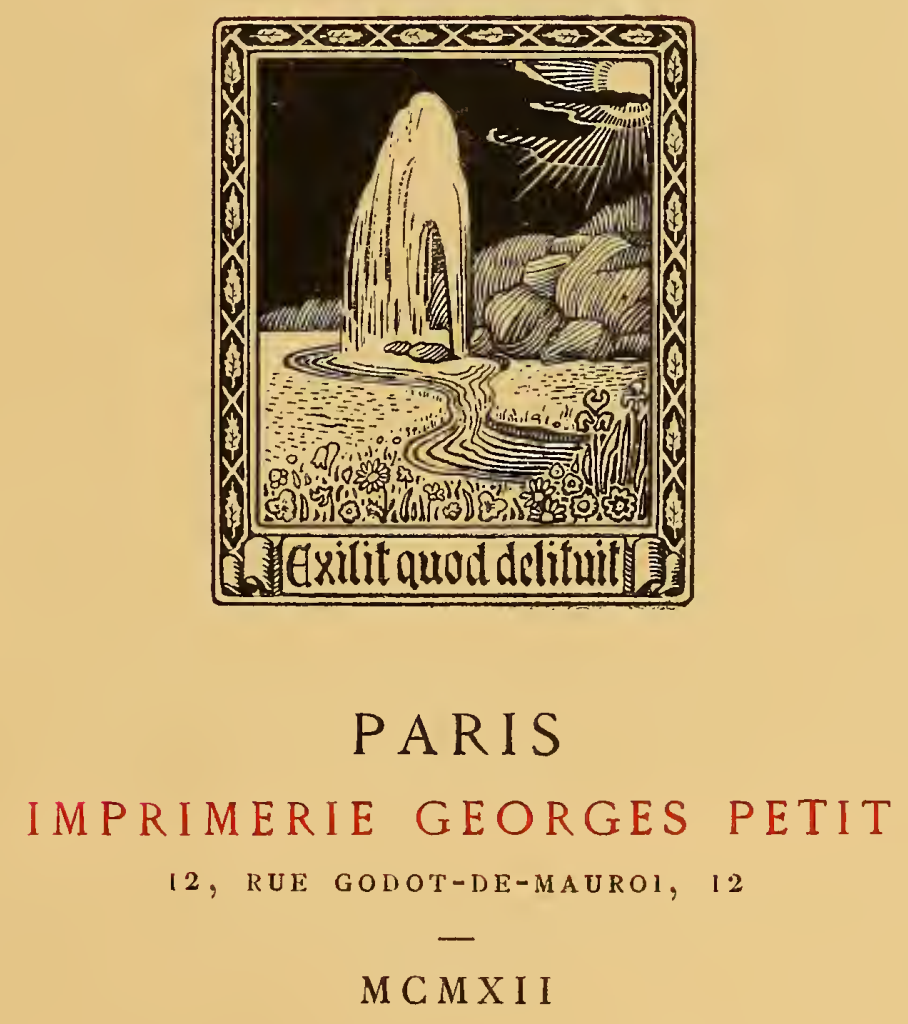




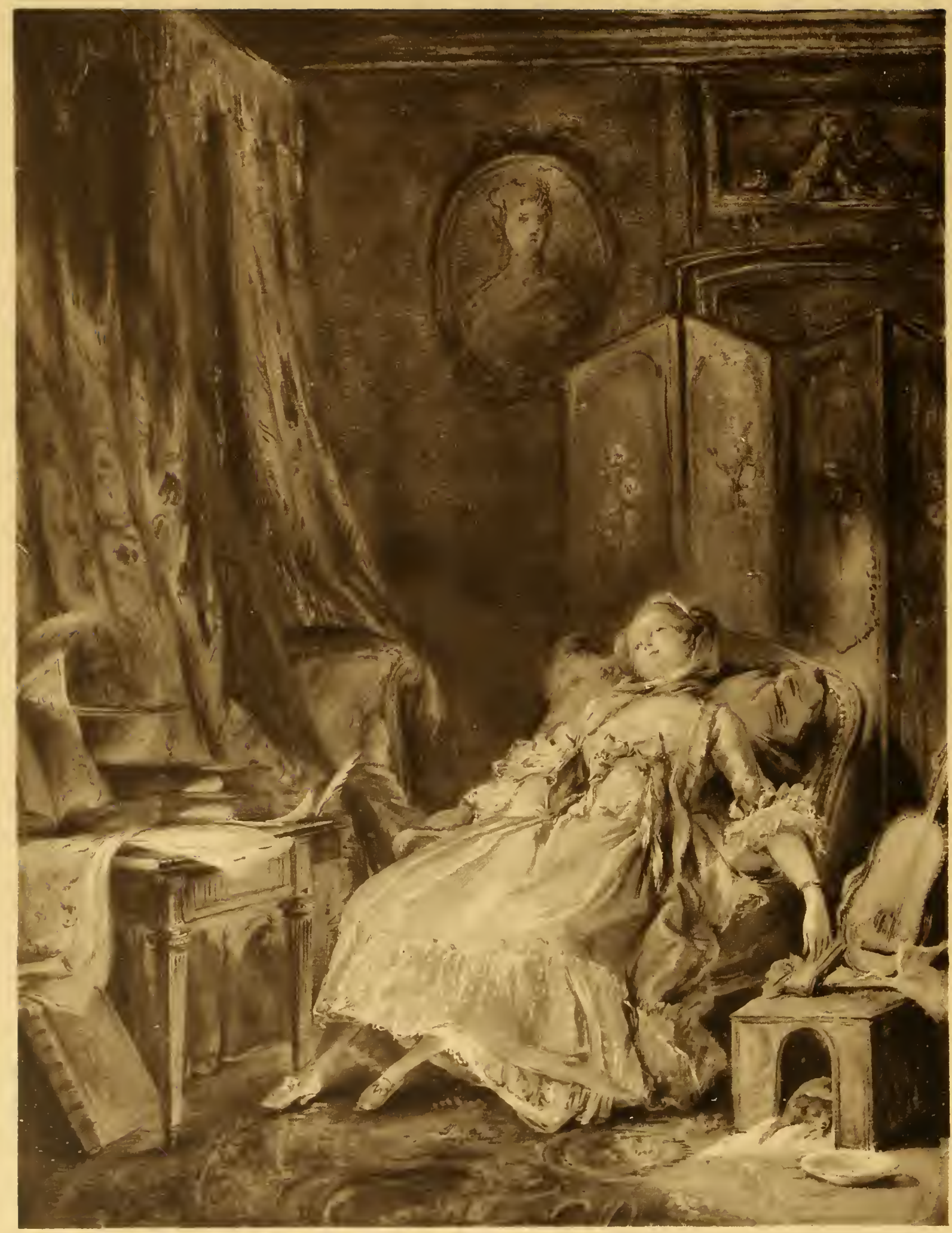




\title{
Botal peneral: 13.894 .360 manch \\ Dessins, Aquarelles, Gouaches
}

\author{
BAUDOUIN \\ (PIERRE-ANTOINE) \\ Paris, $1723+$ Paris, 1769 .
}
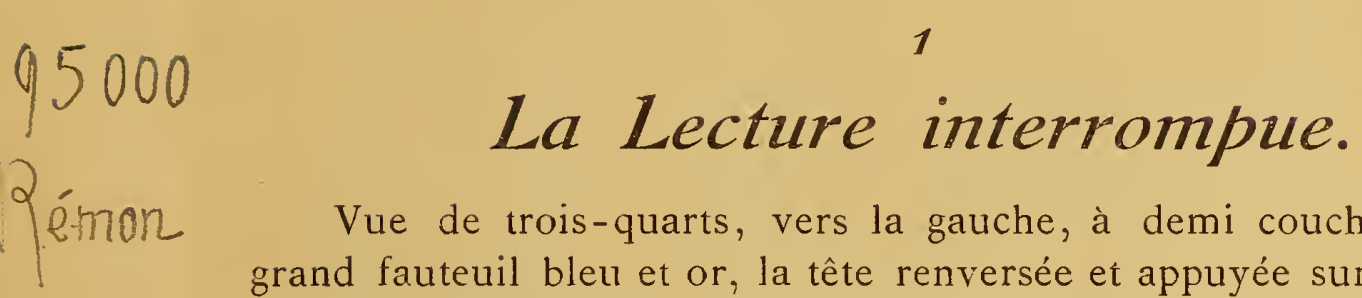

Vue de trois-quarts, vers la gauche, à demi couchée dans un grand fauteuil bleu et or, la tête renversée et appuyée sur un coussin bleu, une jeune femme, dont le déshabillé bleu pâle, orné de rubans et de mousseline, est largement ouvert sur la poitrine, rêve, les yeux au ciel. Le livre qu'elle tenait s'échappe de sa main gauche, étendue dé côté, et tombe sur une petite niche à chien où s'appuie une guitare. A gauche, on voit un lit de repos drapé de rideaux bleus à crépines et glands d'or, derrière une table-bureau chargée de papiers, de cartes, d'une mappemonde et de plusieurs livres, dont l'un, ouvert, est intitulé : Histoire des voyages. Au mur du fond, qu'on aperçoit au delà d'un paravent à fleurs, un portrait est accroché dans une bordure ovale et, plus à droite, un trumeau à sujet de singerie surmonte la porte.

Gouache.

$$
\text { Haut., } 295 \text { millim.; larg., } 225 \text { millim. (1). }
$$

Au dos de la peinture, sur le carton de l'encadrement, on lit en haut, à gauche, d'une écriture ancienne: Bauduin (sic).

Repr. dans Maurice Tourneux, la Collection Jacques Doucet: Pastels et Dessins (les Arts, $\mathrm{n}^{\circ} 36$, décembre r 904, p. 28), sous le titre : Jeune Femme endormie.

Le même sujet a été traité par Baudouin dans une autre gouache: le Midi, gravée par E. de Ghendt (Bocher, les Gravures françaises du XVIII e siècle; Paris, 1875 ; t. II, P.-A.Baudouin, $\mathrm{n}^{0} 33$ ), à cette différence près, entre autres, que le lieu de la scène est un jardin. N. Lavreince a également traité le même sujet dans le Roman dangereux, gravé par Helman. Enfin, on notera, dans l'arrangement, divers détails rappelant la Philosophie endormie, de Greuze, exposée au Salon de 765 et gravée par Moreau le Jeune et Aliamet.

Cadre ancien, époque Louis XV, bois sculpté et doré.

(I) Les dessins n’ayant pas été décadrés, les mesures injiquées ont été prises sur le cadre. 


\title{
BAUDOUIN
}

\author{
(PIERRE-ANTOINE)
}

2

\section{Le Jardinier galant.}

Assise à droite sur une pierre, dans un jardin, une jeune fille vêtue d'un corsage gris et d'un jupon jaune, détourne vers la droite sa tête couverte d'une coiffe blanche, et fait un geste de la main, comme pour se défendre des attaques d'un galant jardinier, en veste rougeâtre, chausses jaunes et bas bleus, agenouillé à sa gauche, de profil, et qui la lutine. A terre, au premier plan, le chapeau de paille du jardinier; à gauche, un peu en retrait, un arrosoir; au fond, derrière des arbustes, une habitation.

Gouache.

Haut., 185 millim.; larg., 140 millim.

Repr. en fac-similé par la Société de reproduction des dessins de maitres (3e année, I911), avec une notice par E. Dacier.

C'est une première pensée pour le Jardinier galant, la célèbre gouache exécutée par Baudouin en 1768 , exposée par lui au Salon de 1769 et gravée par Helman en 1778 (cf. Bocher, les Grav. franç. du XVIII s.; Baudouin, n²5).

Cadre ancien, époque Louis XV, bois sculpté et doré. 


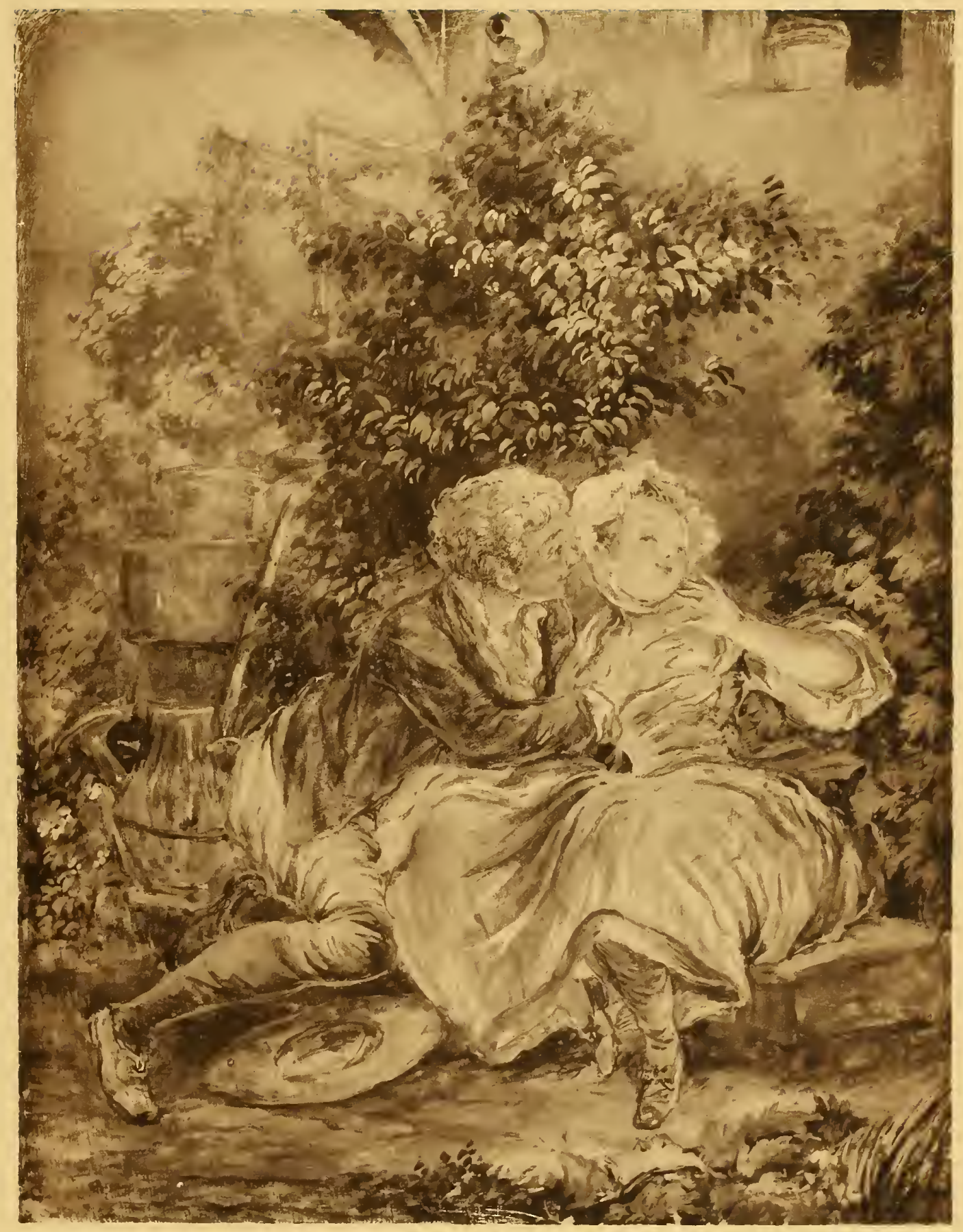






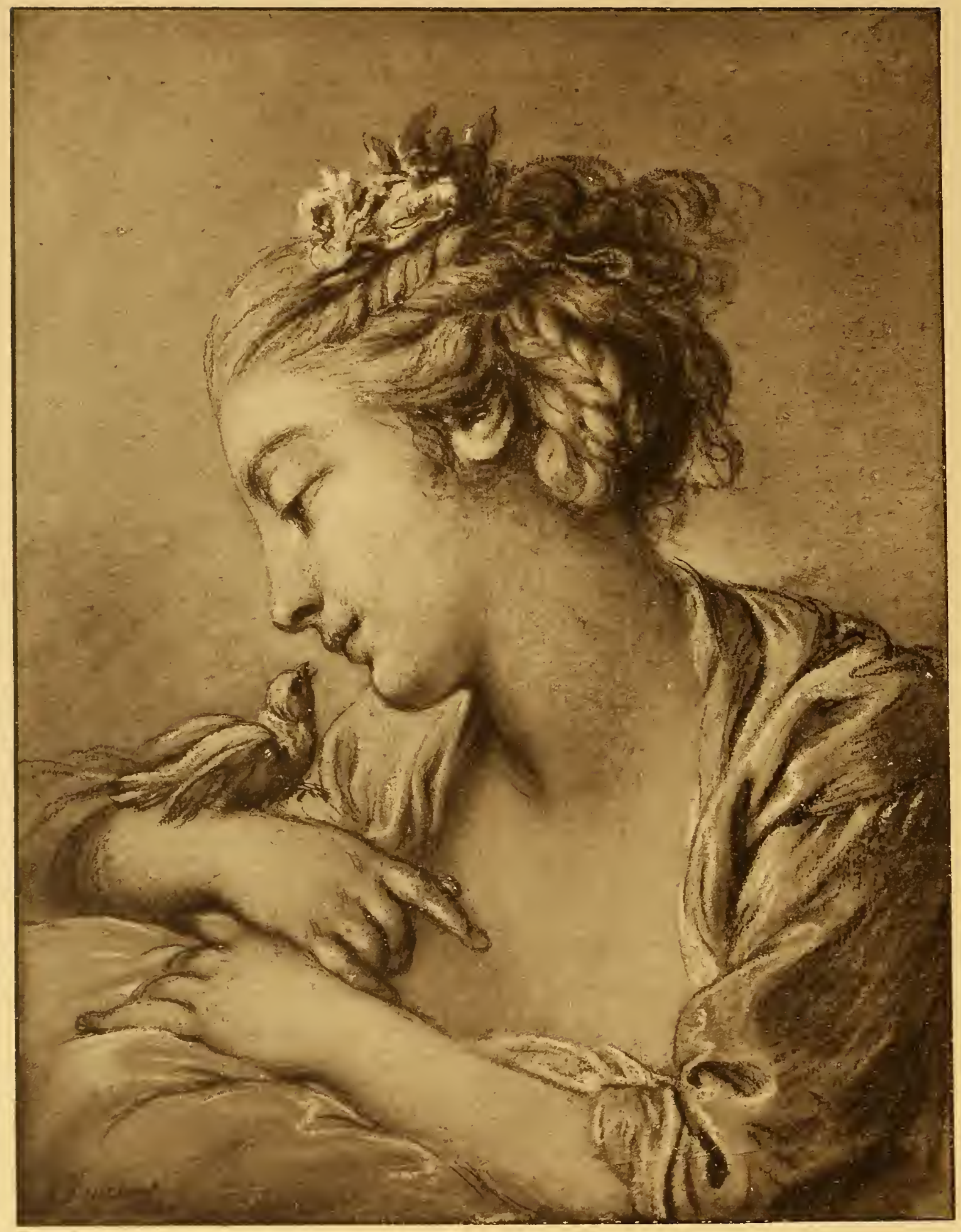




\title{
BOUCHER
}

\author{
(FRANÇOIS)
}

Paris, $1703+$ Paris, 1770 .

\section{3}

\section{La Jeune Fille à la colombe.}

En buste, le visage de profil et le corps de trois-quarts à gauche, la jeune fille a les cheveux tressés et relevés, ornés d'un ruban bleu et d'un bouquet de roses roses, le cou et la gorge nus, les épaules recouvertes d'une draperie bleue. Sur un coussin, à gauche, ses bras nus sont à demi-croisés et ses mains appuyées l'une contre l'autre. Elle incline légèrement la tête, le regard baissé vers l'oiseau qui s'est posé sur son bras droit.

Signé dans l'angle inférieur gauche : $F$. Boucher, ${ }_{7} 768$.

Pierre noire rehaussée de pastel, sur papier gris.

$$
\text { Haut., } 3 \text { I I millim.; larg., } 239 \text { millim. }
$$

Repr. dans M. Tourneux, la Colt. J. Doucet: Pastels et Dessins (les Arts, op. cit., p. 26); - et dans P. de Nolhac, François Boucher (Paris, 1907), pl., p. 168.

Sujet fréquemment traité par l'artisce et dont il existe plusieurs variantes gravées, d'ailleurs très différentes du présent dessin : la Fille à l'oiseau, par Huquier; l'Oiseau chéri, par Daullé; l'Oiseau privé, par Flipart.

Cadre ancien, époque Louis XV, bois sculpté et doré, fronton coquille. 


\title{
BOUCHER
}

\author{
(FRANÇOIS)
}

\section{4 \\ L'Amour porté par les Grâces.}

Les trois Grâces, nues, sont debout et forment un groupe ingénieusement balancé. La première, au centre et un peu en avant d'une de ses compagnes, - que l'on voit à droite, le corps de face et légèrement incliné, - a le visage de profil et le corps presque de face; une couronne passée dans son bras gauche ramené sur la poitrine, elle tient, de la main droite, la main de sa troisième compagne, vue de dos, à gauche, au second plan, et renverse la tête tournée vers la gauche. Soutenu sur les épaules des trois jeunes femmes, l'Amour brandit d'une main une flèche et de l'autre une torche. A terre, une guirlande.

Signé dans l'angle inférieur gauche, au crayon: $F$. Boucher, 1768 .

Pierre noire, légèrement relevée de craie et de sanguine, sur papier gris.

Haut., 295 millim.; larg., 193 millim.

On lit, à l'encre, au dos de l'encadrement, sur un papier ancien : "Vente Norblin, 1855 ; vendu $260 \mathrm{fr}$. à Blaizot, payé à lui 325. Voir le Trésor de la curiosité, tome deuxième, page 509 \%. - On trouve en effet au no 4I de la vente Norblin de La Gourdaine (février I 855): "Les Trois Grâces et l'Amour, charmante composition aux crayons noir et blanc, sur papier de couleur ". - La fin de la note n'est qu'un renvoi à un compte rendu de la vente Norblin, paru dans le Trésor de la curiosité, de Charles Blanc (t. II, Paris, 1858).

Collection Alfred Le Ghait (vente anonyme, Paris, 28 février 1877, n$^{\circ}$ เ 8 )

Repr. dans : l'Art, 1877, t. I, p. 2 1 3 ; - dans André Michel, François Boucher(Paris, I 886) p. 1 I 5 ; -et dans P. Mantz, Boucher, Lemoyne, Natoire (Paris, 188o), p. 1 10.

Ce dessin est sans doute la première pensée d'un tableau non exécuté, connu par la miniature de Charlier, qui se trouvait autrefois dans le cabinet du prince de Conti. L'esquisse peinte de ce tableau a passé en vente le 27 décembre 7777 (les Trois Grâces supportant l'Amour tenant deux flambeaux), et est entrée au Louvre avec la collection La Caze (toile ovale; h. 0,80 sur $1.0 .65 ; n^{\circ}$ r 62 du catal. de la coll. La Caze et no 47 du catal. sommaire; cf. Goncourt, l'Art du XVIIIe siècle, éd. in-r $8, \mathrm{I}^{\mathrm{re}}$ série, p. $\left.2 \$ \mathrm{r}\right)$. Cette esquisse, qui diffère un peu du présent dessin, a été gravée par J.-B. Simonet. - Une autre variante, celle-ci très différente, puisqu'elle ne comprend que deux des Grâces, a été gravée par Daullé, d'après le dessin original de Boucher, sous le titre: l'Amour porté par les Grâces (17j8).

C. P. Mantz, Boucher, etc., op. cit., p. I1 12.

Cadre ancien, époque Louis XV, bois sculpté et doré, fronton coquille. 


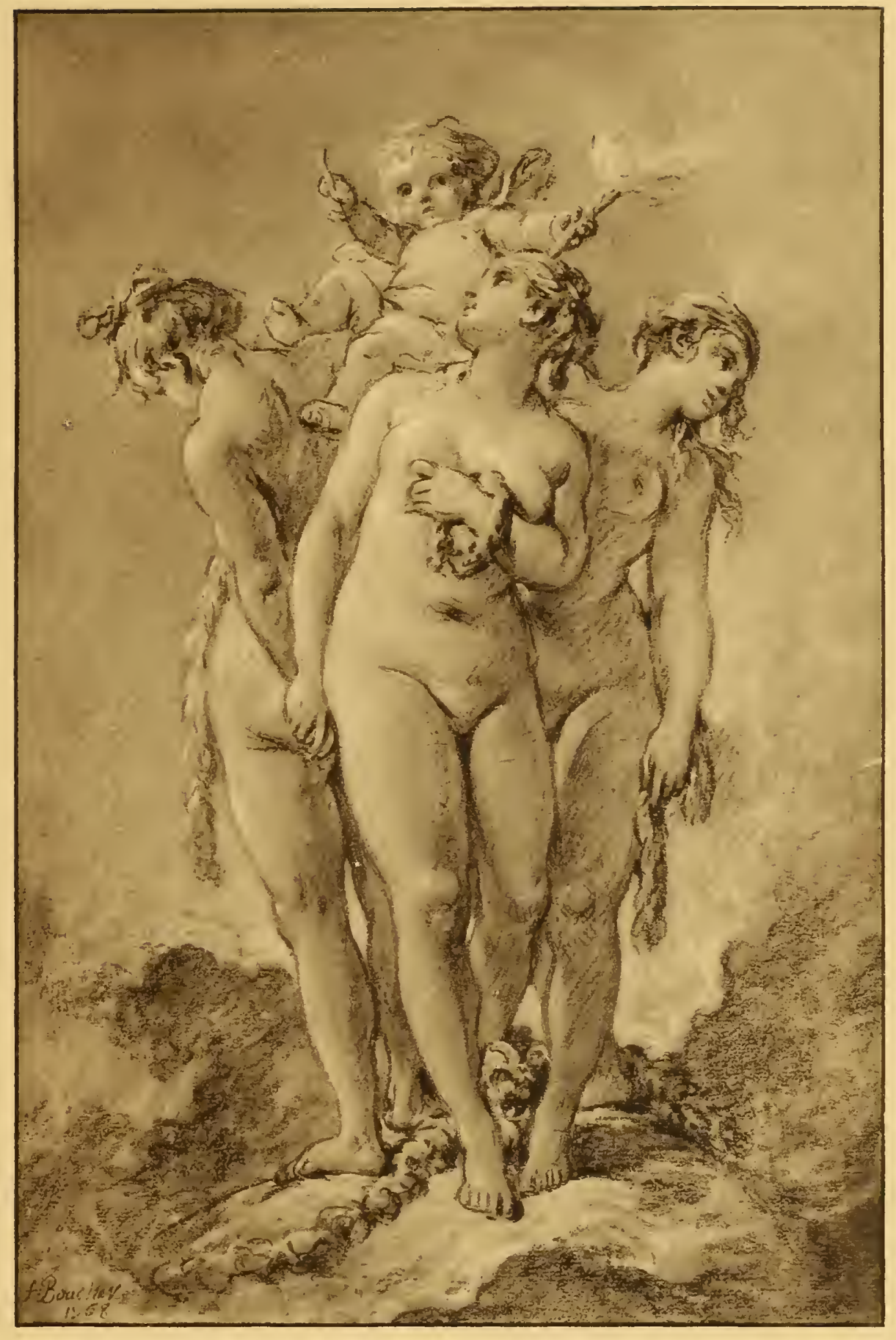






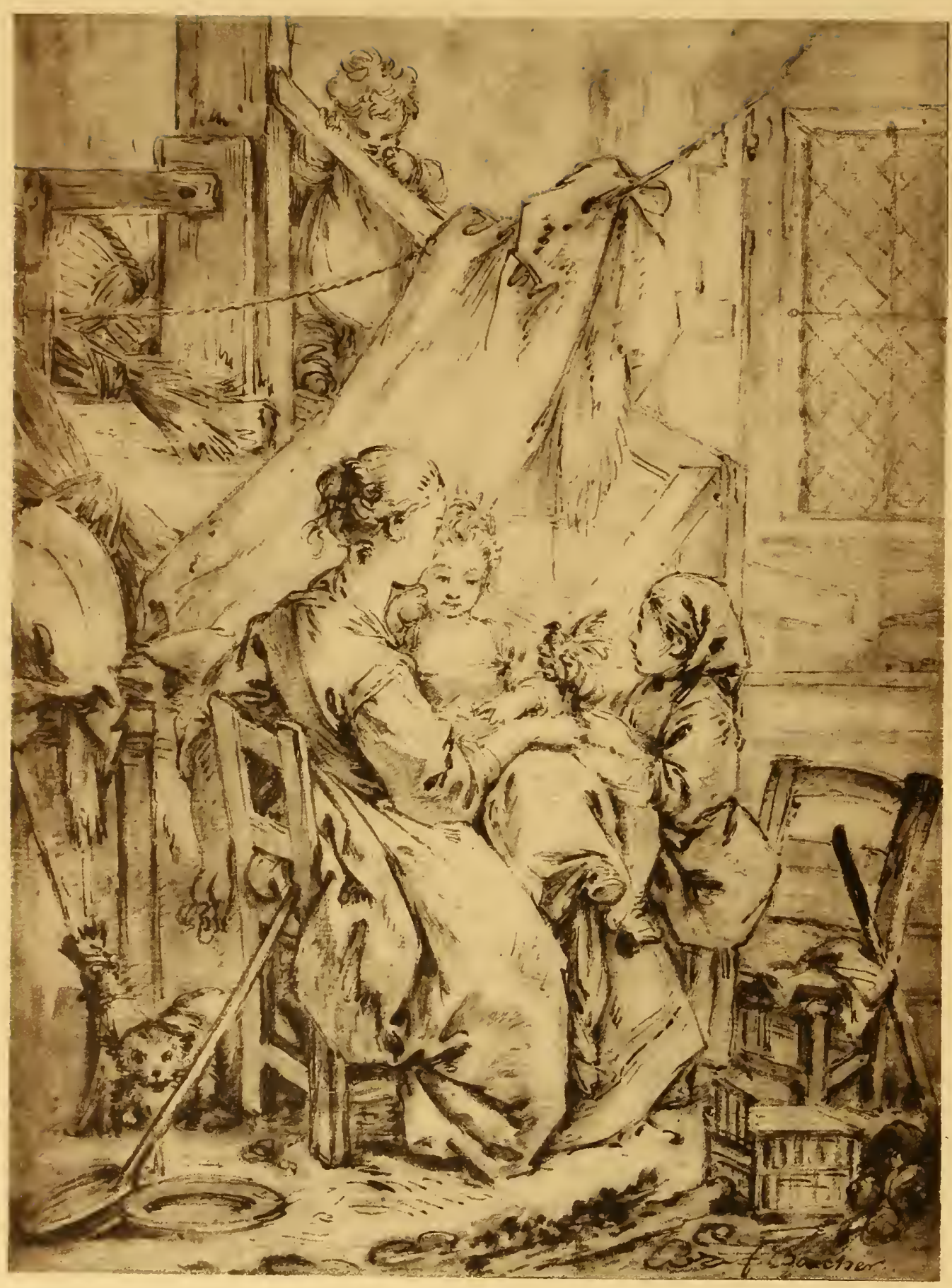




\title{
BOUCHER
}

\author{
(FRANÇOIS)
}

5

\section{Intérieur rustique.}

Assise sur une chaise et tournée vers la droite, dans une chambre encombrée de meubles et d'ustensiles de ménage, une jeune femme, vue de dos, le visage en profil perdu, montre à une fillette assise sur ses genoux, l'oiseau qu'un autre enfant, debout près d'elle, tient dans sa main droite. Au fond, derrière une draperie jetée sur une corde, un petit enfant contemple la scène du haut d'un escalier.

Signé en bas, à droite : $F$. Boucher.

Dessin à la plume, lavé d'un peu de bistre.

Haut., 260 millim.; larg., 193 millim.

Repr. en fac-simile dans les Maîtres du dessin (Paris, 3e année, 1901-1 902, pl. 109).

Cadre ancien, époque Régence, bois sculpté et doré. 


\title{
BOUCHER
}

\author{
(FRANÇOIS)
}

6

\section{Les Enfants aux pampres.}

Ce sont deux enfants nus, qui jouent avec des pampres. Le premier, couché, de droite à gauche, en travers de la composition, la jambe gauche repliée et l'autre étendue, lève les deux bras vers la droite et attire à lui un rameau de vigne chargé de grappes. Au second plan, on aperçoit de profil un autre enfant, adossé au premier, couché dans le même sens et tenant une grappe de raisins.

Pierre noire, légèrement relevée de sanguine et de craie, sur papier gris.

Haut., 233 millim.; larg., 342 millim.

Vraisemblablement le $\mathrm{n}^{0} 186$ de la vente Blondel d'Azincourt (février I783): "Un groupe de deux enfants pressant des raisins; ce dessin est aux trois crayons sur papier gris".

Gravé en manière de crayon et en contre-partie par G. Demarteau ( $n^{\circ} 5$ r 8 de l'œuvre), sans titre et avec cette note : "tiré du cabinet de Mme d'Azaincourt".

Cadre ancien, époque Louis XV, bois sculpté et doré 


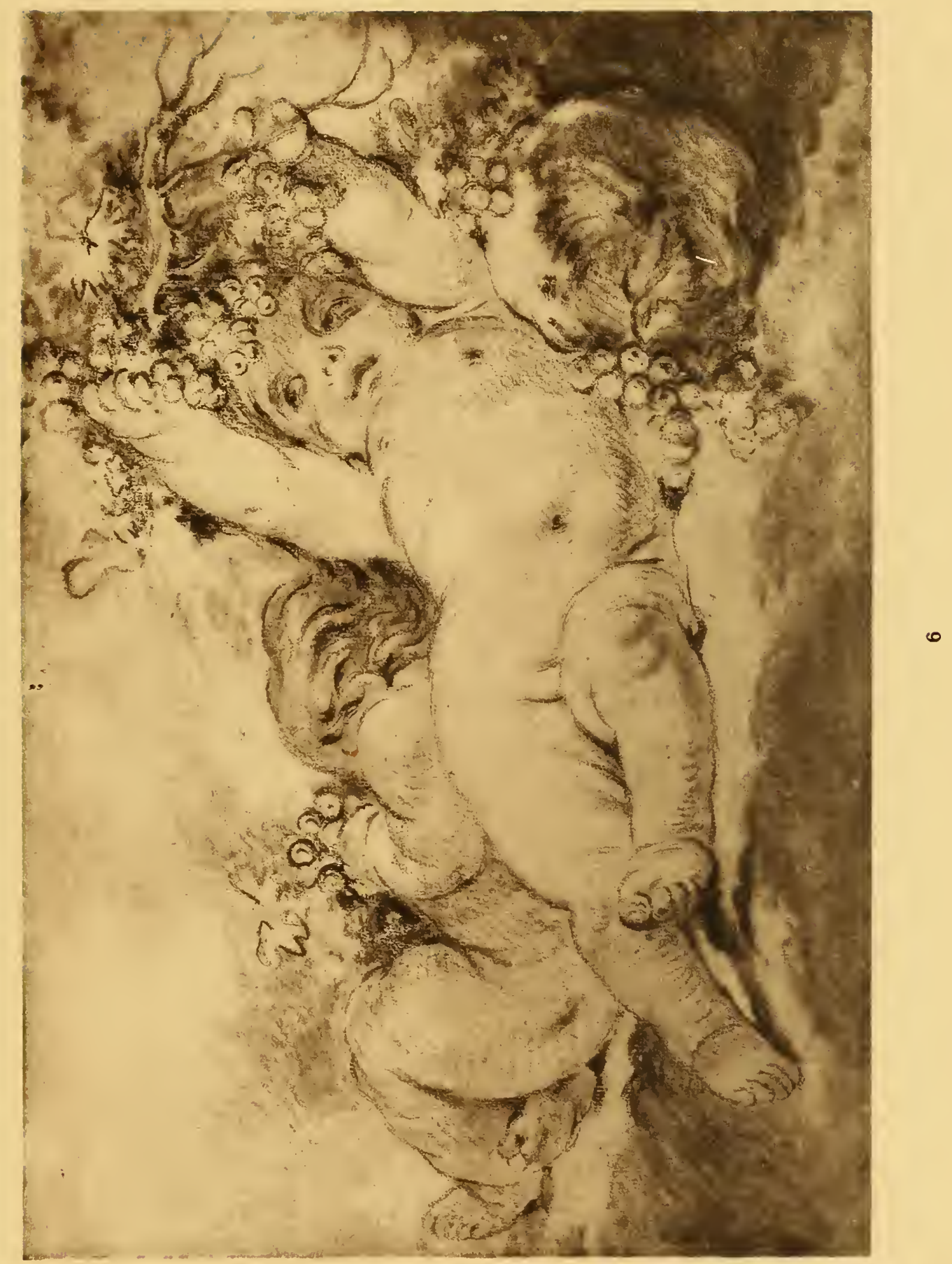






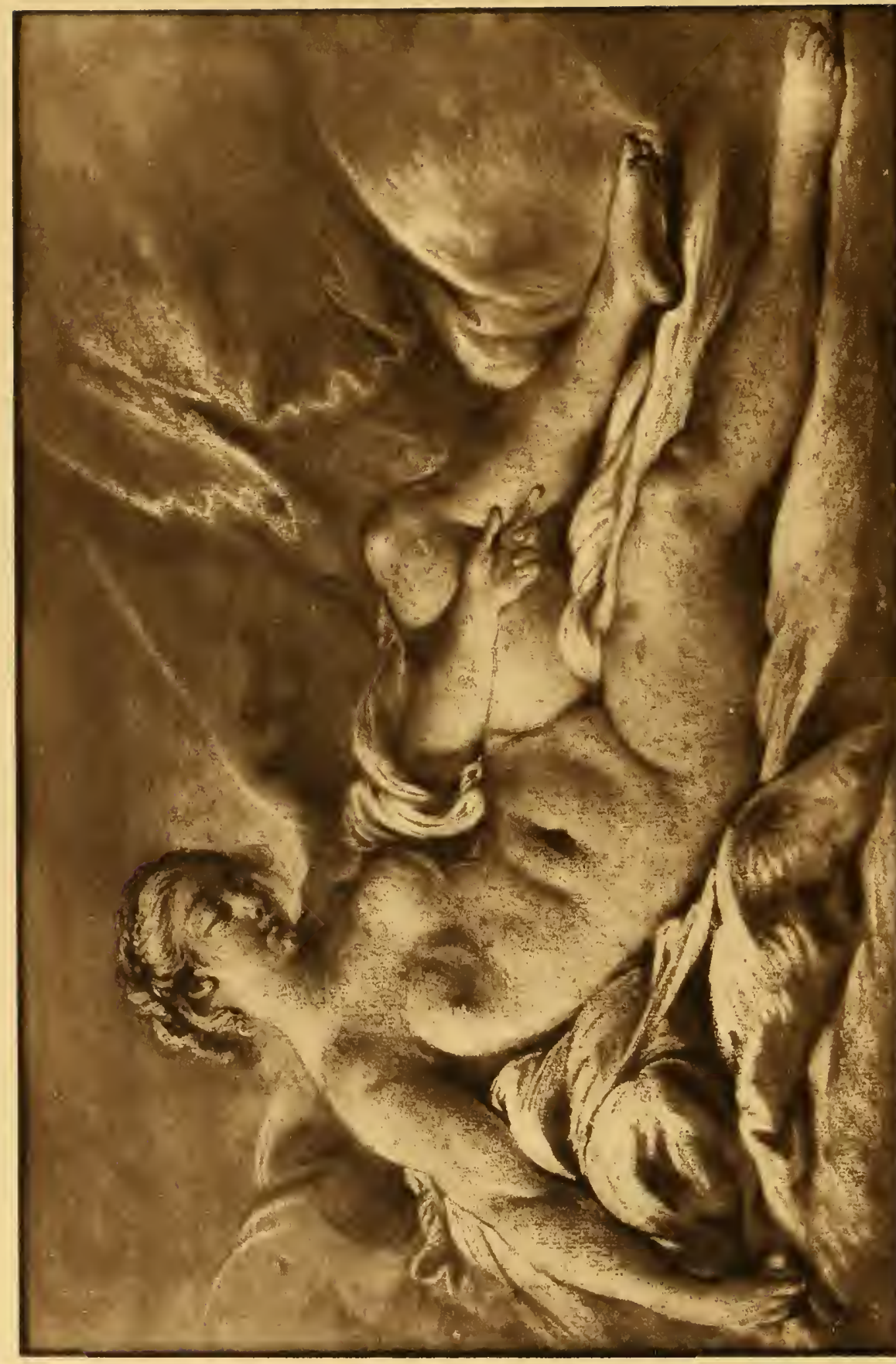

r 


\section{BOUCHER}

(FRANÇOIS)

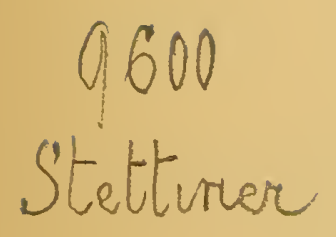

\section{7 \\ Étude de femme nue.}

Elle est vue de trois-quarts, à demi couchée, de gauche à droite, sur un lit de repos, derrière lequel tombent des draperies. Le visage, aux yeux mi-clos, est penché sur l'épaule gauche; le bras droit, écarté du corps, s'allonge avec abandon sur les coussins qui soutiennent le buste, et le bras gauche, autour duquel s'enroule une légère draperie, repose sur la cuisse ouverte, la main faisant le geste d'indiquer un objet vers la droite. La jambe droite est étendue, la gauche repliée et écartée.

Pierre noire relevée de craie, sur papier brun.

Haut., 276 millim.; larg., 424 millim.

Étude pour la figure, reproduite à peu près identiquement, avec addition de divers accessoires, dans le Réveil de Vénus, gravé en manière de crayon par L. Bonnet ( $\mathrm{n}^{\circ} 20$ de l'œuvre).

Cadre ancien, époque Louis XIV, bois sculpté et doré. 


\section{BOUCHER}

(FRANÇOIS)

\section{8 \\ Feuille d'études.}

Quatre études.

a. En bas, à gauche : une esquisse de bras.

b. Au-dessus : une étude de femme nue, vue de profil, à demi couchée de gauche à droite, la jambe gauche passée sous la droite étendue, le corps appuyé sur le coude gauche et le bras droit tombant naturellement, la main repliée.

c. Au milieu: une femme en buste, la tête de profil et le corps de trois-quarts à droite, penchée vers le spectateur.

d. A droite : une femme en buste, de dos, le corps de trois-quarts à droite, penchée vers le spectateur.

Sanguine, avec rehauts de craie, sur papier gris.

Haut., 252 millim,; larg., 323 millim.

b. L'étude de femme couchée a été utilisée par Boucher dans un tableau représentant Vénus couchée et endormie près de l'Amour, qui passa à la vente du chevalier de Cene (1786) et dans une vente anonyme faite en avril I793, et qu'on ne connaît plus que par une gravure de Michel Aubert, accompagnée d'un quatrain commençant par ce vers, devenu le titre de l'estampe : Ne cessons de craindre une belle (cf. Goncourt, l'Art du $X V I I I$ e siècle, éd. in- $\mathrm{r} 8$, I re série, p. 278).

c. La femme en buste, vue de trois-quarts, est une étude pour la nymphe de gauche de la Naissance de Vénus, gravée par Daullé.

Cadre ancien, époque Louis XV, bois sculpté et doré. 


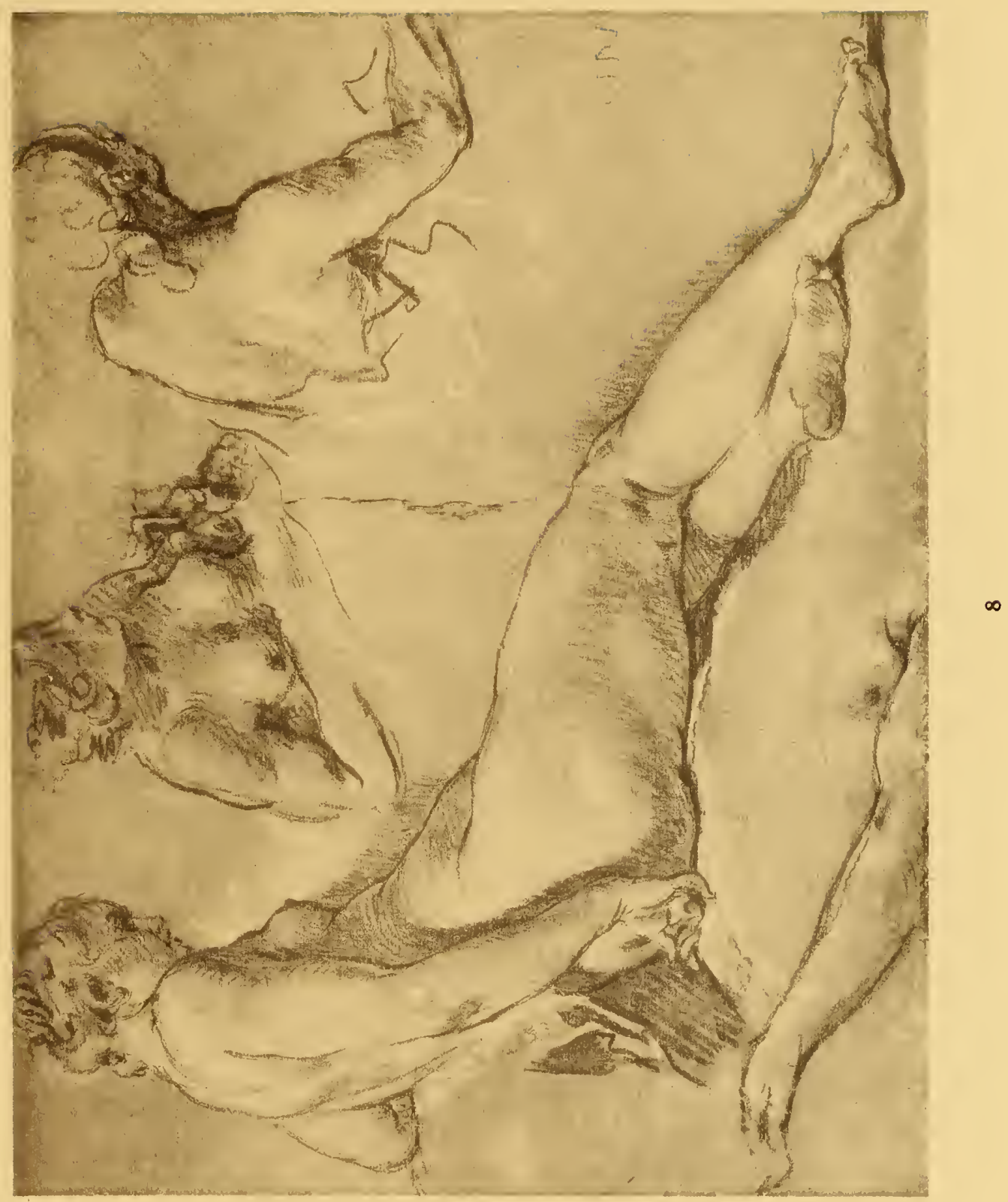






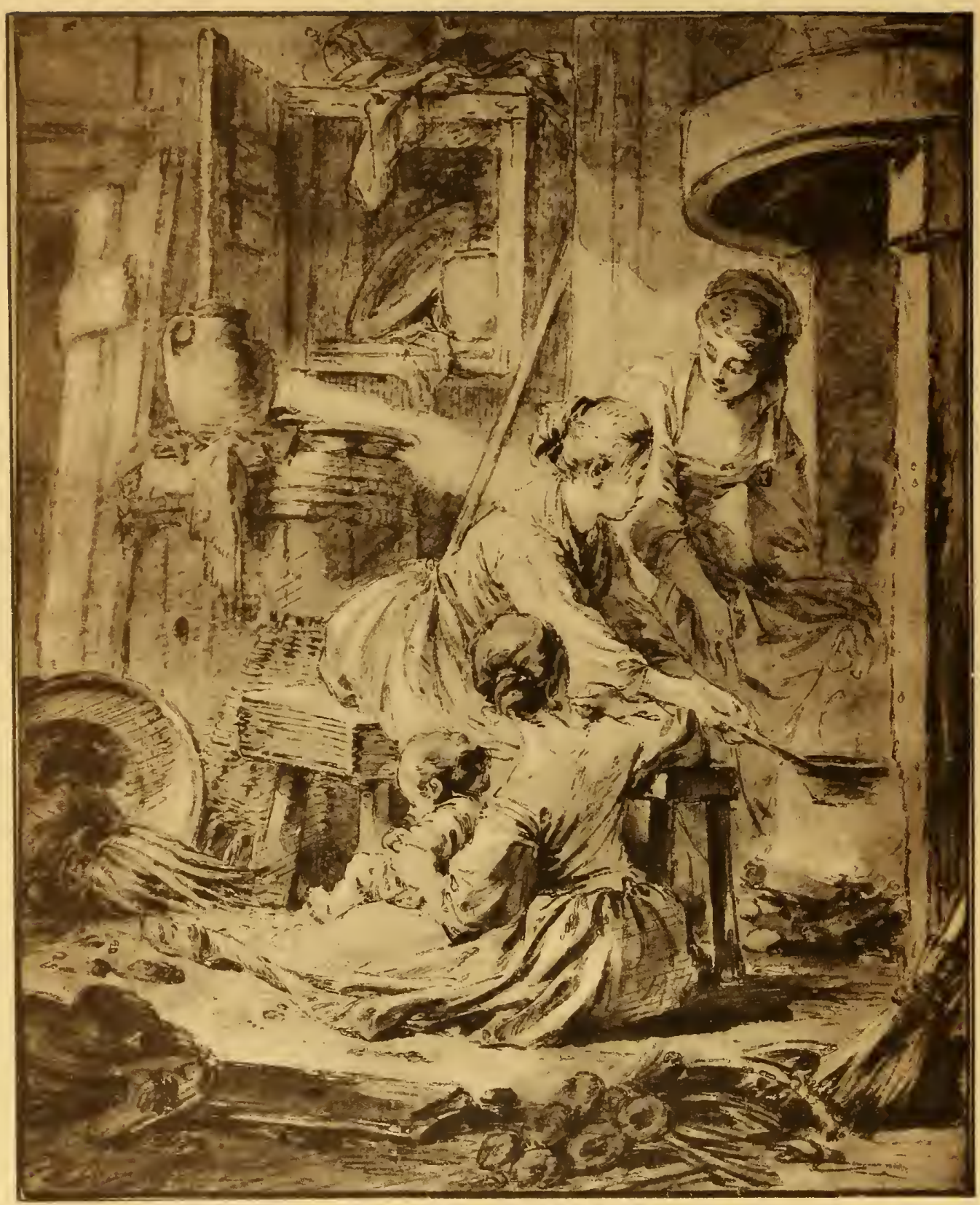

9 


\title{
BOUCHER
}

\author{
(FRANÇOIS)
}

\section{9 \\ Les Crêpes.}

Dans un cellier, encombré d'ustensiles divers, trois jeunes femmes sont réunies à droite, devant l'âtre. L'une, debout à l'arrière-plan et vue de face, se penche légèrement pour étendre son tablier devant le foyer, tout en suivant des yeux les gestes de la seconde qui, assise sur un banc, de profil à droite, tient à deux mains une poêle au-dessus du feu. La troisième, assise par terre au premier plan, le dos tourné à la cheminée et tenant un bébé sur les genoux, se détourne à demi, en s'accoudant à un escabeau, pour regarder ses compagnes.

Signé en bas, à gauche : Boucher.

Dessin à la plume lavé de bistre.

Haut., 222 millim,; larg., 177 millim.

Collection J. de Bryas (vente à Paris, avril 1898), $\mathrm{n}^{\circ} 20$ du catalogue, où il est indiqué par erreur comme ayant été gravé par Bonnet.

Gravé par Huquier, directement; et par Demarteau l'aîné ( $\mathrm{n}^{\circ} 72$ de l'œuvre), en sanguine et en contre-partie, avec cette indication : "tiré du cabinet de M $M^{\text {me }}$ Dazaincourt ». - N'est pas décrit au catalogue de la vente Blondel d'Azincourt (février i 783).

La gravure de G. Demarteau est reproduite sous le nom de Bonnet dans le François Boucher d'André Michel (op. cit.).

Il existe plusieurs études pour ce dessin, soit à la sépia (vente de la coll. Derenaucourt, Paris, 1883); soit au crayon noir (vente de la coll. E. Féral, Paris, 1901); soit à la sanguine (vente de la coll. Roblin, Paris, 1900).

Cadre style Louis XVI, bois sculpté et doré; au fronton, un nœud de ruban. 


\section{COCHIN le Fils}

(CHARLES-NICOLAS)

Paris, $1715+$ Paris, 1790.

\section{0}

\section{Portrait de M. Bailleul.}

En buste jusqu'au-dessous de l'épaule, le visage et le corps de profil à gauche, il porte une petite perruque à trois rangs de boucles, un col de lingerie et un habit sans ornements.

Signé en bas: C.-N. Cochin filius delin. I 765 .

Crayon noir, légèrement relevé de sanguine dans les chairs.

Rond. Diam. roo millim.

Collection Alfred Le Ghait (vente anonyme, Paris, 28 février 1877), no 47, avec le dessin suivant.

Il s'agit sans doute ici de Bailleul, "géographe et graveur du roi pour les finances ", qui fut de bonne heure en relation avec C.-N. Cochin : en $\mathbf{r} 739$, il éditait les estampes de l'artiste concernant les fêtes du mariage de Madame Première de France avec l'Infant, et en ${ }_{1747}$, il signait un état de paiement pour la gravure des inscriptions des quatre estampes du même Cochin, retraçant les principaux épisodes du mariage du Dauphin, en i $74^{5}$ (cf. Mercure de France, o乞t. i 739 , p. 2438 , et Nouvelles archives de l'art français, 3 e série [Revue de l'art français ancien et moderne], t. 1I, r885, p. 163).

\section{$10^{\text {bis }}$ \\ Portrait de $M^{\text {me }}$ Bailleul.}

Disposée de la même façon et tournée du même côté, elle est coiffée d'un bonnet de dentelles dans lequel est passé un ruban noué derrière la tête, et porte autour du cou un petit fichu.

Signé en bas: C. $-N$. Cochin filius delin. 1763 .

Crayon noir, relevé de sanguine dans les chairs, le ruban du bonnet et le haut du corsage.

Pendant du précédent.

Rond. Diam., roo millim.

On lit au dos de l'encadrement, d'une écriture ancienne : Dessiné par M. Cochin en 1763. Portrait de Madame Bailleul donné par elle-même à M.A.S $f$ [le nom a été effacé], le $107^{\text {bre }} 1784$.

Cochin avait fait une première fois le "portrait de $M$. Bailleul et de son épouse ", en 1750. C'est par erreur que Goncourt signale les deux dessins de 1750, exposés au Salon de cette année (sans $n^{\circ}$ ), comme ayant passé à une vente faite à Paris, le 28 février 1877 (Goncourt, l'Art du XVIII'e siècle, éd. in-18, ze série, p. 435) : il s'agit en réalité des deux portraits décrits ici.

Cadres anciens, époque Louis XVI, de forme ronde; bois sculpté et doré, avec nœud de ruban au fronton. 


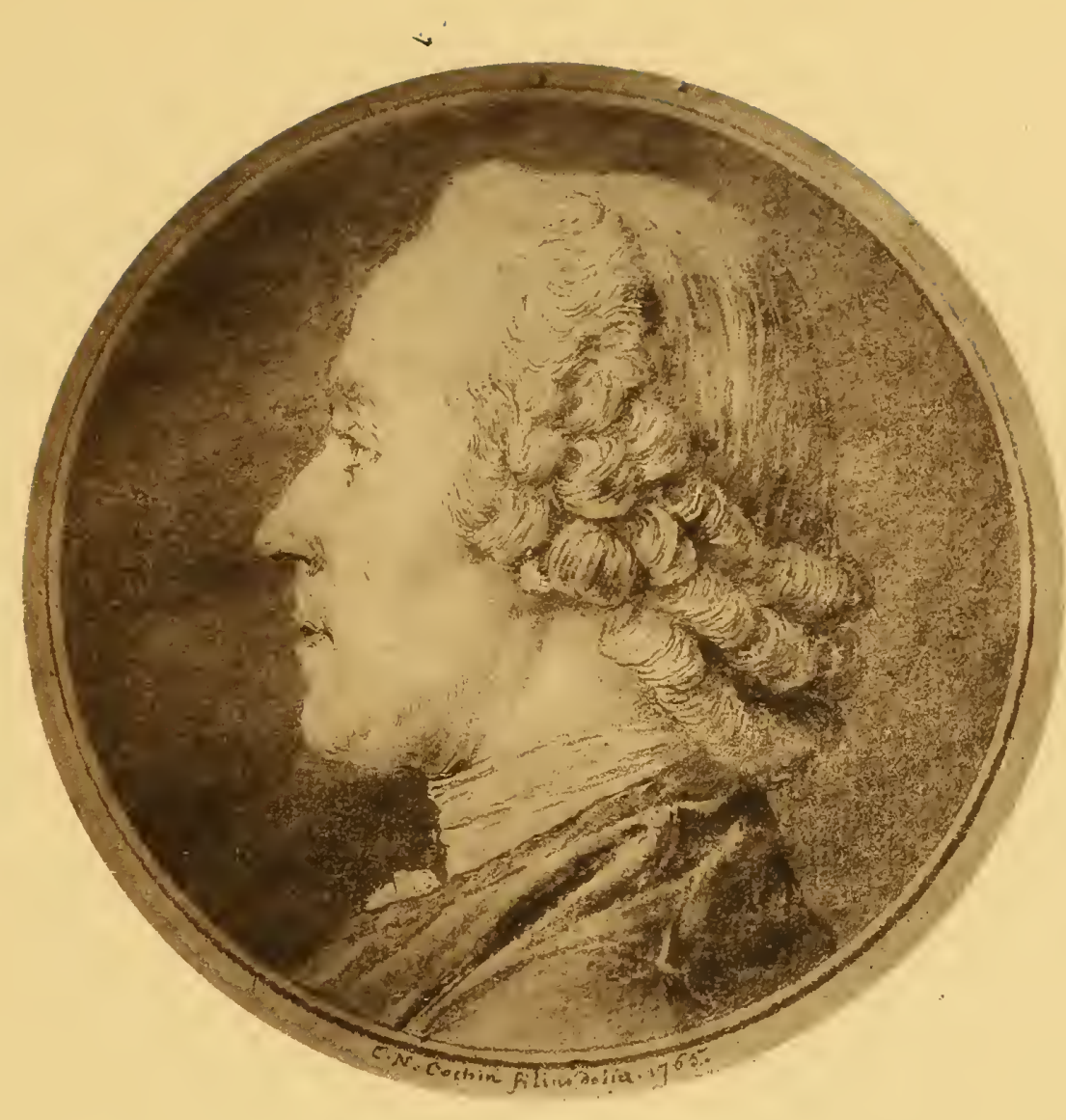

10

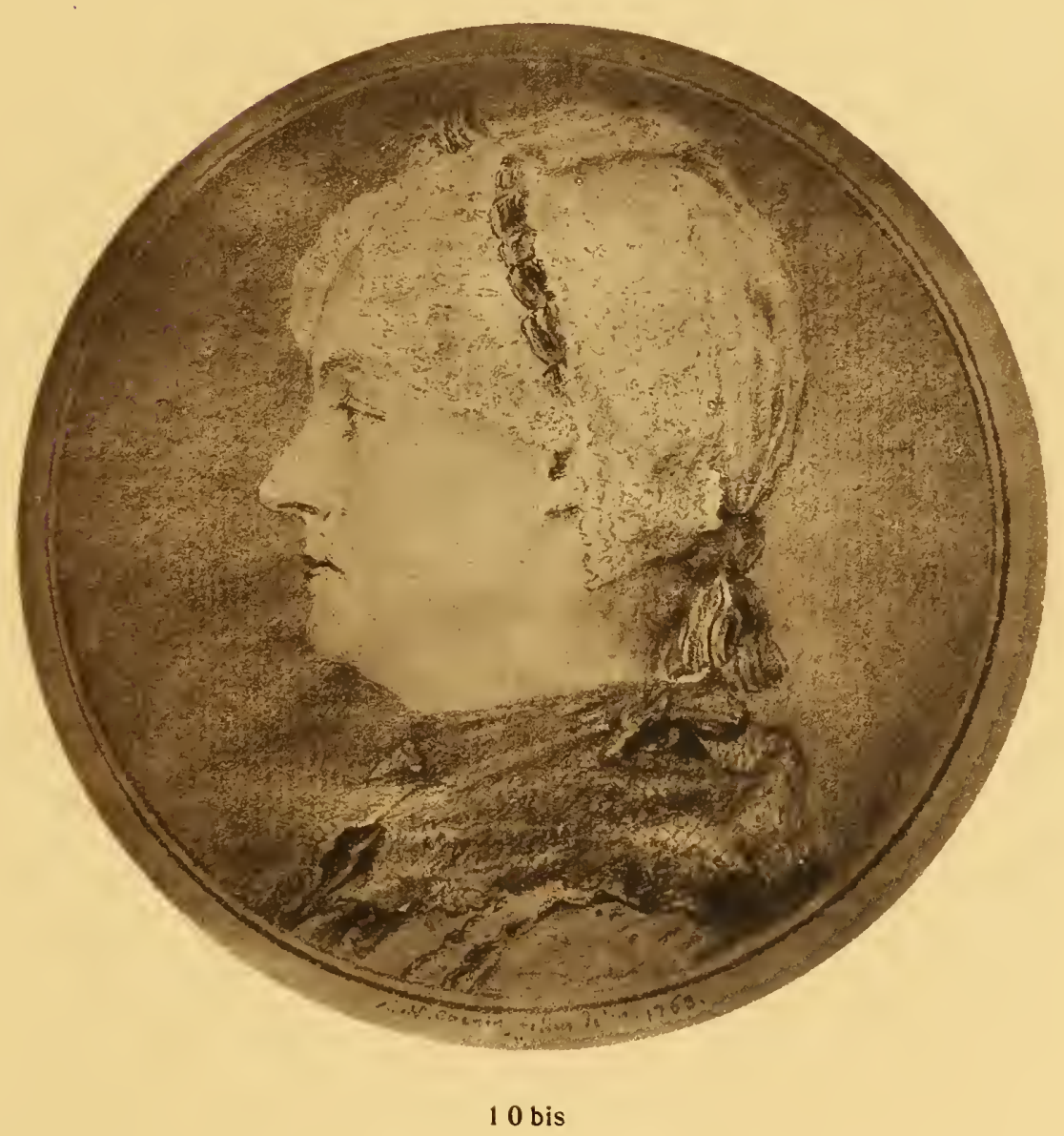






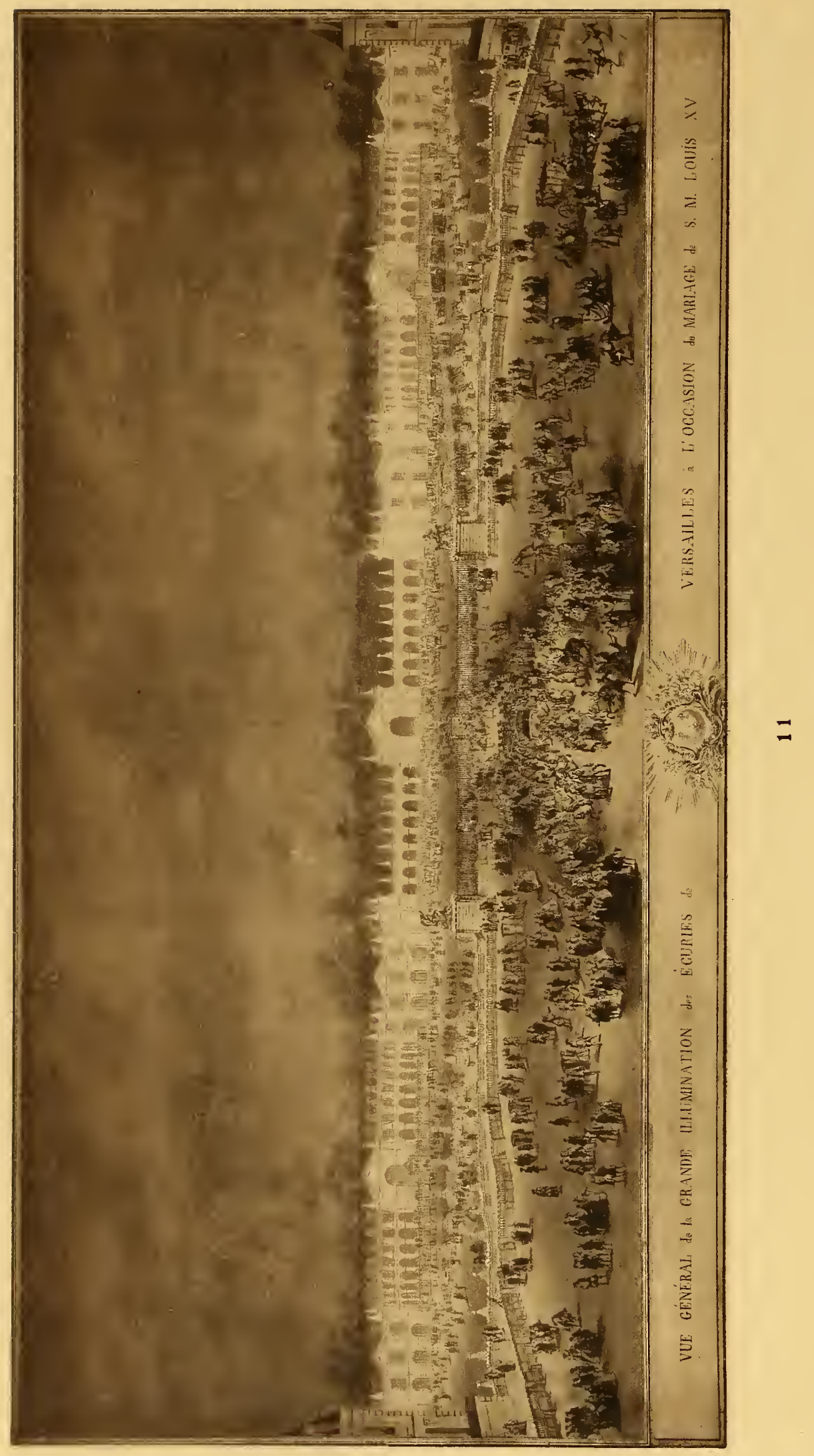




\section{COCHIN le Fils}

(CHARLES-NICOLAS)

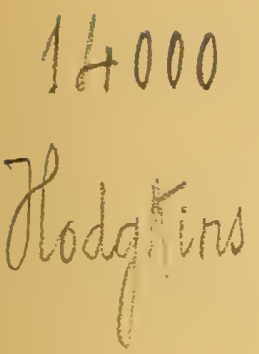

\section{1 \\ Illumination des Écuries de Versailles à l'occasion du second mariage du Dauphin (9 février 1747).}

Le spectateur, tournant le dos au Château, embrasse toute l'avantcour, dont les balustres sont garnis d'une ligne de pots-à-feu; plus loin, la place Royale, ornée d'ifs illuminés; et, au fond, les deux Écuries, dont les façades sont dessinées par des lumières et les entablements couronnés de girandoles. Une architecture simulée, de semblable décoration, relie entre eux les bâtiments des deux Écuries, d'un côté à l'autre de la Grande Avenue (aujourd'hui avenue de Paris). Une foule nombreuse remplit la place Royale; des carrosses sortent du bâtiment figuré à droite, dont la porte est ouverte. Dans l'avant-cour du château, où vont et viennent des groupes de personnages, un carrosse attelé de six chevaux, encadré de cavaliers portant des torches, s'avance vers le château, au milieu d'une haie de spectateurs.

Dessin à la plume et au lavis; les lumières à la gouache.

Haut., 445 millim.; larg., 905 millim.

Salon de $1750\left(\right.$ sans $\left.n^{\circ}\right)$. - Gravé par Ingram (Catalogue de l'auvre de Ch.-Nic. Cochin le fils, par Jombert, Paris, I770, no $16 \mathrm{r}$; Chalcographie du Louvre, no 4034).

On lit, dans un encadrement ménagé au-dessous du dessin et coupé d'un cartouche aux armes royales: Vue général (sic) de la grande illumination des écuries de Versailles à l'occasion du mariage de $S . M$. Louis XV. Cette indication est inacceptable : le mariage de Louis XV fut célébré à Fontainebleau, et il n'y eut aucune fête à Versailles à cette occasion. 11 s'agit ici des fêtes données à l'occasion du second mariage du Dauphin, fils de Louis XV, avec Marie-Josèphe de Saxe. Le dessin a vraisemblablement été gratifié d'un titre à une époque où le souvenir de ce qu'il représente s'était perdu.

$\mathrm{Au}$ Salon de $\mathbf{1} 750$, Cochin exposait deux dessins consacrés à cet événement : le Roy tenant grand appartement dans la grande galerie de Versailles et les Illuminations des deux grandes écuries de Versailles, jointes ensemble par des arcades de lumières. Le livret ajoute: "Les deux dessins se gravent actuellement ". En effet, le premier a été gravé par Cochin le père, et le second - celui qui nous intéresse ici-par Ingram. Dans le catalogue de la Chalcographie, l'estampe est donnée comme anonyme ( $\left.n^{\circ} 403_{4}\right)$, sans doute parce qu'elle est avant toute lettre; c'est le catalogue publié par Jombert qui dévoile le nom d'Ingram.

On remarquera que le dessin, préparé spécialement pour la gravure, est en sens inverse de l'estampe; leurs dimensions sont identiques. D'après le Mercure (février 1745, p. 177), l'illumination eut lieu, pour la première fois, le jour du mariage, à l'issue du bal paré donné dans le manège de la Grande Écurie. Ce bâtiment se trouve à gauche, quand on tourne le dos au château. Sur l'estampe, il occupe sa situation véritable.

Cadre style Louis XV; au fronton, les armes royales. 


\section{DESCAMPS}

(JEAN-BAPTISTE)

Dunkerque, $1706+$ Rouen, 1791 .

\section{Lancement de navires au Havre, en présence du roi (20 septembre 1749).}

Au delà d'un môle garni de spectateurs, s'étend une partie de la rade sillonnée de barques, et la plage d'où le roi et la Cour, descendus de leurs carrosses et debout sous un pavillon en forme de dais, assistent à la fête. Plus loin, une foule de spectateurs. Vers la gauche, au fond, un navire est déjà lancé; un autre, à droite, est vu au moment où son avant entre dans la mer; derrière celui-ci, un troisième est encore soutenu par ses étais; enfin un quatrième, au milieu, a chaviré sur bâbord.

Dessin à la plume et au lavis.

Haut., 390 millim.; larg., 555 millim.

On lit en bas sur la monture, dans un cartouche encadré d'attributs maritimes: Le Roy étant sur la plage de la rade du Havre voit lancer 3 navires à la mer et représenter un combat naval. $207^{\text {bre }} 1749$.

C'est sous ce titre que J.-Ph. Le Bas a gravé, en 1752 , cette scène "dessinée sur les lieux par Descamps ", en même temps que cinq autres épisodes du voyage du roi au Havre, les 19 et 20 septembre 1749. - Les six dessins commandés à Descamps représentaient : l'Entrée du roi au Havre; la Carenne d'un navire dans le bassin; une Joute sur l'eau; l'Illumination de la Grande-rue (ceci pour la journée du 19 septembre); un Combat de plusieurs vaisseaux qu'onvenait de lancer; et le Roi sur la hauteur d'Ingouville, entouré des grands de sa Cour (ceci pour celle du 2o).

Cf. sur le voyage du roi au Havre, "complaisance du roi pour $\mathrm{M}^{\mathrm{m}}$ de Pompadour qui n'a jamais vu la mer": Barbier, Chronique de la Régence, etc., 1. IV, p. 39o; et la relation détaillée des fêtes dans le Mercure de France, nov. 1749, p. 203; enfin : Notice historique sur J.-B. Descamps, par son fils, J.-B.-M.-A. Descamps (1807), p. 78.

Cadre style Louis XVI, bois sculpté et doré; au fronton, cartouche encadré de faisceaux d'armes et d'attributs maritimes. 


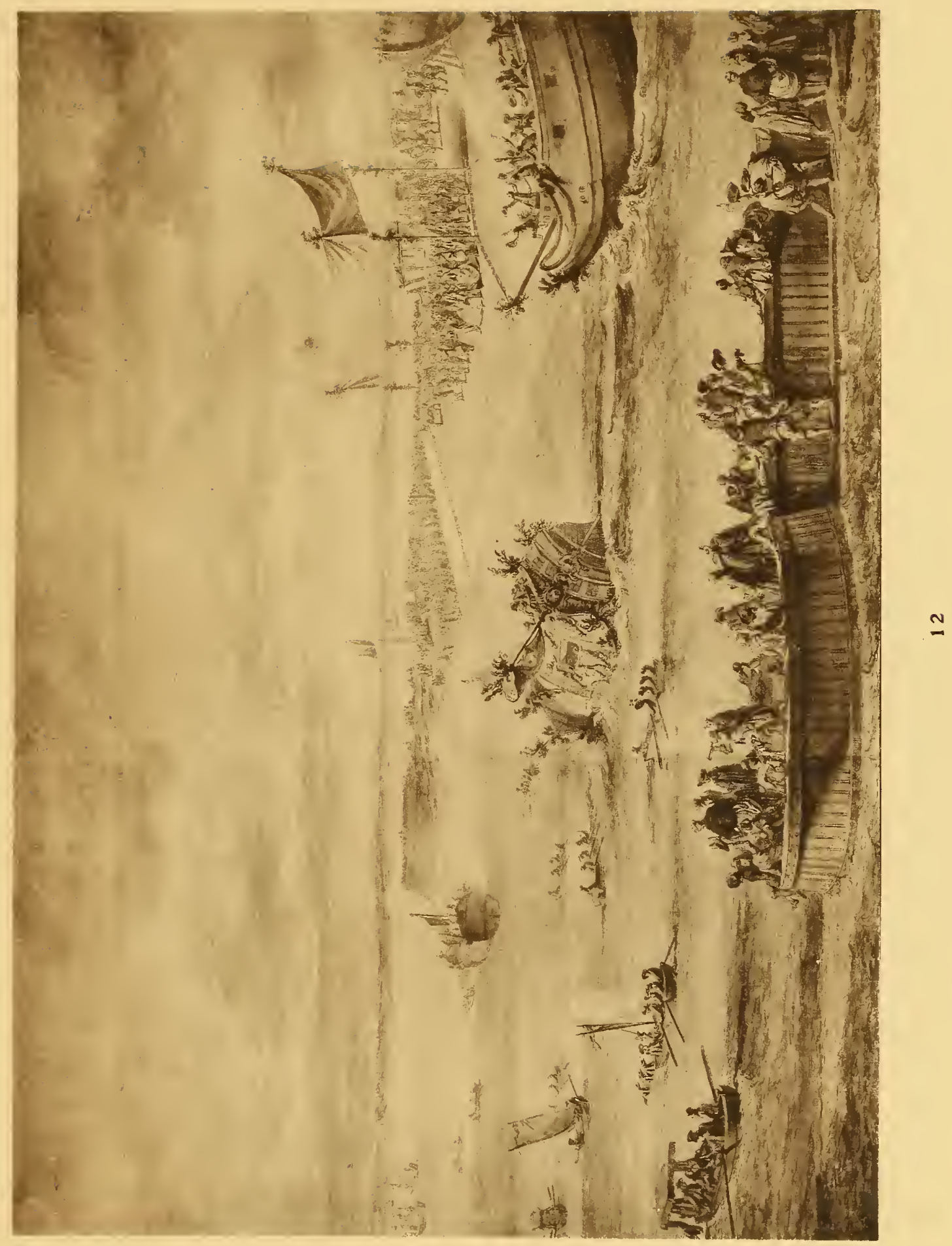






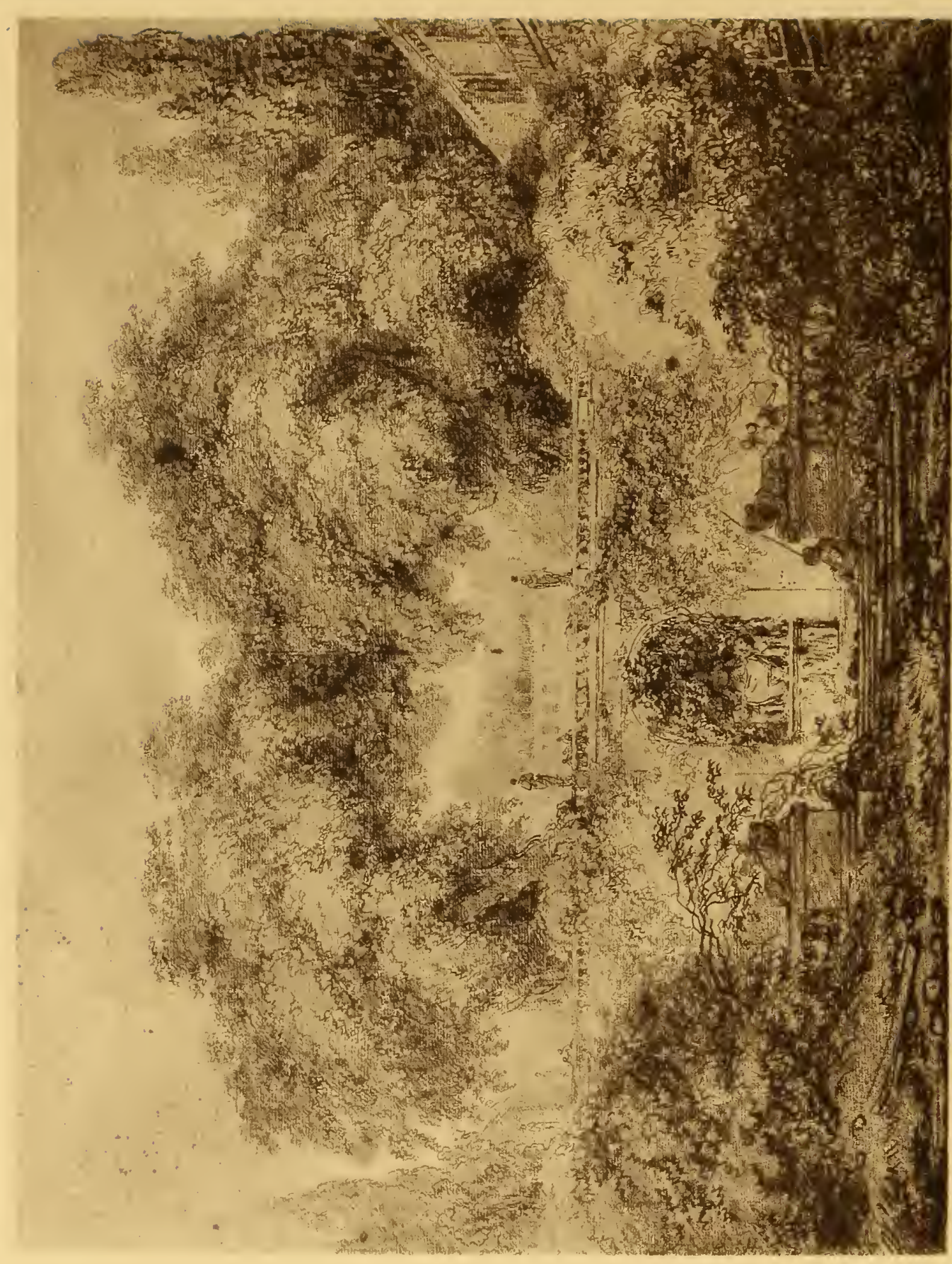




\section{FRAGONARD}

(HONORE)

Grasse, $1732+$ Parik, 1806 .

\section{3}

\section{Les Jardins de la Villa d'Este.}

Deux lions de pierre, couchés à l'extrémité d'une balustrade, gardent l'entrée d'un escalier conduisant aux terrasses de la villa, dont on découvre les perspectives étagées. C'est d'abord un haut mur creusé d'une niche, où quelque déesse antique trône entre deux animaux, et couronné par une ligne de balustres, surmontés de deux statues. Plus loin, sous la voûte touffue de vieux arbres dont les cimes se rejoignent, on aperçoit la façade d'une chambre de verdure, aux arcades soigneusement dessinées; et, tout au fond, dautres arbres encore.

Sanguine.

Haut., 350 millim.; larg., 464 millim.

Vente Lempereur $\left(\mathbf{1} 77^{3}, \mathrm{n}^{\circ} 729\right) ;-$ Collection Walferdin (vente à Paris, avril ı 880 $n^{\circ}$ I 88). - - Une sanguine analogue, qui se trouvait dans la collection Mahérault (vente à Paris, mai $1880, \mathrm{n}^{\circ} 5 \mathrm{l}$ ), passa ensuite dans la collection La Béraudière (vente à Paris, avril ı $883, n^{\circ}$ 1 I 4 ), et enfin dans la collection Beurdeley (vente à Paris, mars 1905, $\mathrm{n}^{\circ} 66$; repr. au catal.).

Gravé à l'eau-forte par Fragonard: c'est la planche connue sous le titre de : le Parc ou le Petit Parc; - gravé également à l'eau-forte par l'abbé de Saint-Non.

Repr. dans le baron R. Portalis, H. Fragonard (Paris, 1889), pl., p. I68, sous le titre de : le Petit Parc; - dans M. Tourneux, la Coll. J. Doucet, etc. (les Arts, no 36, déc. 1904), p. 14, sous le titre : Environs de Tivoli; - et, en fac-similé, par la Société de reproduction des dessins de maîtres (3e année, 1911 ), avec une notice par $\mathrm{E}$. Dacier, revisée ici sur plusieurs points.

Le même sujet a été peint par Fragonard, dans une toile conservée au musée Wallace, à Londres, qui ne diffère du dessin que par quelques petits personnages introduits par l'artiste au premier plan (repr. dans P. de Nolhac, H. Fragonard; Paris, I 906 ; frontisp., p. I09, sous le titre : Villa d'Italie).

On peut assigner comme date à cette sanguine les mois de l'été de 1760 , pendant lesquels Fragonard séjourna à la villa d'Este, en compagnie de son camarade Hubert Robert et de leur protecteur l'abbé de Saint-Non (cf. baron R. Portalis, Fragonard, pp. 34 et ss.). C'est une eau-forte de Saint-Non reproduisant, avec un titre explicite, un autre aspect des jardins de la ville d'Este, qui justifie le titre adopté ici pour le Petit Parc.

Cadre ancien, époque Louis XVI, bois sculpté, peint et doré. 


\section{FRAGONARD}

(HONORE)

\section{4 \\ Réunion à la lisière d'un bois.}

A l'orée d'un chemin sombre, qui, au milieu du tableau, s'enfonce sous un bois de vieux chênes, les uns touffus, les autres à demi dépouillés de leur feuillage et montrant leurs branches tordues, cinq personnages sont assis ou couchés sur l'herbe, écoutant les propos d'un homme debout. Assise à l'écart, à gauche, une femme se retourne et regarde le groupe. A droite, un homme entraîne une femme dans un chemin qui descend entre les arbres.

Signé en bas, vers le milieu, sur l'herbe : Frago.

Sanguine bistrée.

Haut., 380 millim.; larg., 495 millim.

Cadre ancien, époque Louis XVI, bois sculpté et doré: 


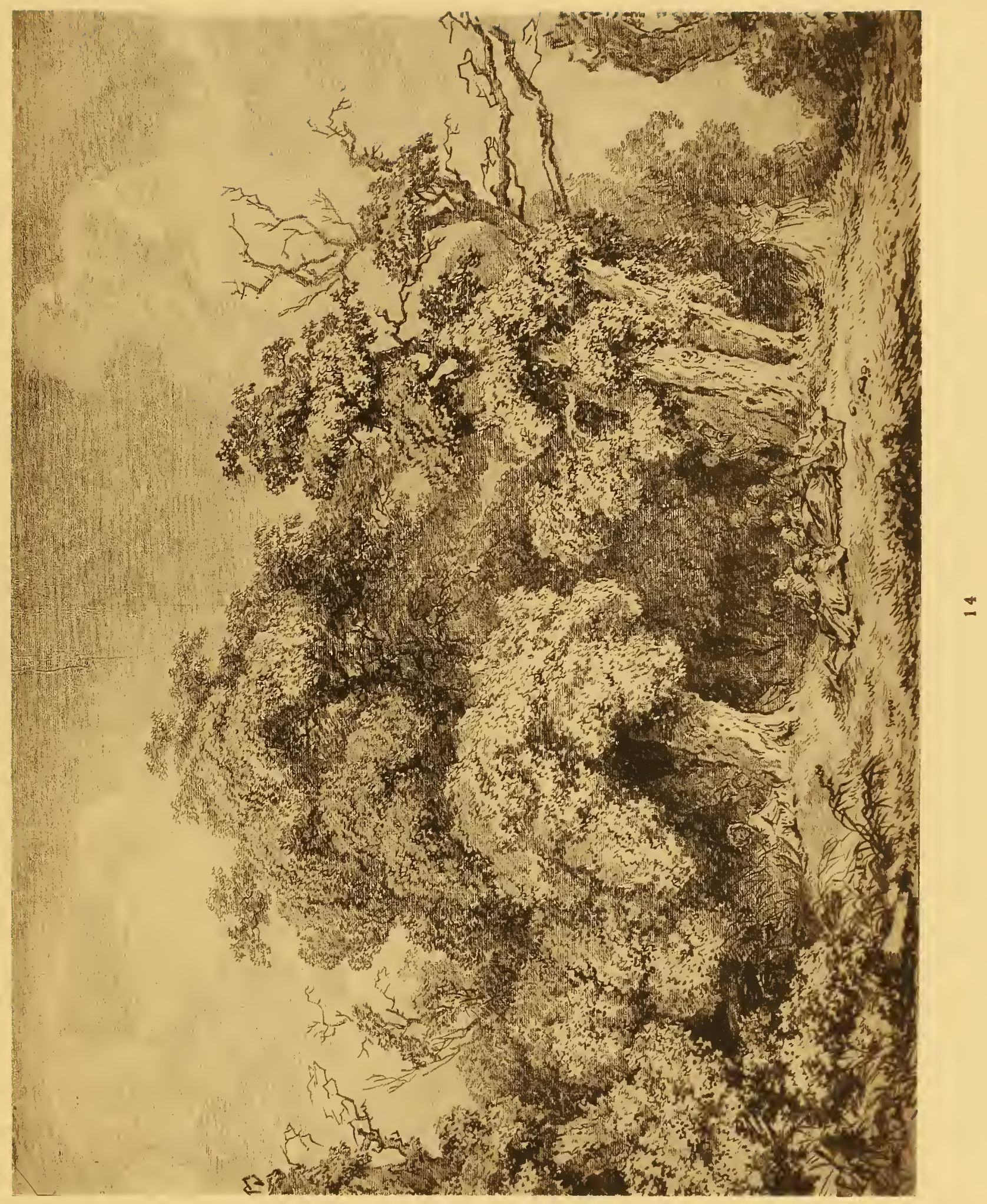






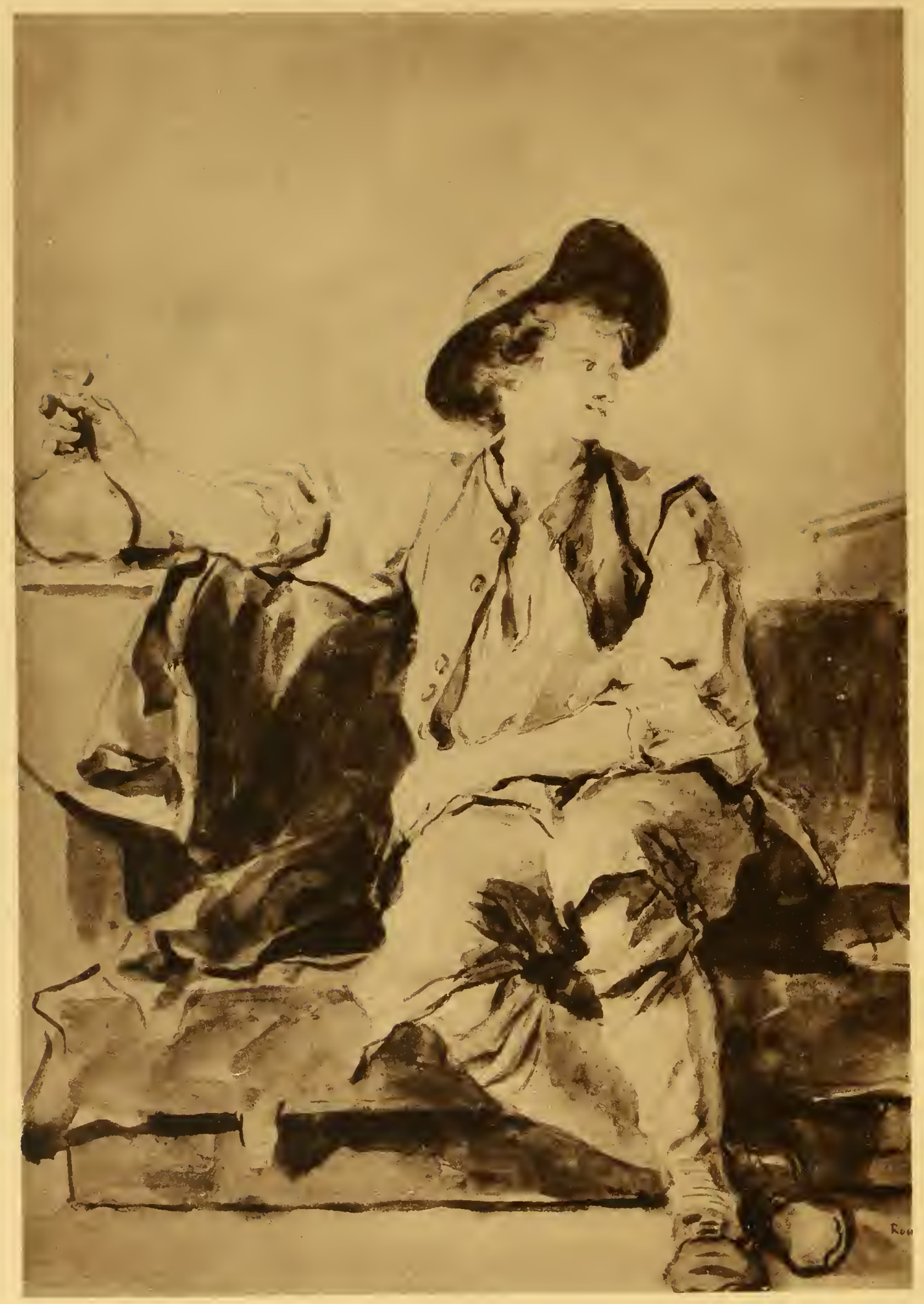




\title{
FRAGNARD
}

\author{
(HONORE)
}

\section{5}

\section{Jeune Italien tenant une fiasque.}

Il est assis un peu à droite, sur une caisse, le corps de face, la tête de trois-quarts et tournée vers la droite. Le bras gauche ramené sur le devant du corps, il a le bras droit étendu de côté et tient une fiasque par le col. La jambe droite est croisée derrière l'autre. Chapeau à larges bords, relevé sur le devant; gilet déboutonné; chemise ouverte sur la poitrine et retroussée jusqu'aux coudes; chausses et bas, laissant les genoux libres; souliers à boucles. Derrière lui, une draperie.

On lit au bas, à droite : Roma.

Sépia.

Haut., 367 millim.; larg., 254 millim.

Peut-être le no 311 de la vente Le Brun (Paris, avril 1791): «H. Fragonard. Un jeune homme assis et tenant de la main droite une bouteille. Ce dessin, lavé au bistre sur papier blanc, est de l'effet le plus piquant et de la touche la plus facile et la plus spirituelle. H. 17 pouces; 1. I4 pouces " (les dimensions diffèrent sensiblement, mais le papier a pu être rogné); - Collection Walferdin (vente à Paris, avril $1880, n^{\circ}$ I 84 ).

Sans doute un des croquis exécutés par Fragonard pendant son voyage avec Bergeret, c'est-à-dire datant du mois de décembre $177^{3}$ ou des premiers mois de 1774 , époque du second séjour de l'artiste à Rome.

Cf. Baron R. Portalis, H. Fragonard, op. cit., catalogue, p. 303, sous le titre: Hommedu peuple assis.

Cadre ancien, époque Louis XVI, bois sculpté et doré. 


\section{FRAGONARD}

(HONORE)

\section{6 \\ Le Sacrifice au Minotaure.}

Au milieu de la composition, à droite d'un petit autel circulaire sur lequel une urne est posée, la jeune fille désignée par le sort tombe évanouie dans les bras de ses compagnes, en levant les mains au ciel, tandis que sa mère, étendue sur le dos, au premier plan, se tord les bras avec désespoir. A droite, un groupe de femmes, les unes pleurant, d'autres suivant la scène avec émotion. A gauche, deux prêtres debout devant l'autel et un homme agenouillé près d'un trépied. Dans le ciel planent des divinités infernales.

Sépia et aquarelle.

Haut., 335 millim,; larg., 442 millim.

Collection Bruun-Neergaard (vente à Paris, août $1814, \mathrm{n}^{\circ} 127$ ) : "Jeunes hommes et jeunes filles à Athènes, tirant au sort pour être livrés au Minotaure. Morceau colorié et d'un bel effet. H. 10 p.; L. 16 p. 61 . "Les dimensions diffèrent légèrement.

La peinture, dont cette aquarelle est l'esquisse, appartient également à la collection Jacques Doucet; voir : Peintures, no 146.

Cadre ancien, époque Louis XVI, bois sculpté et doré. 


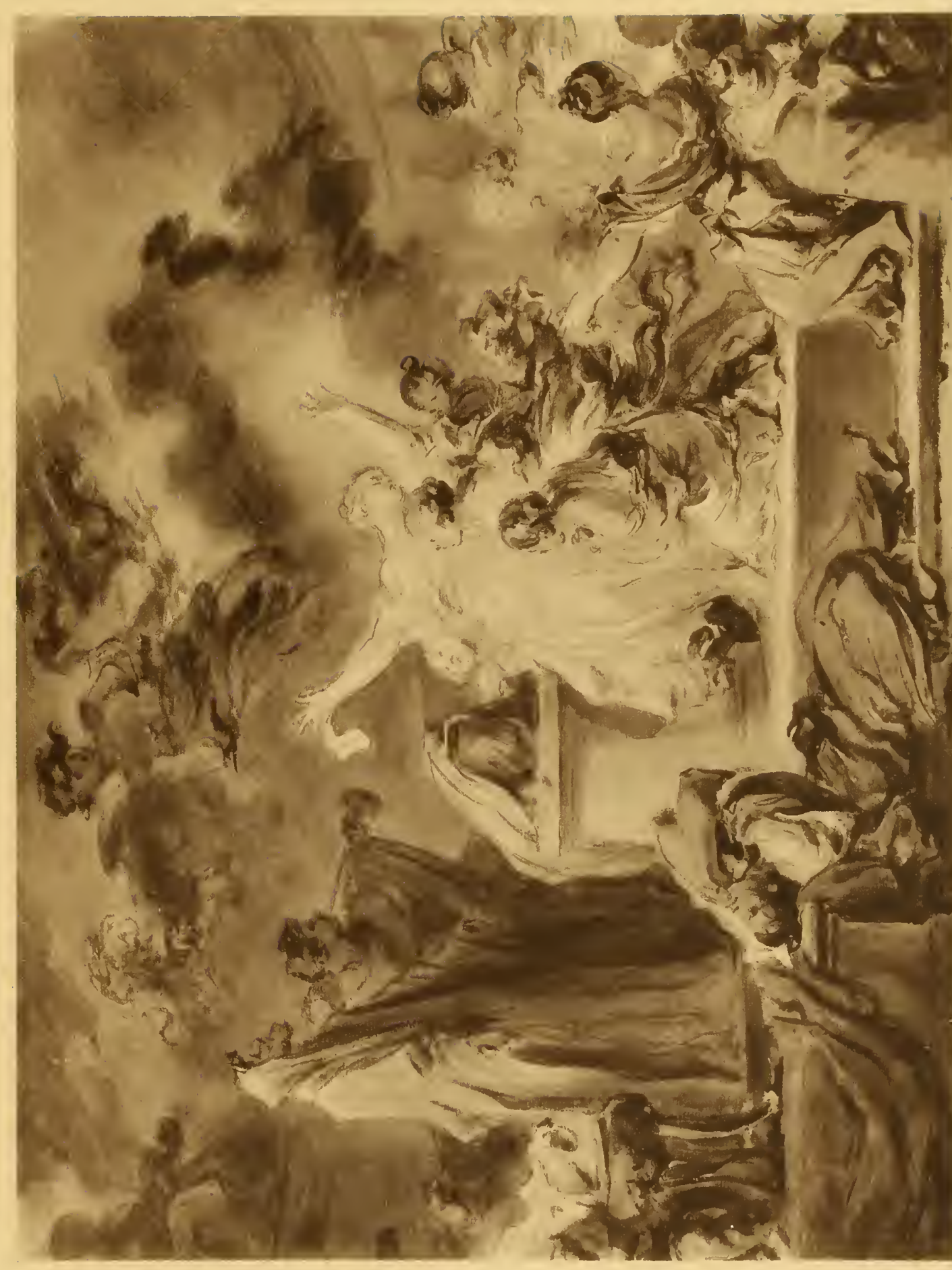






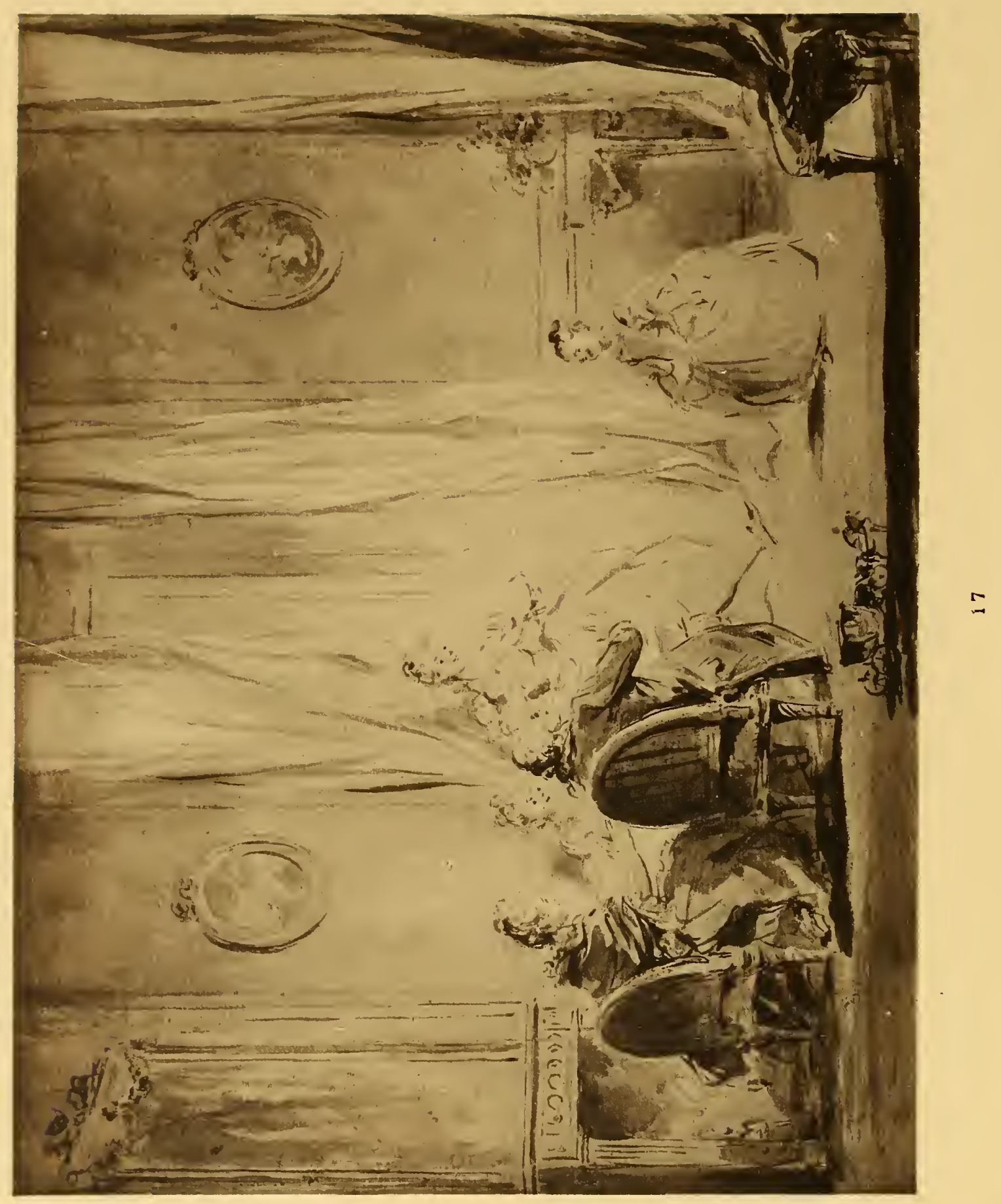




\section{FRAGONARD}

(HONORÉ)
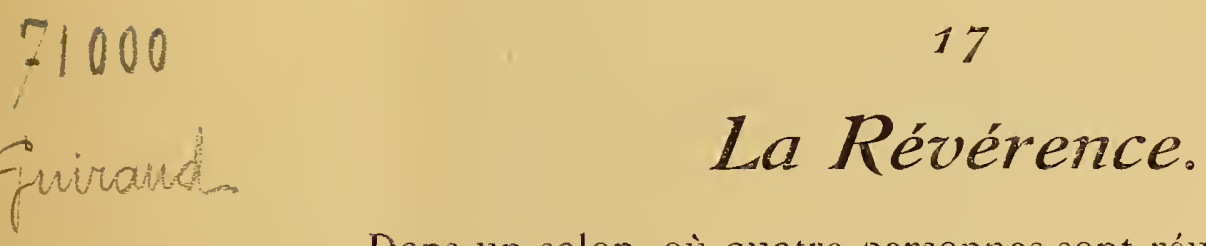

\section{La Révérence.}

Dans un salon, où quatre personnes sont réunies à gauche près de la cheminée, une fillette a laissé de côté son joujou - un petit carrosse, attelé de deux chevaux, que l'on voit au premier plan - pour montrer à la compagnie comment elle met à profit les leçons de son maître à danser; éclairée à droite par une haute fenêtre, le corps bien d'aplomb, la tête légèrement penchée, tenant à deux mains sa jupe bouffante, elle fait la révérence aux parents qui l'applaudissent.

Bistre.

$$
\text { Haut , } 2 \text { rg millim,; larg., } 2 S_{+} \text {millim }
$$

Collection de M. Léon Roux, architecte. achée a amiant 20004

Repr. dans les Maîtres du dessin (Paris, 3e année, 1901-1902, pl. 137), sous le titré de Scène d'intérieur; - dans P. de Nolhac, H. Fragonard (pl., p. 86); - dans M. Tourneux, la Collection J. Doucet, etc. (les Arts, op. cit., p. 2o); -- et en fac-similé par la Société de reproduction des dessins de maîtres (3e année, 1911), avec une notice par E. Dacier.

Cadre ancien, époque Louis XVI, bois sculpté et doré; fronton à cartouche et chutes de guirlandes de feuillage. 


\section{FRAGONARD}

(HONORE)

\section{8}

\section{Mère défendant son enfant contre les attaques d'un chien.}

A gauche, une femme debout lève les bras et pousse des cris pour effrayer un gros chien qui, venant de la droite, se précipite vers un bambin qui lui a pris un de ses petits et se sauve, en criant, derrière un baquet à lessive occupant le centre de la composition. A droite, au fond, une corbeille posée à terre devant un meuble rustique.

Sépia.

Haut., 239 millim.; larg., 376 millim.

Cadre ancien, époque Louis XVI, bois sculpté et doré, à entrelacs et fleurettes. 


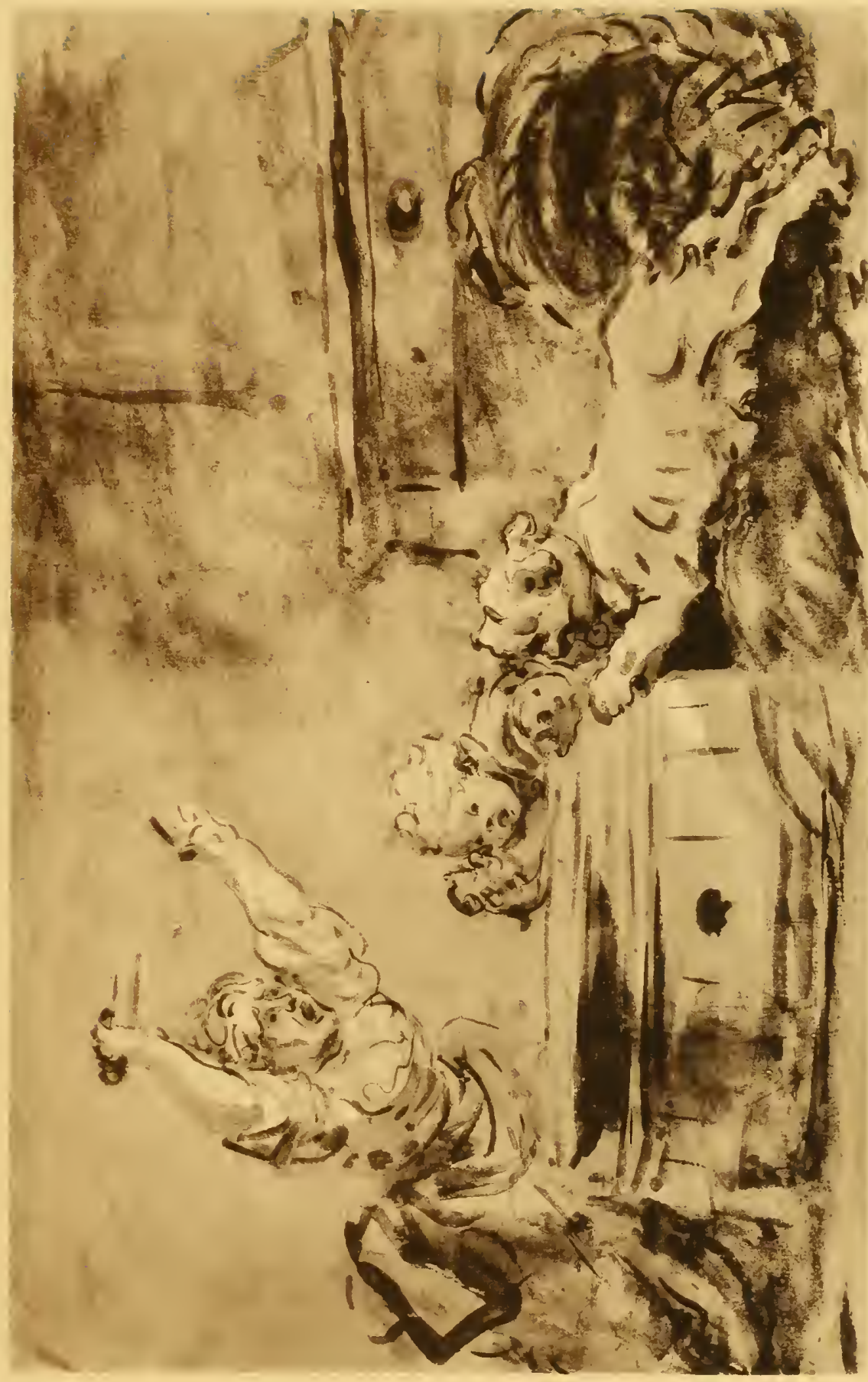






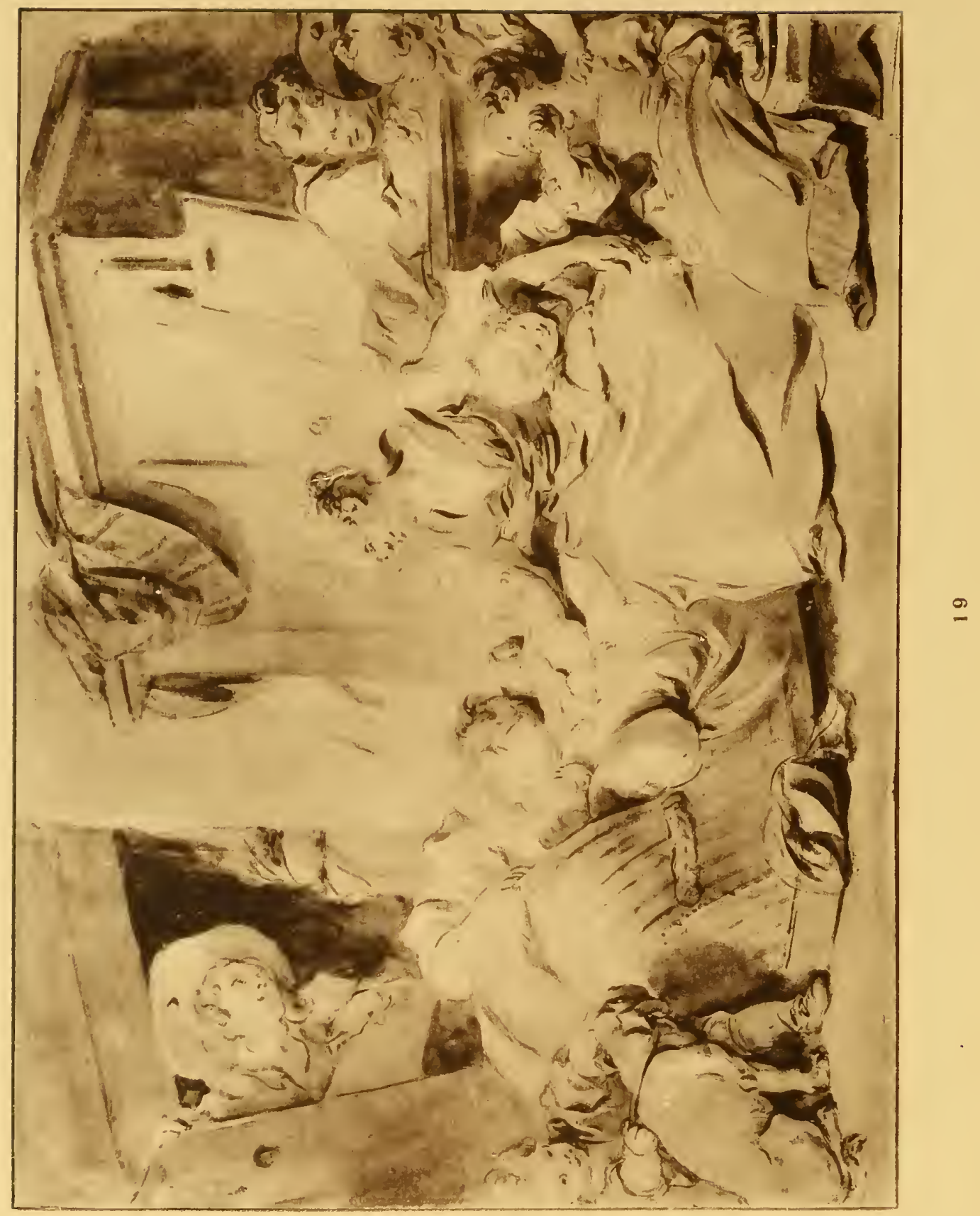




\title{
FRAGONARD
}

\author{
(HONORÉ)
}

\section{0}

19

\section{L'Heureuse Famille.}

Dans un intérieur rustique, une femme assise de face tient auprès d'elle un petit garçon qui taquine deux fillettes, l'une assise et l'autre debout, à droite. Elle se penche à gauche pour caresser un bébé nu, couché dans son berceau, et qu'une autre femme, agenouillée derrière, embrasse. A la tête du berceau, tout à fait à gauche, un bambin joue avec un chien. Au fond, deux hommes, - l'un à gauche, coiffé d'un grand chapeau et accoudé à une clôture; l'autre, à droite, tête nue, appuyé à une table, - contemplent la scène en souriant.

Sépia.

Haut., $33_{4}$ millim.; larg., 454 millim.

Repr. dans M. Tourneux, la Collection J. Doucet, etc. (les Arts, op. cit., p. I7), sous le titre: Visite à la nourrice.

Variante de l'Heureuse Fécondité, gravée par C.-P. Marillier et par N. de Launay.

Cadre style Louị XVI, bois sculpté et doré. 


\section{FRAGONARD}

(HONORE)

20

\section{Le Songe du mendiant.}

Dans une salle voûtée, un vieux mendiant s'est endormi, assis par terre, à gauche, entre deux coffres, près de son chien. La tête inclinée sur la poitrine, le chapeau tombé par derrière, le bras droit étendu, le gauche accoudé et ramené sur le front, il croise ses jambes nues devant le feu qui flambe au milieu de la pièce et voit en rêve une femme, debout à droite, se pencher au-dessus du foyer pour lever le couvercle d'une marmite, d'où s'échappe un nuage de vapeur, tandis qu'au fond, trois jeunes femmes et deux fillettes suivent des yeux la scène.

Signé à gauche, en oblique, sur un morceau de bois : Frago.

Bistre.

Haut., 336 millim, ; larg., 505 millim.

Collection Walferdin (vente à Paris, avril $1880, \mathrm{n}^{\circ} 202$ ), sous le titre : le Songe; collection de $\mathrm{M}^{\mathrm{me}}$ Ernesta Stern. -.. Une composition analogue, mais de dimensions moindres (h. 0,240 sur 1. o,350) a passé à la 3e vente Thibaudeau (Paris, avril 1857 , $\left.\mathrm{n}^{0} 726\right)$, sous le tilire: le Songe.

Repr. dans P. de Nolhac, H. Fragonard (frontisp., P. 49); - dans M. Tourneux, la Collection J. Doucet, etc. (les Arts, op. cit., p. 16); - et en fac-similé par la Société de reproduction des dessins de maîtres (1 re année, 1909).

Le vieillard endormi a été presque identiquement replacé par Fragonard dans une de ses peintures, Souviens-toi, qui appartient également à la collection Jacques Doucet. Voir aux Peintures, no 147.

Cf. le baron R. Porialis, H. Fragonard, op. cit., catal., p. 3 r3.

Cadre en partie ancien, époque Louis XV, bois sculpté et doré. 


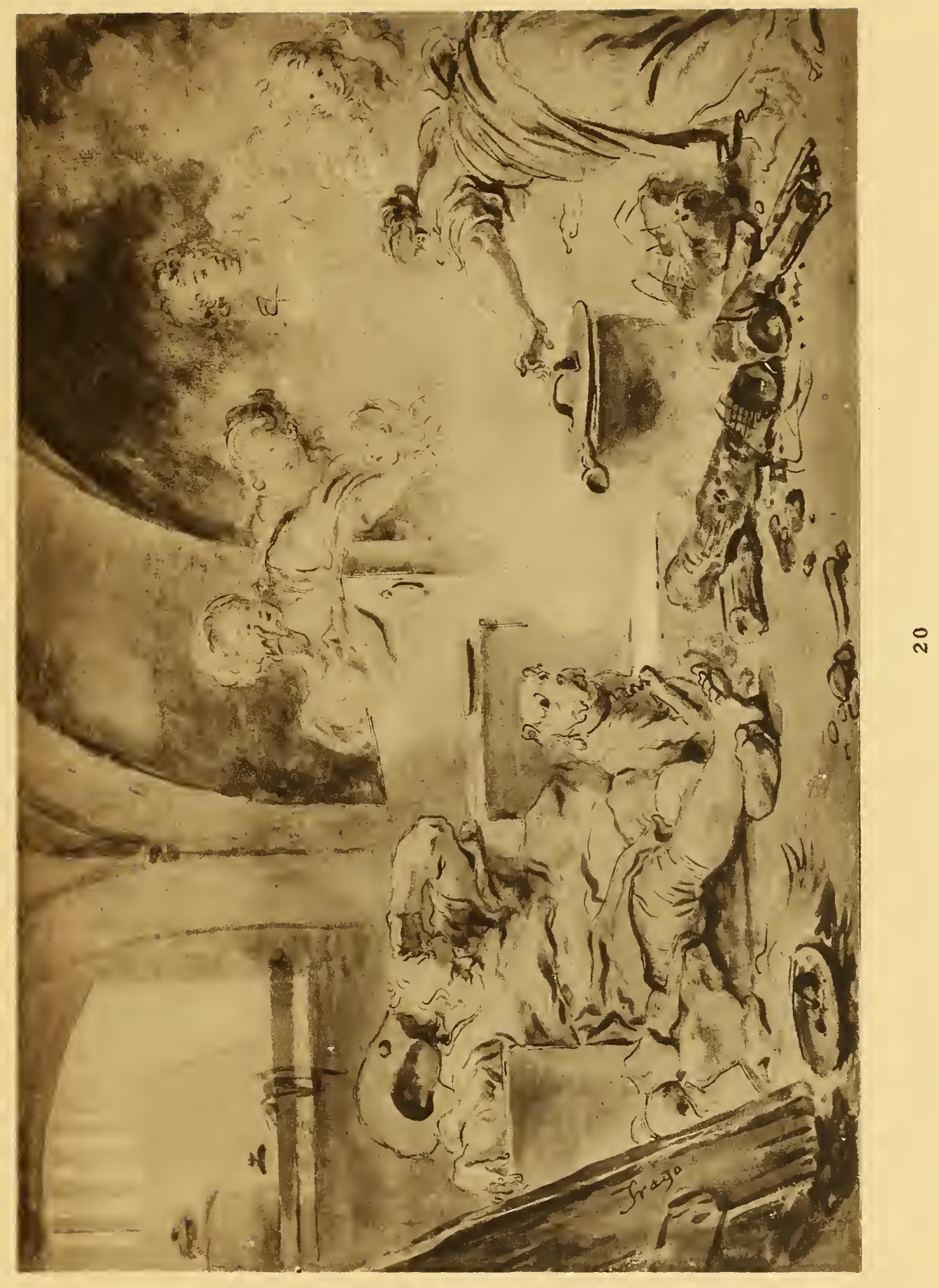






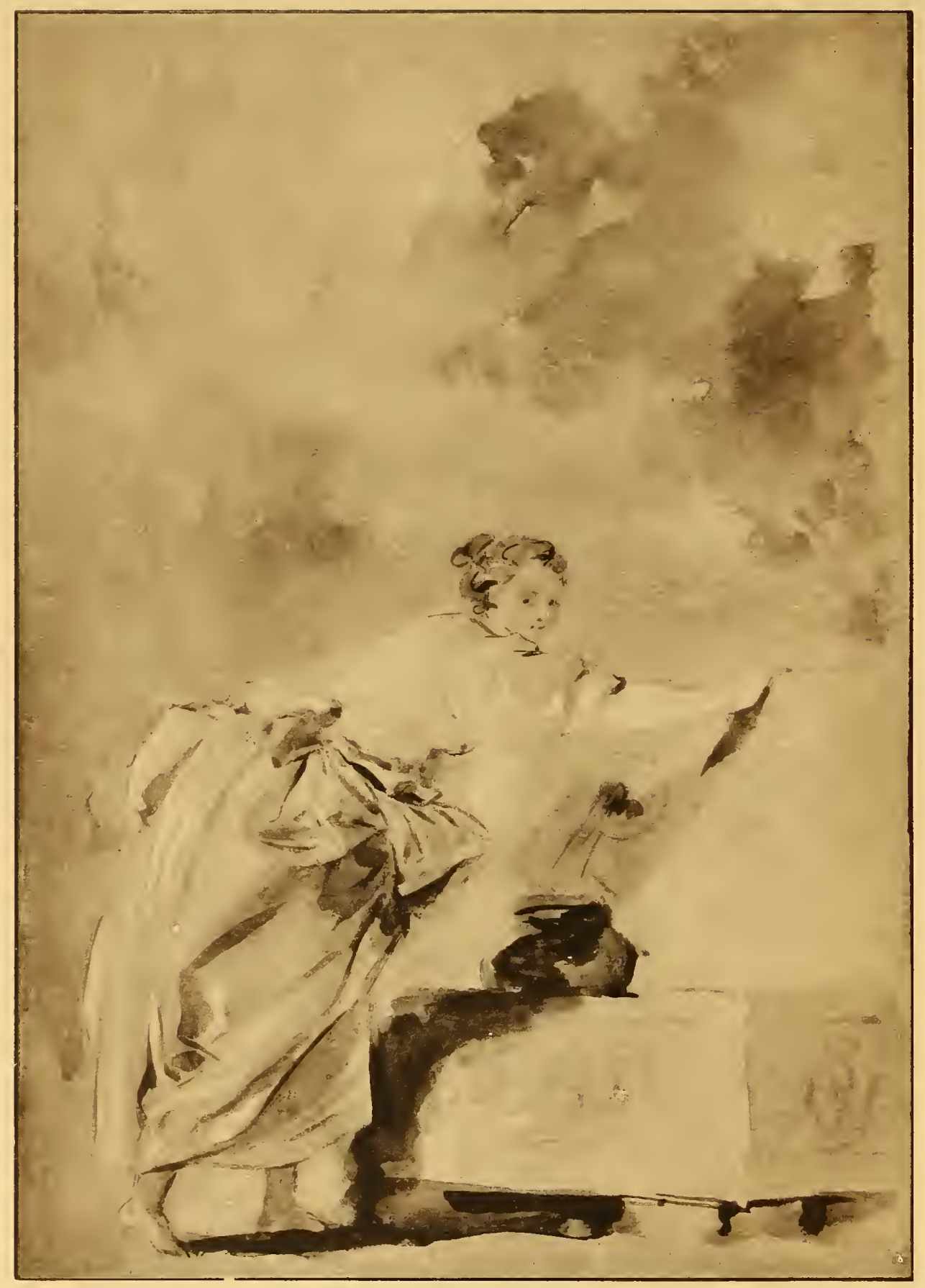

21 


\section{FRAGONARD}

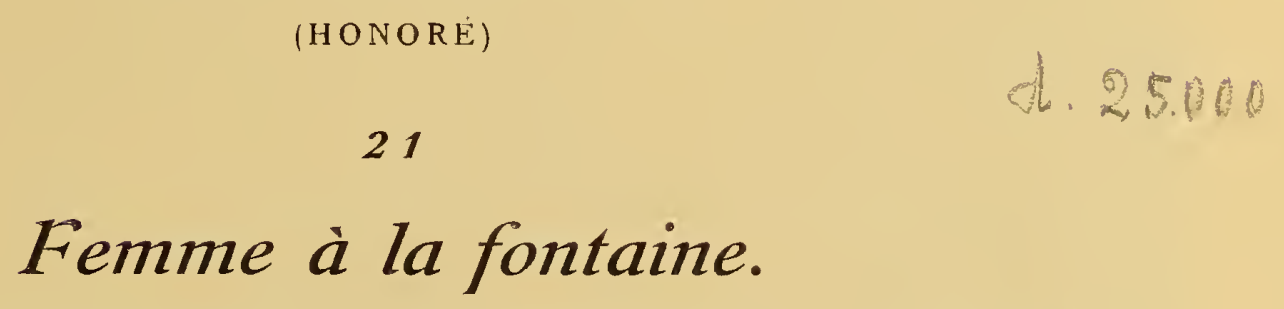

Tête nue, la jupe légèrement retroussée, elle est debout, le corps de profil vers la droite, le visage de trois-quarts tourné vers le spectateur, et se penche en avant, la main droite appuyée sur le mur de la fontaine. L'eau coule dans un vase posé sur une vasque rectangulaire. Fond d'arbres à peine indiqués.

Sépia.

$$
\text { Haut., } 345 \text { millim.; larg., } 242 \text { millim. }
$$
fronton.

Cadre ancien, époque Louis XVI, bois sculptė et doré, avec fleuron et ruban au 


\section{FRAGONARD}

(HONORE)

\section{Passage au chemin de Savone à Gênes.}

Sur un chemin en travers duquel un arbre est tombé, - que deux hommes, l'un en bas et l'autre monté sur un mur à droite, débitent à coups de hache, - toute une compagnie de voyageurs est arrêtée devant une maison que l'on voit à gauche et à laquelle on accède par un escalier à double rampe. Au pied de cet escalier, deux femmes. chevauchant des mulets, font boire leurs montures dans une auge de pierre, sous les regards d'une troisième femme, debout tout à fait à gauche. Au milieu de la composition, on voit un homme à pied tenant un mulet par la selle, et un autre homme à cheval qui montre du doigt le chemin à un personnage debout près de lui, le chapeau à la mäin. A droite, un groupe de cavaliers sur des mulets.

On lit en bas, à gauche: Passage au chemin de Savone à Gênes. Frago. fecit, le $179^{\text {bre }}$ I 773 .

Sépia.

Hauts 287 millim.; larg., 368 millim.

Peut-ètre la Halte à la fontaine, de la vente Fourau (Paris, $1869, n^{\circ}$ I 15 )......

Repr. dans le baron R. Portalis, H. Fragonard, P. I57, sous le titre : la Halte.

Épisode du voyage de Fragonard en Italie avec le financier Bergeret, en I 773-I 774 . Embarquée à Antibes, la compagnie, qui compreńait Fragonard et sa femme, Bergeret et son fils, une gouvernante et des domestiques, atteignit San Remo le 12 novembre 1773 et partit le lendemain pour Gênes, par la voie de terre. Bergeret a décrit la "cavalcade ": " 12 mulets avec quatre hommes.à pied, et, de notre bande, 10 personnes, dont deux femmes et aussi sur des mulets; voyez tout cet étalage, et 2 mulets garnis de notre menu équipage, couverts de nos peaux de tigre... " (Bergeret et Fragonard, Journal inédit d'un voyage en Italie, publ. par A. Tornézy; Paris, 1895, p. 95). Arrivés à Savone le 16 novembre, les voyageurs en repartirent le lendemain i 7 , quittèrent leurs mulets après sept heures de marche, à Voltri, et gagnèrent Gênes en deux heures de calèche (ibid., p. I05): c'est sans doute au cours de cette journée que se produisit l'épisode dessiné par Fragonard.

Cf. le baron R. Portalis, H. Fragonard, op.cit.,p. 158 ; et catal., p. 296 (avec la date du 23 sept. $(773$ ).

Cadre style Louis XVI, bois sculpté et doré; au fronton, une couronne de roses et des branches de feuillage. 


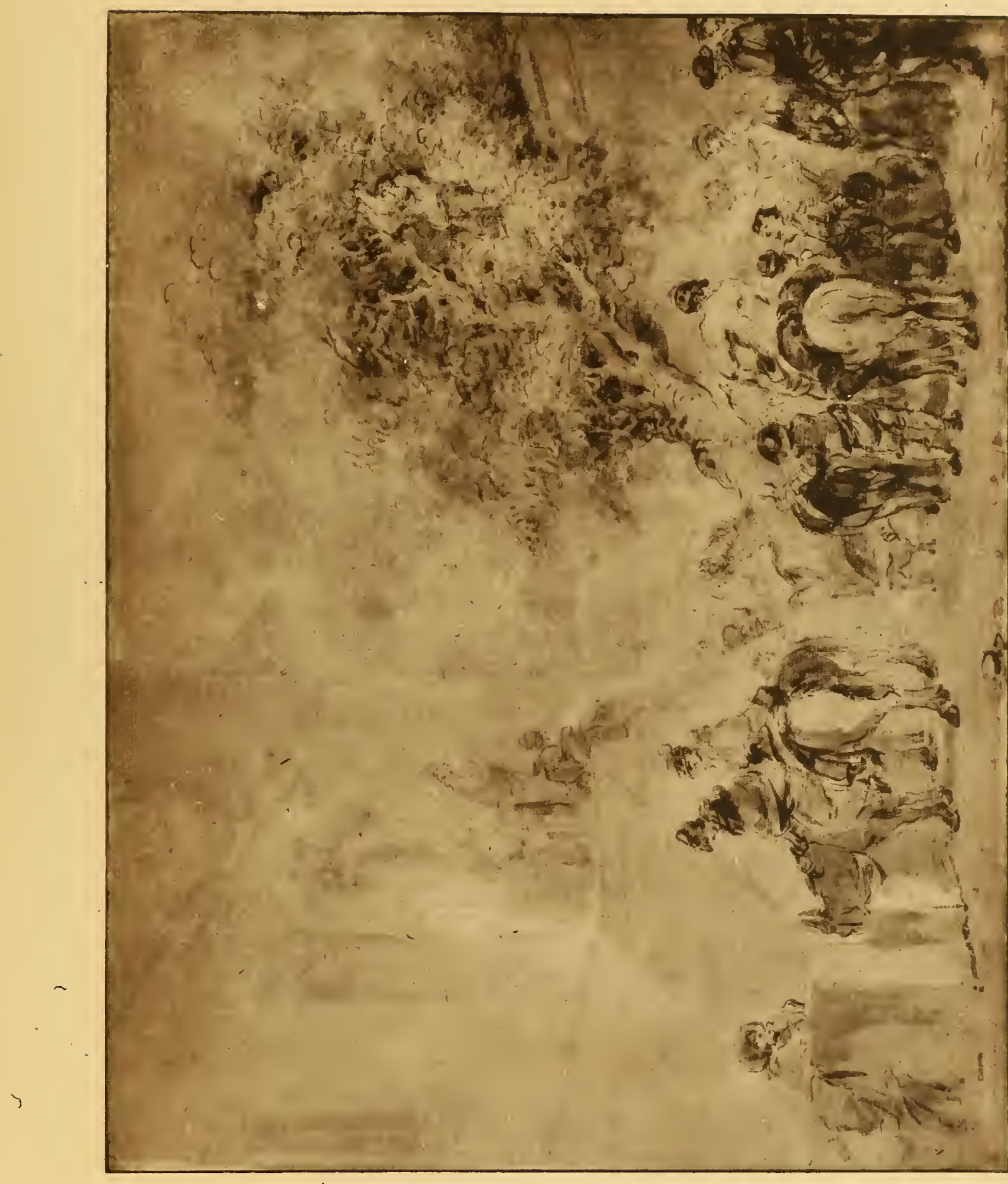






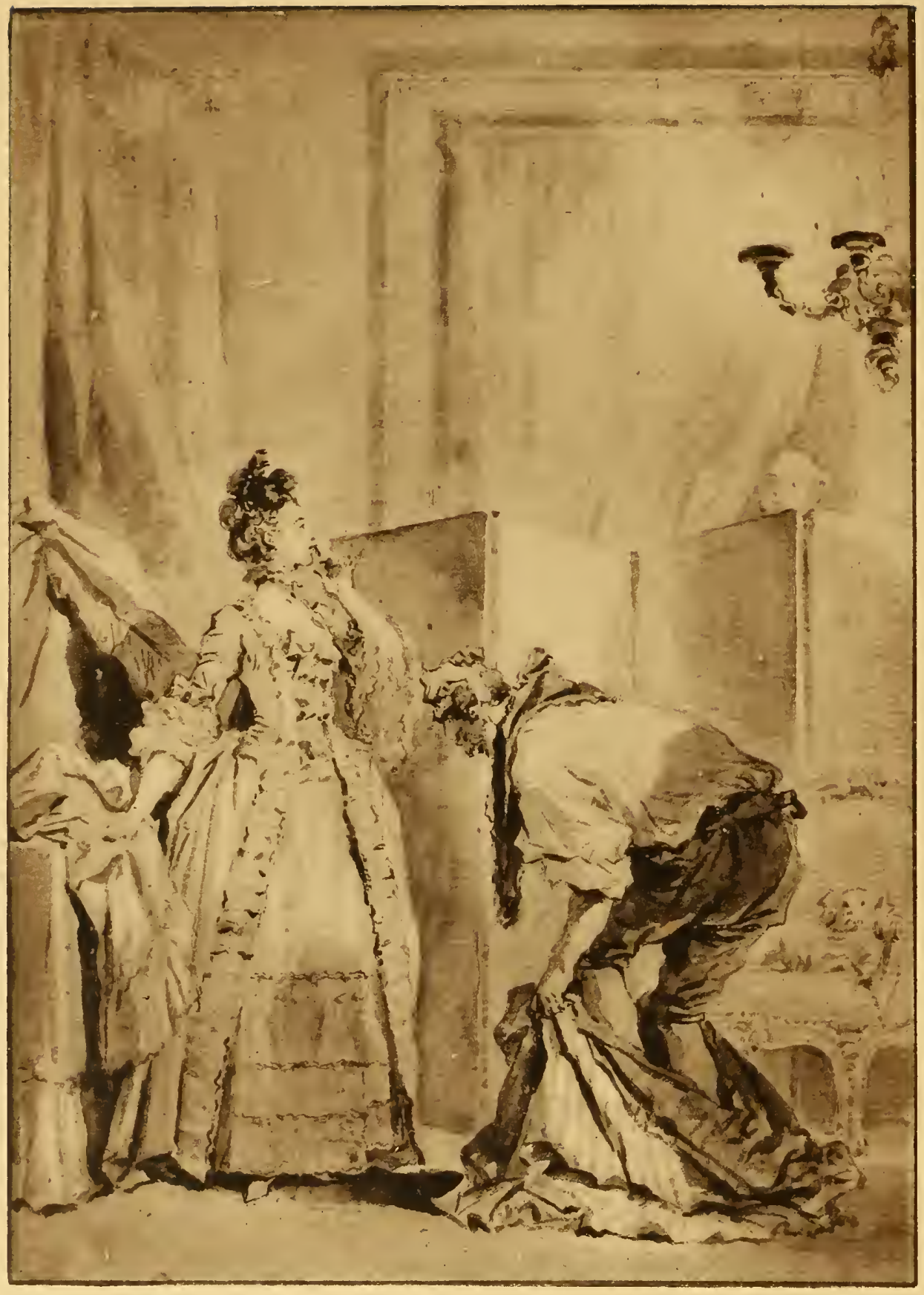

23 


\section{FRAGONARD}

(HONORÉ)

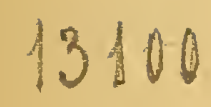

\section{3}

\section{Le Cocu battu et content.}

Dans une chambre à coucher, fermée au fond par une portière, éclairée par un lustre qu'on voit à droite et coupée par un paravent dans le sens de la largeur, "messire Bon ", le barbon jaloux, coiffé d'une cornette et le cou entouré d'une mantille, achève de se déguiser en femme. Pendant qu'il se baisse pour passer un jupon par dessus ses chausses, sa femme debout à gauche, tourne la tête vers'le fond de la pièce et fait un signe de la main pour commander le silence à son galant, qui montre sa tête à la porte en écartant un coin de la draperie.

Sépia.

Haut., 20r millim.; larg., 142 millim.

Dessin exécuté en vue de l'illustration du second des Contes de La Fontaine, le Cocu battu et content, pour l'édition Didot $\left(\mathrm{I} 795, \mathrm{in}-4^{\circ}\right)$. Il a été gravé en contre-partie par J.-L. Delignon.

Sur les illustrations des Contes de La Fontaine par Fragonard, cf, le baron R. Portalis, $H$. Fragonard, op. cit., catal., p. 296.

Cadre style Louis XVI, bois sculpté et doré. 


\section{FREUDEBERG \\ (SIGISMOND FREUDENBERGER ou) \\ Berne, $17+5 \div$ Berne, 180 .}

\section{Zémire et Azor, ou l'Heureuse union.}

Dans un luxueux intérieur, un gentilhomme, vêtu d'un habit gris et d'une culotte noire, coiffé d'une petite casquette à visière, portant des bas blancs, des souliers noirs à talons rouges et à boucles d'argent, est assis, à droite, au coin de la cheminée, dans un vaste fauteuil. Il a le bras droit passé autour de la taille d'une jeune femme, en déshabillé blanc à rubans roses, qu'il tient assise sur son genou et dont il caresse, de la main gauche, les longs cheveux dénoués et tombant jusqu'à la taille. A gauche, devant la cheminée, surmontée d'une glace, un écran à chinoiseries; sur la cheminée, un vase de fleurs et des livres; à droite de la glace, un bras-applique à deux lumières. Derrière le fauteuil, une porte et le montant d'un lambrequin. Sur le tapis, à droite, un livre ouvert.

Aquarelle.

Haut., 336 millim.; larg., 253 millim.

On lit en bas, à droite, au-dessous du dessin, cette note manuscrite à l'encre : M. le duc de Bourbon-Conti et Mlle Allard, de la Comédie-Italienne. Le titre : Zémire et $A$ zor est celui que porte la monture.

Gravé par L. Bosse, en contre-partie, sous le titre de l'Heureuse union, puis sous celui de la Matinée; la gravure est annoncée dans le Mercure de France de juillet i 776 , p. 204 .

Repr. en fac-similé par la Société de reproduction des dessins de maîtres (3`année, IgI I), avec une notice par E. Dacier.

On a fait remarquer dans cette notice: d'une part, que ce titre de Zémire et Azor peut servir à dater l'œuvre approximativement : elle ne serait donc pas antérieure à la première représentation du célèbre opéra-comique de Grétry (9 novembre 1771); d'autre part, que la note manuscrite fait allusion à la liaison du prince (et non du duc) de Conti avee Mlle Allard, la danseuse de l'Opéra (et non de la Comédie-Italienne), liaison qu'on peut placer aux environs de 1768 (G. Capon et R. Yves-Plessis, Vie privée du Prince de Conti, Paris, 1907, p. 268).

Cadre style Louis XVI, bois sculpté et doré. 


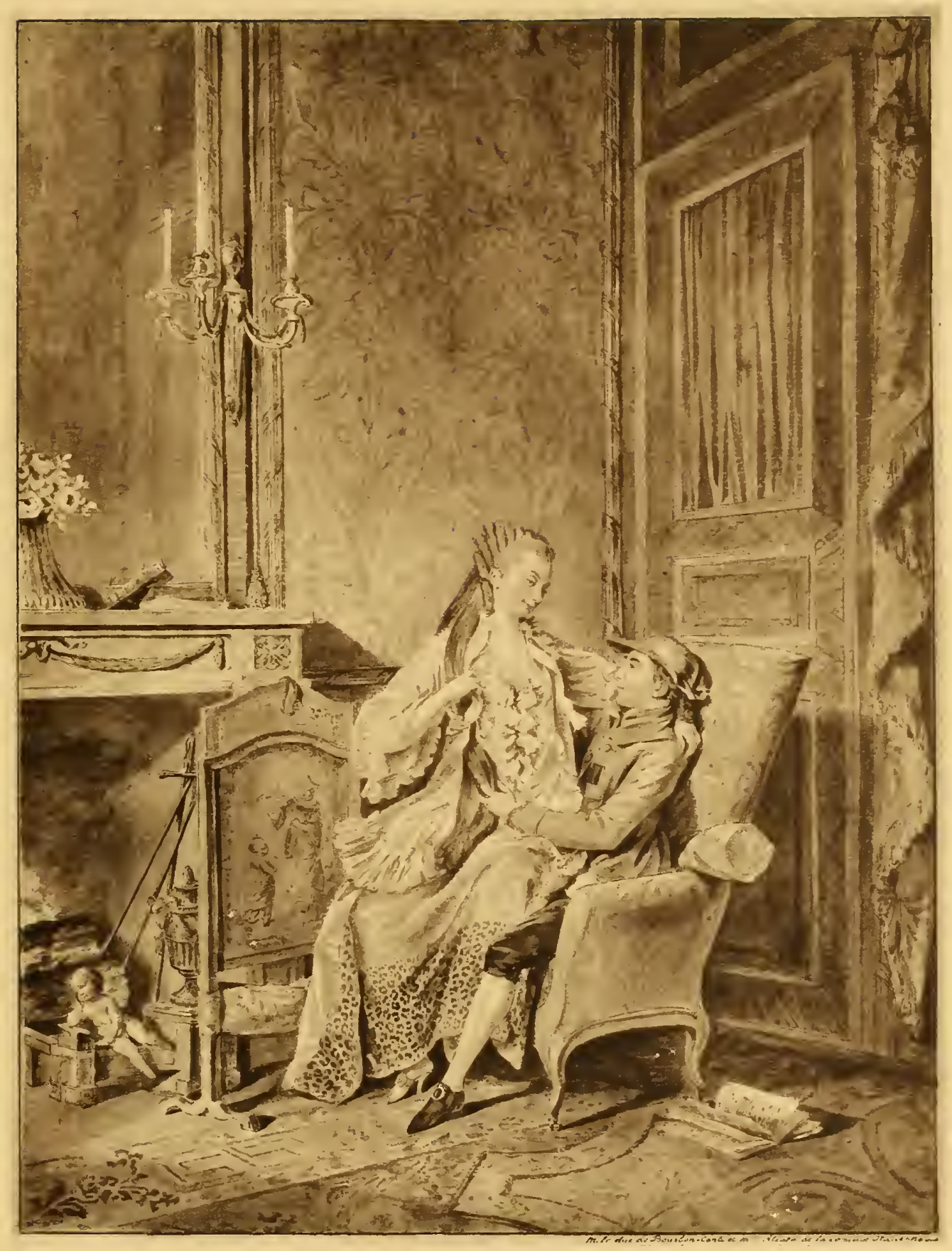

24 




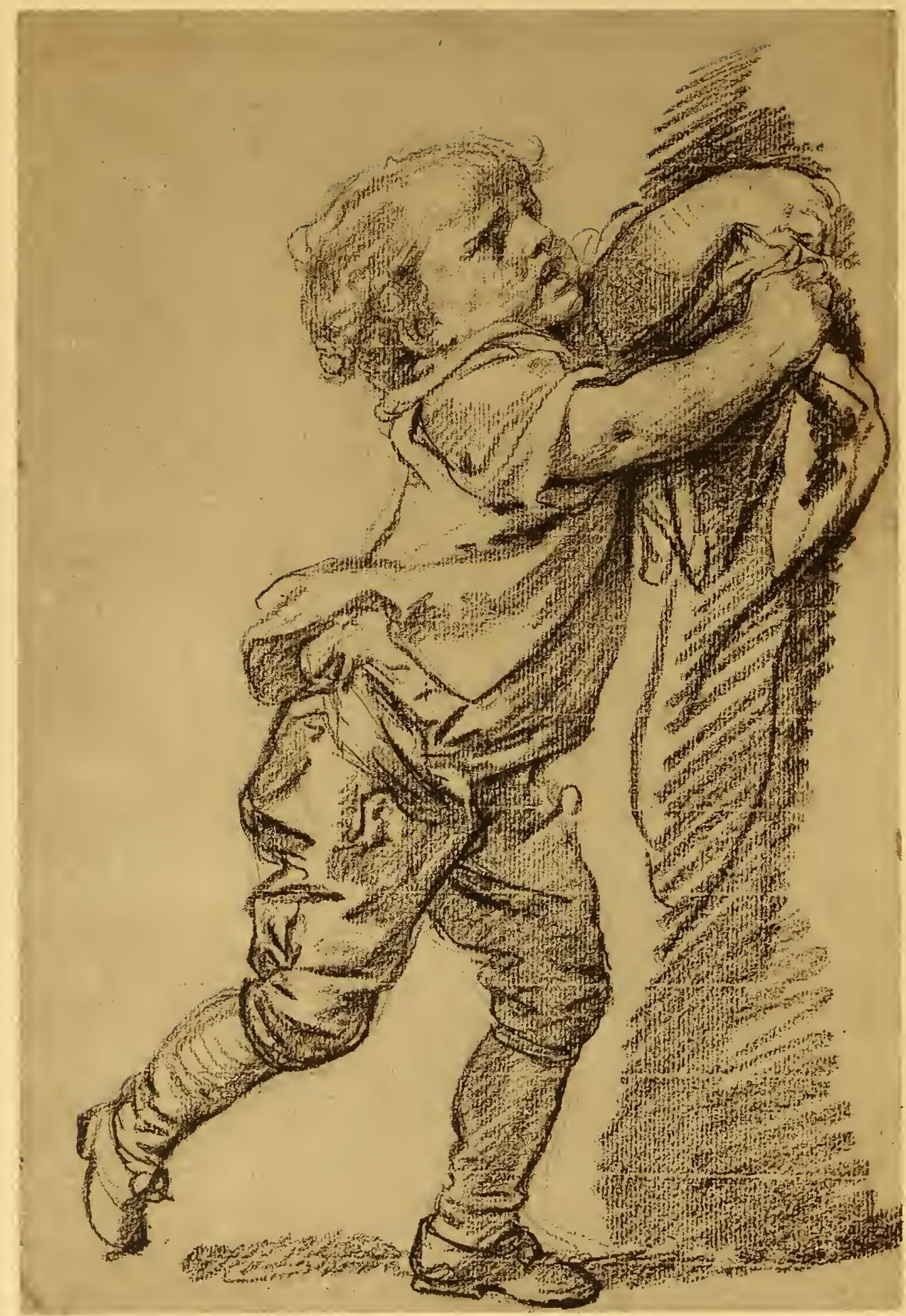

25 


\title{
GREUZE
}

\author{
( JEAN-BAPTISTE)
}

Tournus, $1725+$ Paris, $\mathbf{1} 805$

5600 Pandint

\section{5}

\section{Étude d'enfant.}

Le corps de profil tourné vers la droite, il semble courir en se cramponnant des deux mains, les bras levés, à une draperie; son visage, de trois-quarts à droite, exprime le chagrin.

Sanguine.

Haut., 410 millim.; larg., 284 millim.

Étude pour la Malédiction paternelle (esquisse, Salon de $1765, \mathrm{n}^{\circ} 125$; auj. musée du Louvre, catal. Villot, $n^{\circ} 261$ ) : c'est l'enfant qui, au centre de la composition, se cramponne en pleurant aux vêtements du fils maudit et essaie de le retenir.

Le Catalogue raisonné de l'auvre de Greuze, par J. Martin et Ch. Masson (Paris, 1906), mentionne sous le no 1487 : un "Enfant courant après sa mère, sanguine, étude pour la Malédiction paternelle "; comme il n'y a pas, dans la Malédiction paternelle, d'enfant courant après sa mère, mais seulement un enfant courant après son frère aîné, il semblerait au premier abord que cette désignation, malgré une légère inexactitude, pût s'appliquer au présent dessin. Pourtant, il convient de faire observer que, dans l'ouvrage de MM. J. Martin et Ch. Masson, le n ${ }^{0} 1487$ est indiqué comme provenant de la vente Nicolas J. Soutzo (février 1876 ); or, voici comment est décrit, sous le no 10 du catalogue de la vente Soutzo, le dessin de Greuze auquel il est fait allusion: "La Frayeur. Cette intéressante tête d'étude a été à peu près reproduite par Greuze dans son tableau du Fils puni... etc. " On le voit, ceci ne correspond en aucune façon à notre sanguine. Il semble donc que les auteurs du Catal. raisonné de l'ceuvre de Greuze ont confondu daux études d'enfants, à la sanguine, l'une pour la Malédiction paternelle et l'autre, - une tête, - pour le Fils puni.

Cadre style Louis XVI, bois sculpté et doré, avec ruban au fronton. 


\section{HILAIR}

(JEA N - BAPTISTE)

Exposa à partir de 1780 ; mourut après 1822 .

26

\section{Jeune Femme cueillant une fleur.}

Elle est vue presque de dos et tournée vers la droite, cueillant une fleur. Serrés par un ruban rougeâtre qui fait le tour de la tête, ses cheveux châtains forment une couronne bouffante autour du peigne qui les retient par derrière et d'où tombe un léger voile. Elle a les épaules couvertes d'un mantelet noir, au coqueluchon doublé d'étoffe blanche, et porte une robe rose à gros plis, dont elle relève un peu la traîne de sa main gauche ramenée par derrière et appuyée sur la hanche. Fond bleuté.

Crayon noir rehaussé de pastel.

Haut., 462 millim.; larg., 336 millim.

Catalogué sous le nom de Fragonard, par le baron R. Portalis (Fragonard, op. cit., p. 305), qui le dit provenir de la collection Villot.

Plus encore que la femme debout, dans la Lecture, par Hilair, au musée du Louvre, ce dessin rappelle un des personnages du groupe de droite, dans les Saltimbanques au château, la peinture de cet artiste qui a passé, en 1903, à la vente Lelong et qui est reproduite au catalogue de la vente Lelong ( $\mathrm{xvi11^{e }}$ siècle, t. I, $\mathrm{n}^{\circ} \mathbf{2} \mathrm{I}$ ), et dans une étude d'Henry Marcel sur J.-B. Hilair (Revue de l'art ancien et moderne, t. XIV, 1.903, p. 207).

Cadre style Louis XVI, bois sculpté et doré, à fronton. 


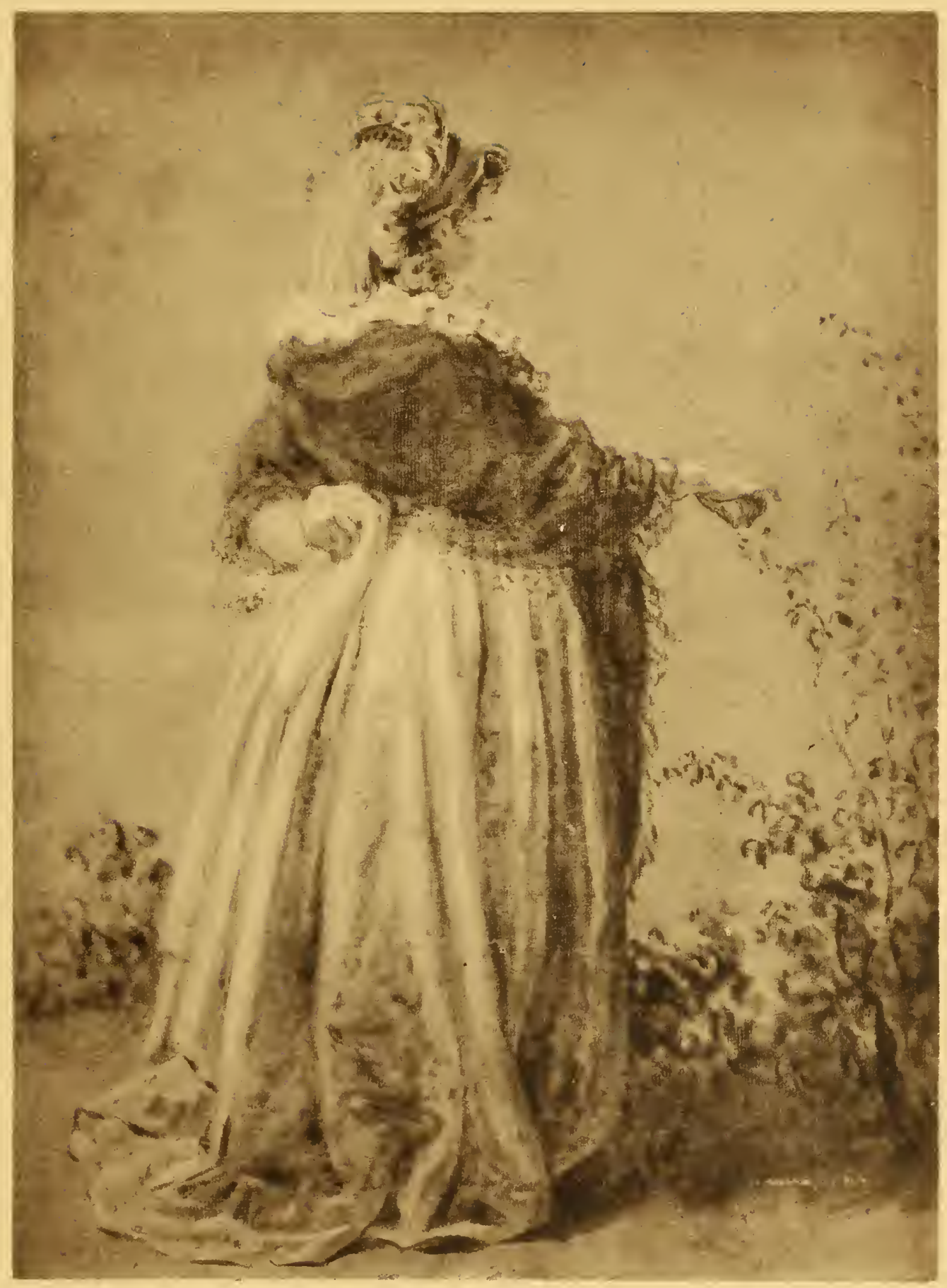

26 




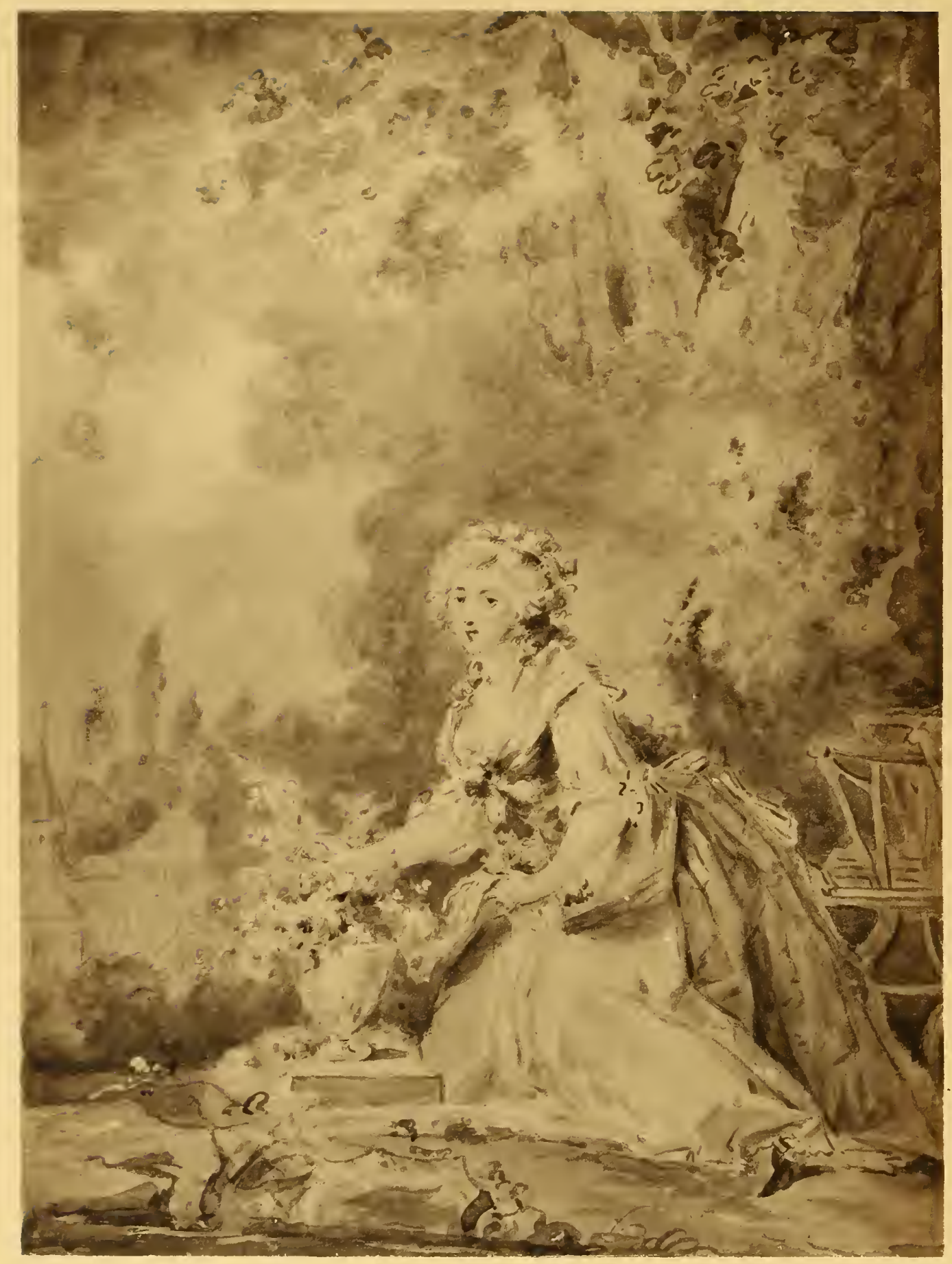




\section{HOIN}

214200

(CLAUDE)

Dijon, $1750 \div$ Dijon, 1817 .

\section{7 \\ Jeune Femme arrangeant des fleurs \\ dans un vase.}

Vêtue d'une jupe bleu ciel et d'un corsage décolleté, d'un bleu plus foncé, au devant duquel s'attachent les deux pointes d'un fichu, elle est agenouillée et tournée de trois-quarts vers la gauche, le regard dirigé vers le spectateur, et dispose dans un vase, placé sur un petit socle, les fleurs qu'elle porte dans son tablier. A droite, derrière un banc rustique, de grands arbres; à gauche, au fond, quelques maisons et le clocher d'une église.

Aquarelle et gouache.

Haut., 178 millim.; larg.. 130 millim.

Cf. le baron R. Portalis, Cl. Hoin (Gazette des Beaux-Arts, 1899, t. II, p. 458).

Cadre ancien, époque Louis XVI, bois sculpté et doré, avec fronton orné d'une couronne de fleurs nouée d'un ruban. 


\section{HUET \\ (JEAN-BAPTISTE) \\ Paris, $1745+$ Paris, 181 r. \\ 28 \\ Le Retour du marché.}

Sur un chemin bordé d'arbres, une jeune femme en rose, tenant un bébé sur ses genoux et assise sur un petit âne chargé d'un panier, regarde une autre femme, en corsage bleu, debout vers la gauche de la composition, et qui semble lui indiquer la route du geste. A gauche de l'âne, deux enfants jouant avec un mouton; au premier plan, un bouc et des brebis qu'un chien effraie par ses aboiements; à droite, derrière l'âne, un mouton et un bœuf. Paysage et ciel bleuâtres.

Signé en bas, à gauche: J.-B. Huet, 1778 .

Pierre noire rehaussée de pastel, sur papier gris.

Haut., 5 т millim.; larg., 6ro millim.

Cadre ancien, époque Régence, bois sculpté et doré. 


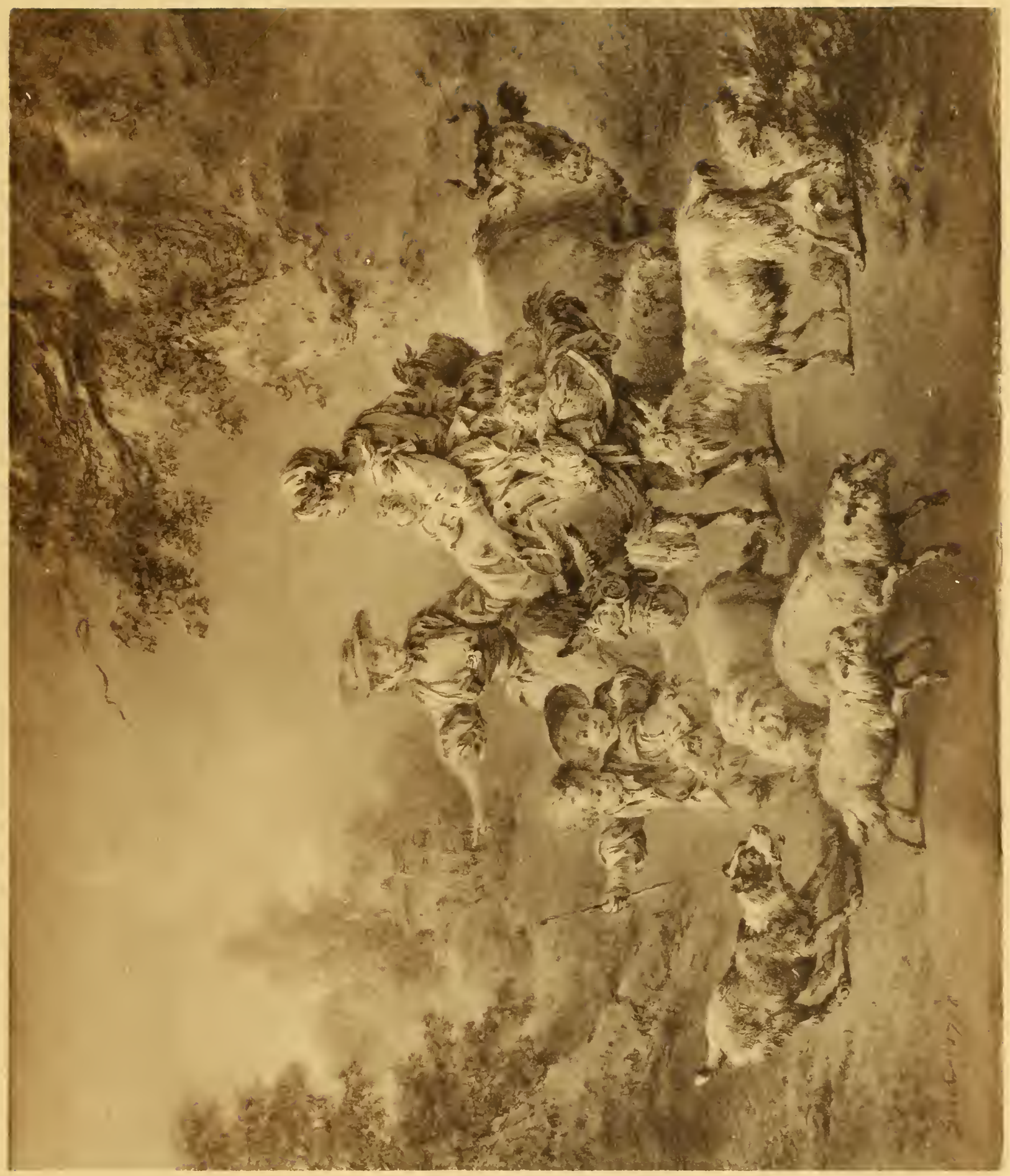






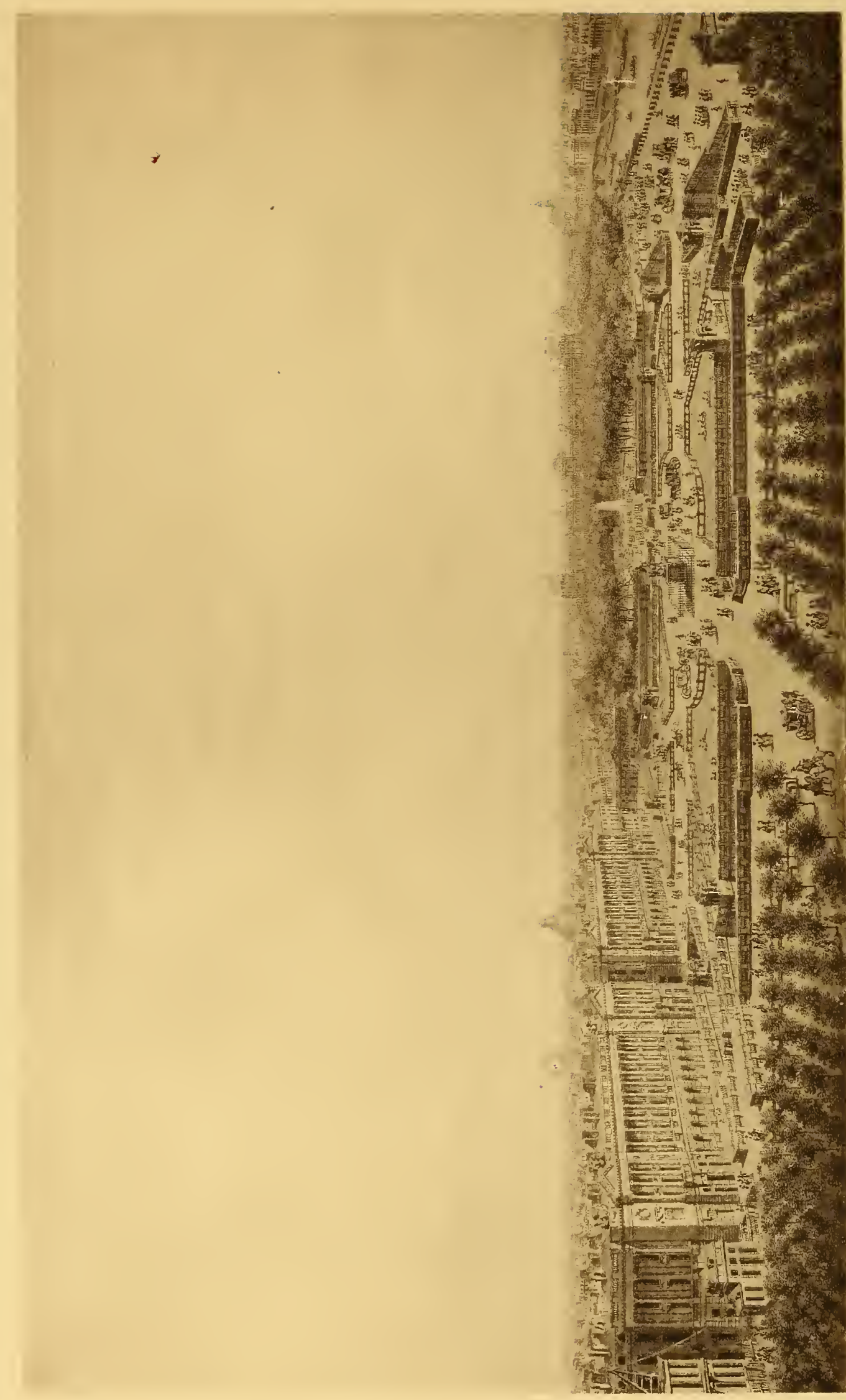

i 


\title{
LESPIN A S S E
}

\author{
(LOUIS-NICOLAS DE)
}

Pouilly (Nièvre), $1734 \div 1808$.

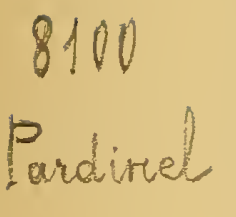

\section{9}

\section{Perspective de la place Louis $X V$ vue du côté des Champs-Élysées, en 1778 .}

La place, dont le monument de Bouchardon, inauguré en 1763, occupe le centre, est entourée d'un fossé gazonné, bordé de balustrades. $\mathrm{Au}$ nord, c'est-à-dire à gauche : les deux pavillons du Garde-Meuble, séparés par la rue Royale; en face : les jardins et le palais des Tuileries; à droite : la Seine et les quais; au premier plan: l'avenue des Champs-Élysées entre ses deux quinconces d'ormes taillés. Au loin, par-dessus les toits, on aperçoit la tour Saint-Jacques, la flèche de la Sainte-Chapelle, les tours de Notre-Dame, le Louvre, le collège des Quatre-Nations, etc.

Signé en bas, sur l'avenue des Champs-Élysées : $D$. $L$.

Aquarelle et gouache sur trait de plume.

Haut., 206 millim.; larg., 339 millim.

Exposition rétrospective de la Ville de Paris, à l'Exposition universelle de rgoo, $\mathrm{n}^{\circ} 183$ bis.

Gravé par Née en 1781 , pour le Voyage pittoresque de la France [par de La Borde, Guettard, Beguillet, etc.] (Paris, $1784^{-1} 79^{2}, 8$ vol.); la gravure se trouve dans le t. I, Estampes, $\mathrm{I}^{\text {er }}$ cahier, 6e livraison, pl. 9 .

Une aquarelle du même auteur, représentant le même sujet, mais de dimensions plus importantes (h. 12 pouces 2 lignes sur 1.23 pouces), a passé à la vente BruunNeergaard (Paris, août $1814, \mathrm{n}^{\circ} 221$ ).

Le titre : Perspective de la place Louis $X V$, yue du côté des Champs-Élisés en 1778 , est écrit à l'encre sur une tablette, à la partie inférieure du cadre. Il fournit d'ailleurs une date intéressante pour l'historique de la place de la Concorde actuelle, représentée ainsi quelques années après son achèvement et telle que la conçut AngeJacques Gabriel. - Voir plus loin, no 53, la composition allégorique de Gabriel de Saint-Aubin relative à l'inauguration de la place Louis XV.

Cadre style Louis XVI, bois sculpté et doré, avec tablette et petite guirlande à la partie inférieure. 


\section{LES P IN A SSE}

(LOUIS-NICOLAS DE

30

Vue du château de Versailles, de l'Orangerie et de la pièce d'eau des Suisses.

Nombreux promeneurs au premier plan, sur l'esplanade entourant la statue équestre de Marcus Curtius et descendant en pente douce vers la pièce d'eau; au fond, l'Orangerie et le Château.

Aquarelle et gouache sur trait de plume.

Haut., 206 millim,; larg., 339 millim.

Exposition rétrospective de la Ville de Paris, à l'Exposition universelle de 1900 , no 183 bis.

Gravé par Liénard, pour le Voyage pittoresque de la France (op. cit.), t. Ier,

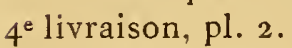

Sur la tablette, à la partie inférieure du cadre, on lit, écrit à l'encre : "Vue du château de Versailles, de l'Orangerie et de la pièce d'eau des Suisses, prise de derrière la statue équestre de Marcus Curtius; ce groupe, qui est de marbre blanc, de même que son piédestal, est du fameux Cavaliero Bernini; et il est à remarquer que le peuple, par corruption et en confondant le nom de l'artiste d'avec celui du sujet, appelle cette statue le Chevalier Berlin (sic), qui, en effet, est généralement connue sous .cette fausse dénomination, de même que la promenade d'alentour. »

Cadre style Louis XVI, bois sculpté et doré, avec tablette et petite guirlande à la partie inférieure. 


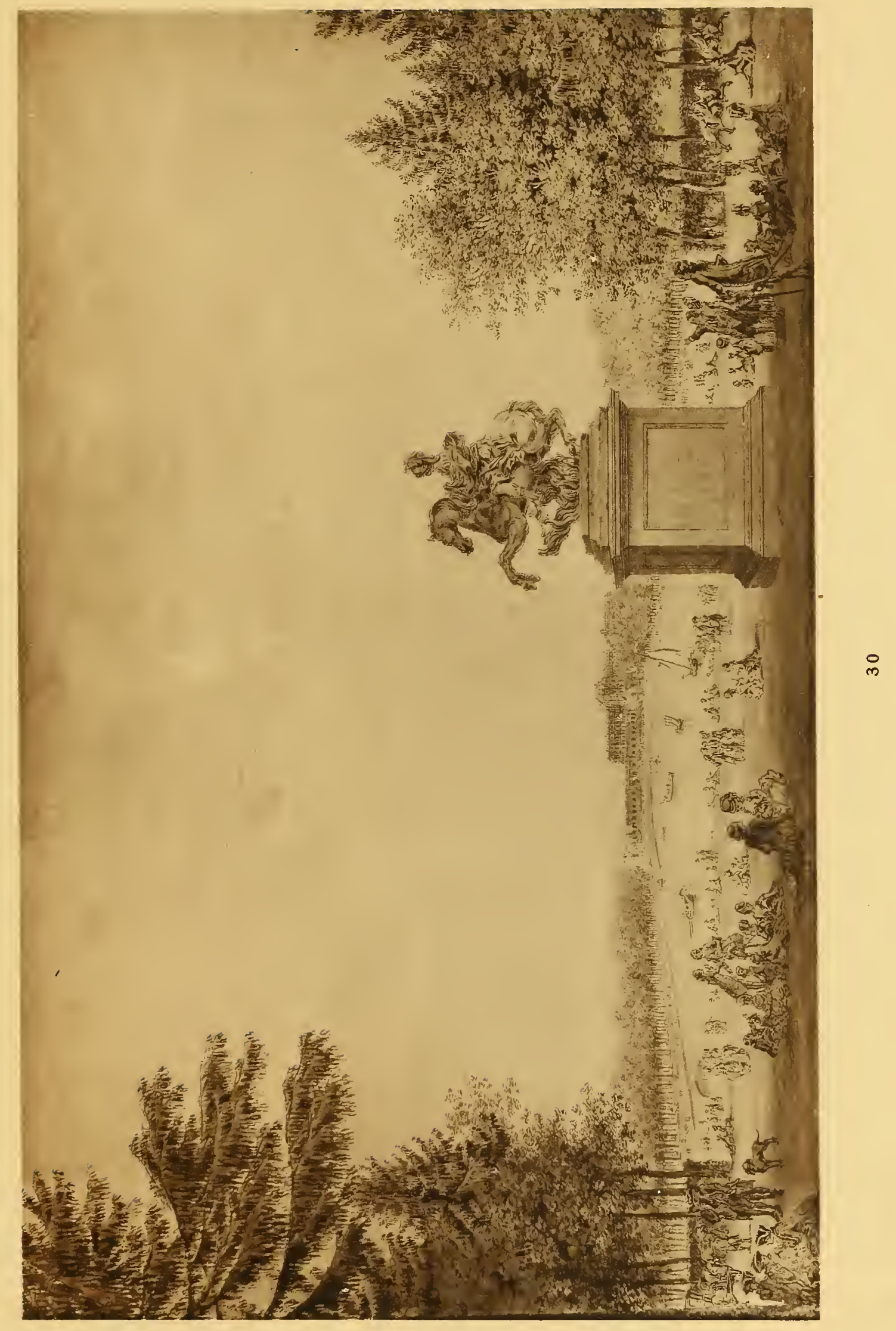






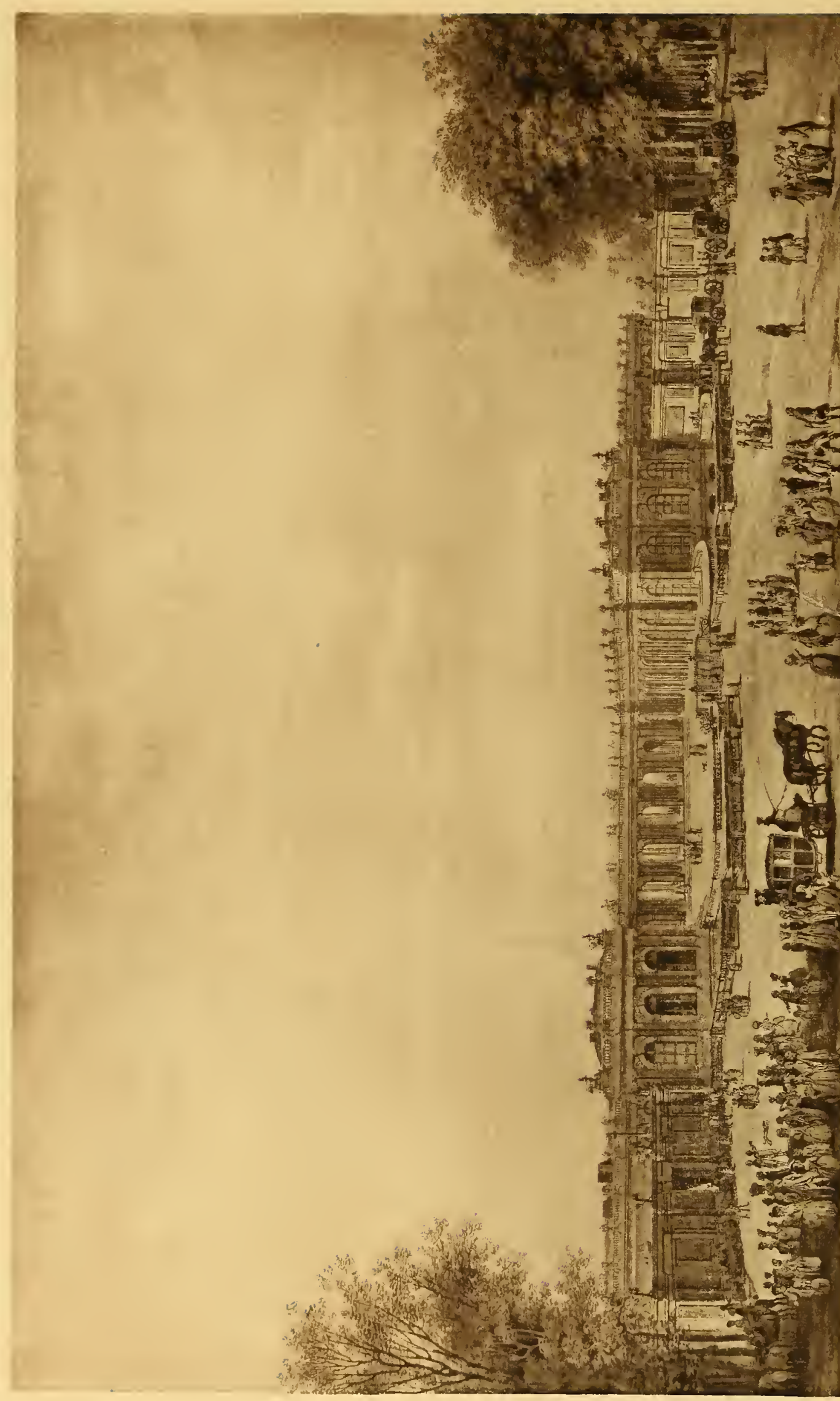




\section{LESPIN ASSE}

(LOUIS-NICOLAS DE)

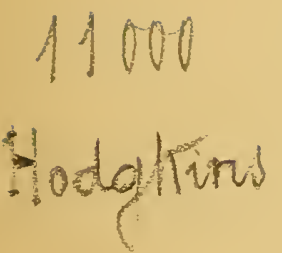

\section{1 \\ Vue du Grand Trianon, prise du côté de l'entrée, en 1780.}

Sur la place qui précède l'entrée, de nombreux personnages, des carrosses, des chevaux attachés aux arbres, etc.

Aquarelle et gouache sur trait de plume.

Haut., 206 millim.; larg., 339 millim.

Exposition rétrospective de la Ville de Paris, à l'Exposition universelle de rgoo, no 183 bis.

Gravé par Née, pour le Voyage pittoresque de la France (op. cit.), t. Ier, $10^{e}$ livraison, pl. 2 I.

Le titre est donné par une inscription manuscrite, à l'encre, sur la tablette inférieure du cadre.

Cadre style Louis XVI, bois sculpté et doré, avec tablette et guirlande à la partie inférieure. 


\title{
LES P I N A S S E
}

\author{
(LOUIS-NICOLAS DE
}

\section{2 \\ Vue du Grand Trianon, prise du côté du canal, en 1780.}

La vue est prise de la rive gauche du canal, sur lequel voguent diverses embarcations de plaisance; à gauche, les deux escaliers conduisant à la terrasse, au delà de laquelle s'étend la façade du palais, avec, en retour d'angle à gauche, la galerie de Trianon-sous-Bois. Quelques promeneurs sur les bords du canal.

Aquarelle et gouache sur trait de plume.

Haut., 206 millim.; larg., 339 millim.

Exposition rétrospective de la Ville de Paris, à l'Exposition universelle de 1900 , n० 183 bis.

Gravé par Duparc pour le Voyage pittoresque de la France (op. cit.), t. Ier, $9^{\text {e livraison, pl. } 15 .}$

Le titre est donné par une inscription manuscrite, à l'encre, sur la tablette inférieure du cadre.

Cadre style Louis XVI, bois sculpté et doré, a vec tablette et guirlande à la partie inférieure. 


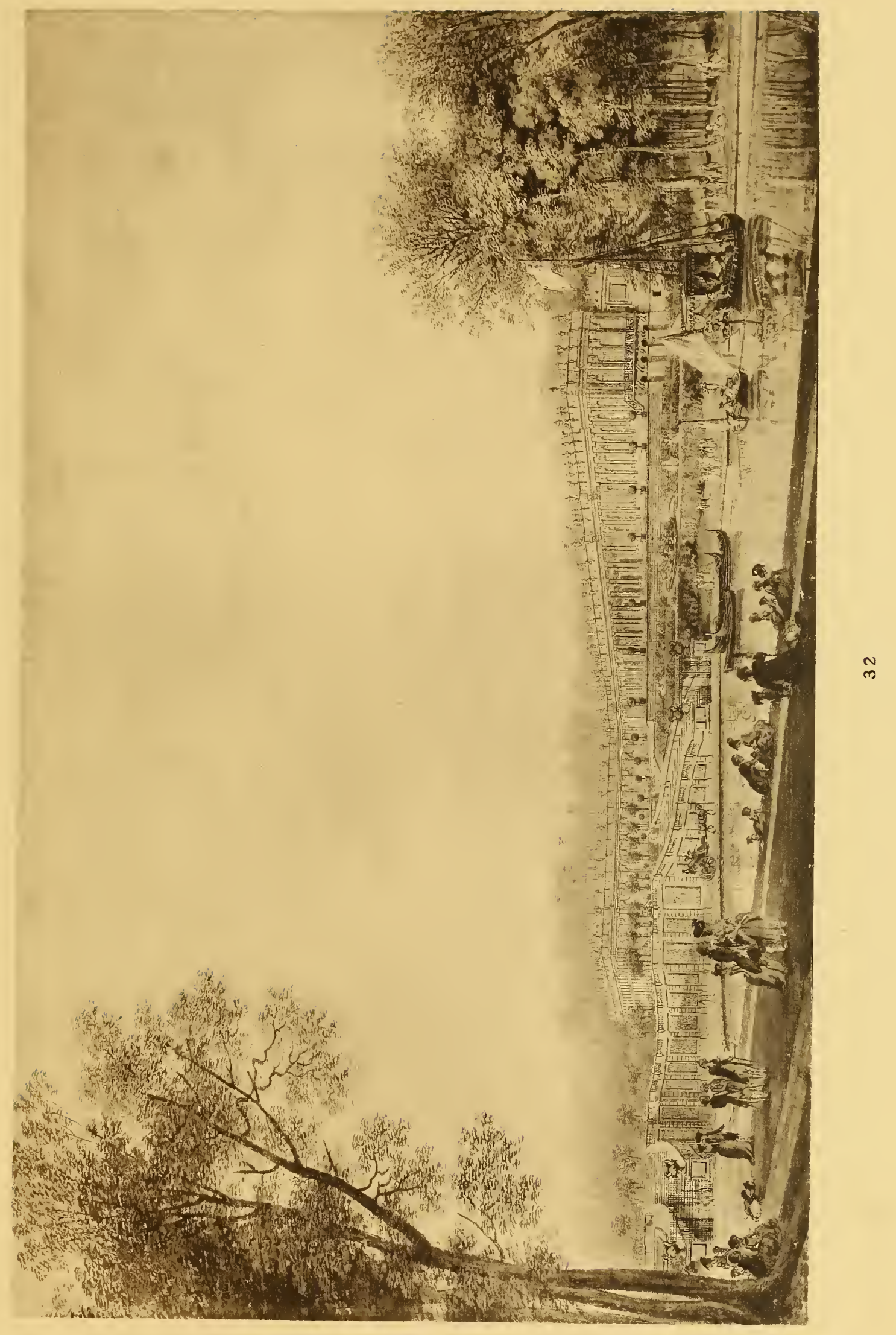






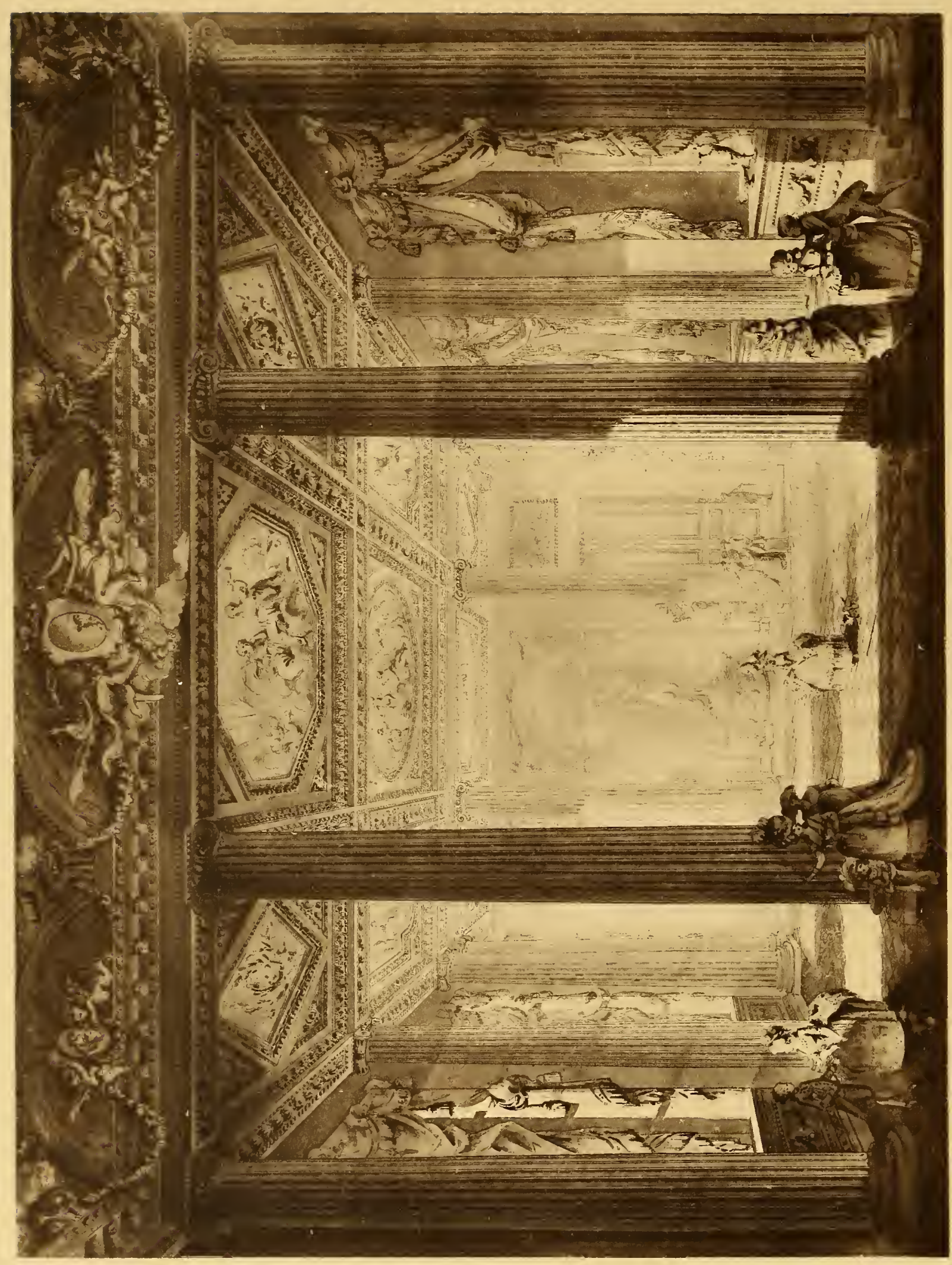




\title{
MARÉCHAL
}

\author{
( J. B. $)$
}

Fin du $x \mathrm{xII}^{\circ}$ et commencement du $\mathrm{x} I \mathrm{x}^{\bullet}$ siècle.

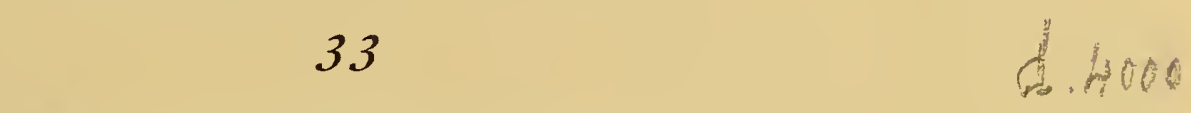

\section{Intérieur de palais.}

C'est une sorte d'imposant atrium rectangulaire dont le riche plafond à caissons est supporté par huit colonnes engagées, - quatre sur la paroi de gauche et quatre sur celle de droite, - et par quatre autres colonnes, - deux au premier plan et deux au fond, sur la paroi qui fait face au spectateur. Là, une petite niche, ménagée entre les colonnes, abrite une statue d'Apollon Citharède debout sur une base sculptée. A gauche, par trois fenêtres garnies de rideaux à crépines, drapés et retenus par des embrasses, le soleil pénètre dans la pièce, le premier plan restant dans l'ombre. Sur la paroi de droite, on voit deux fenêtres et, plus loin, une porte, également drapées de rideaux. Dallage en damier noir et blanc. De petits personnages çà et là.

Signé à l'encre, dans l'angle inférieur droit : J.-B. Maréchal, I 779.

Lavis légèrement relevé d'aquarelle, sur trait de plume.

$$
\text { Haut., } 480 \text { millim.; larg., } 650 \text { millim. }
$$

L'auteur de ce dessin est sans doute ce Maréchal dont Bellier de La Chavignerie (Diction. général des artistes de l'éc. franç.; Paris, 1882-1885, 3 vol.) ne donne ni le prénom ni les dates de naissance et de mort, mais dont il cite les envois aux Salons de 1819 et de 1824 ; ces envois sont tous des vues de Paris. La collection de dessins sur Paris, formée par Destailleur et aujourd'hui conservée au Cabinet des estampes de la Bibliothèque nationale, possède plusieurs dessins de cet artiste, datés de 1786-1787. Divers autres ont passé en ventes publiques au cours de ces dernières années : la collection Destailleur $\left(2^{\mathrm{e}}\right.$ vente, 1896$)$ en contenait trois, datés 1780 et 1788 ; la collection Beurdeley (vente, 1905 ) quatre, dont deux datés 1782 et 1787 ; etc.

On notera que le catalogue de la vente Beurdeley donne à cet artiste les prénoms de Charles-Laurent, alors qu'il signe très lisiblement ici J.-B. Maréchal.

Cadre ancien, époque Louis XVI, bois sculpté et doré. 


\section{MAR I L LIER}

(CLÉMENT-PIERRE)

Dijon, $\mathbf{r} 740+$ Beaulieu, près Melun, 1808 .

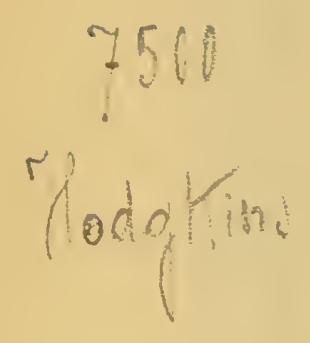

\section{4 \\ La Corbeille de mariage.}

Dans tine pièce aux murs ornés de colonnes et de sculptures, qui va s'arrondissant, à gauche, où elle prend le jour par deux hautes fenêtres, une jeune femme, debout et tournée vers la gauche, arrange de la main droite un ornement autour de son cou. Un homme, debout derrière elle, lui passe le bras gauche autour de la taille et lui indique de la main droite une glace, disposée entre les fenêtres, et qui reflète leurs deux images. A gauche, une soubrette debout et une marchande de modes assise sur un tabouret présentent à la jeune femme des bijoux et des dentelles qu'elles tirent, la première d'un coffret placé sur une console devant la glace, la seconde d'un carton posé à terre. A droite, un homme et une femme déroulent des coupons d'étoffes et les étalent sur le dossier d'une chaise; derrière eux, un homme en livrée et une femme dont on n'aperçoit que la tête regardent le groupe principal. Au fond, portés sur un nuage, deux amours tiennent une guirlande de fleurs dont ils ont enchaîné le jeune couple.

Signé à l'encre, en bas, à gauche, au-dessous du dessin, sur la monture : C. P. Marillier inv. et del. ${ }_{177}$.

Sanguine.

Haut., 357 millim.; larg., 285 millim.

Le médaillon formant trumeau, qui surmonte la glace où se mire la jeune femme, est décoré des initiales $\mathrm{L}$. B. entrelacées.

Cadre style Louis XVI, bois sculpté et doré, portant en or sur fond noir, dans un médaillon formant fronton et encadré de fleurs, les initiales L. B. entrelacées. 


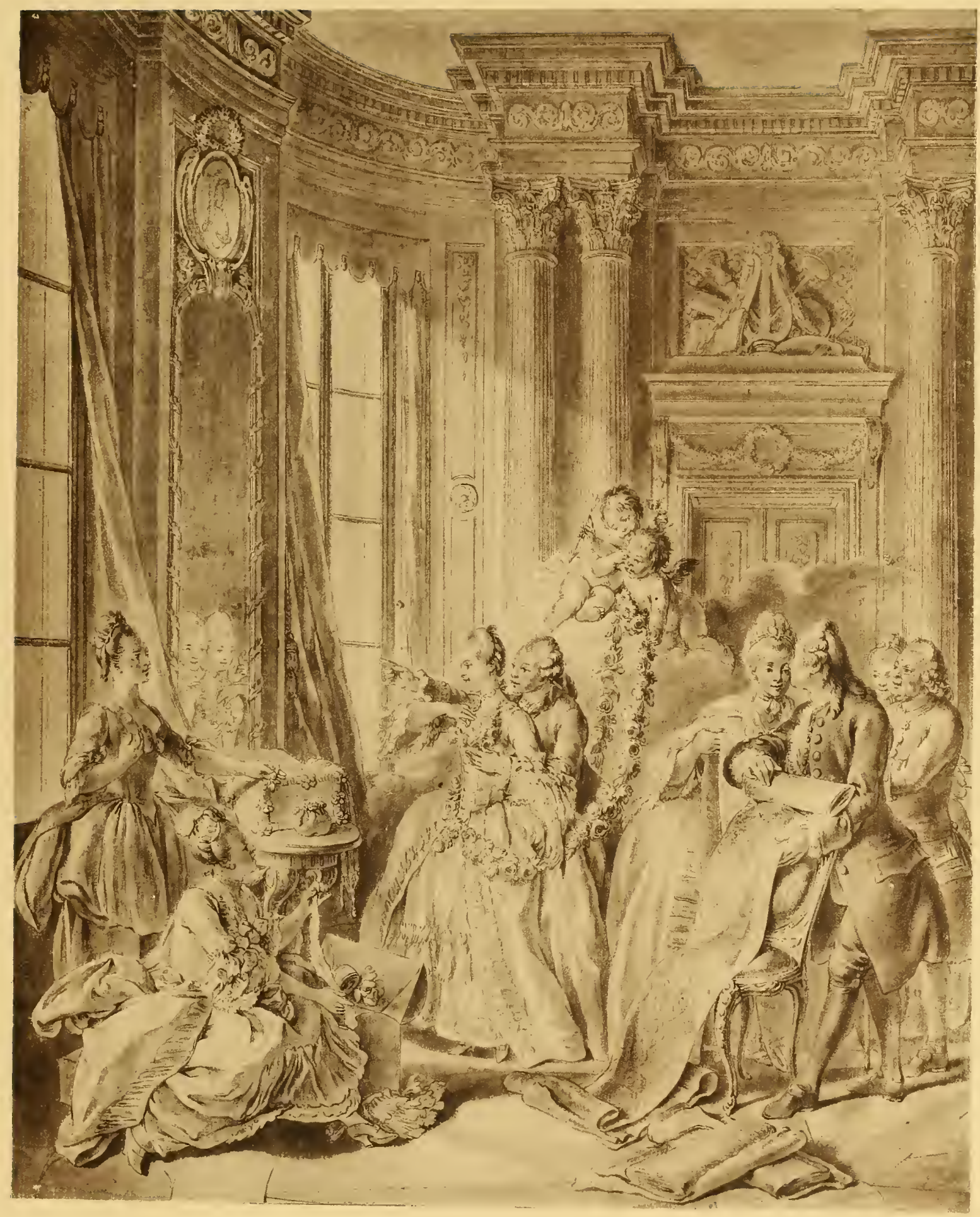






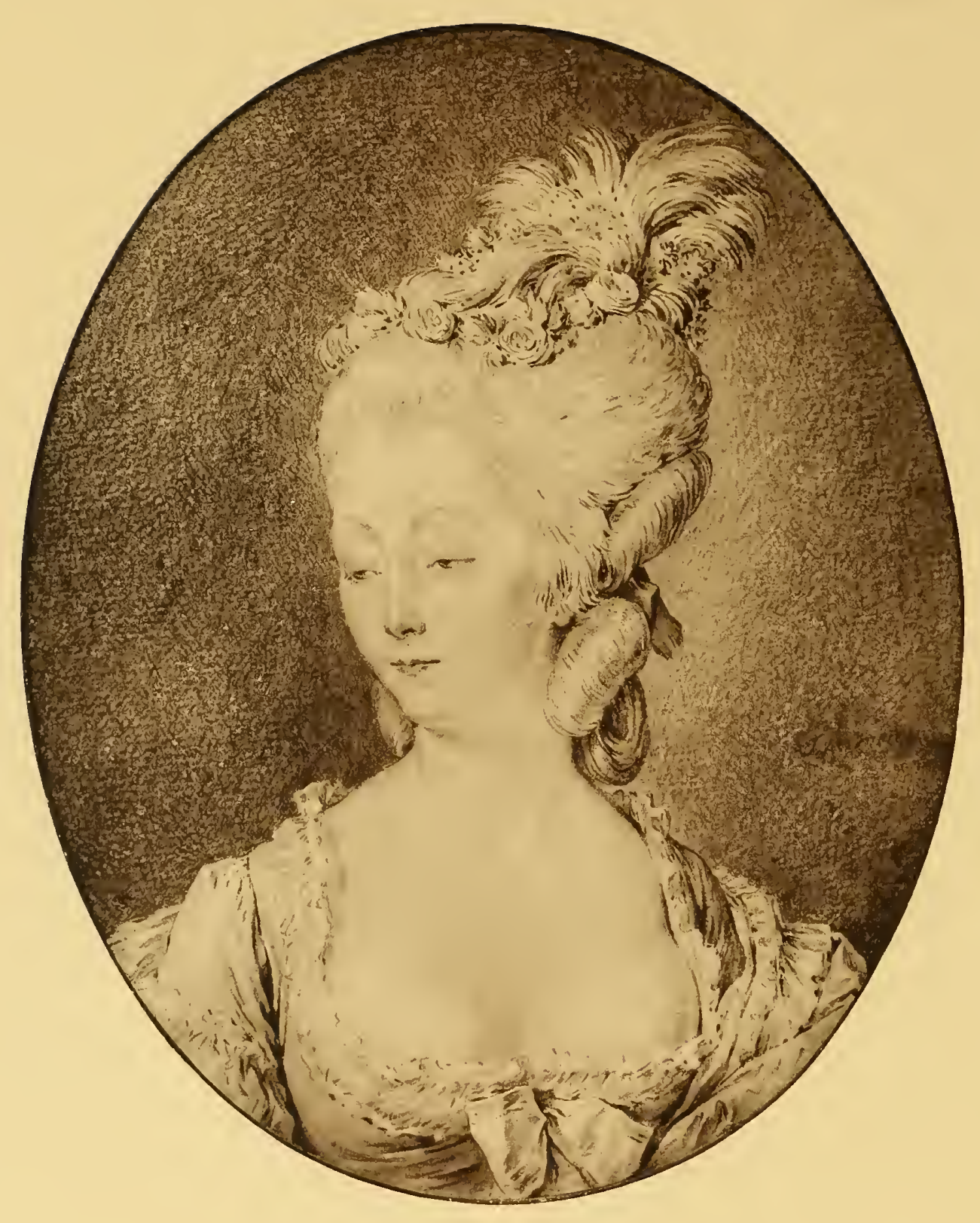

35 


\title{
MOREAU le Jeune
}

\author{
( JEAN-MICHEL) \\ Paris, $1741+$ Paris, 1814 .
}

\section{5}

\section{Portrait de $M^{m e}$ Papillon de La Ferté.}

Elle est vue en buste, le corps de face. Le visage aux traits délicats est tourné de trois-quarts vers la gauche et très légèrement incliné, le regard abaissé. Ses cheveux poudrés et relevés au sommet de la tête sont coiffés d'un pouf de roses et de plumes; deux grosses boucles descendent en diagonale, l'une derrière l'oreille et l'autre au-dessous. Elle porte un corsage largement décolleté en carré, bordé d'une ruche et orné d'un petit nœud sur le devant.

Signé à droite, au-dessus de l'épaule : J.-M. Moreau.

Crayon noir, rehaussé de sanguine dans les chairs, les roses de la coiffure et le vêtement.

Ovale. Haut., I 58 millim.; larg., 26 millim.

Provient des descendants de Papillon de La Ferté.

Salon de $1783: n^{\circ} 312$. Portrait de Madame de La Ferté.

Repr. dans M. Tourneux, la Collection J. Doucet, etc., (les Arts, op. cil., p. 22), sous le titre : Mlle Papillon de La Ferté; - et en fac-similé par la Société de reproduction des dessins de maîtres (2 ${ }^{e}$ année, 1910 ).

Papillon de La Ferté, intendant et contròleur de l'argenterie, menus plaisirs et affaires de la Chambre du roi (1 $\left.7^{2} 7^{-1} 794\right)$, dont Moreau le Jeune avait dessiné et gravé le portrait en 1770 , se remaria en 1782 avec une toute jeune femme, Catherine-LouiseHenriette de Villers; la présence d'un Portrait de $M^{\text {me }}$ de La Ferté, dessiné par Moreau le jeune, au Salon de 1783 , autorise à croire que le présent dessin est bien le portrait de la seconde femme de l'intendant des Menus, et non le portrait de sa fille, comme on l'a cru quelquefois.

Cadre ancien, époque Louis XVI, de forme ovale, bois sculpté et doré; au fronton, les armes royales entre deux palmes croisées. 


\section{MOREAU le Jeune \\ (JEAN-MICHEL)}

\section{6 \\ Fêtes du mariage de Marie-Antoinette. d. 25000 Illumination du parc de Versailles (I9 mai I770).}

Le spectateur, placé à l'extrémité du Tapis vert et tournant le dos au Château, a devant lui une foule compacte, à travers laquelle voitures et carrosses peuvent à peine se frayer un passage; tous ces curieux se pressent autour du bassin d'Apolion, dont les eaux jouent, et, au delà, sur les borcis du grand canal. A droite et à gauche, dessinant la ligne des parterres et suivant le canal pour aller rejoindre un grand motif lumineux qu'on distingue au loin, des portiques et des girandoles de lumières se détachent sur le fond sombre des arbres, éclairant toute la composition.

Lavis d'encre de Chine sur trait de plume.

Haut., 2i 3 millim. (y compris une très mince bande rapportée en biseau dans le haut, à gauche); larg., 373 millim.

Reproduit en fac-similé par la Société de reproduction des dessins de maîtres (1 re année, 1909).

Esquisse du grand dessin commandé à Moreau le Jeune, nouvellement nommé dessinateur des Menus-Plaisirs, en mème temps que plusieurs autres représentations des principales cérémonies et fêtes ayant eu lieu à l'occasion du mariage du Dauphin, plus tard Louis XVİ, et de Marie-Antoinette. - Le dessin terminé, exécuté à l'encre de Chine, dans un format plus grand (H. 390 millim.; larg., 800 millim.) et suivant une perspective un peu modifiée, fut exposé au Salon de $1781, n^{\circ} 300$, sous cette désignation : "Dessin de l'illumination ordonnée par $M$. le duc d'Aumont pour le mariage $d u$ Roi. Cette vue est prise du bas du Tapis vert, d'où l'on voit toute l'étendue du canal ". Il est aujourd'hui conservé au musée du Louvre (no 31558). Au contraire des autres vues des cérémonies de la cour dessinées par Moreau le Jeune à l'occasion du sacre du roi et de la naissance du Dauphin, il n'a pas été gravé (cf. Goncourt, l'Art du XVIII siècle, éd. in-18, 3e série, p. $\left.{ }^{\circ} 57\right)$.

Le mariage eut lieu le 16 mai i 770 , mais, par suite d'un orage survenu dans la soirée, le feu d'artifice et l'illumination ne purent avoir lieu ce jour-là; on les donna seulement le 19. Pour la description de cette fète de nuit, cf: Mercure de France, juin 1770 , f. 177 ; Journal de Papillon de La Ferté (éd. E. Boysse; Paris, 1887 , in-80), p. 276; et Description des fêtes, etc. donnés à Versailles à l'occasion du mariage de Mor le Dauphin (Paris, s. d.), Fp. 33-48.

Cadre ancien, époque Louis XVI, bois sculpté et doré. 


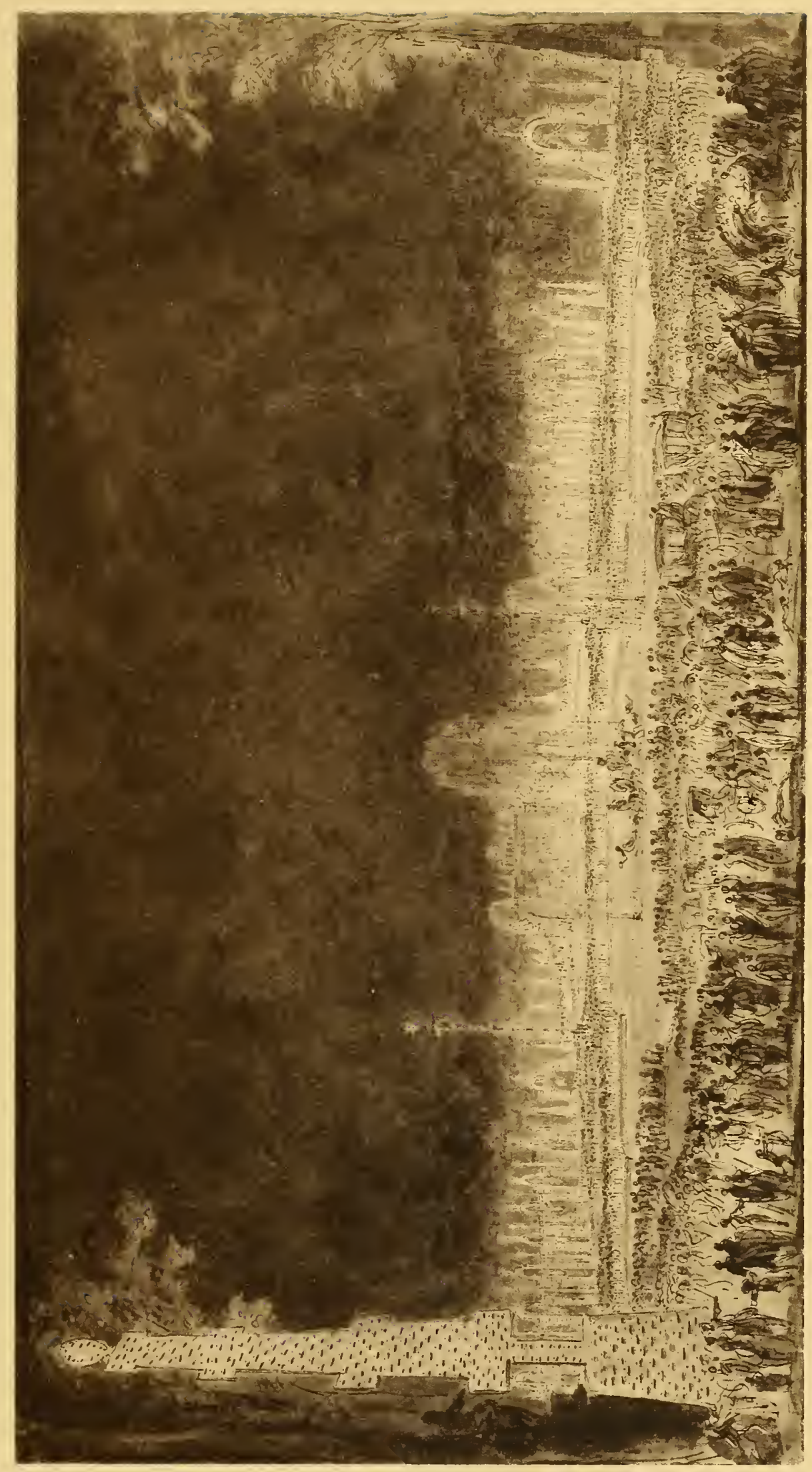






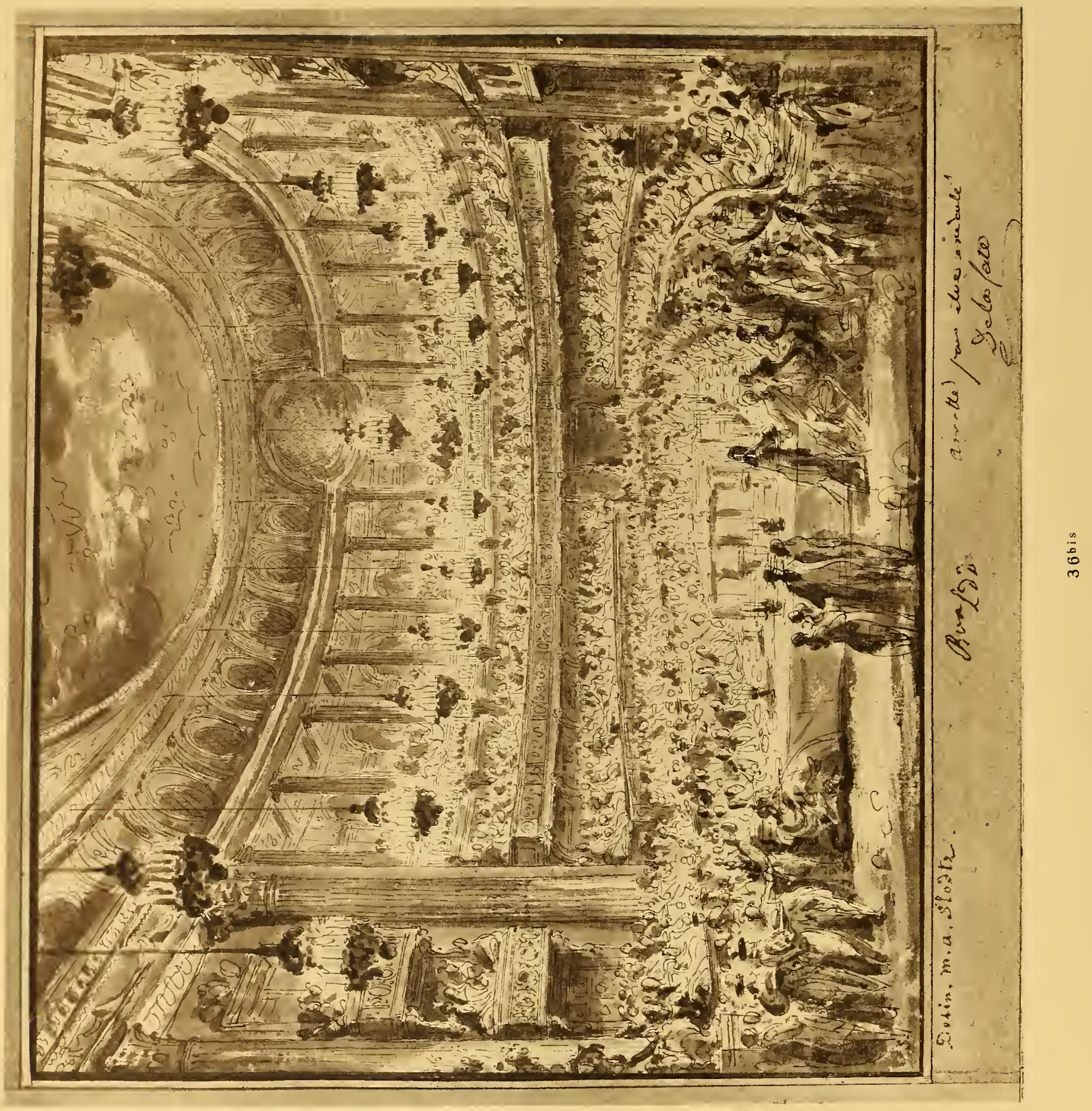




\section{MOREAU le Jeune}

(JEAN-M I C HEL)

\section{$36^{\text {bis et }} 36$ is \\ 23000 \\ Fêtes du mariage de Marie-Antoinette. \\ Festin royal dans la salle de l'Opéra de Versailles

$$
\text { ( } 6 \text { mai I } 770 \text { ). }
$$

Dans la salle de l'Opéra de Versailles, splendidement illuminée par des lustres, une vaste table rectangulaire a été dressée, dont un surtout à colonnade, entouré de candélabres, décore la partie centrale, et autour de laquelle sont assis, en fer à cheval, les seigneurs et les dames de la Cour admis au grand couvert. D'autres seigneurs, sur deux ou trois rangs, se tiennent debout autour des convives; les avant-scène, les balcons et les loges sont garnis d'une foule de spectateurs. Au premier plan, à gauche, des officiers de service portant des plats.

Lavis de sépia sur trait de plume.

$$
\text { Haut., } 230 \text { millim ; larg., } 263 \text { millim. }
$$

Sur la monture, on lit, à l'èncre, en bas, à gauche: Desin. M. A. Slodtz; au milieu : Bon L. D. D. [le duc d'Aumont, premier gentilhomme de la Chambre]; et à droite: Arretté pour être exécuté. De la Ferté [Papillon de La Ferté, intendant des Menus-Plaisirs].

Repr. en fac-similé par la Société de reproduction des dessins de mâ̂tres (3e année, 1911), sous le titre de : Banquet à la cour, avec une notice par E. Dacier, attribuant par erreur le dessin à M.-A. Slodtz. Cette notice est entièrement reprise ci-dessous d'après des documents nouveaux, réunis par M. A. Vuaflart.

Cadre ancien, fin époque Louis $\mathrm{XV}$, bois sculpté et doré, à fronton coquille et chutes de guirlandes de feuillage.

L'indication portée sur la monture du dessin : Desin. M. A. Slodtz, sur laquelle on s'appuyait pour attribuer le Festin royal (n $\mathrm{n}^{\circ} 36^{\text {bis }}$ ), et le Bal paré, qui lui fait pendant ( $\mathrm{n}^{\circ} 36 \mathrm{ter}$ ), au plus célèbre des Slodtz, le sculpteur René-Michel, dit Michel-Ange (1705-1764), doit avoir été écrite postérieurement au visa du duc d'Aumont et de Papillon de La Ferté; il y a, en tout cas, la plus formelle impossibilité matérielle à la considérer comme une signature de l'auteur du dessin; et voici pourquoi.

Ce dessin et le suivant ne sont point, comme on l'avait cru jusqu'ici, des projets exécutés par un dessinateur des Menus-Plaisirs en vue d'une décoration éphémère des salles de Versailles, ordinairement réservées aux fêtes de la Cour (par exemple, le manège de la Grande Écurie); ils représentent des fêtes ayant eu lieu réellement et qu'il 
a été possible d'identifier en route certitude, grâce aux descriptions minutieuses que nous en ont laissées les contemporains: il s'agit là, à n'en pas douter, de deux des solennités données dans la salle de l'Opéra de Versailles, à l'occasion du mariage du Dauphin, plus tard Louis XVI, et de Marie-Antoinette, le 16 mai 1770 et jours suivants.

Le duc d'Aumont, premier gentilhomme de la Chambre, en exercice pendant l'année 1770 , et Papillon de La Ferté, intendant des Menus-Plaisirs, furent les grands ordonnateurs de ces fêtes du mariage, préparées dès longtemps. Papillon de La Ferté en a publié lui-même le compte rendu complet dans un ouvrage anonyme extrêmement rare, puisqu'on n'en connaît plus à l'heure actuelle que deux exemplaires (l'un à la Bibliothèque de l'Arsenal, l'autre à la Bibliothèque d'art et d'archéologie), intitulé : Description des fêtes et spectacles donnés à Versailles à l'occasion du mariage de Monseigneur le Dauphin (Paris, chez Vente, libraire des Menus-Plaisirs du Roi, s. d., in-8o de 64 p.). C'est précisément cette brochure qui permet de reconnaître les deux cérémonies représentées dans les deux dessins dont il est ici question.

Le Festin royal eut lieu le soir du mariage, le 16 mai 1770 , "dans la salle de spectacle, dont on releva le plancher à la hauteur de celui du théâtre " (c'est-à-dire de la scène). Cette salle de spectacle est d'autant mieux facile à identifier qu'elle existe encore aujourd'hui : c'est la salle de l'Opéra de Versailles, construite sur les dessins d'AngeJacques Gabriel, hâtivement terminée en vue du mariage du Dauphin et inaugurée à cette occasion (cf. Papillon de La Ferté, Journal, éd. Boysse, r887, p. 204 et 214 ; G.Brière, le Cháteau de Versailles, architecture et décoration, Paris, 1910, t. 1 er, p. 39 , et t. II, pl. 163 et 164 ; et le comte de Fels, A.-J. Gabriel, Paris, 1912, pp. 89 et suiv.).

D'ailleurs, la salle fût-elle disparue que le livret consacré par Papillon de La Ferté aux fêtes du mariage permettrait encore de reconnaître aisément le lieu où se fit le Festin royal. La description de la salle du festin occupe les pages 5 à 1 i : on y traite, non seulement de la disposition de la salle, mais aussi de sa décoration et de son illumination. Entre autres détails caractéristiques, on retiendra notamment la surélévation du plancher remonté au niveau de la scène et l'installation d'une balustrade entourant la table à distance et séparant " les officiers qui servoient d'avec les spectateurs qui se trouvoient en dehors"; tous ces détails, et celui que "les balcons qui sont au bas des premières loges et toutes les loges étoient occupés par une nombreuse quantité de personnes de distinction ", concordent trait pour trait avec le dessin ( $n^{\circ} 36$ bis).

Le lendemain I 7 , il y eut spectacle dans la même salle, transformée en une nuit, et le 19, avant l'illumination des jardins représentée dans le dessin de Moreau le jeune décrit ci-avant sous le $n^{\circ} 36$, se donna le Bal paré (cf. Papillon de La Ferté, Journal, p. 273 et 274 ). La description de la salle de bal occupe les pages 17 à 32 de la Descriptiun des fêtes : elle est si minutieuse et à la fois si précise qu'elle permet d'identifier en toute certitude le dessin de la collection Doucet qui fait pendant au Festin royal $\left(\mathbf{n}^{\circ} 35\right.$ ler $)$.

On utilisa pour le bal la scène même de l'Opéra de Versailles, aménagée et décorée pour la circonstance : la salle ainsi obtenue mesurait 88 pieds de largeur sur 78 de profondeur et 55 de hauteur (l. $28^{\mathrm{m}}, 50$; prof. $\left.25^{\mathrm{m}}, 27 ; \mathrm{h} .17^{\mathrm{m}}, 8 \mathrm{o}\right)$; elle avait la forme d'un carré long, pris sur la largeur " et dont les quatre angles formoient des pans coupés, deux desquels joignoient les colonnes de l'avant-scène par deux avant-corps ; les deux autres étoient réunis au fond par une partie circulaire ". Les trois étages de galerie sont ensuite décrits dans le détail, ainsi que leur décoration et leur luminaire. Tous ces renseignements - nombre des colonnes et des pilastres, place des bustes, des statues 
dans les niches des pans coupés, des peintures des arcades, etc. - concordent rigoureusement avec le dessin auquel ils s'appliquent ligne à ligne.

Il n'y a donc aucun doute quant aux sujets de ces deux dessins. Reste à en déterminer l'auteur.

Malgré la mention du nom de M.-A. Slodtz, inscrite sur la bordure de l'un des dessins (le Festin roral), il est matériellement impossible de songer à cet artiste. Slodtz mourut, en effet, le 26 novembre 1764 , c'est-à-dire six ans avant le mariage du Dauphin, à une époque où il ne pouvait être question de l'aménagement du théâtre de Versailles, alors en cours de construction, pour une solennité qu'on ne prévoyait encore qu'à longue échéance.

On ne peut pas davantage proposer le nom de Michel-Ange Challes, nommé dessinateur du Cabinet du roi le 23 février 1765 , peu après la mort de Slodtz: des raisons de technique s'y opposent, comme aussi ce fait que les lettres de noblesse accordées à l'artiste en novembre 1770 , mentionnent expressément et exclusivement le concours qu'il a apporté aux illuminations, lors des fêtes du mariage.

Reste Moreau le jeune. Deux sortes de faits, les uns d'ordre documentaire et les autres d'ordre technique, militent en sa faveur, et tous deux sont également convaincants. D'une part, on sait par Papillon de La Ferté (Journal, p. 412), que Moreau le jeune, protégé par le duc d'Aumont, avait été chargé "de faire les dessins et les gravures du mariage en $177^{\circ}$ ». Un état de paiement conservé aux Archives nationales (O' 3.044) le porte comme ayant touché, en 1774, 2.00o livres " à compte de différents dessins auxquels il travaille, lesquels dessins doivent servir à exécuter les gravures des fêtes données à l'occasion du mariage de S. M. en 1770 ”.

Aucune de ces gravures ne fut exécutée, soit qu'on ait renoncé à commémorer des fêtes attristées par la catastrophe de la place Louis XV, où plus de cent trente personnes périrent étouffées et écrasées le soir du feu d'artifice tiré le 30 mai (Mémoires secrets, t. V, p. 138), soit pour toute autre raison.

Quant aux "différents dessins", on n'en connaissait jusqu'ici que deux. et qui représentent tous deux le mêne sujet : l'illumination du parc de Versailles, le soir du I 9 mai 1770 ; on vient de voir que l'esquisse d'après nature pour le dessin définitil, conservé au Louvre, appartient à la collection Doucet (n³6).

Il paraît démontré maintenant que le Festin royal et le Bal paré font partie de la même série d'esquisses croquées et lavées par Moreau le jeune d'après nature, en vue des dessins définitivement préparés pour la gravure, comme l'est l'Illumination du musée du Louvre. L'un de ces dessins a d'ailleurs conservé sur sa monture le visa du duc d'Aumont (Bon.L.D. D.) et celui de Papillon de La Ferté (Arretté pour étre exécuté. La Ferté), auxquels on ajouta postérieurement et erronément le nom de M.-A. Slodtz.

Outre ces arguments d'ordre documentaire, il est permis d'achever la démonstration, au point de vue technique, par le simple rapprochement entre l'Illumination d'une part, le Bal paré et le Festin royal de l'autre. La comparaison avec quatre esquisses de Moreau le jeune, à la plume et sans lavis, sur papier calque, pour les quatre grands dessins gravés à l'occasion des fêtes données, les 21 et 23 janvier 1782 , par la Ville de Paris à l'occasion de la naissance du Dauphin, n'est pas moins convaincante. Ces esquisses, signées par l'artiste et paraphées par les échevins, sont conservées aux Archives nationales (K. 1018 ); les gravures appartiennent à la Chalcographie. Au cours d'une communication faite à la Société d'iconographie parisienne, le 1o décembre 1910, M. A. Vuaflart a présenté la photographie de ces esquisses, dont la facture est manifestement identique à celle du Festin royal et du Bal paré. 


\title{
MOREAU le Jeune
}

\author{
(JEAN-MICHEL) \\ $36 \cdot 36$ ter

\section{Fêtes du mariage de Marie-Antoinette. Bal paré sur la scène de l'Opéra de Versailles (19 mai 1770).}

Le bal se donne dans une salle magnifiquement illuminée par des lustres, sur trois côtés de laquelle une galerie formant balcon ouvre entre de hautes colonnes cannelées. Entre ces colonnes et dans des loges ménagées au-dessus de l'entablement, se presse une foule de spectateurs. Dans la salle même, des seigneurs et des dames, celles-ci assises au premier rang, forment le cercle autour d'un espace laissé libre, où la Dauphine et le Dauphin, se faisant vis-à-vis, ouvrent le bal.

Lavis de sépia sur trait de plume.

Haut., 227 millim.; larg , 268 millim.

Pour la notice historique, voir le $n^{\circ}$ précédent.

Cette salle de bal, construite pour la circonstance, était due à la collaboration d'un certain nombre d'artistes, tels que de Machy pour l'architecture, Canot pour la figure, Boquet fils pour les petits plafonds, Baudon père et fils pour le paysage; le grand plafond, peint par Briard, représentait Psyché conduite à l'immortalité par l'A mour et admise au rang des divinités. - Les spectateurs occupaient non seulement les galeries et les loges de ce salon, mais aussi celles de la salle de théâtre, brillamment illuminée comme au jour du festin royal. Le rez-de-chaussée de la salle de bal était garni de banquettes pour les princes, princesscs, ambassadeurs et seigneurs de la Cour, dans l'ordre accoutumé ; on distingue, sur le dessin, le roi assis un peu en avant de la Cour. - Le bal ouvrit à six heures; il fut suivi du feu d'artifice, qui devait être tiré trois jours plus tôt - le soir du mariage - et qu'un orage avait obligé de remettre au 19. Pendant le souper, on prépara l'illumination du parc et du canal, qui dura une partie de la nuit (voir le $n^{\circ} 36$ ).

Cadre ancien, fin époque Louis XV, bois sculpté et doré, à fronton coquille et chutes de guirlandes de feuillage. 


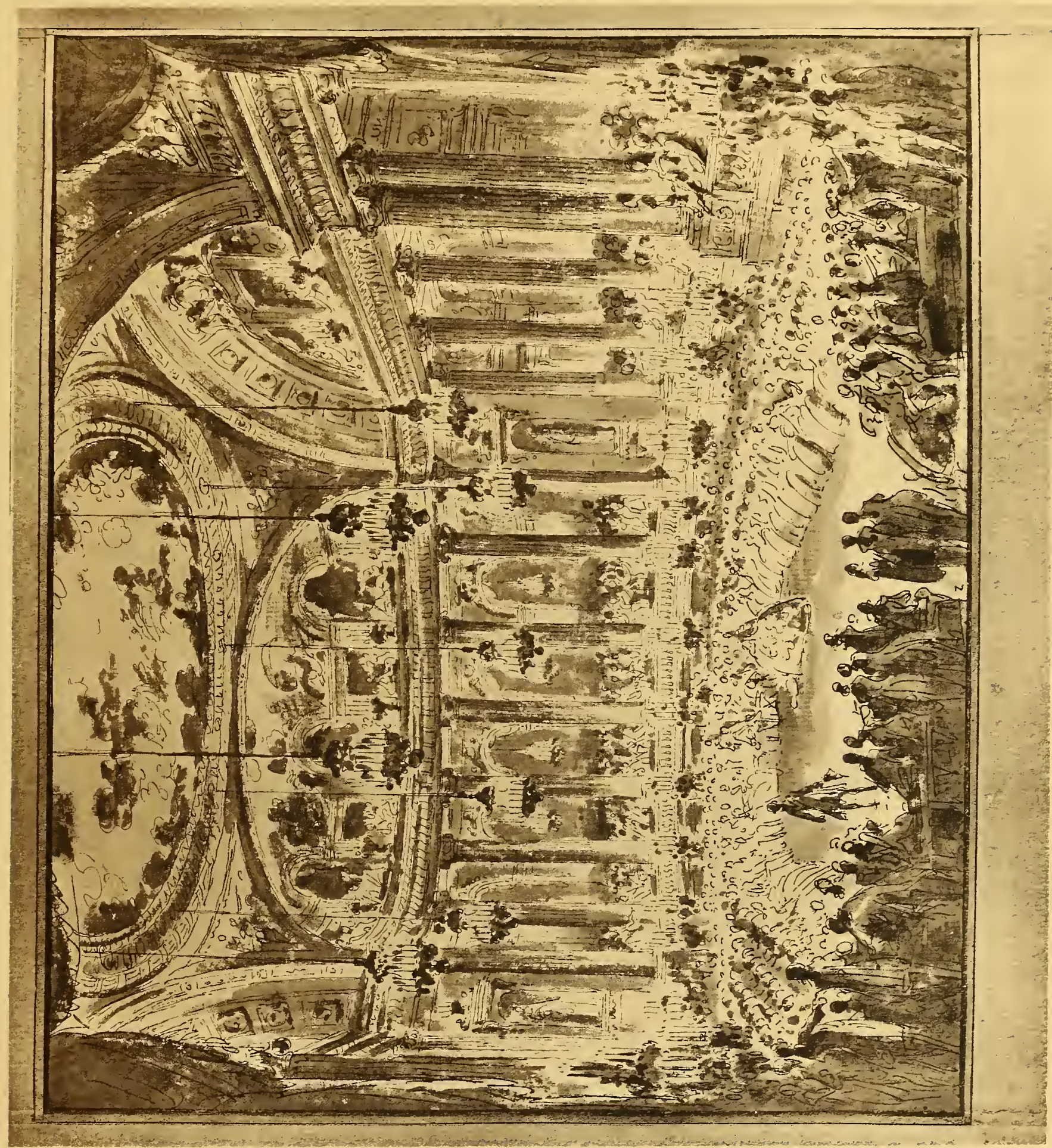






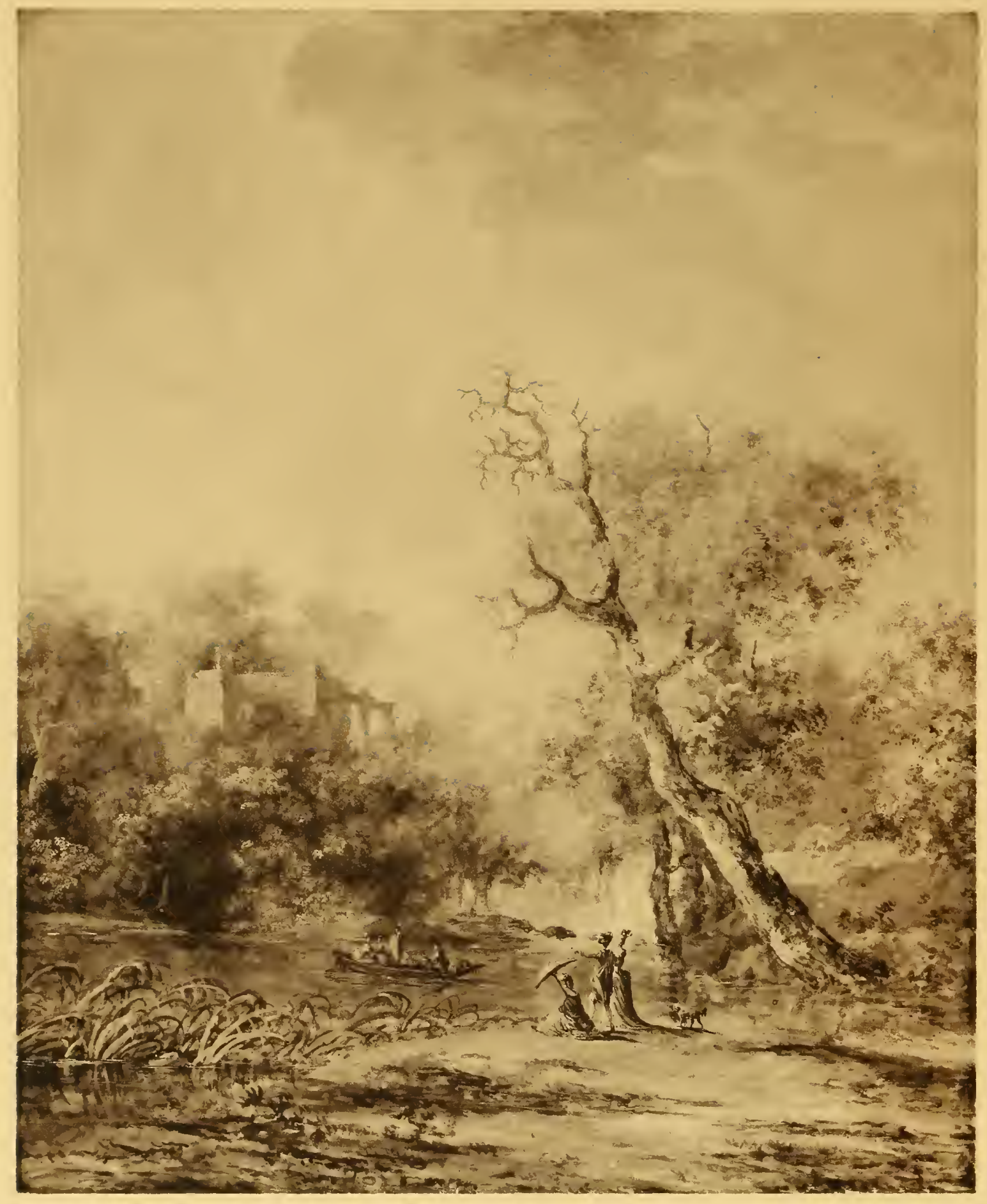




\title{
MOREAU l'Aîné
}

\author{
(LOUIS-GABRIEL) \\ Paris, $1740+$ Paris, 1806 .$$
37 \text { et: } 38
$$ \\ Paysage : la Rivière.
}

Sur le bord d'une rivière venant de la gauche et contournant une éminence boisée, verdoyante et couronnée par un palais en ruines, qui occupe le fond de la composition, un homme vu de dos, accompagné de deux femmes, l'une debout, l'autre assise et tenant une ombrelle ouverte, désigne du doigt une barque dans laquelle se trouvent quatre personnages. A gauche, des roseaux; à droite, le tronc et les branches d'un vieil arbre mort, se détachant sur la verdure un peu jaunie d'autres arbres.

Gouache.

$$
\text { Haut., } 3 \text { I } 5 \text { millim; larg., } 257 \text { millim. }
$$

Collection Léon Roux, architecte.

Cadre en partie ancien, époque Régence, bois sculpté et doré. 


\title{
MOREAU l'Aîné
}

\author{
(LOUIS.GABRIEL) \\ 37.538 \\ Paysage : le Parc.
}

Dans un parc, une femme et un enfant sont assis, face au spectateur, au second plan, un peu à droite, sur le bord d'une pièce d'eau; près d'eux, un homme debout rappelle son chien qui poursuit un cygne. Derrière ce groupe, un escalier en pente douce, bordé de deux rampes à balustres, conduit à un bosquet où l'on aperçoit, à droite, deux promeneurs, et une statue, à gauche, dans une échancrure du feuillage vert tendre, un peu jauni par endroits. A gauche, au delà de la pièce d'eau, un homme aide une femme à se relever; à droite, au fond, des arbres.

Gouache.

Haut,, 3 I 5 millim.; larg., 257 millim.

Collection Léon Roux, architecte.

Pendant du précédent.

Cadre en partie ancien, époque Régence, bois sculpté et doré. 


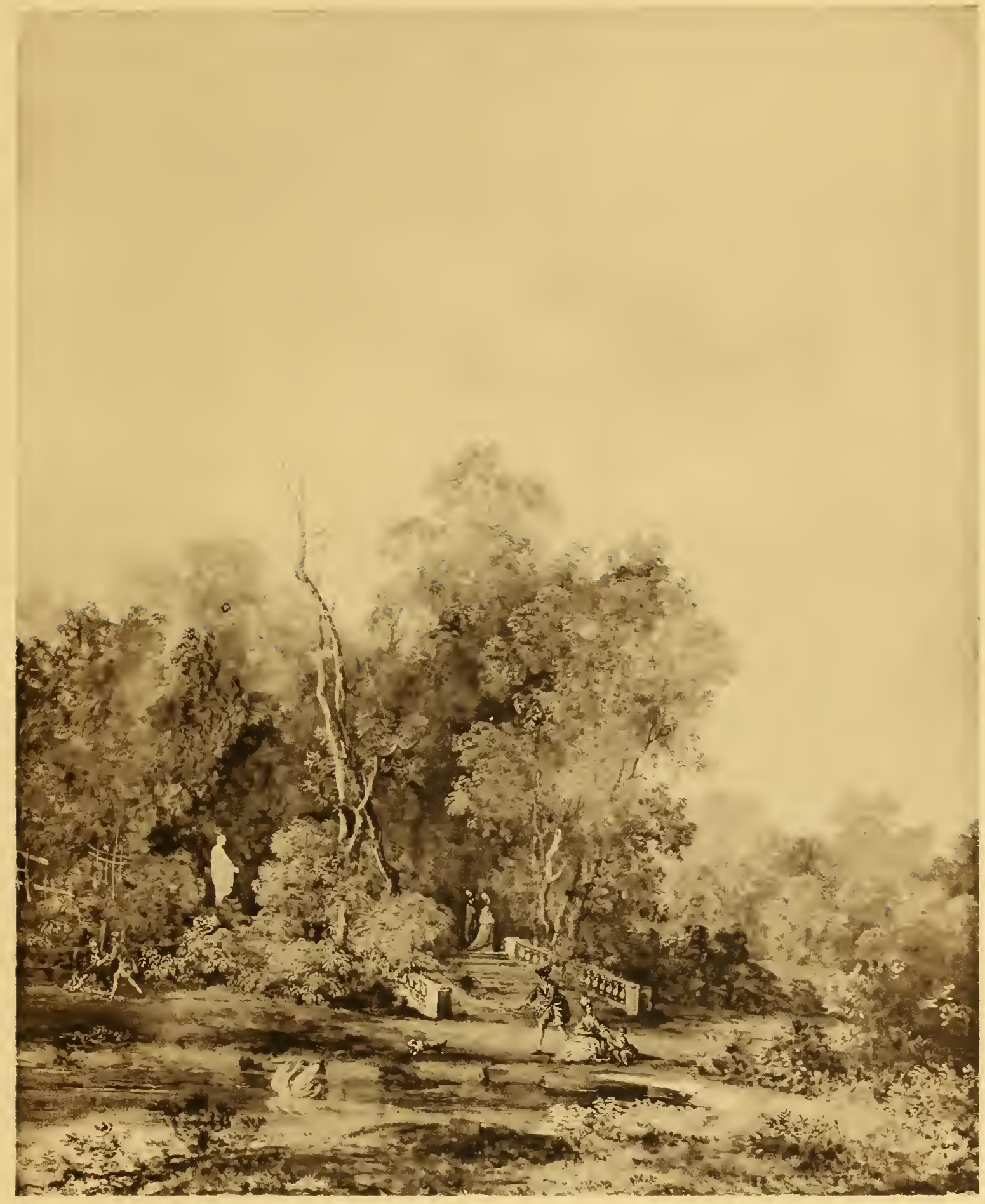






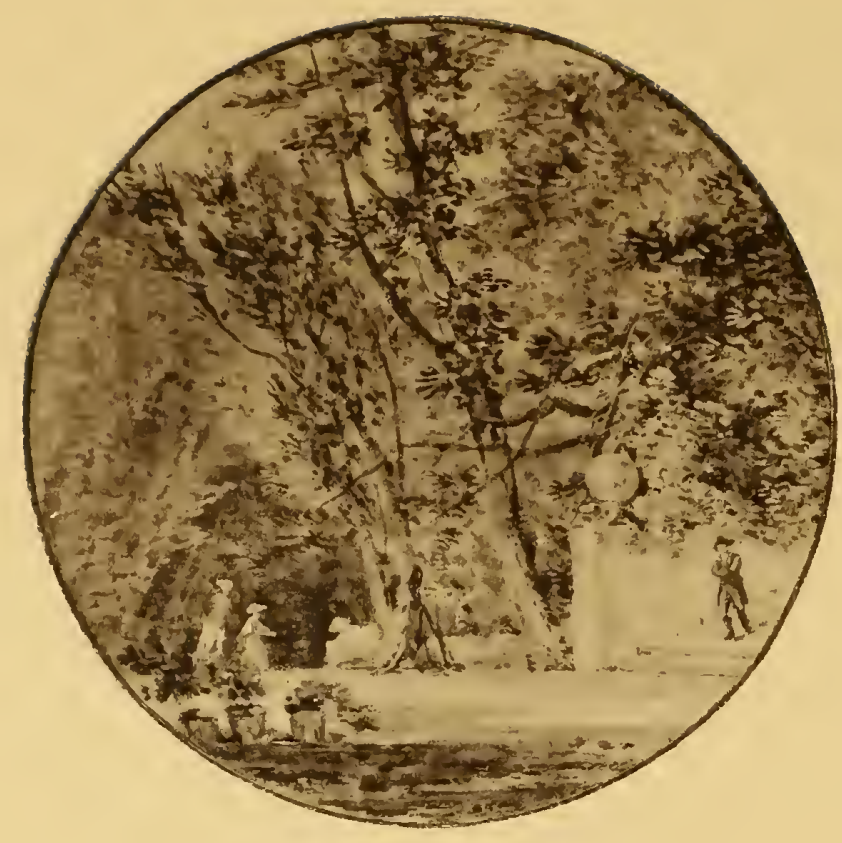

39

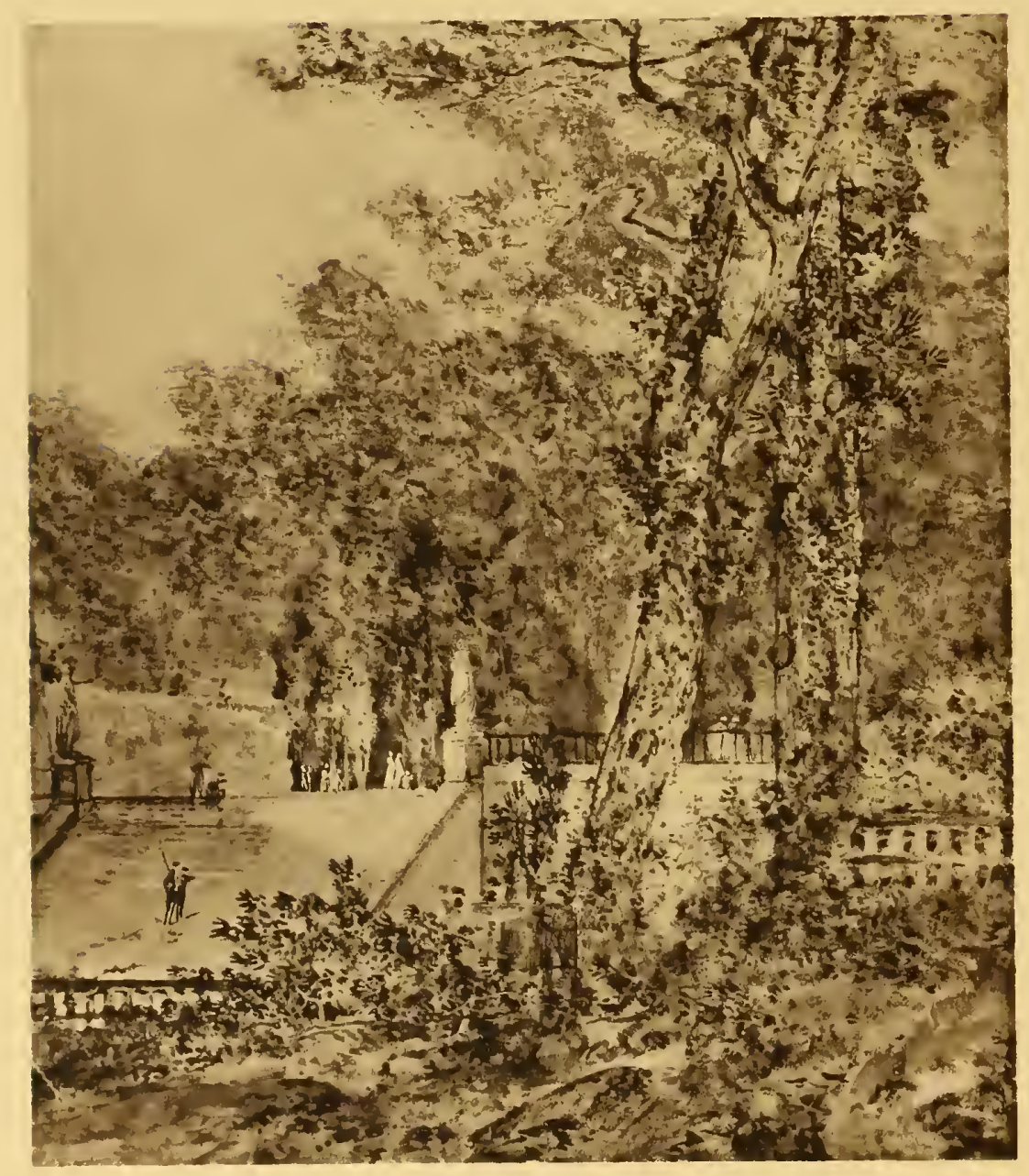

39 bis 


\section{MOREAU l'Aîné}

( LOUIS.GABRIEL)

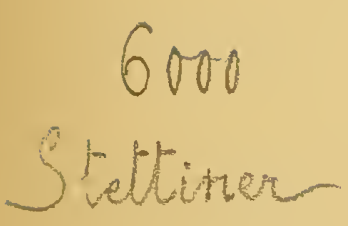

\section{9 \\ Paysage (Bagatelle?).}

D'un large escalier de pierre, dont on voit à droite les dernières marches, un homme en habit gris descend à un parterre d'où s'en va, vers le fond, une allée en berceau. A l'entrée de ceite allée, à gauche. une fillette en rouge et une femme; à droite, un lion de pierre couché. Vers le milieu, deux arbres s'élevant jusqu'en haut de la composition. Au premier plan, à gauche, trois pots de fleurs. Verdure vive et fraîche ; sol jaunâtre.

Gouache.

Rond. Diam., 83 millim.

Cadre en partie ancien, époque Louis XVI, bois sculpté et doré, de forme ronde, surmonté de guirlandes de fleurs et de rubans retenant une couronne.

\section{$39^{\text {bis }}$ \\ Paysage (Saint-Cloud?).

A gauche, un large et haut escalier conduit à une terrasse fermée au fond par de grands arbres verdoyants et sur laquelle on distingue des groupes de promeneurs. Cette terrasse se prolonge sur la droite : on aperçoit son mur et sa balustrade de fer au delà de deux arbres superbes, qui partent du bas et s'élèvent jusqu'au sommet de la composition.

Gouache.

Haut,, I 70 millim.; larg., 142 millim.

Cadre ancien, époque Louis XVI, bois sculpté et doré. 


\section{PORTAIL}

(JACQUES-ANDRÉ)

Nantes $(?) \div$ Versailles, $175 \mathrm{~g}$.

\section{0 \\ La Musicienne.}

Assise sur un siège dont le dossier est recouvert d'une étoffe bleue, la jeune femme est vue à mi-corps, de trois-quarts vers la droite, le visage de profil. Un cahier à musique ouvert devant elle, sur une table, près d'une écritoire et d'un pupitre supportant un livre, elle pince d'une guitare incrustée d'écaille et d'ivoire, qu'un ruban bleu retient autour de son épaule. Une coiffe noire, nouée sous le menton, couvre en partie ses cheveux poudrés; elle a un ruban garni d'un nœud rose autour du cou et un joyau à l'oreille. Sa robe rose décolletée est relevée de nœuds de ruban bleu ciel au devant-de-corps et aux manches, lesquelles, arrêtées au coude, se terminent par des volants de mousseline. Fond d'appartement, de tonalité grise, avec une fenêtre ouverte sur un jardin.

Crayons de couleur.

Rond. Diam., 375 millim.

Repr. dans les Maîtres du dessin (Paris, 3e année 1901-1902, pl. 114); -- dans M. Tourneux, la Coll. J. Doucet, etc. (les Arts, op. cit., p. 24); - et en fac-similé par la Société de reproduction des dessins de mâ̂tres (3e année, I 9 I I), avec une notice par E. Dacier.

Cadre ancien, époque Louis XVI, bois sculpté et doré, de forme ronde; au fronton, un nceud de ruban retombant de chaque côté. 


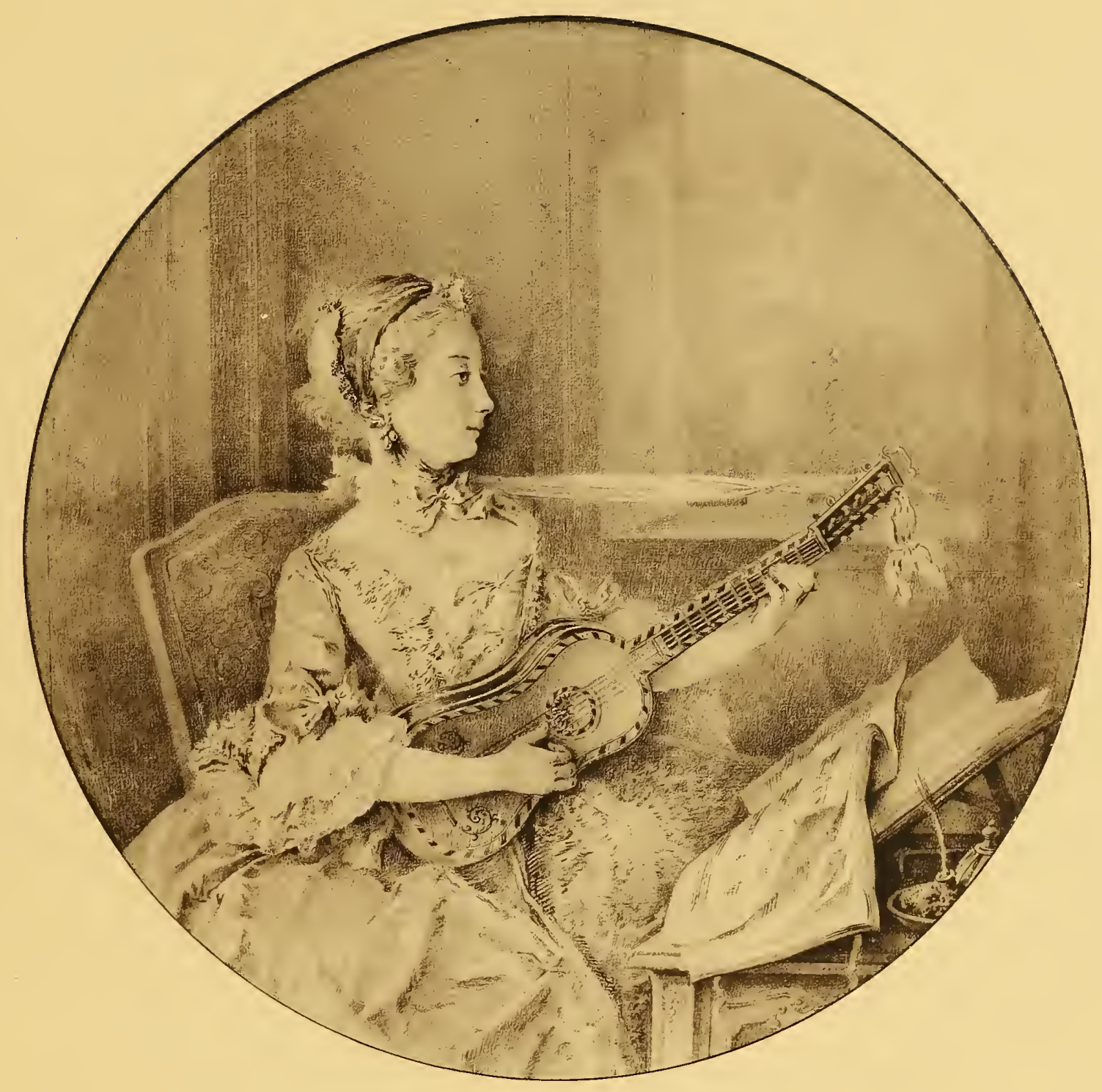






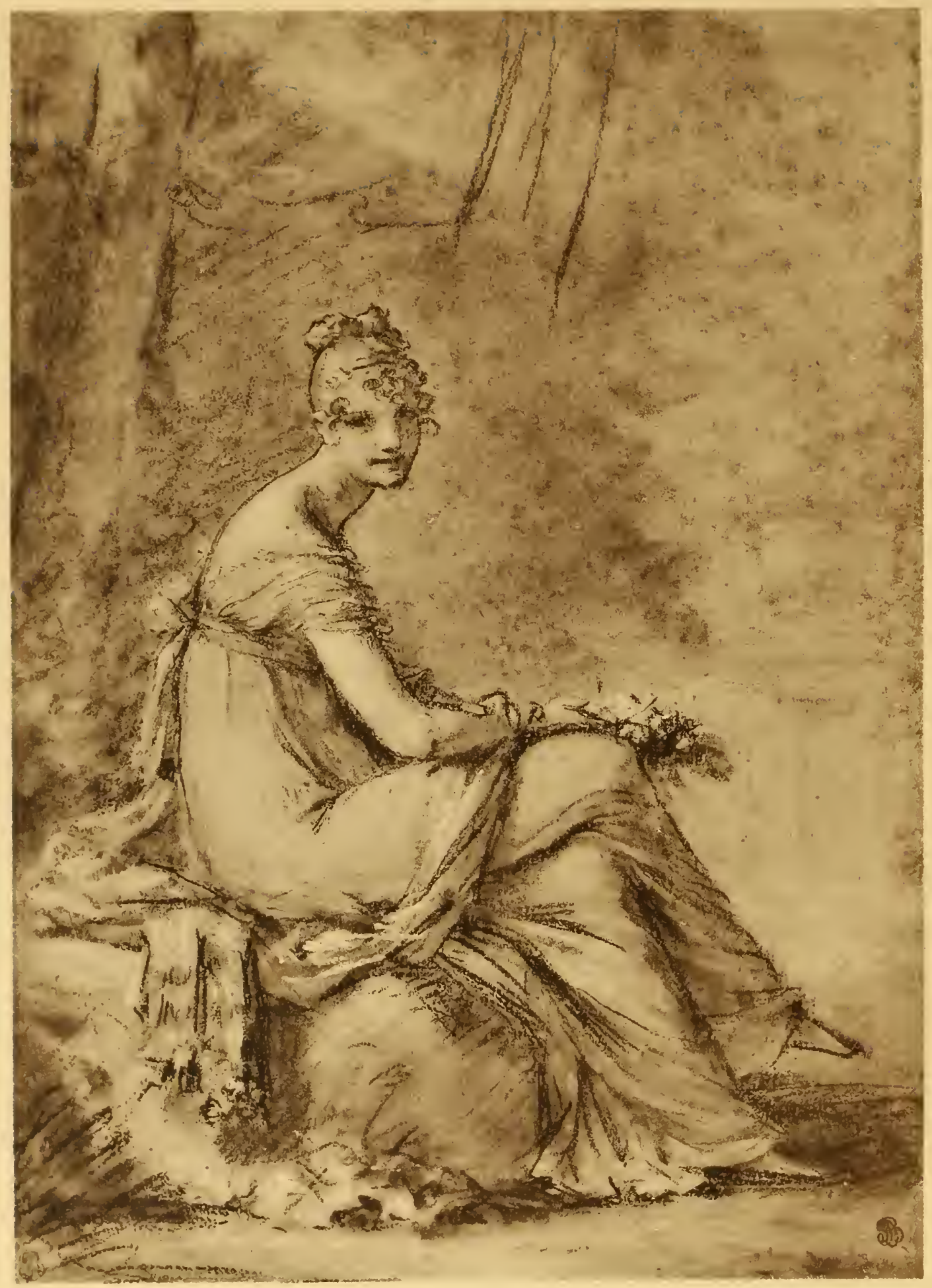




\section{PRUDHON \\ (PIERRE-PA UL) \\ Cluny, $1758+$ Paris, 1822 . \\ 41 \\ Portrait de $M^{\text {me }}$ Dufresne.}

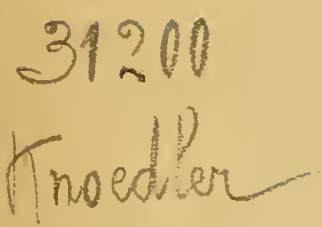

Elle est représentée en pied, assise sur un tertre dans un parc, le corps de profil à droite; la tête nue, presque de face, portée par un col long et gracile, et un peu penchée; le regard dirigé vers le spectateur. Légèrement inclinée en avant, la jambe droite croisée sur la gauche, elle tient une gerbe de fleurs de la main droite qu'elle appuie sur son genou. Sa robe-tunique, décolletée et laissant les bras nus, est serrée sous les bras par une ceinture en ruban, nouée par derrière; une écharpe est tombée en travers de ses jambes.

Crayon noir relevé de craie, sur papier bleu.

Haut., 283 millim; larg., 202 millim.

Au bas, à droite et à gauche, une marque de collection, monogramme imprimé en rouge.

Au dos de l'encadrement, on a collé deux notes manuscrites provenant d'un encadrement ancien. Sur la première on lit, à l'encre, sur quatre lignes : Dessin $p^{r}$ le portrait de Made D... par Prud'hon. Vte Boisfremont fils. 9 ayril I $870 .-$ La seconde, au crayon et à demi effacée, porte, sur neuf lignes : Portrait de $M^{m e}$ Dufresne, femme d'un marchand de tableaux. L'esquisse peinte appartient à M.Jeanne Deslandes. M. Eudoxe Marcille possède un pastel [représentant] Mine Dufresne vue [de trois] quarts et de grandeur nature.

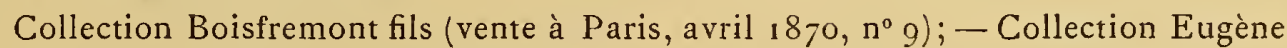
Lecomte (vente à Paris, juin $1906, \mathrm{n}^{\circ} 26$ ).

Repr. au catalogue de la vente Eugène Lecomte; - et en fac-similé par la Société de reproduction des dessins de maîtres (1 re année, 1909).

Première idée d'une petite esquisse peinte (h. 0,$23 ; 1.0,16$ ), représentant Mme Dufresne, femme d'un marchand de tableaux, ami de Prudhon; cette esquisse un peu noirâtre, provenant de la vente Boisfremont fils $\left(1870, \mathrm{n}^{\circ} 8\right)$, a passé dans la collection Norzy, puis dans celle de M. Jeanne Deslandes.

En dehors du présent croquis, on connaît une étude plus avancée, également au crayon noir et à la craie sur papier bleu, avec quelques variantes, et en largeur. Elle appartenait à la collection Alfred Sensier, quand clle figura à l'Exposition des dessins de maîtres anciens de l'École des beaux-arts $\left(1879, \mathrm{n}^{\circ} 118\right)$, comme un portrait de l'impératrice Joséphine. C'est d'ailleurs avec cette désignation qu'elle passa à la vente A. Sensier (Paris, décembre $1877, \mathrm{n}^{\circ} 458$ ).

Enfin $M^{\text {me }}$ Jahan-Marcille possède un pastel représentanı $M^{\text {me }}$ Dufresne en buste, vue de face et coiffée de papillotes dépeignées, provenant de la collection Eudoxe Marcille et mentionné dans la note citée plus haut.

Cf. Goncourt, Calalogue raisonné de l'cuvre, peint, dessiné et gravé, de P.-P. Prudhon (Paris, 1876 ), pp. 45 et 74 .

Cadre style Louis XVI, bois sculpté et doré. 


\title{
ROBERT
}

\author{
(HUBERT)
}

Paris, $1733+$ Paris, 1808 .
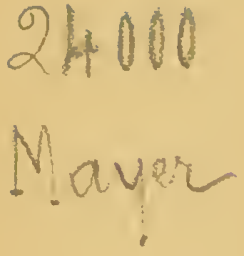

\section{2}

\section{La Fontaine.}

D'énormes blocs, posés sur deux rangs, supportent deux lourdes pierres sculptées de mascarons et, au-dessus, une longue dalle, où l'on distingue des vestiges de décoration. De l'un des mascarons, l'eau jaillit dans une grande cuve circulaire de pierre, soutenue par un robuste plancher, auquel on accède par un escalier de pierre, sur le devant de la composition. Debout sur ce plancher, une femme, qui vient de puiser de l'eau dans la cuve, remplit un bassin; un enfant assis près d'elle joule avec un chien, et un autre chien, les pattes posées sur le rebord de la cuve, lève la tête vers la dalle qui couronne la fontaine, où deux chiens sont assis auprès d'un homme couché tout de son long et tourné vers la gauche, en conversation avec une jeune femme debout sur un des blocs inférieurs. A gauche, au premier plan, du fourrage; plus loin, divers récipients; au fond, du linge étendu devant une maison. A droite, au fond, un vieil arbre rompu à mi-hauteur.

Lavis et aquarelle sur trait de plume.

$$
\text { Haut., } 565 \text { millim.; larg., } 723 \text { millim. }
$$

Collection Allard de Meeus.

Sur les deux premiers rangs de pierres, on lit :

$$
\begin{gathered}
\text { FONTEM HANC PUBLICAM } \\
\text { VIATORUM COLM }] \text { MODITATI STRUXIT } \\
\text { H.ROBERTUS. ANNO DOMINI MDC[C]LXXXII. }
\end{gathered}
$$

Cette inscription donne donc clairement à entendre qu'il s'agit ici d'un dessin de composition. Toutefois, on peut rapprocher de cette "fontaine publique construite par Hubert Robert pour la commodité des voyageurs, en 1782 ", une autre fontaine assez analogue, mais représentée d'après nature : c'est celle qui a été gravée par Adélaïde Allou, en 177I, pour le frontispice des Différentes vues dessinées d'après nature par Mrs Robert et Fragonard, peintres du Roy, dans les environs de Rome et àe Naples. La fontaine de fantaisie n'est qu'une amplification et un arrangement de celle-ci.

Cadre ancien, époque Louis XVI, bois sculpté et doré. 


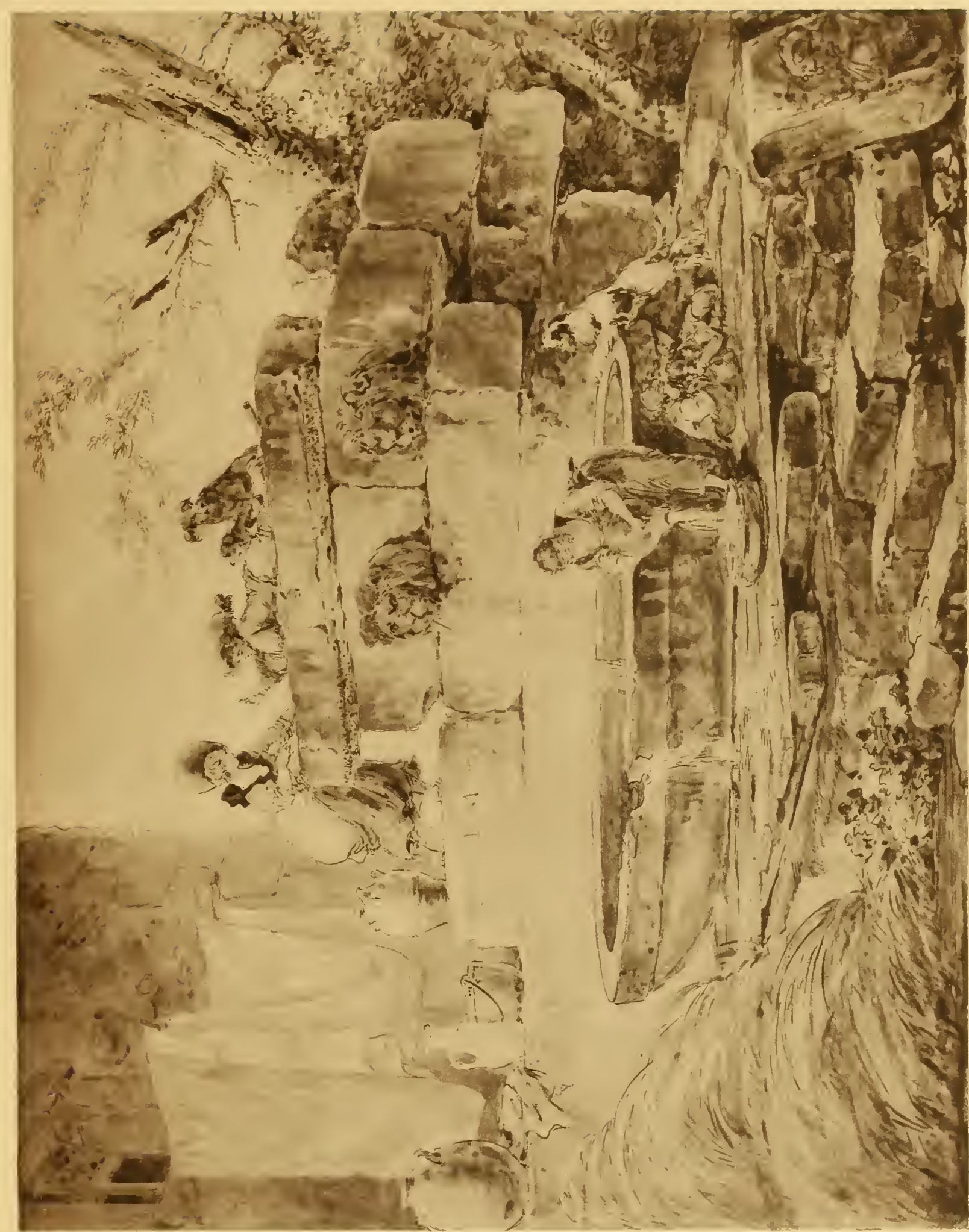






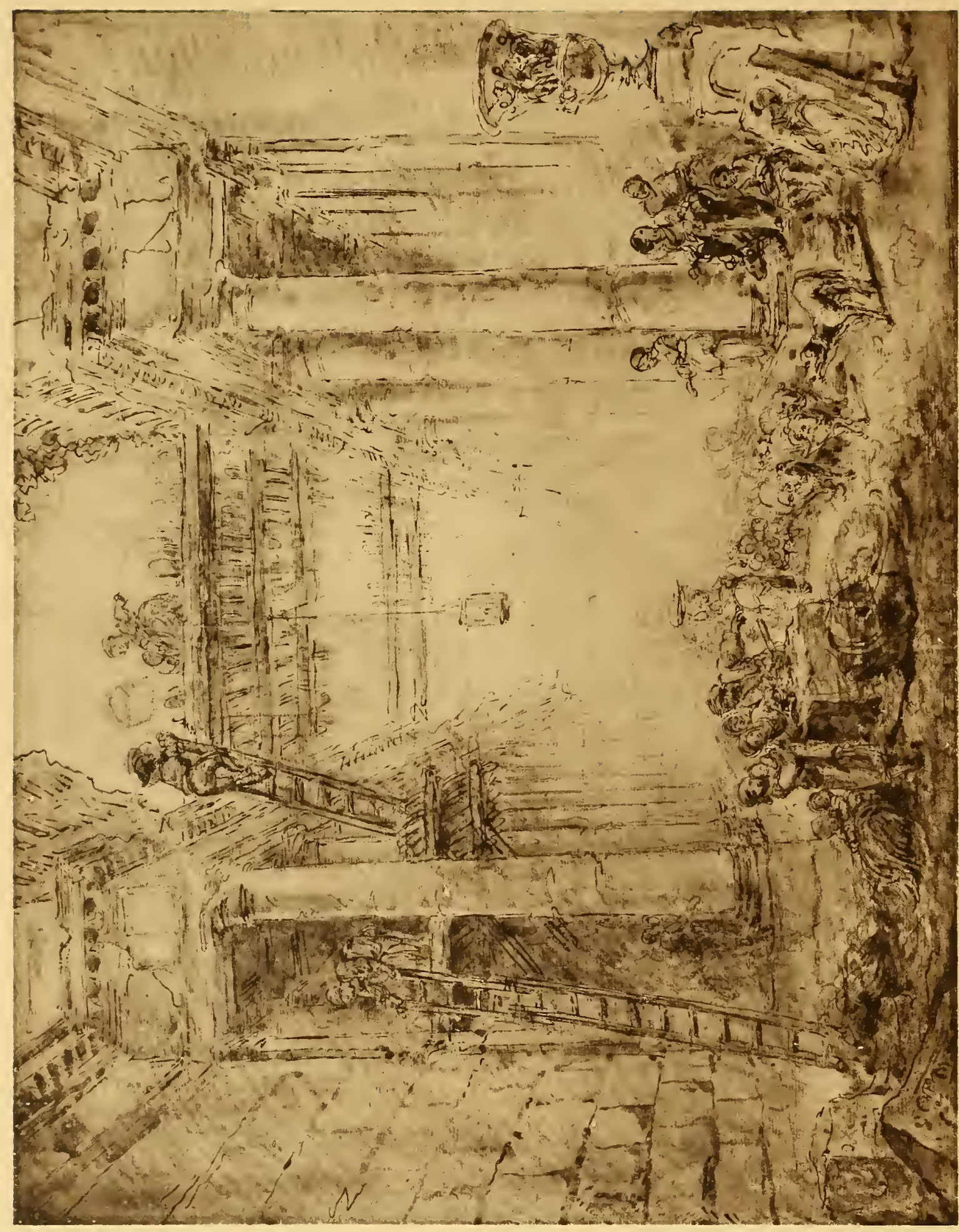




\section{ROBERT}

(HUBERT)

20000

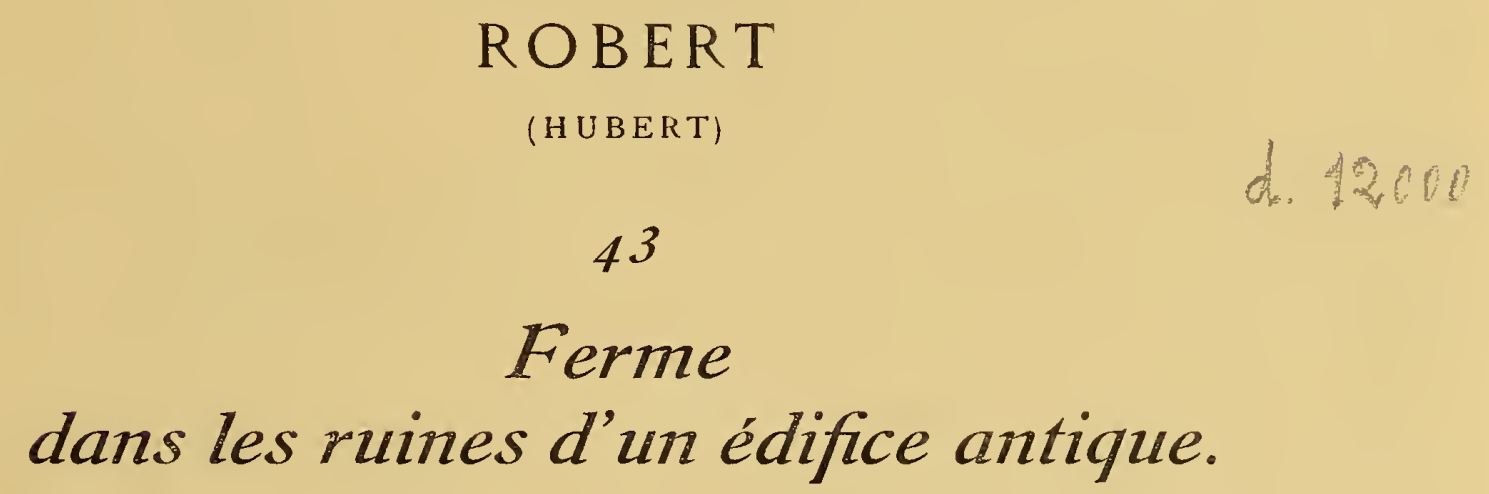

Dans une galerie divisée par des colonnades en deux bas-côtés et une nef centrale, dont la voûte s'est écroulée, un troupeau de moutons s'avance, venant du fond, escorté par une femme portant un fardeau sur la tête et par un enfant brandissant un bâton. A droite, divers personnages, un chien, des fragments d'architecture, un vase encore debout sur son socle. Au milieu, un groupe d'enfants et de femmes, à l'une desquelles un homme fait un geste de commandement en lui désignant le troupeau. A gauche, une échelle conduit à un plancher installé dans le bas-côté, à mi-hauteur des colonnes, et sur lequel on voit une femme; de ce plancher, qui s'avance un peu dans la nef centrale, part une autre échelle, aboutissant à un second étage, constitué par des planches jetées en travers de la galerie, d'un entablement à l'autre. Un homme gravit la dernière échelle; une femme est debout sur le plancher supérieur, d'où pend une lanterne.

Mine de plomb et plume, relevés de bistre par endroits.

$$
\text { Haut., } 283 \text { millim:; larg., } 362 \text { millim. }
$$

Repr. en fac-similé par la Société de reproduction des dessins de maîtres (2ªnnée, I 9 Io).

Cadre ancien, début de l'époque Louis XV, bois sculpté et doré. 


\section{ROBERT}

(HUBERT)

\section{4 \\ Le Jet d'eau.}

Dans un parc à l'italienne, une cascade jaillit entre des rochers, sous une arche couronnée de balustres. A droite et à gauche, circonscrivant un bassin où tombe la cascade, des escaliers conduisent à une première, puis à une seconde terrasse, dont on aperçoit la perspective fuyante, arrêtée tout au loin par une statue colossale. Des mascarons décorant la paroi des escaliers et des lions couchés sur les rampes crachent de l'eau dans le bassin; sur la première terrasse, un jet d'eau s'élève en colonne légère jusqu'au sommet de la composition. De petits personnages çà et là, les uns au pied des escaliers, d'autres gravissant les marches.

Signé en bas, à gauche : H. Robert.

Aquarelle sur trait de plume.

Hau1., 285 millim.; larg., 361 millim.

Repr. en fac-similé par la Société de reproduction des dessins de maitres (3e année, 19I I), avec une notice par E. Dacier.

La collection Jacques Doucet possède une première esquisse pour cette aquarelle; voir le numéro suivant.

D'autre part, on a vendu à l'Hòtel Drouot, le 17 avril $\mathbf{1} 889$, une sanguine d'Hubert Robert représentant ce même sujet, vu sous un autre angle, l'artiste se trouvant placé tout à fait à droite de la composition (H. o, fo; L. 0,$53 ; \mathrm{n}^{0} 9^{2}$ du catal. avec une reproduction).

Enfin, ces aquarelles et dessins ont trouvé leur forme définitive dans une peinture, qui fait partie de la collection Camille Groult et qui a été reproduite dans P. de Nolhac, Hubert Robert (Paris, 1910), pl., p. 134 , sous le titre : Escalier d'une villa romaine.

Cadre style Louis XVI, bois sculpté et doré, fronton à chutes de feuillage.

$$
\text { Le Jet d'eau. }
$$

Même composition que la précédente, sauf quelques variantes dans les petits personnages.

Mine de plomb, légèrement relevée de bistre.

Haut., 264 millim.; larg., 359 millim.

Cadre ancien, époque Louis XVI, bois sculpté et doré; fronton avec nœud de ruban et guirlandes retombantes. 


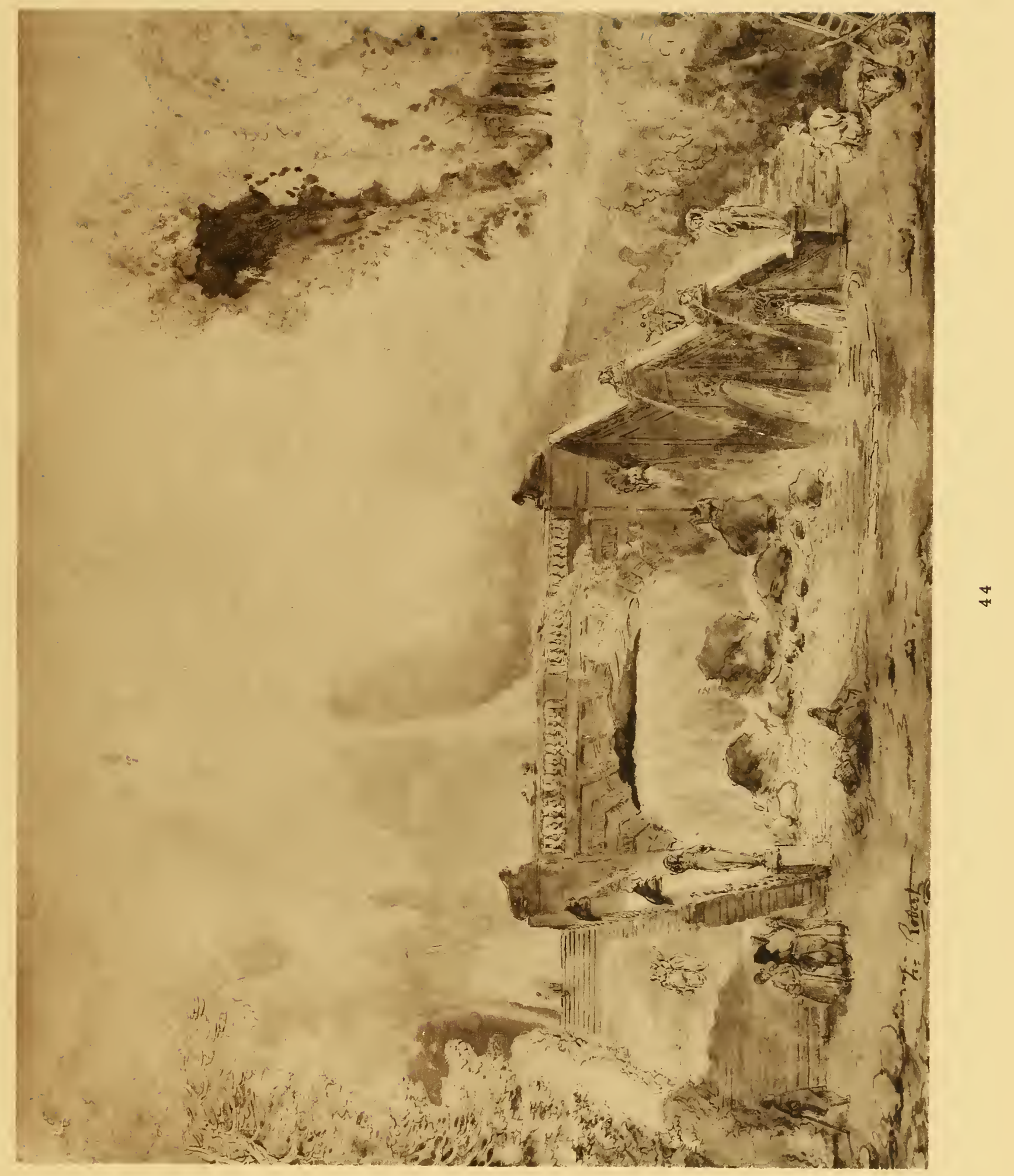






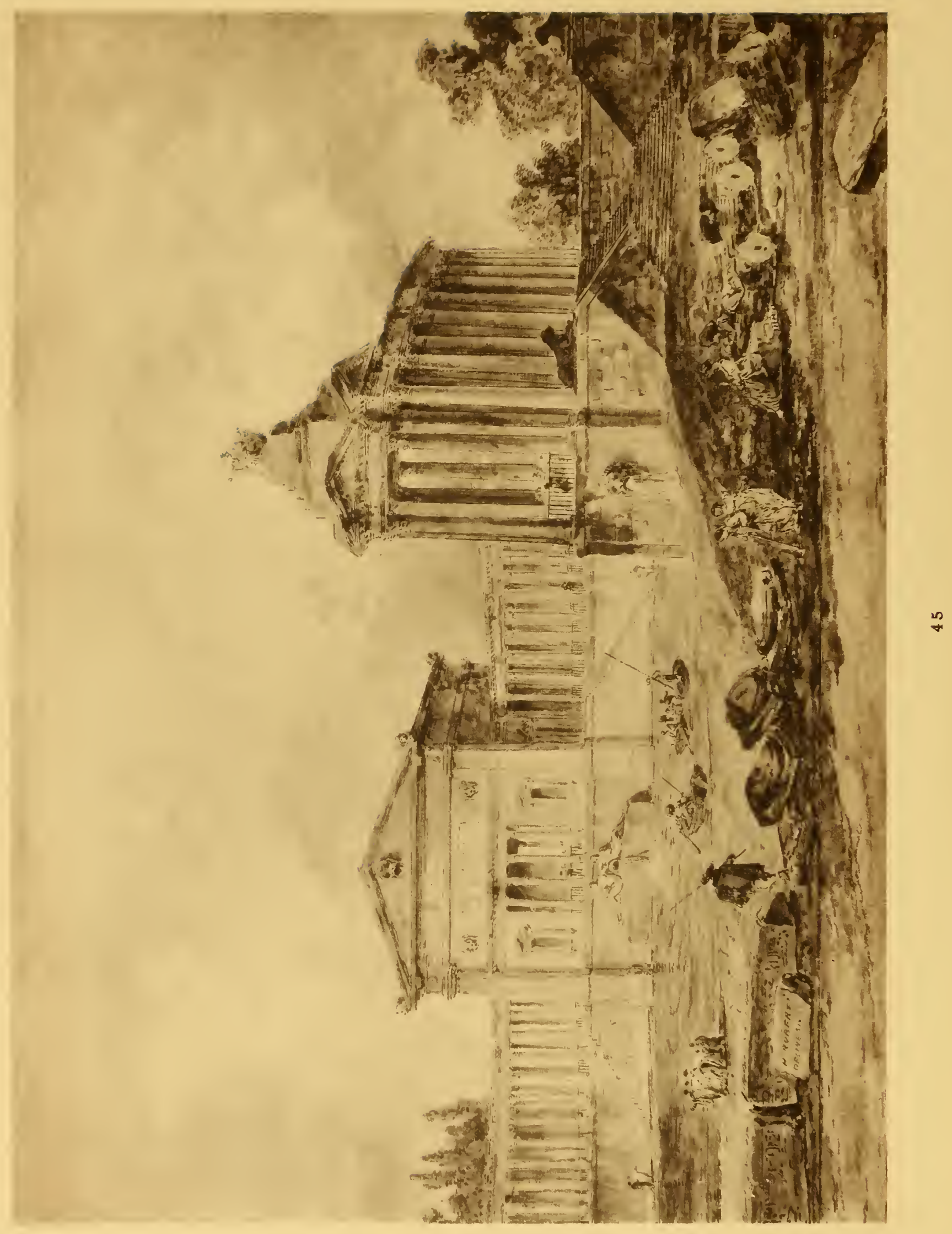




\title{
ROBERT
}

\author{
(HUBERT)
}

\section{0 45 \\ Monument à colonnades.}

Au delà d'un premier plan encombré de débris d'architecture, s'étend une pièce d'eau, sur laquelle on voit des barques et qui est entourée d'un mur en terrasse supportant un monument semi-circulaire. Ce monument se compose, au centre, d'une sorte de temple à fronton triangulaire, flanqué de deux ailes à colonnades formant galeries et soutenant une statue à leur extrémité. Au-dessous du portique ouvert à la partie centrale du temple, se trouve une fontaine, formée de deux statues couchées de part et d'autre d'une urne d'où l'eau tombe dans le bassin. Divers personnages çà et là. A gauche, l'aile est coupée vers le milieu; à droite, derrière la colonnade, des escaliers, et, au loin, des arbres.

Signé sur une pierre, en bas, à gauche : H. Roberti delineabat. Aquarelle sur trait de plume. Haut., 343 millim. (y compris une bande de 27 millim.
rapportée en bas); larg., 474 millim.

Cadre ancien, époque Louis XVI, bois sculpté et doré; fronton avec nœud de ruban et guirlandes retombantes. 


\section{SAINT-AUBIN \\ (AUGUSTIN DE)}

Paris, $1736+$ Paris, 1807 .

\section{0 Ricoi}

\section{6 \\ Portrait de $M^{m e}$ de Saint-Aubin.}

En déshabillé, elle est vue en buste, de profil à droite; son manteau de lit, dont le galon s'est dénoué, laisse voir un corsage ruché, ouvert sur la poitrine. Les cheveux, relevés sur le sommet de la tête, forment par derrière une touffe épaisse retenue par un ruban; trois boucles partant des tempes et de l'oreille, ornée d'un anneau, remontent vers le haut du chignon; une quatrième, entourée par le ruban de la coiffure, descend sur le cou. A gauche, le haut du dossier arrondi d'une chaise; à droite, un pan de draperie.

Signé à gauche, au-dessus de la chaise : de $S^{t}$ Aubin delin. ${ }_{1778}$ [le prénom est sans doute caché par la monture].

Mine de plomb très légèrement relevée d'aquarelle dans les chairs et de lavis dans le vêtement.

Ovale. Haut., 150 millim.; larg., I 27 millim.

On lit, à l'encre, au dos de l'encadrement, les deux inscriptions suivantes; la première sur trois lignes: Donné à Madame helman par sa meilleure amie fe ${ }^{t} t$ aubin ;la seconde, d'une autre main, sur quatre lignes: à rendre à $M^{r} S_{t}$. aubin le $I 27^{b r e} I 82 I$, helman; - et plus bas: coiffure à la mode en 1774 .

Repr. dans M. Tourneux, la Collection J. Doucet, etc. (les Arts, op. cit., p. ₹2).

Le modèle est bien connu : c'est Louise-Nicole Godeau qu'Augustin de SaintAubin avait épousée, alors qu'elle avait vingt-deux ans, le 29 novembre 1764 , et qu'il a représentée bien des fois; c'est elle qu'on trouve notamment dans Au moins; soyez discret! et dans l'Hommage réciproque.

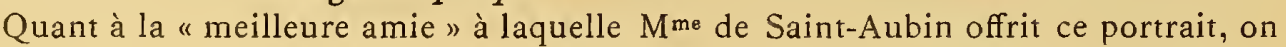
peut croire qu'elle désigne la femme d'Isidore-Stanislas Helman (1743-1806), le graveur de tant d'estampes célèbres, comme le Jardinier galant, le Roman dangereux, plusieurs planches du Monument du costume, et celles des Principales journées de la Révolution, - celles-ci exécutées d'après des dessins de Monnet, qui appartinrent à Augustin de Saint-Aubin et passèrent, en 1808 , à sa vente après décès (H. Beraldi et baron R. Portalis, les Graveurs du XVIIIe siècle, t. II, pp. 393 et 397).

Cadre ancien, époque Louis XVI, de forme ovale, bois doré. 


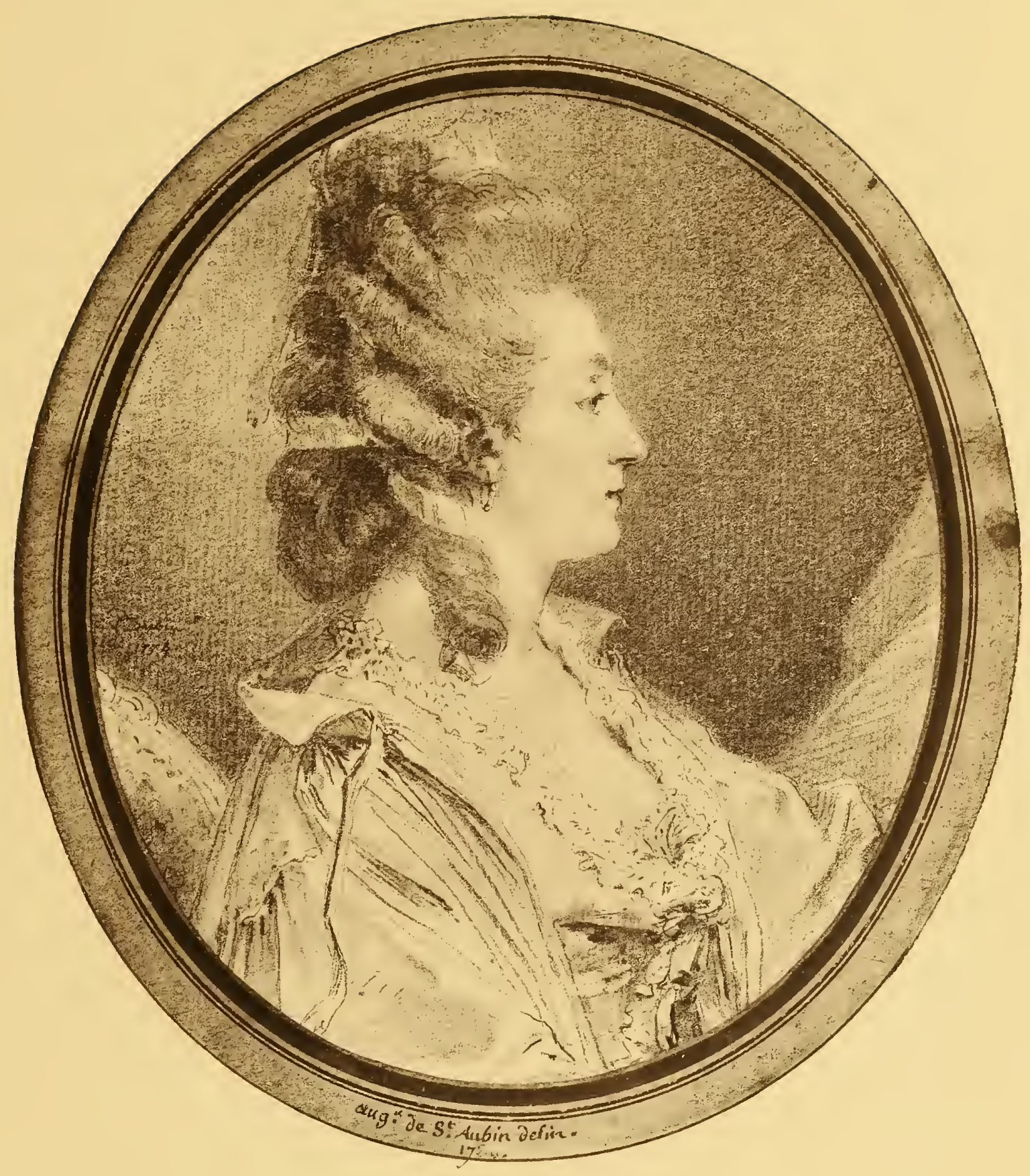






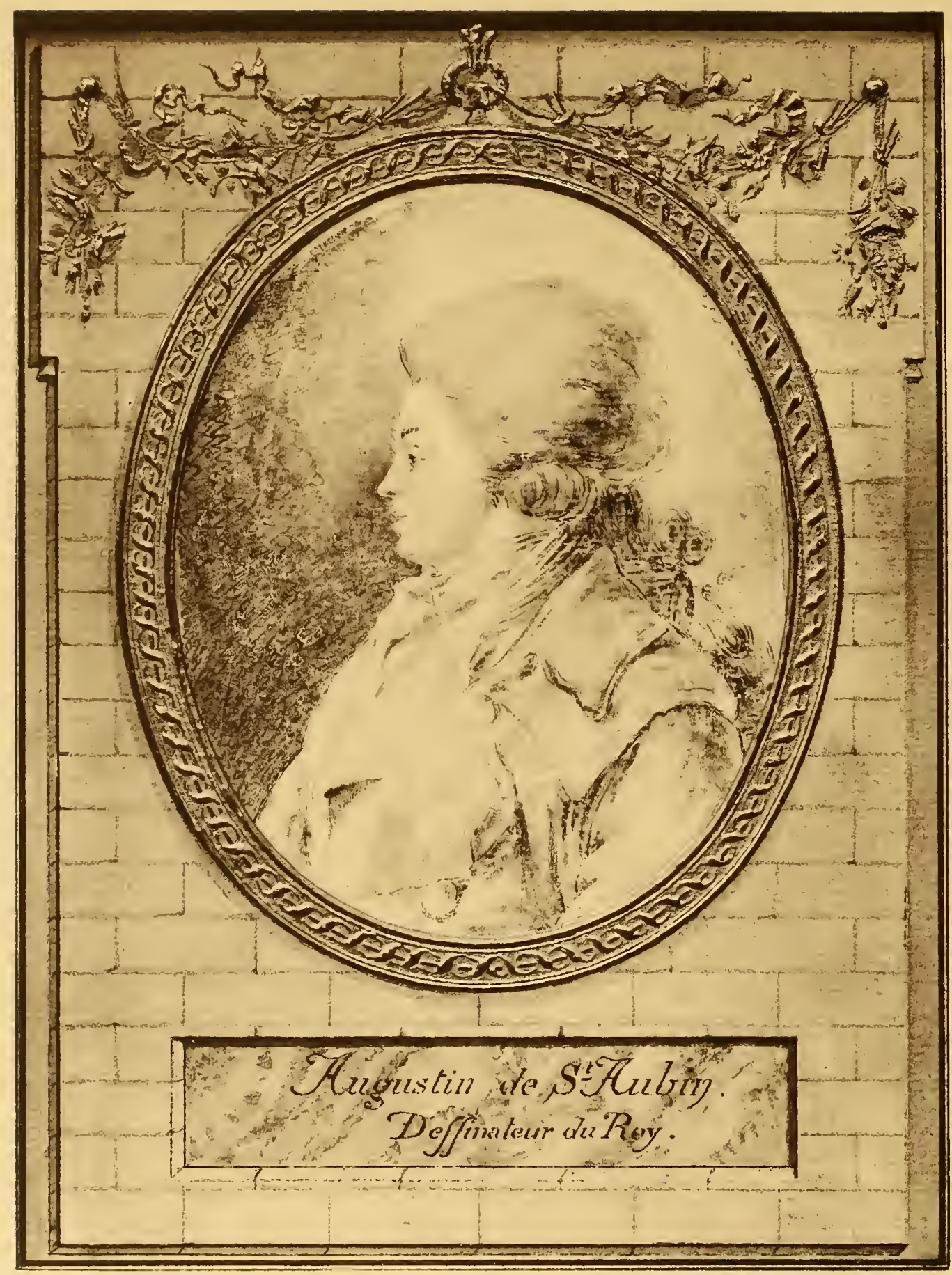




\title{
SAINT-AUBIN
}

\author{
(AUGUSTIN DE)
}

\section{7}

\section{Portrait d'Augustin de Saint-Aubin par lui-même.}

En buste, de profil à gauche, l'œil vif et la bouche entr'ouverte, il a le cou serré par une cravate de lingerie et porte un habit bleu à larges revers, ouvert sur un gilet de même couleur. Sa haute perruque bouffante, agrémentée d'une boucle sur l'oreille, est nouée d'un ruban par derrière. Costume de la fin du xviri ${ }^{\mathrm{e}}$ siècle.

Mine de plomb, relevée d'aquarelle.

Ovale. Haut., i ro millim.; larg., 89 millim.

Repr. en fac-similé par la Société de reproduction des dessins de maîtres (3e année, 1911), avec une notice par E. Dacier.

Monture simulant une ouverture percée dans une muraille et entourée d'ornements et de guirlandes de fleurs dorés en relief; au-dessous, le titre : Augustin de $S^{t}$ Aubin, dessinateur du Roy, écrit sur une tablette de marbre encastrée dans la muraille.

Cadre ancien, époque Louis XVI, bois sculpté et doré. 


\section{S A I N T - A U B I N}

(GABRIEL DE)

Paris, $1724+$ Paris, 1780 .

$$
48
$$

\section{La "Vénus" de Mignot au Salon de 1757.}

Au Salon du Louvre, un groupe de visiteurs examine la Vénus endormie, exposée par Mignot, qui occupe le milieu de la composition : à droite, un Turc et une jeune femme, et devant eux, au fond, trois hommes discutant les mérites de la statue. A gauche, une femme et un enfant montrent du doigt deux sculptures sur des socles : l'une est un buste d'homme, l'autre une nymphe épanchant l'eau d'une urne. Derrière ces sculptures, à la tête de la Vénus, deux hommes en conversation. La muraille du fond est garnie de tableaux.

On lit au bas, de la main de G. de Saint-Aubin : Sallon de 1757 . Figure de M. Mignot.

Encre de Chine et lavis.

$$
\text { Haut., } 137 \text { millim.; larg., } 162 \text { millim. }
$$

Collection des Goncourt (vente à Paris, février $1897, n^{\circ} 273$ ); la marque de la collection des Goncourt se voit en bas, à gauche.

Exposition des dessins de maitres anciens à l'École des beaux-arts, $1879, \mathrm{n}^{\circ} 601$.

Repr. dans Goncourt, l'Art du XVIII siècle (éd. in $4^{\circ},{ }_{1883}$ ), t. Ier, pl., p. I 50 ; dans le catalogue de la vente Goncourt, n० 273; - et dans E. Dacier, Catalogues de ventes et livrets de Salons illustrés par Gabriel de Sainl-Aubin (Paris, I909, gr. in-80), t. Ier, P. 13.

La statue de Mignot figurait au Salon de 1757 , sous le no 150 , avec cette désignation: "Vénus qui ảort. Cette figure est de la même proportion que l'Hermaphrodite antique et doit faire son pendant".

Cf. $\mathrm{Ph}$. de Chennevières, ies Dessins de maitres anciens à l'Exposition ae l'École des beaux-arís (Gaitete des Beaux-Arts, 1879 , t. II, p. 2 10).

Cadre ancien, époque Louis XVI, bois sculpté et doré. 


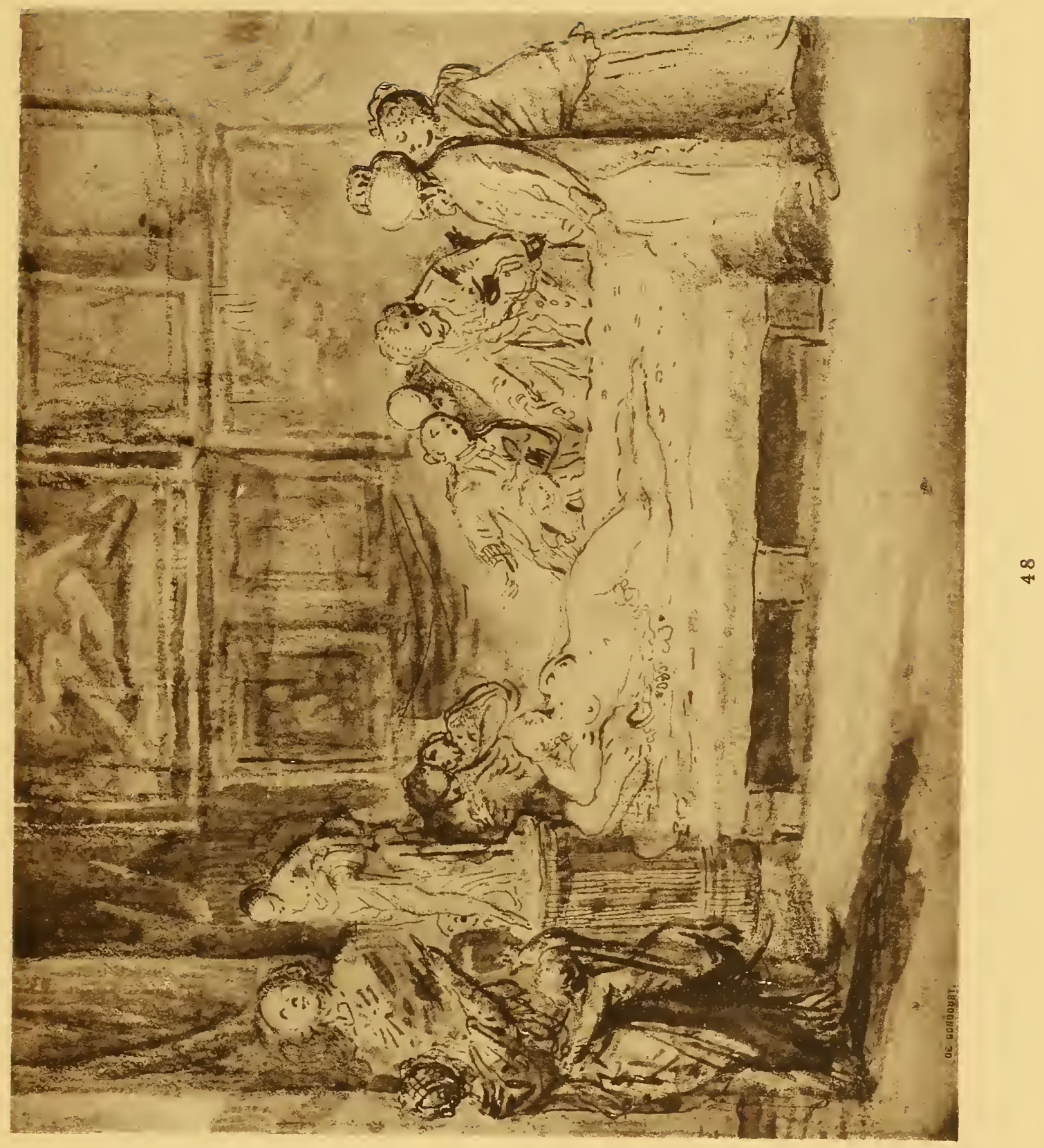






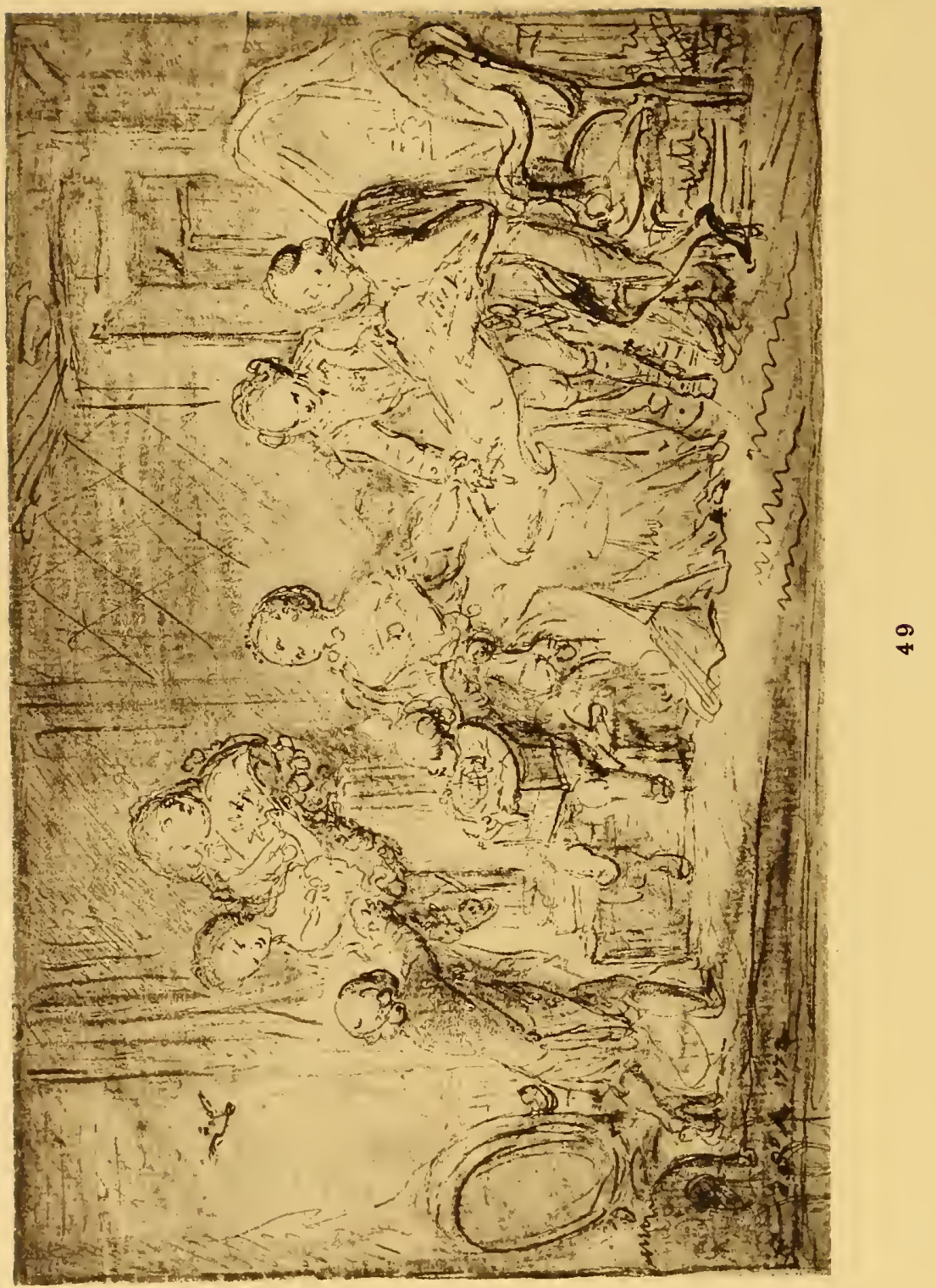




\section{SAINT-AUB IN}

(GABRIEL DE)

\section{Composition allégorique.}

Au milieu de la composition, une femme assise dans un fauteuil, le corps de trois-quarts vers la droite, s'interrompt de suivre les explications que lui donnaient un jeune officier debout, le doigt posé sur une carte déployée, et un petit abbé, assis en face d'elle et tenant un livre ouvert. Elle se retourne et, la main sur le cœur, elle contemple le buste d'un homme, portant une plaque d'ordre et un grand cordon, placé à gauche sur un socle, et que parent de guirlandes une jeune fille et un enfant. Sur la base du socle, un Amour nu ouvre la porte d'une cage et donne la volée à un oiseau qui s'échappe par une fenêtre ouverte à gauche. Au fond, à droite, une porte.

Signé en bas, à gauche : G. $d . S^{t} . A$ I $_{1772}$, corrigé en 1774 .

Pierre noire et encre de Chine.

Haut., I 2 millim.; larg., 175 millim.

Malgré toutes les recherches, il n'a pas été possible de découvrir le sens de cette composition allégorique. Est-elle une allusion à l'affaire de Bellegarde, cet officier d'artillerie emprisonné pour de prétendues malversations et défendu, en $177^{3}$, par un mémoire fameux de Linguet? Représente-t-elle une femme instruite d'une action d'éclat accomplie par son mari et adressant au buste de celui-ci un regard d'admiration, tandis que ses enfants le parent de fleurs? C'est à cette dernière hypothèse qu'on se rallierait plus volontiers, mais sans pouvoir proposer une identification précise.

Cadre ancien, époque Louis XVI, bois sculpté et doré. 


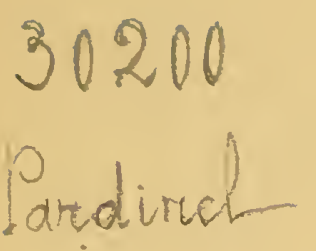

\section{SAINT-AUB I N \\ (GABRIEL DE) \\ 50 \\ Le Cours du chimiste Sage à la Monnaie (1779).}

Dans la grande salle de la Monnaie, dont le plafond est décoré de peintures allégoriques, les auditeurs du cours de minéralogie et de métallurgie docimastique professé par B.-G. Sage sont assis autour d'une vaste table rectangulaire, encombrée de cornues, de ballons, de matras, de balances, etc. A gauche, devant la haute cheminée dont on n'aperçoit que le profil, le professeur est debout, élevant et présentant un verre à expériences. Sur le côté gauche de la pièce, trois fenêtres; au fond, deux portes, entre lesquelles se trouve un poêle dont le tuyau traverse obliquement la salle; à droite, un garde-française debout, le fusil sur l'épaule.

Signé en bas, à gauche, à l'encre : Gabriel de St. Aubin, I779; on lit ensuite, au crayon : Leçon de M. Sage à l'Hôtel de la Monoye.

Pierre noire relevée d'encre de Chine.

Haut., 200 millim.; larg., I 29 millim.

Repr. dans Lady Dilke, French engravers and draughtsmen of XVIIIth century (Londres, 1902), pl., p. 134; - dans M. Tourneux, la Collection J. Doucet, etc. (les Arts, op. cit., p. 22); - et, avec le numéro suivant, en fac-similé, par la Société de reproduction des dessins de mâtres ( 3 e année, 1911 ), avec une notice par E. Dacier, rédigée d'après une communication faite, en 1909, à la Société d'iconographie parisienne, par M. A. Vuaflart.

La chaire de minéralogie et de métallurgie docimastique fut créée, à l'Hôtel des Monnaies, par lettres patentes du i i juin 1778 , en faveur de B.-G. Sage, qui commença son cours le 2 décembre suivant et le poursuivit au milieu d'un nombreux public (Mémoires secrets, t. XII, 3 août 1778 ; et t. XVII, 17, 18, 20 janvier 1781).

Gabriel de Saint-Aubin a représenté plusieurs fois ces solennités scientifiques. Outre le présent dessin et le suivant, on connaît une troisième vue du cours de Sage, ne comprenant que le portrait du chimiste et celui des auditeurs placés près de lui ; signé $G$. d. S. A., I779, ce dessin, reproduit dans l'Art du XVIIIe siècle (éd. in- $4^{\circ}$, 1883 , t. II, pl., p. $\left.44^{3}\right)$, provenait de la vente A.-N. Pérignon père $\left(1865, n^{\circ} 151\right)$; il a été acquis à la vente des Goncourt $\left(1897, \mathrm{n}^{\circ} 27^{\circ}\right.$ du catalogue, où il est reproduit), par Mme la marquise de Ganay.

C. Goncourt, l'Art du XVIII' siècle, éd. in-18, $2^{\circ}$ série, p. 224.

Cadre ancien, époque Louis XV, bois sculpté et doré, à fronton. 


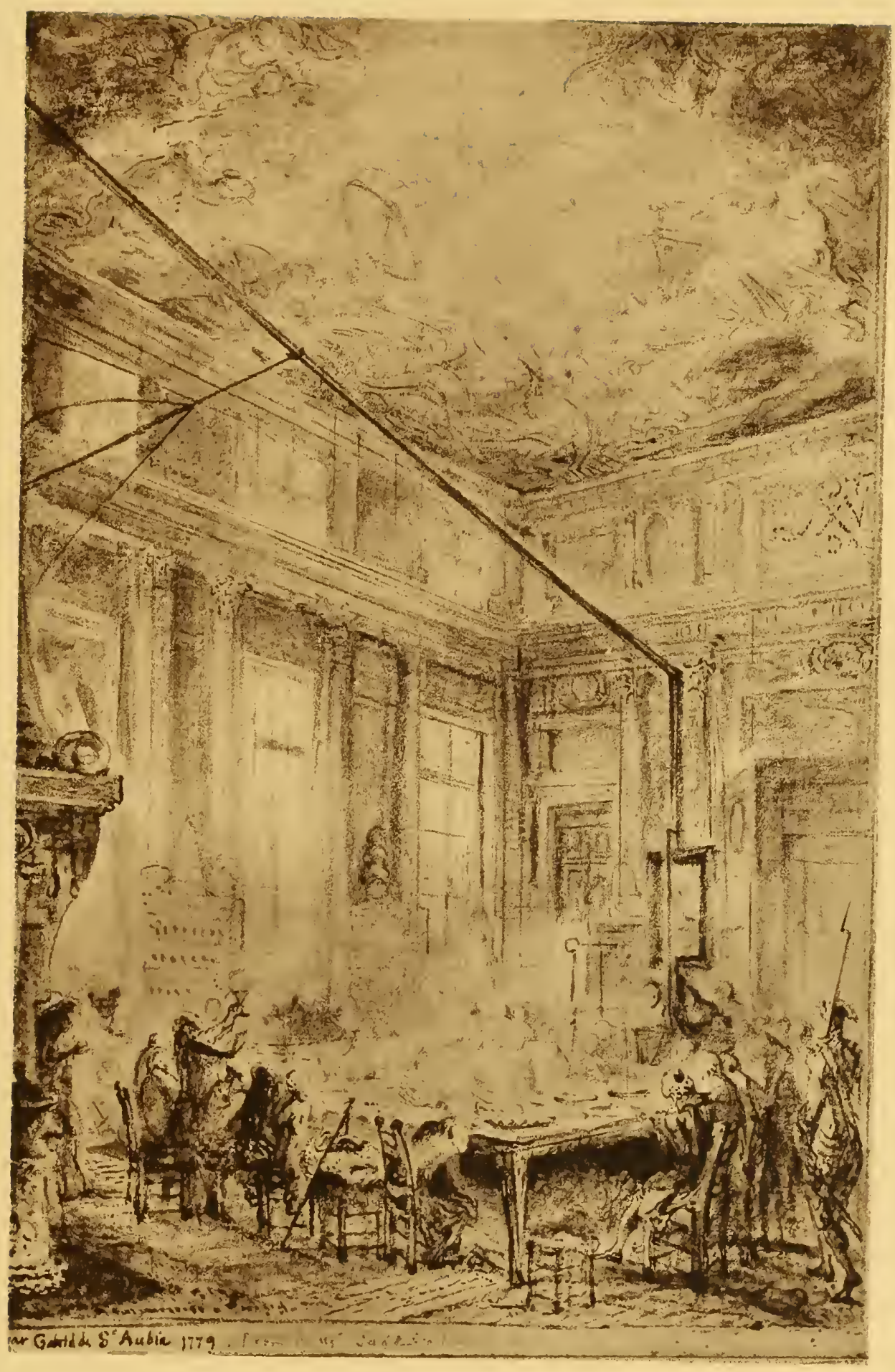

50 




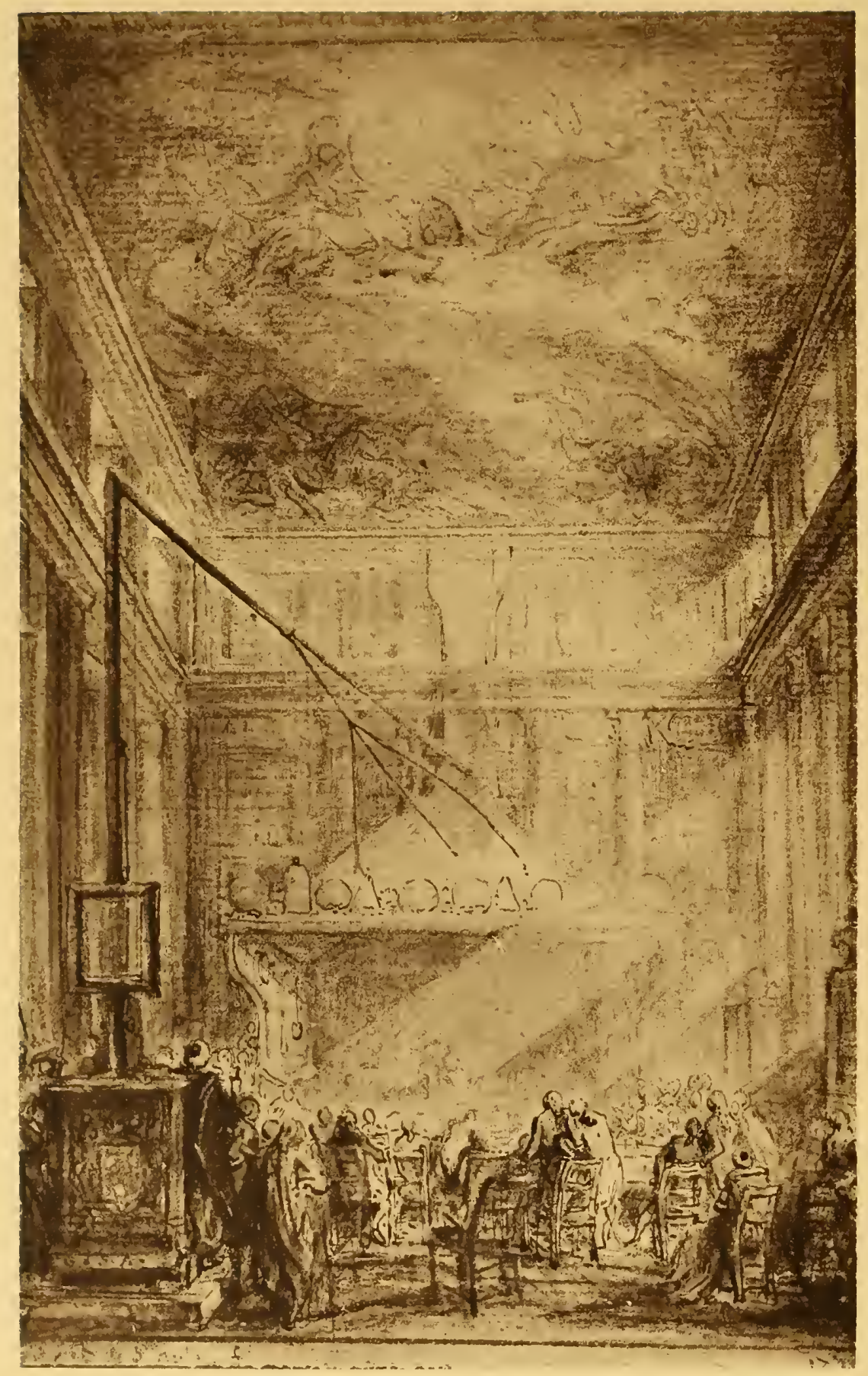




\title{
SAINT-A UB I N
}

\author{
(GABRIEL DE)
}

\section{1 \\ Le Cours du chimiste Sage à la Monnaie (1779).}

C'est la même salle de la Monnaie, au plafond décoré de peintures allégoriques, que Saint-Aubin a représentée dans le dessin précédent; mais la vue est prise en sens inverse, c'est-à-dire que l'artiste s'est placé, non pas derrière le professeur, mais en face de lui, de l'autre côté de la grande table entourée d'auditeurs assis ou debout, et près du poêle dont le tuyau, soutenu par une armature à plusieurs branches, traverse obliquement la pièce. Des rayons de soleil, entrant par les hautes fenêtres de droite, baignent la salle dans une lumière diffuse, à travers laquelle on distingue la silhouette du professeur debout devant le manteau de la haute cheminée chargée de cornues et de bocaux.

On lit en haut, au crayon : Une vue en face de M. Sage soutenant un vase d'essai dans les mains; - en bas, à gauche : G. de St Aubin f., et à droite : 1779. Sur le poêle, se voient également les initiales de l'artiste : G. d. S. A.

Pierre noire relevée d'encre de Chine.

Haut., 194 millim.; larg., 120 millim.

On a collé au dos de l'encadrement une note ancienne, à l'encre, portant cette indication: Laboratoire de la chaire de minéralogie docimastique établie à la Monoie en 1778 , en faveur de B.-G. Sage.

Collection Muhlbacher (vente à Paris, mai $1899, n^{\circ} 270$, où il est catalogué sous le nom d'Augustin de Saint-Aubin).

Repr. en fac-similé, avec le numéro précédent, par la Société de reproduction des dessins de maîtres (3e année, 1911 ), avec une notice par E. Dacier.

Pour la notice historique, voir le nº précédent.

Cadre ancien, époque Louis XIY, bois sculpté et doré, à coins fleuris. 


\title{
S A I N T - A UB I N
}

\author{
(GABRIEL DE)
}

52

\section{L'Arrivée du roi à Sainte-Geneviève (1779).}

Les cavaliers de l'escorte pénètrent, à droite, sur la place de la nouvelle église Sainte-Geneviève, qu'on voit au fond, et dont le dôme n'est pas encore construit. A gauche, au premier plan, un homme et une femme; derrière eux, des troupes formant la haie sur le côté de la place. Au fond, de ce même côté, le clocher de Saint-Étiennedu-Mont.

Signé en bas, à gauche : G. d. S. $A$., et daté à droite : 1779 .

Dessin à la plume relevé de lavis.

$$
\text { Haut,, } 20 \text { millim.; larg., } 65 \text { millim. }
$$

Collection A. Beurdeley (vente à Paris, mars $1905, n^{\circ} 2$ 19), sous le titre: l'Arrivée du roi au Panthéon. n०26I,

Exposition rétrospective de la Ville de Paris, à l'Exposition universelle de Igoo,

On sait que Gabriel de Saint-Aubin mourut le 5 février 1780 et qu'il ne produisit presque rien à partir du mois de juillet 1779, - "étant malade depuis plus de six mois qu'il traînait ", dit l'acte d'apposition des scellés rédigé après le décès de l'artiste. Il est donc vraisemblable de supposer que ce dessin fut exécuté pendant la première moitié de 1779 .

Or, on lit dans le Mercure de février 1779 (p. 226), que le 8 de ce mois le roi et la reine vinrent à Paris, accompagnés de la Cour, allèrent à Notre-Dame remercier Dieu de l'heureux rétablissement de la reine (la naissance de Madame Royale avait eu lieu le 19 décembre précédent), et se rendirent de là à Sainte-Geneviève, au milieu d'un grand concours de population. Le croquis de Saint-Aubin est sans doute un souvenir de cette cérémonie.

On le rapprochera d'un autre dessin du même artiste, gravé par Chenu pour les Étrennes françoises de l'abbé de Petity (1766), et représentant la Pose de la première pierre de la nouvelle église Sainte-Geneviève (en 1764 ).

Cadre ancien, époque Louis XIII, bois sculpté et doré. 


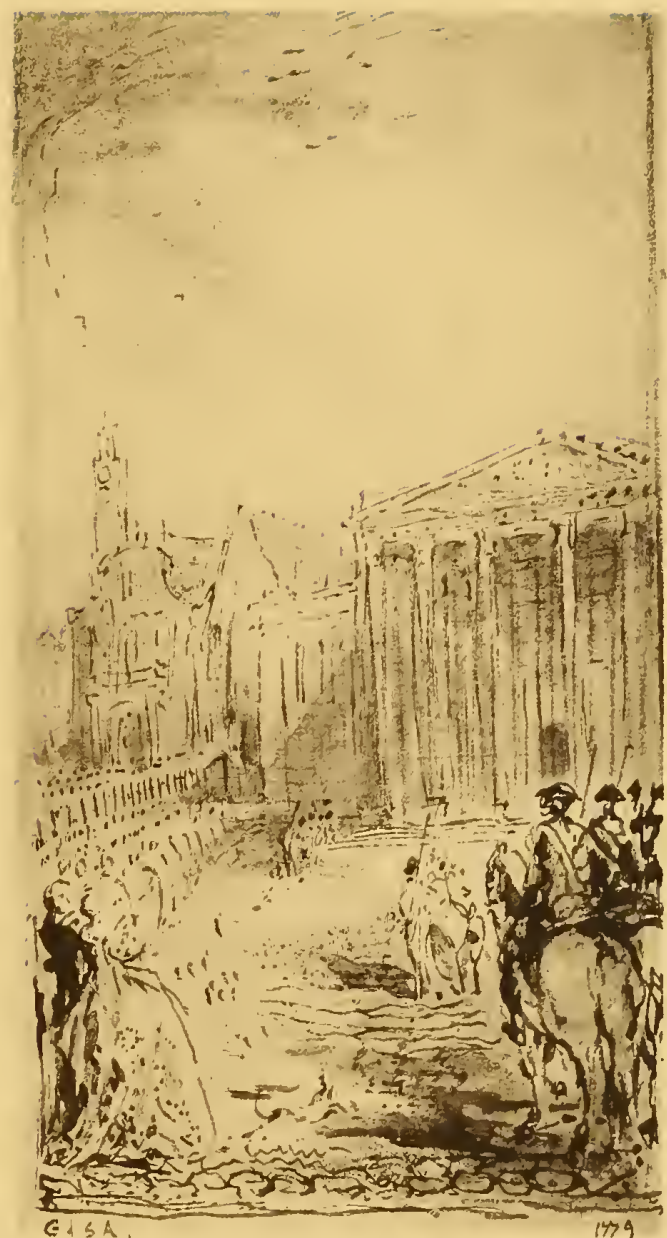

52 




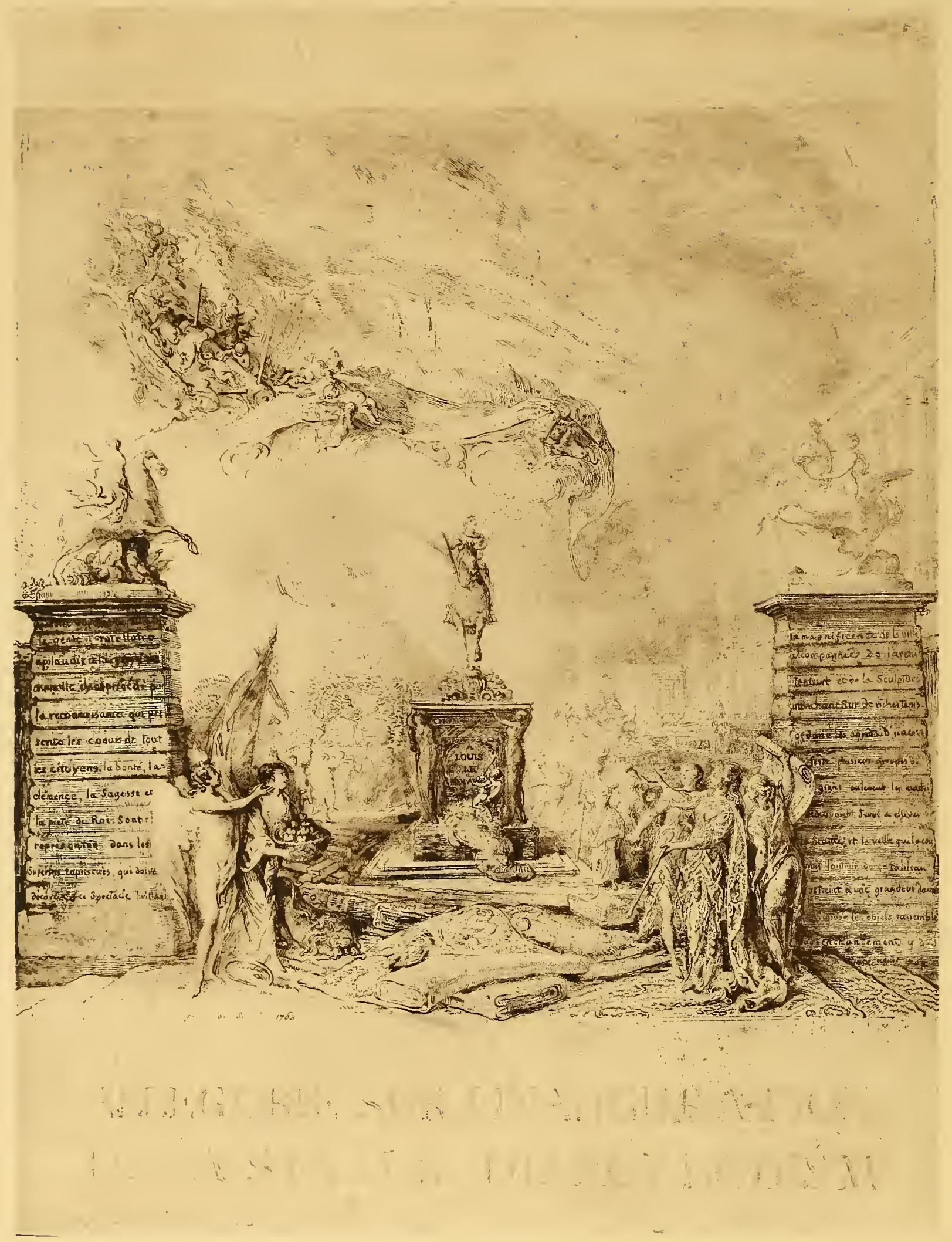




\section{SAINT-AUBIN}

(GABRIEL DE)

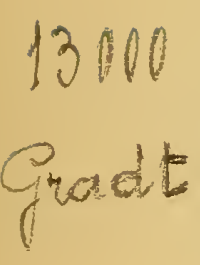

\section{3 \\ Allégorie sur l'érection de la statue de Louis XV (1763).}

Entre les deux pilastres supportant le Mercure et la Renommée de Coysevox, à l'entrée des Tuileries, on voit dans les airs une troupe de petits génies enlevant le voile qui recouvrait la statue du roi par Bouchardon. Sur le devant, à gauche, un génie ailé accompagne une jeune femme qui vient offrir au roi une corbeille remplie de cœurs; à droite, entre la Sculpture et l'Architecture, une autre jeune femme, représentant la France, indique de la main le monument. Au fond, à gauche, une estrade supportant des tonneaux, pour une distribution de vin au peuple; et à droite, devant l'un des pavillons du Garde-Meuble, l'orchestre d'un bal en plein air.

Signé en bas, vers la gauche : G. $d . S .{ }_{17} 63$.

Mine de plomb, plume et lavis, recouvrant le trait d'une eau-forte.

Haut., 3i I millim.; larg., 240 millim.

On lit en bas, en capitales, sur deux lignes: Allegorie sur l'inauguration de la statue du roy Louis $X V$. - Sur le piédestal de gauche, on lit, en minuscules, à l'encre, surchargeant le trait gravé : Gabriel de $S_{t}$. Aubin delin. Le génie tutellaire applaudit à la joye universelle; il est précédé par la Reconnaissance qui présente les cour de tout les citoyens. La bonté, la clémence, la sagesse et la piété du roi sont représentées dans les superbes tapisseries qui doivent décorer ce spectacle brillant. - Sur le piédestal de droite : La Magnificence de la Ville, accompagnée de l'Architecture et de la Sculpture marchant sur de riches tapis, ordone les aprêts d'une feste. Plusieurs groupes de génies enlèvent les machines qui ont servi à ellever la statue et le voile qui la couvroit. L'auteur de ce tableau astreint a une grandeur donnée supose les objets rassemblés par enchantement. G. d. S. data [?] aoust 1762 .

Collection Destailleur (vente à Paris, 1893 , no 111 , pièce 34 ).

L'eau-forte de G. de Saint-Aubin est décrite dans P. de Baudicour, le Peintre-graveur français continué (Paris, I859-61), t. II, G. de Saint-Aubin, n 6, et mentionnée dans Goncourt, $l^{\prime} A r t d u X V I I I^{\circ}$ s., éd.in-18,2 $2^{\circ}$ série, p. $197 .-$ Goncourt estime qu'il est impossible de savoir s'il y a, dans ce dessin, un dessous de trait gravé; ce dessous est pourtant visible en maint endroit.

En 1748 , Louis XV accorda à la Ville de Paris l'autorisation de lui élever une statue équestre et désigna comme emplacement un terrain encore inculte, devenu depuis la place Louis XV, aujourd'hui place de la Concorde. Vingt-huit plans furent proposés; A.-J. Gabriel les revit et en tira le projet qui fut exécuté, tel qu'on le voit dans la gouache du chevalier de Lespinasse, décrite précédemment sous le no 29 . Au centre de la place, fut érigée une statue de Louis XV par Bouchardon, portée sur un piédestal que Pigalle orna aux angles de quatre figures allégoriques. L'inauguration eut lieu le 23 février i 763 (cf. Barbier, Chronique, elc., t. VIII, pp. 65 et ss.).

Cadre ancien, époque Louis XV, bois sculpté et doré. 


\section{SAINT-AUBIN}

(GABRIEL DE)

\section{4 \\ Intérieur d'artistes.}

A droite, une jeune femme assise, vue de profil et tournée vers la gauche, vêtue d'une robe d'intérieur et coiffée d'un petit bonnet, travaille à une statuette de Vénus posée devant elle sur un escabeau. A gauche, au premier plan, un homme qu'on voit seulement en buste, assis dans un fauteuil, le corps de profil à gauche, la figure de trois-quarts et regardant en face, indique de la main droite un objet rond qu'il tient appuyé sur son bras gauche. Derrière lui, une sorte de coupe ornée d'une figure d'oiseau, et un portrait de Louis XVI en buste, sur le cadre duquel est posé un casque. L'homme et la femme sont assis de part et d'autre d'une cheminée, dont la tablette porte, de gauche à droite, une statuette d'ange ou d'amour, un petit groupe formant candélabre, une statuette de femme assise et vue de dos, et enfin une sorte de trophée d'instruments de musique enguirlandés de feuillages.

Pierre noire, relevée de plume et de lavis d'encre de Chine.

Haut., I 72 millim.; larg., 225 millim.

On lit dans l'angle inférieur droit, à l'encre, d'une écriture qui n'est pas celle de l'artiste: St. Aubin; - au-dessus du cadre, à l'encre, de l'écriture de G. de SaintAubin : Casque de l'empereur d'Orient et d'Occident, I775; - en haut, à gauche, au crayon, cette note, de l'écriture de G. de Saint-Aubin : I775. Voy. la statue du Roi en tere de Lorraine, au Salo'u d'Hercule, vue par Mr. Bonieu [?].

Collection Sigismond Bardac.

Repr. en fac-similé dans les Maîtres du dessin (3e année, 1901-1902, pl. 132).

Cadre ancien, époque Louis XVI, bois sculpté et doré; guirlandes et ruban rapportés. 


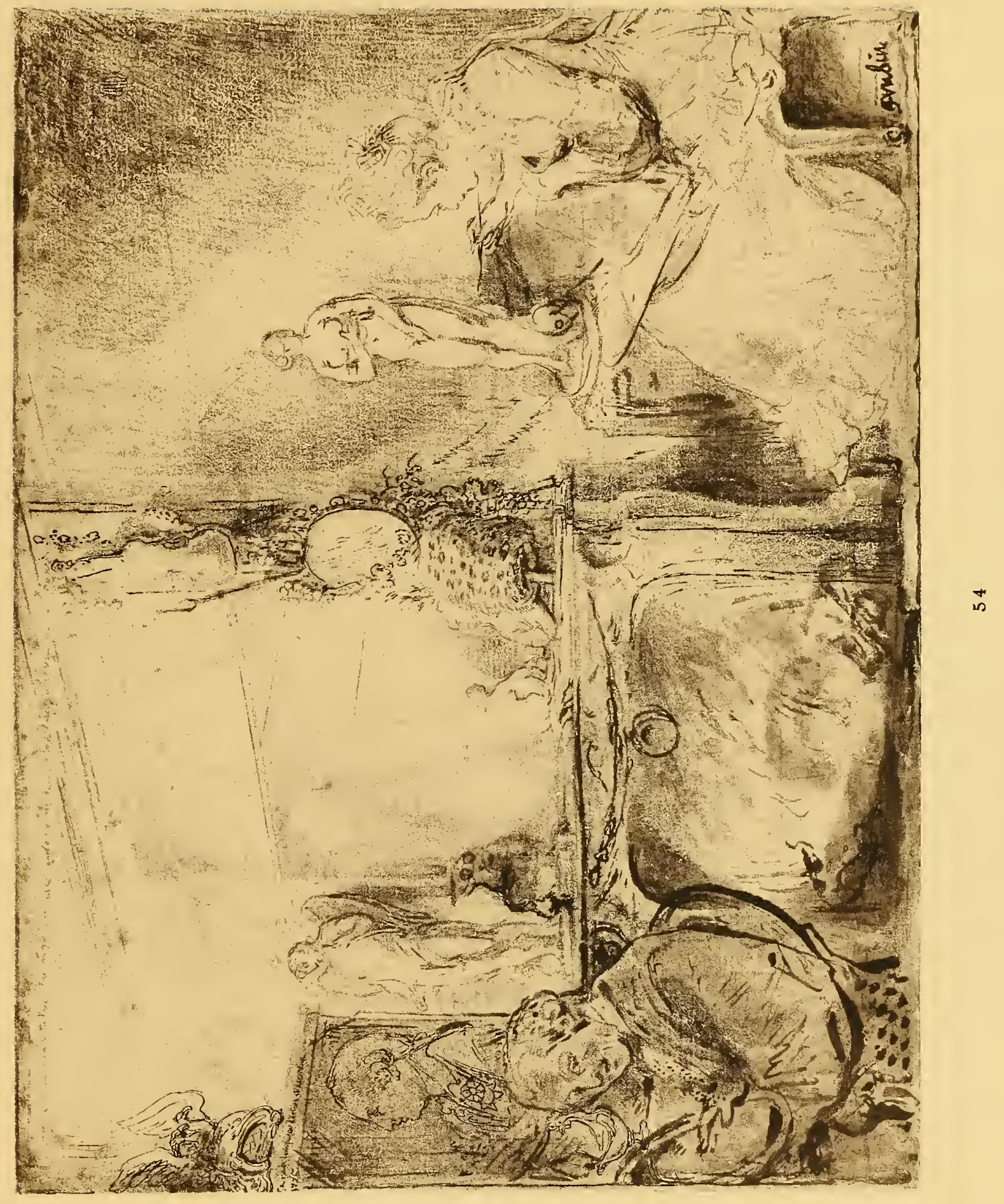






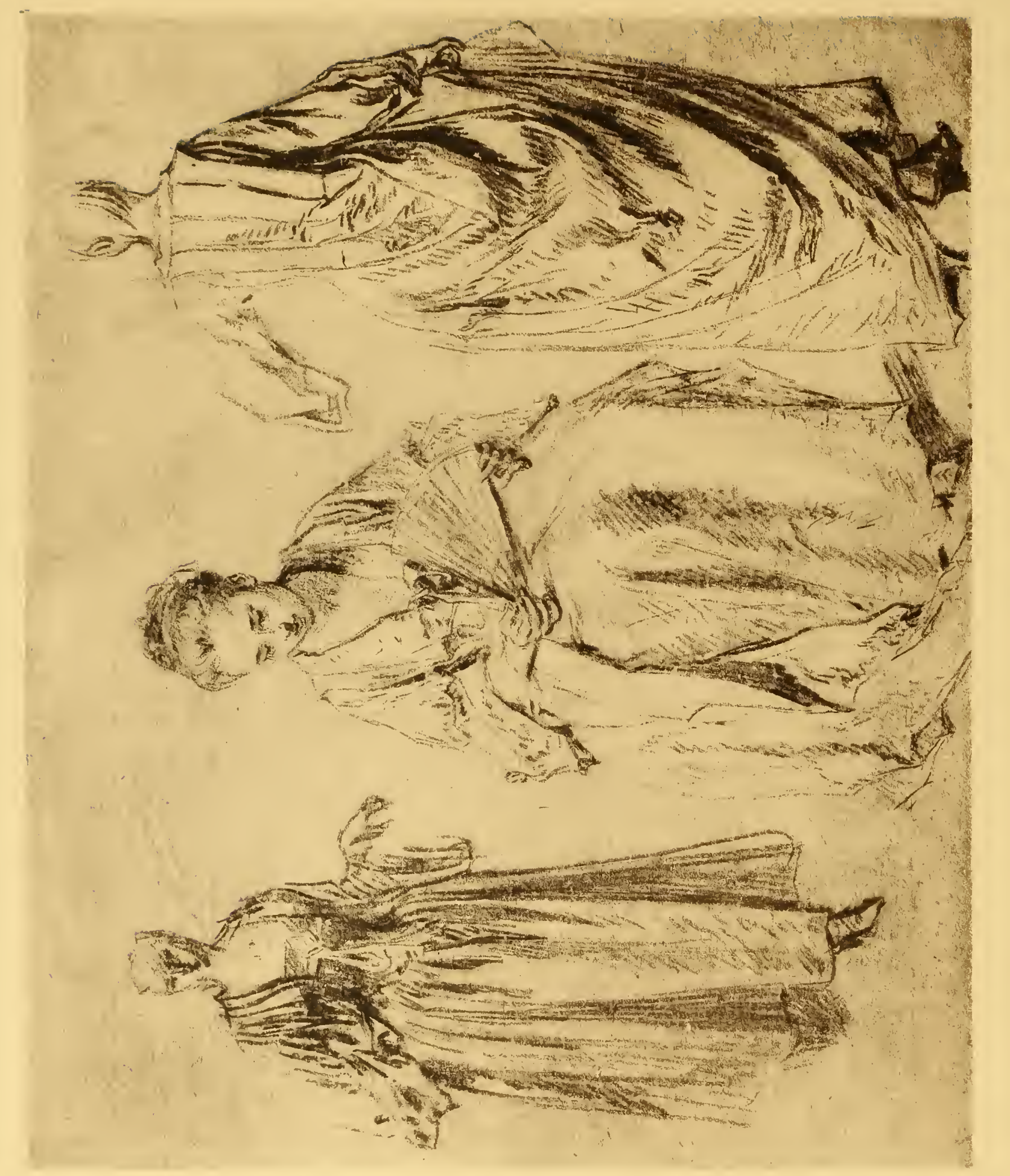




\section{W A T TEA U}

(ANTOINE)

Valenciennes, $1684 \div$ Nogent-sur-Marne, 1721 .

\section{Feuille d'études : trois femmes en pied.}

a. A gauche, une femme debout, vue de face, le bras droit dissimulé par une mante, la main gauche un peu avancée; la mante, ouverte sur le corsage décolleté, est retenue par un galon noué.

$b$. Au milieu, une femme assise, vue de face, la tête légèrement inclinée et tournée vers la gauche, le regard abaissé; elle joue avec un éventail entr'ouvert qu'elle tient de la main droite.

c. A droite, une femme debout, vue de dos; le bras gauche écarté, comme dans le geste de s'appuyer au bras d'un cavalier, elle relève de la main droite le bas de son manteau à plis.

$a$. Sanguine; $b$. Pierre noire et sanguine, légèrement relevées de craie; $c$. Sanguine et pierre noire. Papier grisâtre.

Haut., 264 millim. ; larg., 320 millim.

Collection Auguste (vente à Paris, mai 1850, un des dessins réunis sous les nos 101-102); - Collection du baron de Schwiter (vente à Paris, avril 1883, n 157); - Collection H.-A. Josse (vente à Paris, mai ${ }_{1894}$, n 46 ).

Repr. dans: G. Dargenty, Antoine Watteau (Paris, 1841, p. 47); - et dans le catalogue de la vente du baron de Schwiter, n ${ }^{\circ} 57, \mathrm{pl}$.

a. Rappelle, à quelque différence près dans le mouvement de la main gauche, la jeune femme qui tend la main, dans la Diseuse d'aventure, gravée par L. Cars.

b. Cette étude de femme a été utilisée dans l'Embarquennent pour Cythère (musée du Louvre et collection de l'empereur d'Allemagne) : c'est la femme assise à droite de la composition, écoutant les propos d'un galant pèlerin agenouillé près d'elle. - C'est elle également qui forme, avec ce pèlerin, le groupe principal du petit tableau gravé par Audran sous le titre de: Bon voyage.

c. Gravée directement par J. Audran dans les Figures de différents caractères $\left(n^{\circ} 205\right)$ : elle donne le bras à un homme ell petit manteau et en toquet (E. de Goncourt, Catalogue raisonné de l'œuvre peint, dessiné et gravé d'Antoine Watteau; Paris, 1875 . $\mathrm{n}^{\circ} 582$ ). On retrouve ce groupe légèrement modifié dans les Plaisirs du bal, gravés par Scotin (à droite, dans la gravure). - Gravée seule, directement et en manière de sanguine, par Demarteau (selon P. Mantz, qui reproduit cette pièce dans son Watteau, p. 37 ), à gauche d'une gravure où l'on voit, à droite, une femme assise au bas d'un escalier.

Cf. E. de Goncourt, Catal. raisonné, etc., p. 366.

Cadre ancien, époque Louis XVI, bois sculpté et doré, avec cartouche à la partie inférieure. 


\title{
W A T TEAU
}

\author{
(ANTOINE)
}

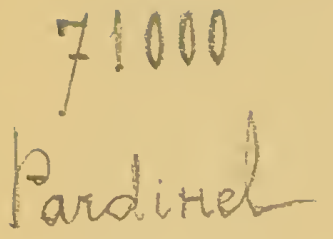

56

\section{Feuille d'études : deux femmes, l'une en pied, l'autre en buste.}

a. A gauche, une femme assise, le corps de trois-quarts et la tête, coiffée d'un bonnet de linge, de profil à gauche, le regard abaissé ; elle est décolletée en pointe et porte au cou un fil de perles; le bras droit tombe le long du corps, le gauche est légèrement écarté.

$b$. A droite, buste de la même femme, de profil à gauche; elle est coiffée d'une toque et décolletée en pointe; au cou, un fil de perles.

Sanguine et craie, avec quelques rehauts de pierre noire, sur papier chamois.

Haut, 230 millim.; larg., 263 millim.

Repr. dans A. Dayot, l'Image de la femme (Paris, 1899, p. 201); - dans M. Tourneux, Collection J. Doucel, etc. (les Arts, op. cit., F. 3), sous le titre : Études pour "l'Assemblée galante ".

a. Gravé en contre-partie par Boucher dans les Figures de différents caractères, n० 5 1 (Goncourt, Catalogue, n० 402 ); c'est la première idée de la femme assise, qui pose sa main droite sur la main d'un homme, dans le tableau de l'Assemblée galante, gravé par Le Bas.

b. Gravé en contre-partie dans les Figures de différents caractères, no 23.1 (Goncourt, Catalogue, n० 6o8).

Cadre style Louis XV, bois sculpté et doré. 


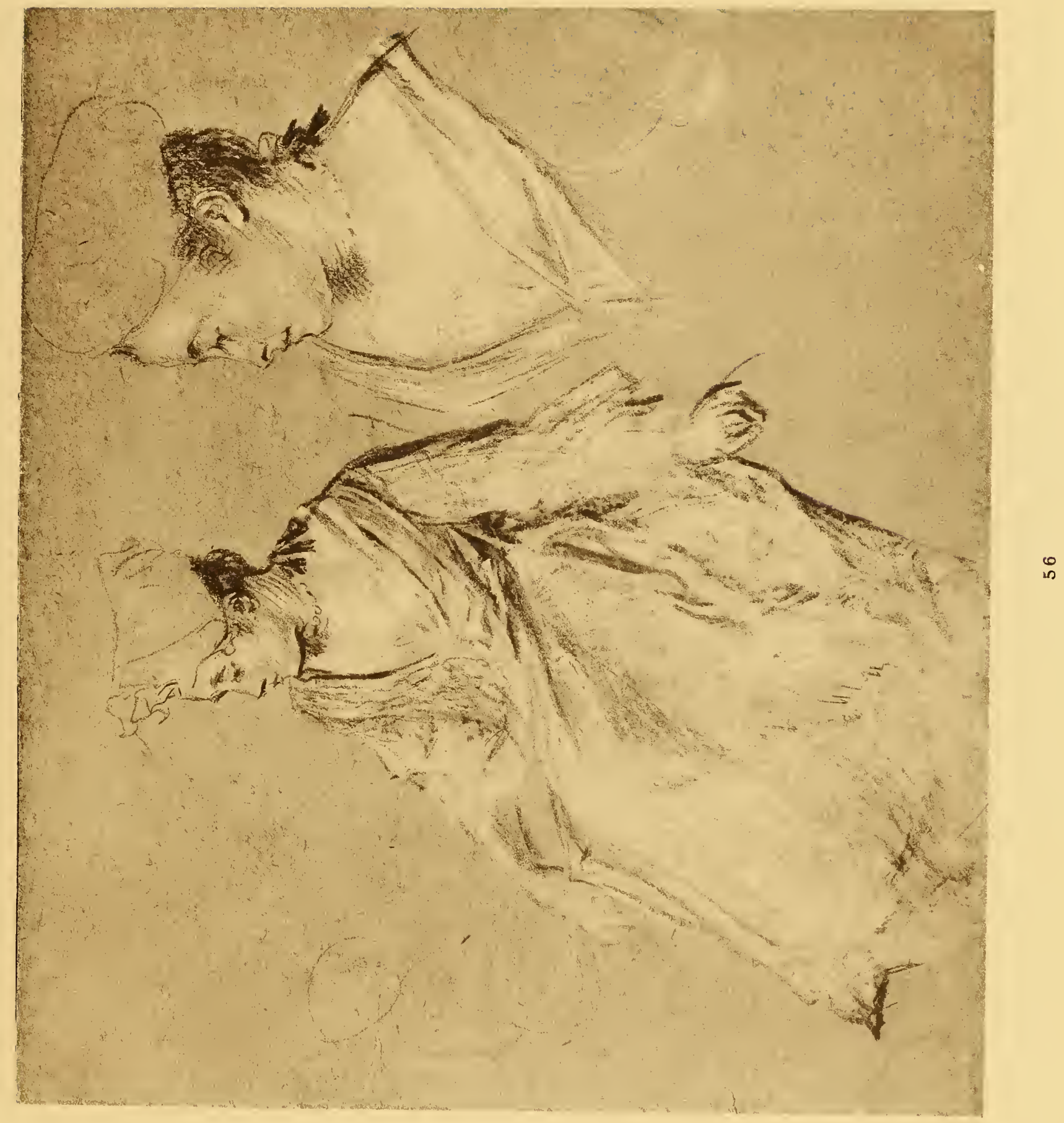






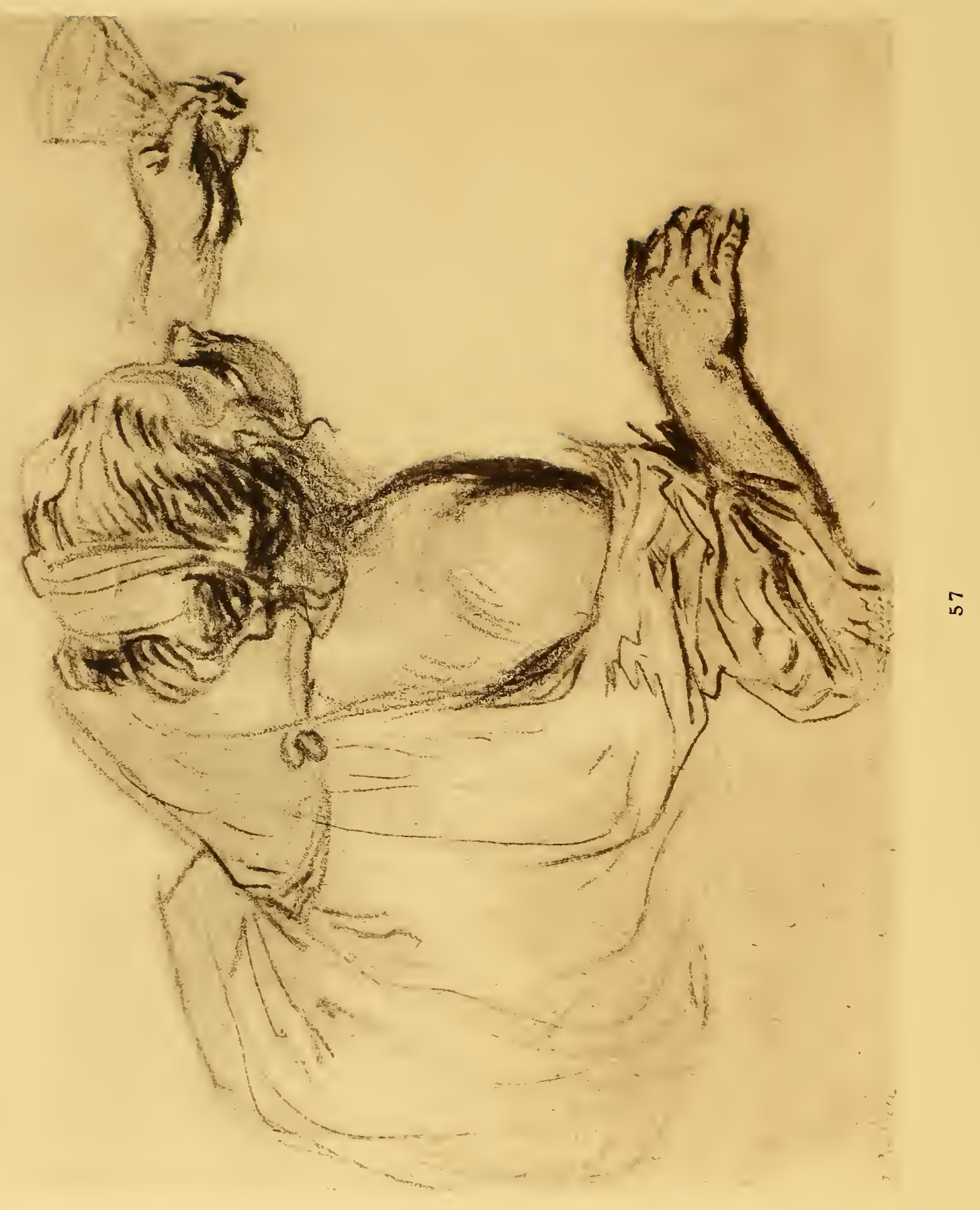




\title{
W A T T EA U
}

\author{
(ANTOINE)
}

\section{Stettirur Feuille d'étude : une femme couchée.}

Elle est vue de dos, à mi-corps, appuyée sur le bras droit, l'épaule nue; elle tient un verre de la main gauche, le bras étendu au-dessus du visage levé et tourné vers la droite.

On lit dans l'angle inférieur gauche, à l'encre : Watau.

Sanguine rehaussée de pierre noire et de craie, sur papier chamois.

$$
\text { Haut., } 170 \text { millim.; larg., } 194 \text { millim. }
$$

Collection Johann Conrad Spengler, directeur du musée de Copenhague (vente à Copenhague, octobre 1839); la marque de cette collection au timbre sec $: J$. C. S., se voit en bas et au milieu du dessin.

Étude pour l'Automne, une des peintures de la salle à manger de Crozat aujourd'hui perdues, gravée par Fessard : c'est la bacchante couchée au premier plan et tendant son verre au satyre qui remplit la coupe de Bacchus. L'étude pour le Bacchus est dans la collection Walter Gay (repr. par la Société de reproduction des dessins de maîtres, 3e année, 1911, avec une notice par E. Dacier'; l'étude pour le Satyre versant à boire, provenant de la collection du baron de Schwiter, appartient à M. Henry Michel-Lévy.

Cf. E. de Goncourt, Catalogue raisonné, etc., n 48.

Cadre ancien, époque Louis XV, bois sculpté et doré. 


\section{W A T TEA U}

\section{(ANTOINE)}

\section{Feuille d'études : deux enfants,}

a. A gauche, buste d'un enfant riant; vu de face, les yeux tournés vers la droite, il est coiffé d'un bourrelet et a la main droite posée en avant.

b. A droite, buste d'un enfant, la tête coiffée d'un bourrelet et tournée de trois-quarts à droite, à demi couchée sur le bras droit.

Sanguine, relevée d'un peu de pierre noire dans la figure de gauche seulement, sur papier chamois.

$$
\text { Haut., } 133 \text { millim.; larg., } 173 \text { millim. }
$$

Collection His de La Salle, dont on voit la marque en bas, à droite (H. L. en noir).

a. Gravé en contre-partie, par Boucher, dans les Figures de différents caractères, $\mathrm{n}^{\circ} 48$ (Goncourt, Catalogue raisonné, etc., no 399).

b. Gravé en contre-partie, par Boucher, dans les Figures de différents caractères, $n^{\circ} 83$ (Goncourt, Catalogue, $\mathrm{n}^{\circ} 438$ ).

C'est une étude pour le petit garçon appuyé sur un tabouret, du tableau de l'Occupation selon l'âge, gravé par Dupuis. "On le retrouve, dit Goncourt, avec un petit changement dans le mouvement du bras gauche, dans le tableau du musée de Dresde catalogué sous le titre: Groupe de messieurs et de dames réunis sur une terrasse ": c'est l'enfant qu'on voit à droite, au second plan, appuyé sur la hanche d'une femme couchée.

Cadre ancien, époque Louis $\mathrm{XV}$, bois sculpté et doré. 


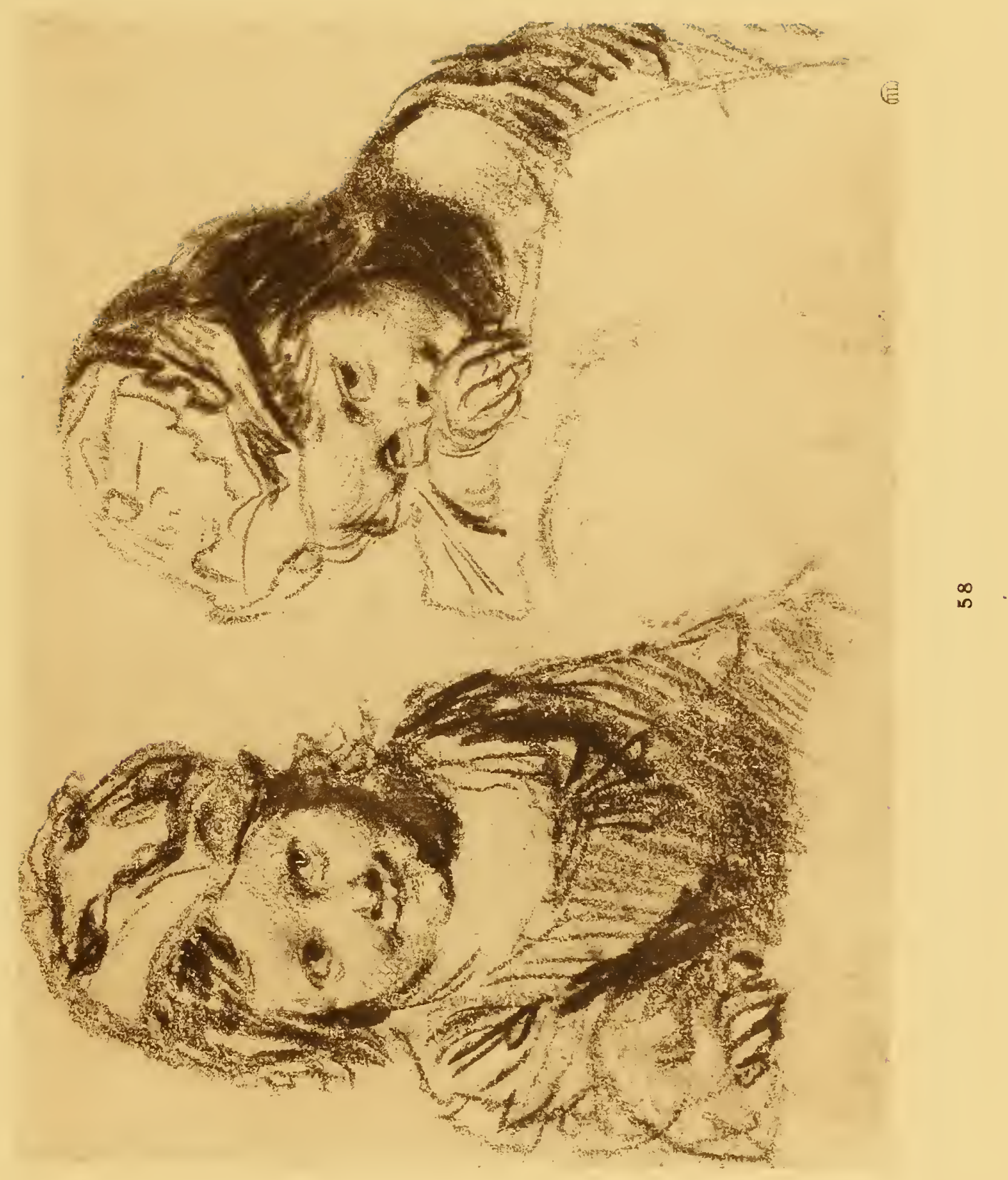






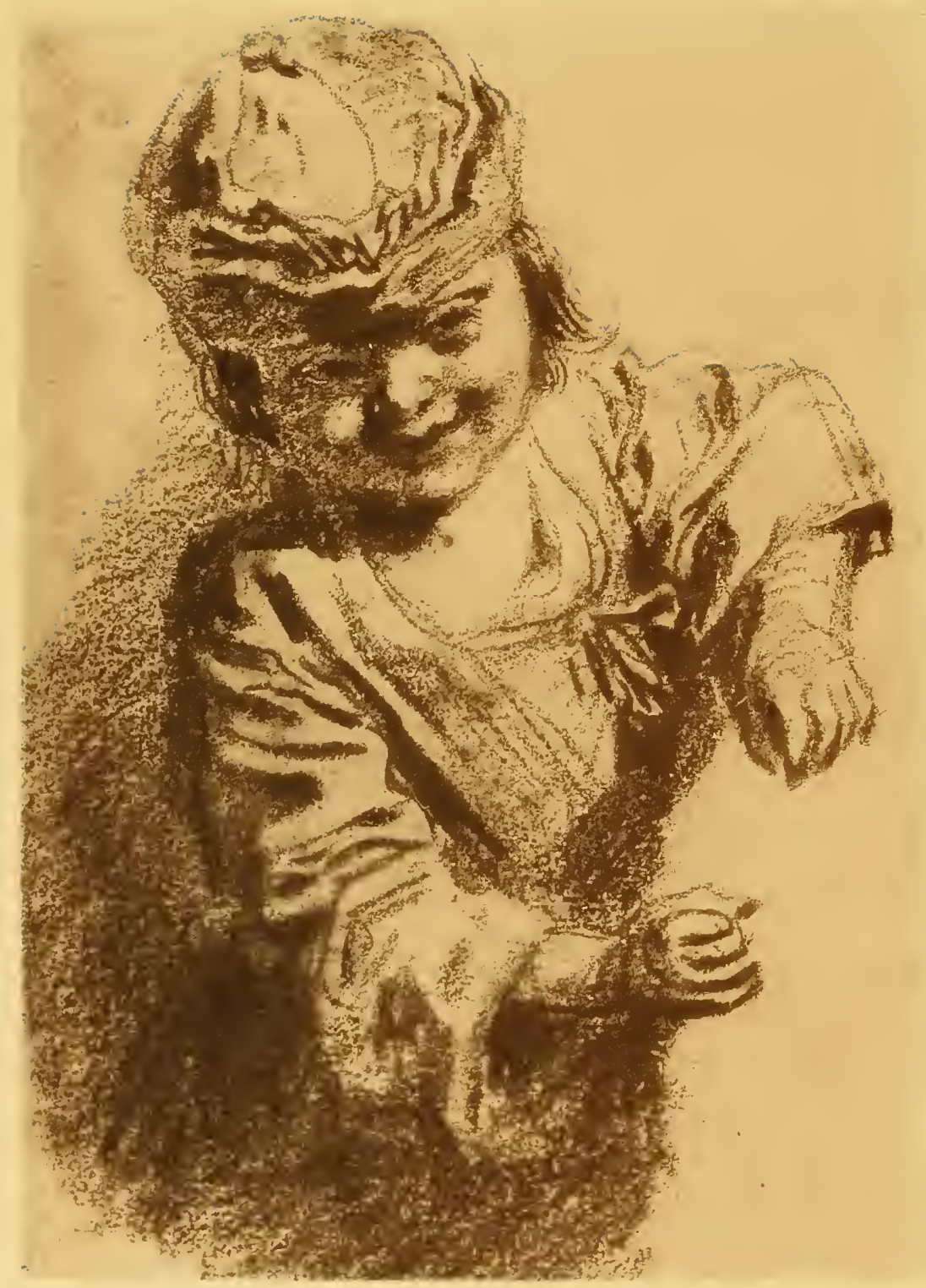

59 


\section{W A T TEAU}

\section{(ANTOINE)}

\section{Feuille d'étude : un enfant.}

Vu à mi-corps, l'épaule gauche remontée, le bras droit ramené sur le devant du corps, il a la tête de face, coiffée d'un bourrelet, et sourit en regardant vers la droite.

Sanguine relevée d'un peu de pierre noire, sur papier chamois.

$$
\text { Haut., I } 54 \text { millim.; larg., i I millim. }
$$

Collection Norblin de La Gourdaine (vente à Paris, février 1855, n² 25 1) : "Enfant coiffé d'une toque, aux crayons noir et rouge, de la belle manière du maître ". - Selon Goncourt, ce dessin a fait partie de la collection Thibaudeau.

Gravé en contre-partie, par Boucher, dans les Figures de différents caractères, $n^{\circ} 53$ (Goncourt, Catalogue, n० 405); sur la gravure, l'épaule droite et la main gauche s'appuient sur un tertre.

Cadre ancien, époque Louis XIV, bois sculpté et doré. 


\title{
WATTEAU
}

\author{
(ANTOINE)
}

60

\section{Le Savoyard à la marmotte.}

Un Savoyard debout, de trois-quarts tourné vers la droite, porte en sautoir une boîte, ramenée sur le devant du corps, sur laquelle est couchée une marmotte; de la main droite, appuyée sur la boîte, il tient un flageolet.

Sanguine et pierre noire, sur papier blanc.

Haut., 32.3 millim.; larg., 200 millim.

Collection John Charles Robinson (vente à Paris, mai ı 868); dans l'angle inférieur droit, se voit la marque de cette collection, composée des initiales $J$. $C$. $R$. à l'encre.

Gravé en contre-partie par Boucher, dans les Figures de différents caractères, n० 6 (Goncourt, Catalogue, no 354 ).

C'est une étude pour le Savoyard à la marmotte, œuvre de jeunesse de Watteau, gravée par B. Audran sous Je titre de la Marmotte, et aujourd'hui au musée de l'Ermitage, à Saint-Pétersbourg (Goncourt, Catalogue, no 85 ; et Somoff, Ermitage impérial, Catalogue de la galerie des tableaux, Saint-Pétersbourg, I9o3, t. III, n 1502 ); dans la peinture, on voit derrière le Savoyard un fond de paysage représentant une place de village avec son église.

Cadre ancien, époque Louis XV, bois sculpté et doré, à fronton orné d'armoiries. 


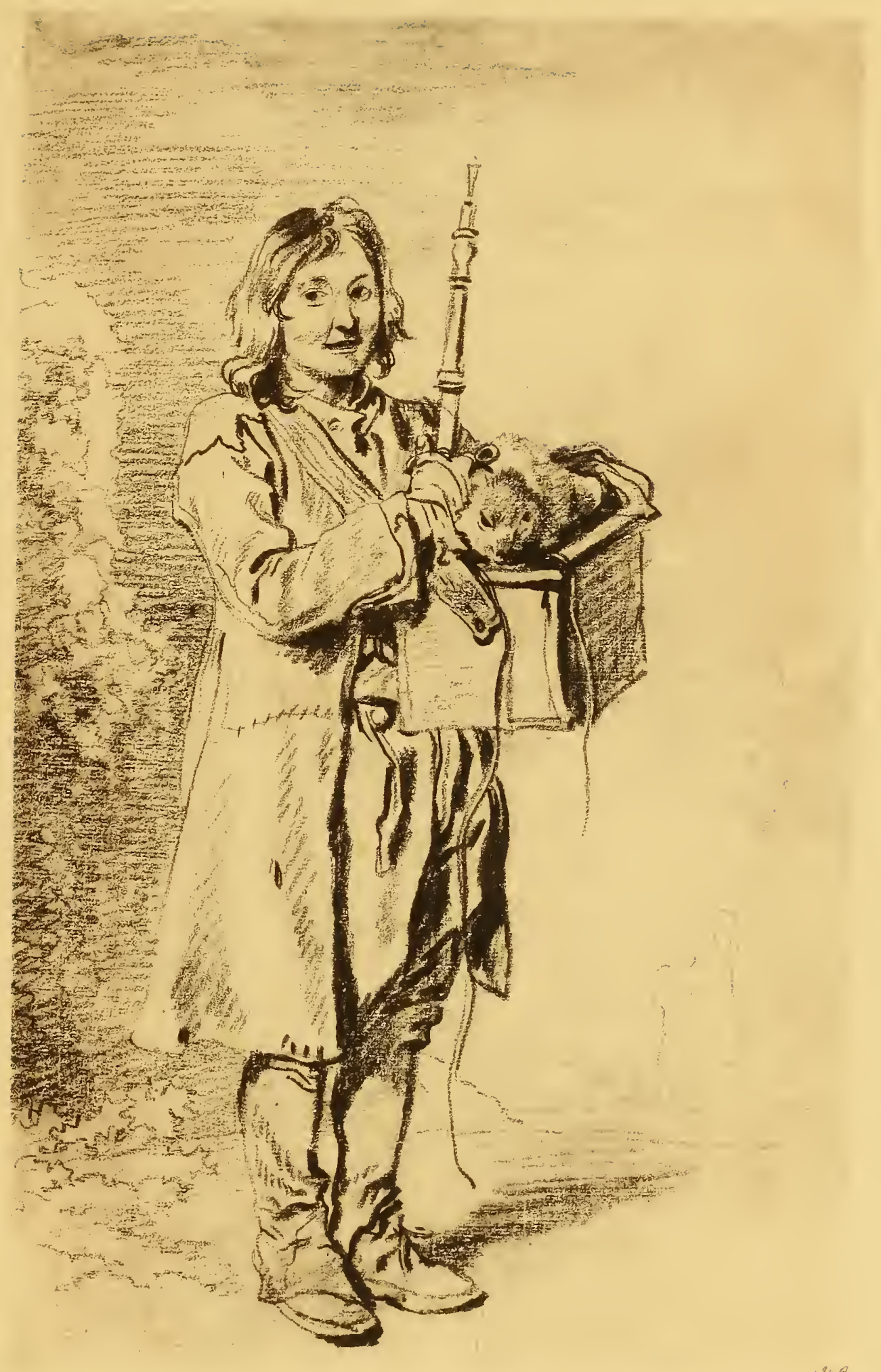






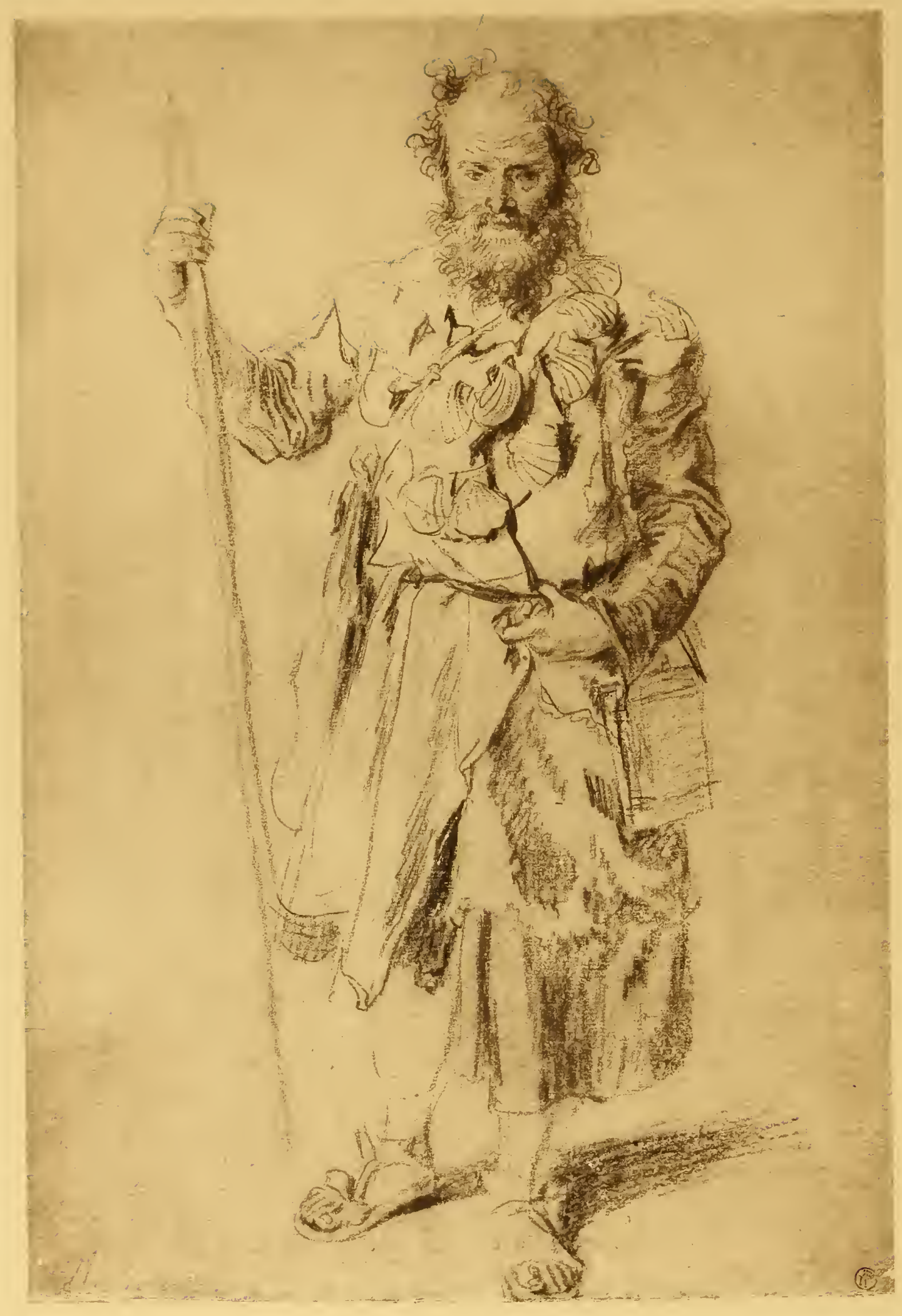

61 


\title{
WATTEAU
}

\author{
(ANTOINE)
}

\section{1 \\ Le Pèlerin.}

C'est un homme barbu, debout, de face, vêtu d'une robe qui lui descend à mi-jambes et chaussé de sandales. La tête nue et légèrement inclinée, il s'appuie de la main droite sur un long bâton et il a le pouce de la main gauche passé dans une ceinture d'où pend, sur le côté, une sorte d'escarcelle; un galon auquel un sac est suspendu lui barre la poitrine, couverte d'un chapelet de coquilles Saint-Jacques.

On lit dans l'angle inférieur gauche, à l'encre : Watteau.

Sanguine et pierre noire, sur papier chamois.

Haut., 372 millim.; larg., 25 I millim.

Dans l'angle inférieur droit, la marque de la collection Warwick.

Étude dans le genre du buste de frère mendiant et des types populaires (rémouleurs, savoyards, artisans) qu'on rencontre dans les Figures de différents caractères, par exemple aux nos $1,6,38,107$, etc.

Cadre ancien, époque Louis XV, bois sculpté et doré, à coquilles. 


\section{WATTEAU}

(ANTOINE)

\section{2}

\section{Feuille d'étude : une fermme vue de dos.}

Vue en pied, de dos, la tête tournée vers la gauche, elle marche, le haut du corps légèrement incliné, la main droite ramenée par derrière et relevant la jupe.

Sanguine sur papier blanc.

Haut., 177 millim.; larg., 80 millim.

Dans l'angle inférieur droit, la marque de la collection Warwick.

Repr. en fac-similé par la Société de reproduction des dessins de maîtres ( $3 \mathrm{c}$ année, I gII), avec une notice par E. Dacier.

Cadre ancien, début de l'époque Louis XV, bois sculpté et doré, avec les armes royales au fronton. 


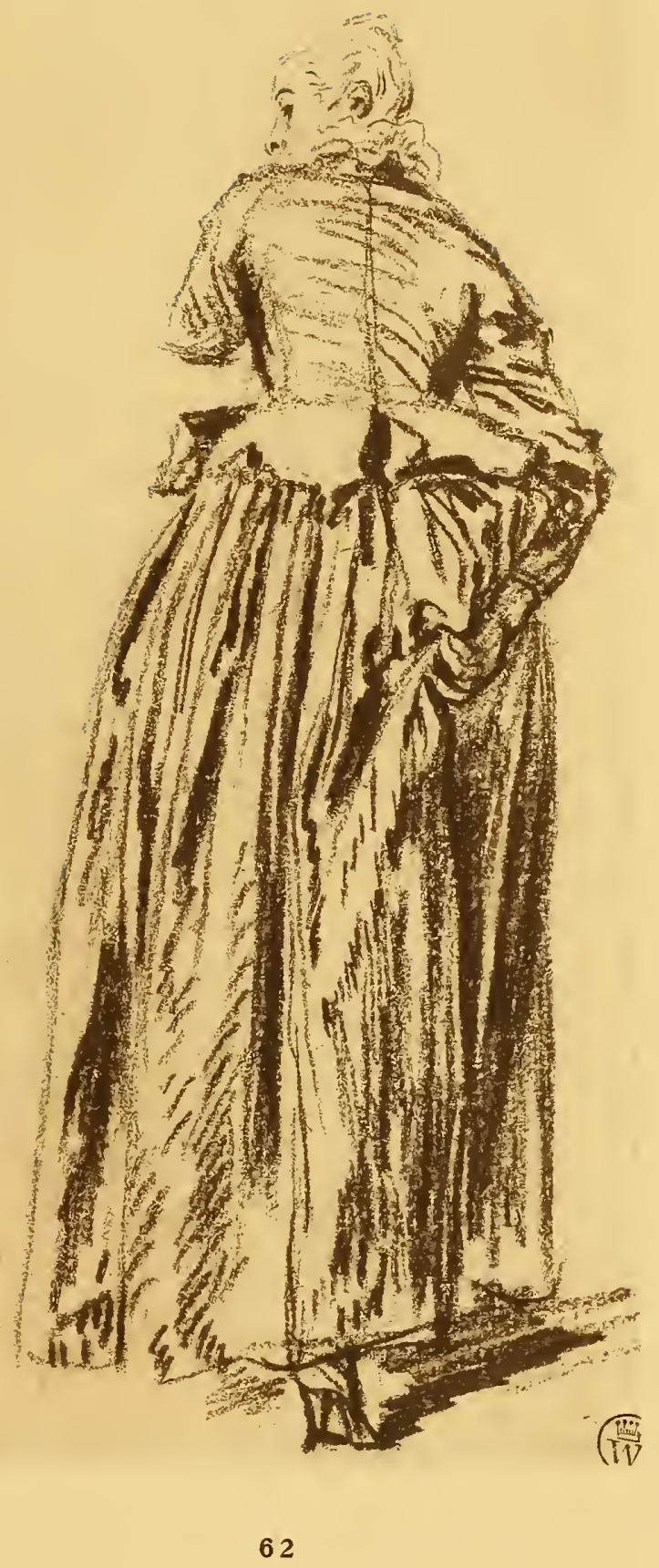






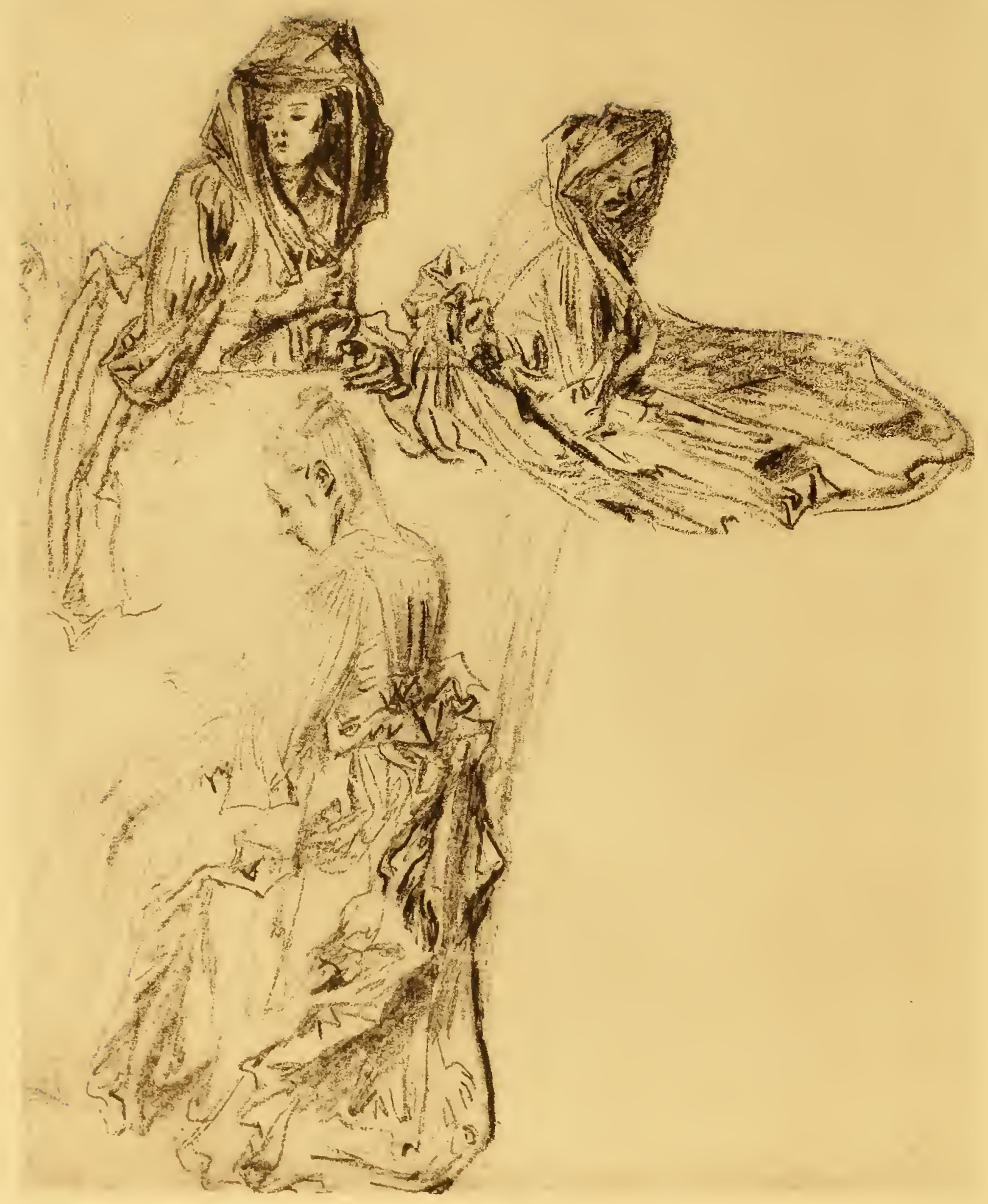




\title{
W A T TEA U
}

\author{
(ANTOINE)
}

\section{0}

63

\section{Feuille d'études : trois femmes.}

a. En haut, à gauche, une femme en buste, la tête couverte d'une mante dont elle réunit les deux bouts dans sa main droite appuyée sur sa poitrine; de la main gauche, elle tient une boîte.

$b$. En haut, à droite, la même femme assise à terre, le corps de profil et tourné vers la droite, la robe étalée sur ses jambes allongées, la tête de trois-quarts et recouverte d'une mante.

c. En bas, une femme assise, vue presque de dos, le corps tourné vers la gauche, la tête en profil perdu et légèrement inclinée.

$a$. Sanguine et pierre noire; $b$. Pierre noire et sanguine; $c$. Mine de plomb, légèrement relevée de sanguine. Papier blanc.

Haut., 226 millim.; larg., 176 millim.

a. Gravé en contre-partie par J. Audran dans les Figures de différents caractères, $n^{\circ} 209$ (Goncourt, Catalogue, n 586).

b. Gravé en contre-partie par J. Audran dans les Figures de différents caractères, $n^{\circ} 294$ (Goncourt, Catalogue, n673).

Cadre ancien, époque Louis XVI, bois sculpté et doré; au fronton, une lyre entre deux guirlandes de feuillage. 


\section{W A T TEA U}

(ANTOINE)

64

\section{Feuille d'études : le violoniste.}

Il est représenté deux fois, l'une au-dessous de l'autre. Vu à mi-corps, de trois-quarts, tourné vers la gauche et légèrement renversé en arrière, il a la tête presque de face et coiffée d'une toque. De la main gauche, il accorde son violon, qu'il a passé sous son bras droit et dont il fait vibrer les cordes de la main droite tenant l'archet.

Les deux études diffèrent en ce que, dans le dessin du bas, la position du violon, relevé, ne permet pas de voir la main droite, aiors que cette main est visible dans le dessin du haut, où le violon est presque horizontal.

Pierre noire et sanguine, sur papier grisâtre.

Haut., 3oo millim.; larg., 212 millim.

Repr. dans M. Tourneux, la Collection J. Doucet, etc. (les Arts, op. cit., p. 4); et en fac-similé par la Société de reproduction des dessins de maitres (2e année, 1910$).$

Cadre ancien, époque Louis XVI, bois sculpté et doré. 


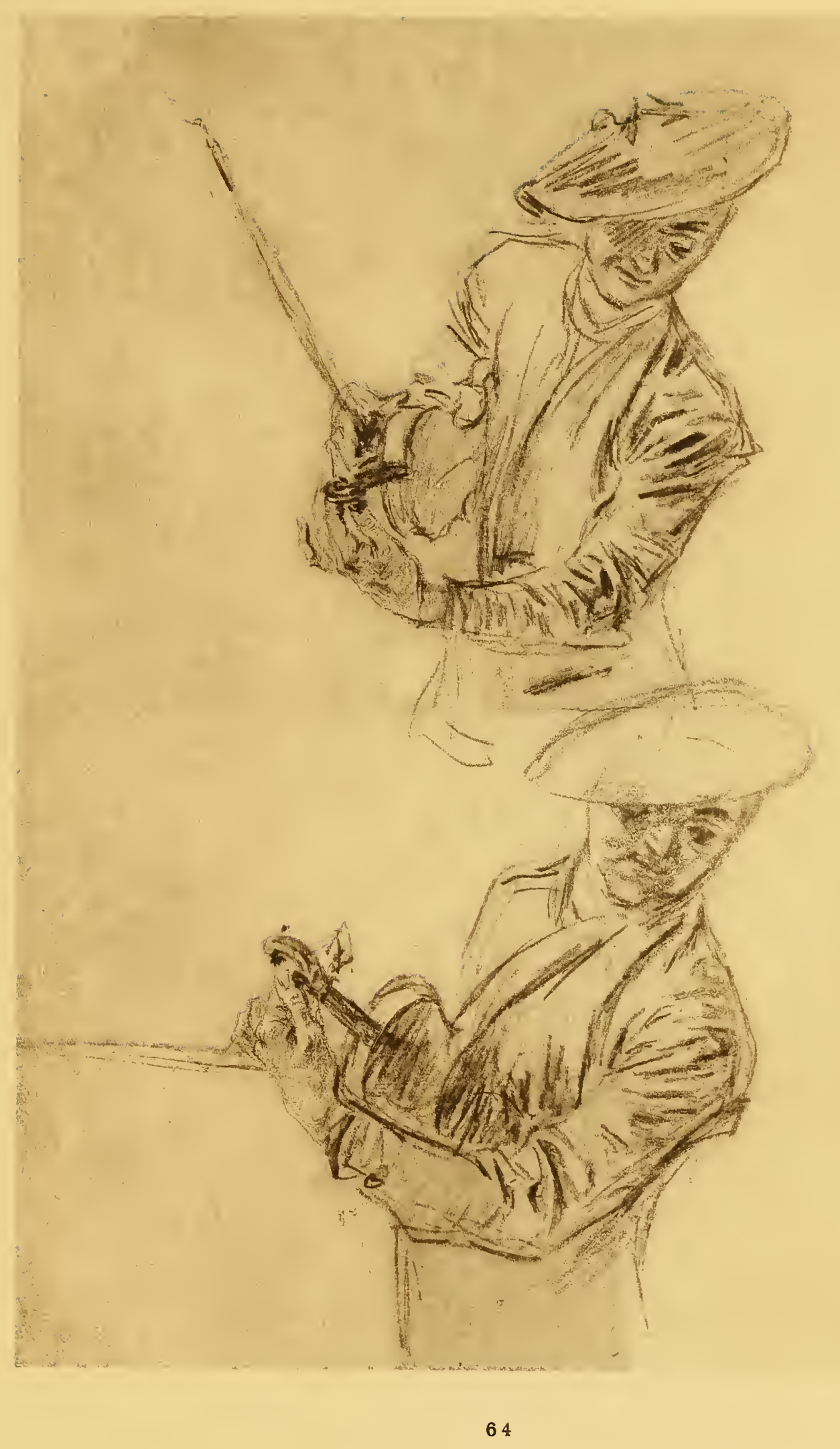






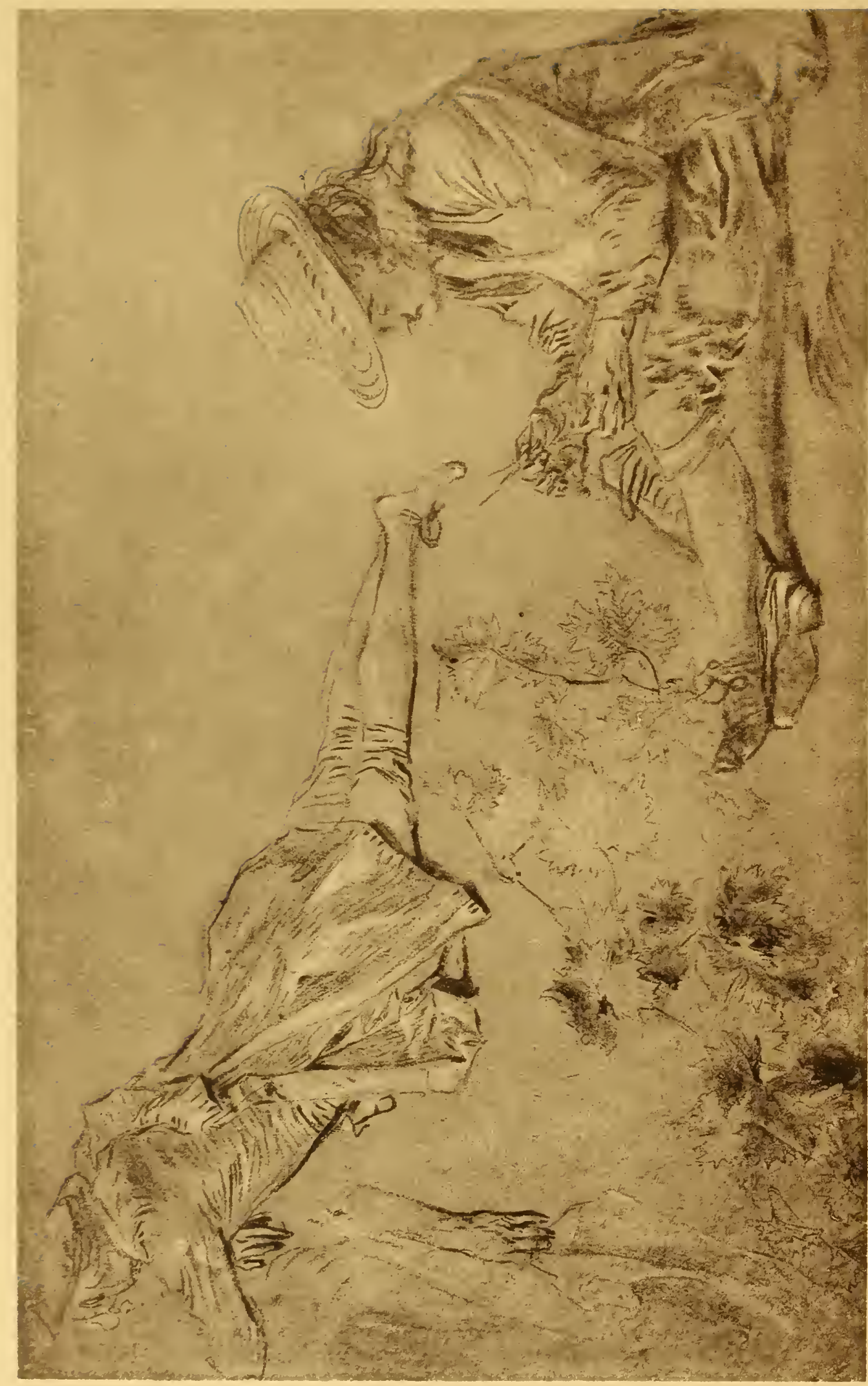




\section{WATTEAU}

(ANTOINE)

\section{0 \\ 65 \\ 1 \\ ahoure \\ Feuille d'études : deux hommes, l'un couché, l'autre assis.}

a. En haut, un homme couché par terre, à plat ventre, tourné vers la gauche, les jambes allongées, le haut du corps un peu soulevé et les bras croisés; il est coiffé d'une toque et porte un petit manteau, qui a glissé de l'épaule gauche et lui tombe en travers du dos. Au-dessous de lui, une étude de bras, avec la main tenant une draperie, et une étude de rameaux de vigne.

$b$. En bas, à droite, un villageois coiffé d'un chapeau de paille, assis de profil et tourné vers la gauche, les jambes allongées et croisées; il se penche en avant et regarde attentivement une herbe qu'il tient entre ses doigts.

Les deux personnages : sanguine relevée de craie; l'étude de vigne: pierre noire et craie; l'étude de bras et de draperie : sanguine et pierre noire. Papier chamois.

Haut., 225 millim.; larg., 364 millim.

a. Gravé en contre-partie par Boucher, dans les Figures de différents caractères, no 53 (Goncourt, Catalogue, no 528 ).

C'est une étude pour l'homme couché sur le devant et vers le milieu de la composition, dans le tableau de l'lle enchantée, gravé par Le Bas.

b. Gravé en contre-partie par Boucher, dans les Figures de différents caractères, $\mathrm{n}^{\circ} 282$ (Goncourt, Catalogue, n० 661).

C'est une étude, non, comme l'a dit Goncourt, pour la Scène d'amour du musée du Prado, mais pour le jardinier assis à droite au premier plan dans la Fête de campagne, le tableau ovale du musée d'Angers (Cf. H. Jouin, Minist. de l'Instruction publique et des beaux-arts, Hist. et description des musées d'Angers, Paris, 1885, p. 48 ; L. Gonse, les Chefs-d'œuvre des musées de France, la Peinture, Paris, 1900, p. 37, avec une fig.; - et L. de Fourcaud, Antoine Watteau, Figures et scènes galantes, dans la Revue de l'art ancien et moderne, t. XVI, 1904, gravure par H. Toussaint, p. 348).

Cadre ancien, époque Louis XV, bois sculpté et doré. 


\section{WATTEAU}

(ANTOINE)

\section{6 \\ Feuille d'études : sept têtes.}

Sur la première ligne, la même tête de femme, avec indication du buste, représentée dans quatre poses différentes : la première, de troisquarts, relevée et inclinée à gauche; la seconde, de profil, tournée vers la droite, le buste vu de dos; la troisième, presque de face et un peu inclinée à droite, les yeux baissés, le buste de profil à droite; la quatrième, de face, inclinée en avant, les yeux baissés.

Au-dessous : une tête de femme, tournée de trois quarts à droite et un peu relevée, le cou tendu; un masque d'homme, vu de face, les yeux baissés; et une tête d'homme, vue presque de face, penchée en avant, les yeux baissés.

Trois crayons sur papier chamois.

Haut., 227 millim.; larg., 285 millim.

Collection des Goncourt (vente à Paris, février ı 897, n० 344); la marque de la collection des Goncourt se voit en bas à droite.

Exposition des dessins de maîtres anciens à l'École des beaux-arts, $1879, \mathbf{n}^{\circ} 47^{2}$.

Repr. Goncourt, l'Art du XVIIIe siécle (éd. in-4, t. I, pl., p. 42); - et catal. de la vente Goncourt, 1897 , pl., no 344 .

Cf. Ph. de Chennevières, les Dessins de maitres anciens exposés à l'École des Beaux-Arts, dans Ia Gaĩette des Beaux-Arts, 1879, t. II, p. IgI; - et E. de Goncourt, Catal. raisonné, etc., p. 346.

Cadre ancien, époque Louis XV, bois sculpté et doré. 


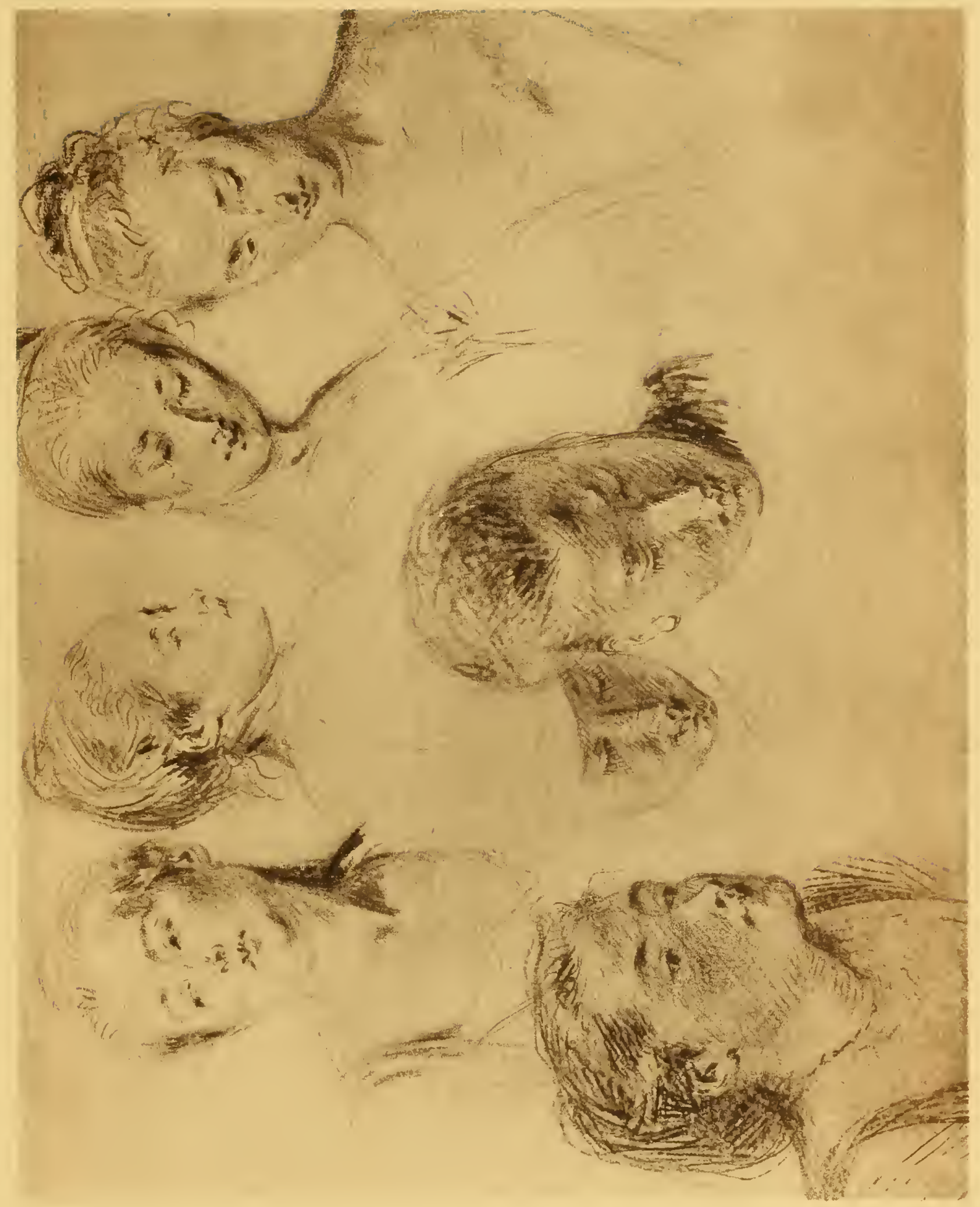






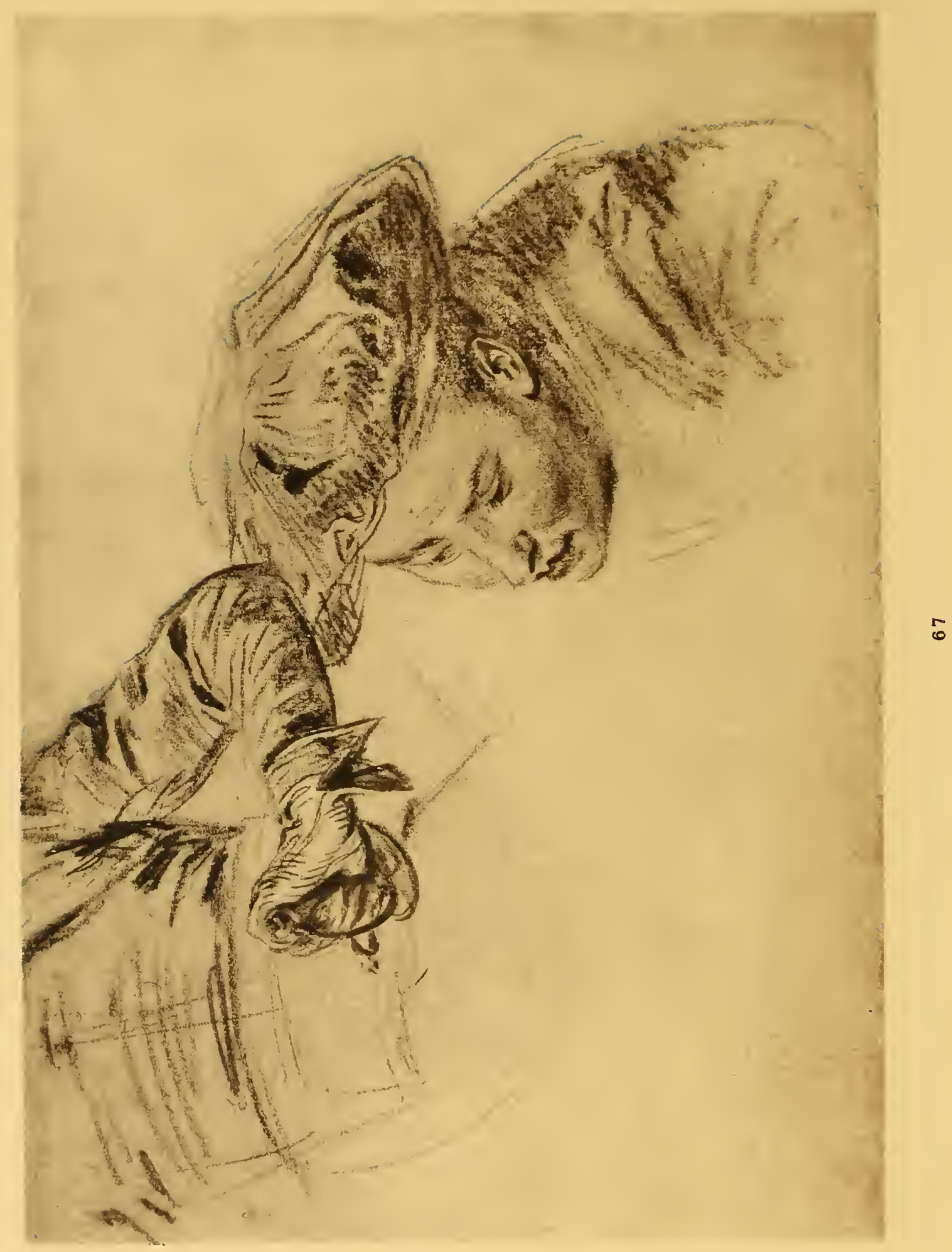




\section{WA TTEA U}

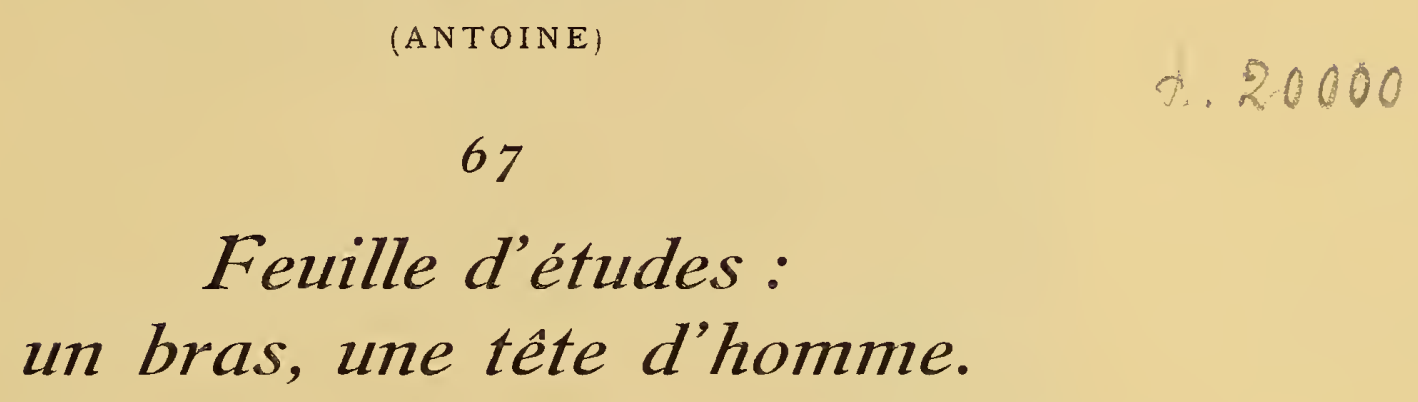

A gauche, en haut, un buste esquissé, la taille serrée par la large ceinture qui faisait habituellement partie du costume de Crispin; le bras gauche est ramené sur le devant du corps et la main gauche gantée, appuyée un peu au-dessus de la hanche et retournée sur la garde d'une épée. A droite, en bas, une tête d'homme coiffée d'un béret, tournée de trois-quarts à gauche et vue en raccourci.

Pierre noire relevée de sanguine, sur papier crème.

Haut., 179 millim.; larg., 255 millim.

Repr. en fac-similé par la Société de reproduction des dessins de maîtres (3a année, I911), avec une notice par E. Dacier.

La main est à rapprocher de celle du Crispin assis, n 57 des Figures de différents caractères (Goncourt, Catalogue, $\mathrm{n}^{\circ} 410$ ).

Cadre ancien, époque Louis XIV, bois sculpté et doré. 


\section{W A TTEA U \\ (ANTOINE) \\ 68 \\ Figures de modes. (Deux dessins dans le même cadre.)}

a. Une femme vue de face, assise, le bras gauche appuyé sur le socle d'un vase, le bras droit tombant sur le devant du corps; elle tient de la main gauche un éventail fermé dont elle se caresse le visage. A l'arrière-plan, à droite, derrière le vase, un arbre.

$b$. Un homme debout, le corps de profil à gauche, et la tête, coiffée d'un tricorne, tournée vers le fond de la composition; l'épée au côté et la main gauche posée sur la hanche, il s'appuie de la droite sur une canne. Au fond, des maisons et, à droite, un arbre.

Sanguine sur papier chamois.

Haut., I ro millim.; larg., 7 I millim. pour chaque figure.

Ces deux dessins appartiennent à la suite des Figures de modes, comprenant onze pièces et un frontispice, dont sept - celles-ci sont du nombre - gravées à l'eau-forte par Watteau et terminées au burin par Thomassin le fils (Goncourt, Catalogue, $\mathbf{n}^{\circ}$ 9, la Femme assise, et $n^{\circ} 3$, l'Homme debout).

Cadre ancien, époque Régence, bois sculpté et doré. 

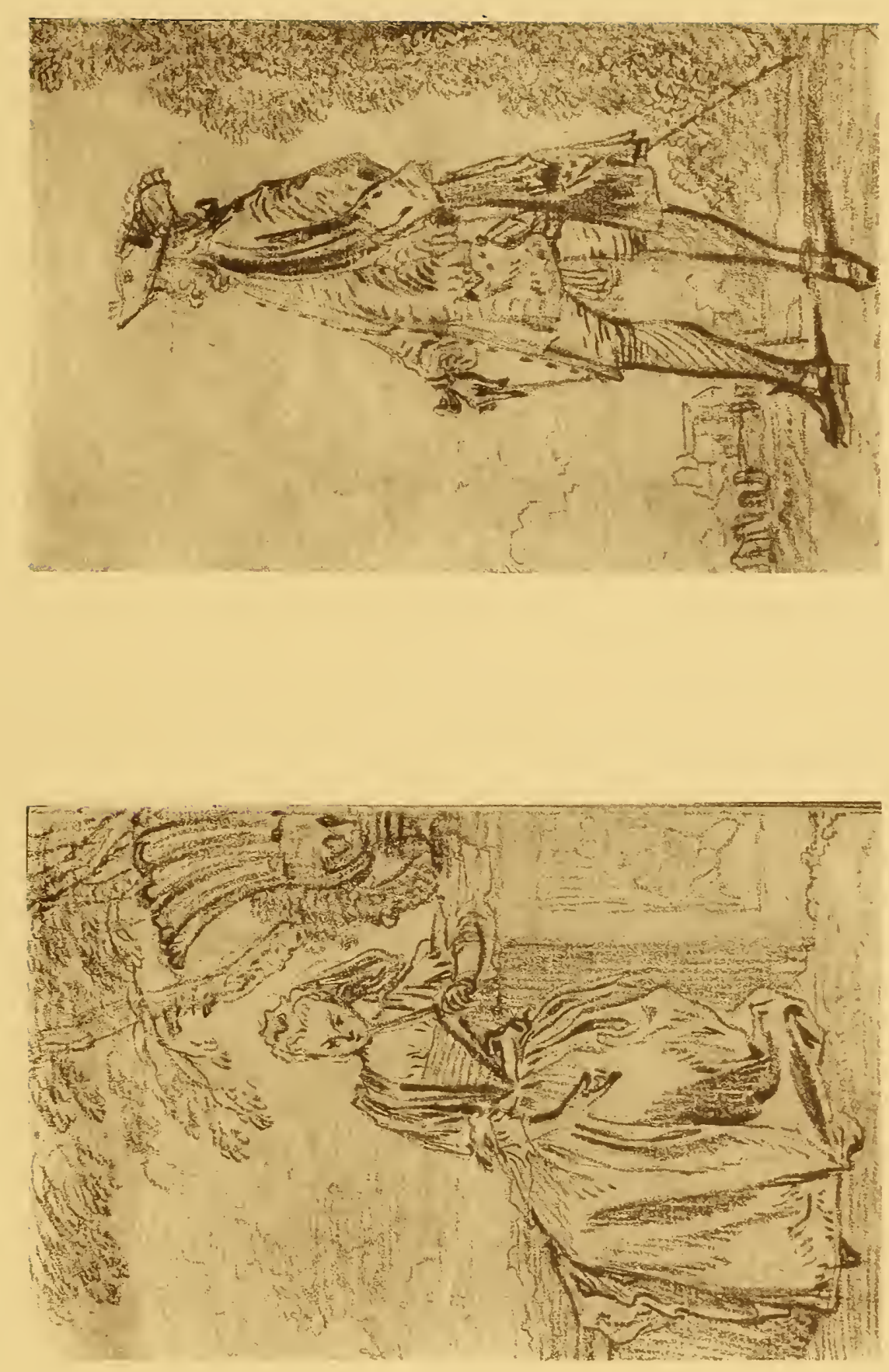




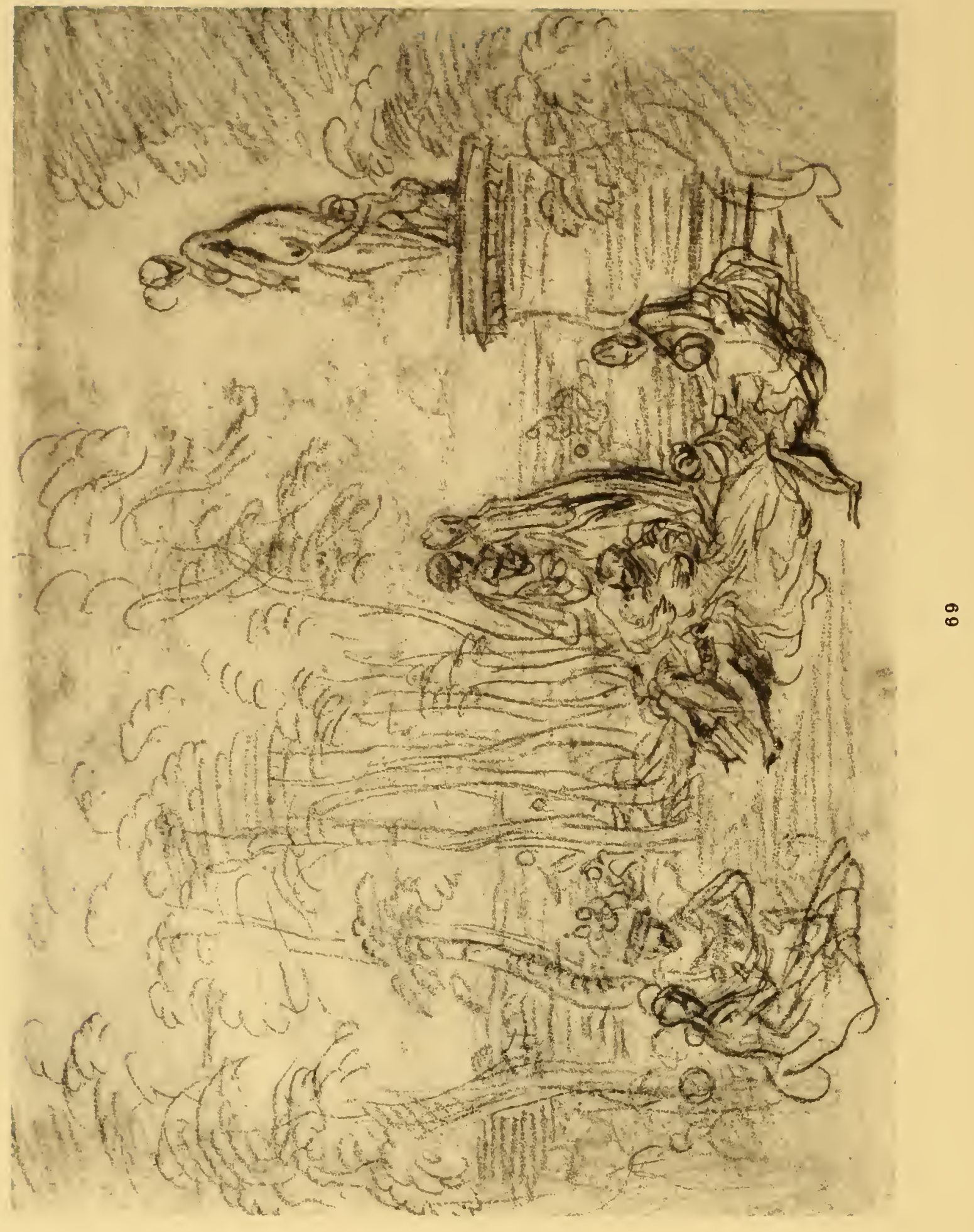




\section{WATTEAU}
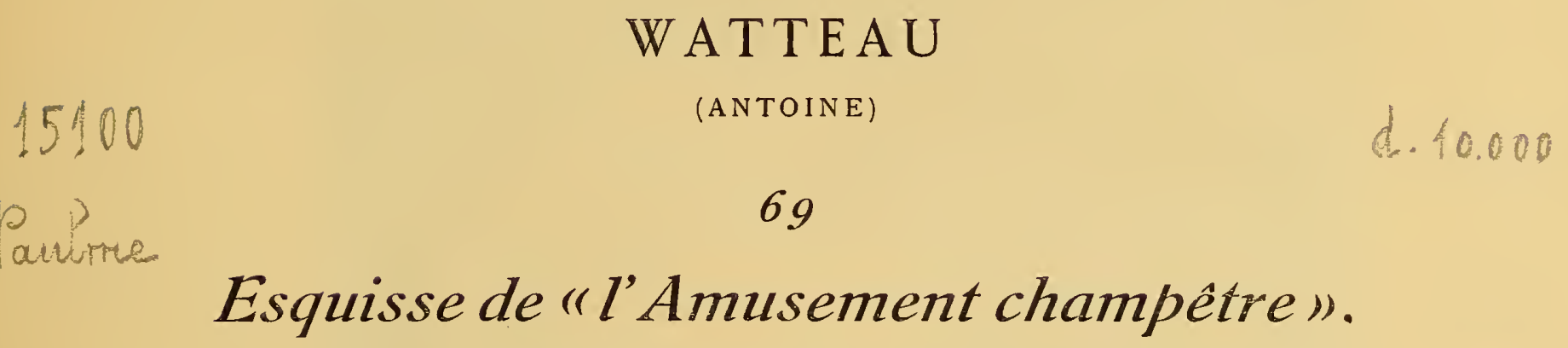

A gauche, une femme et un homme assis par terre; au milieu, un couple debout, qui se retourne et regarde un homme et une femme assis par terre et qui s'embrassent; à droite, au pied d'une statue debout sur un piédestal circulaire, un autre couple assis. Au second plan, allant de gauche à droite, une ligne d'arbres légers, au delà desquels on aperçoit un groupe de personnages assis et debout. crème.

Sanguine, sur une esquisse plus légère à la mine de plomb; papier

Haut., I 94 millim.; larg., 264 millim.

Collection du Marquis de Chennevières (vente à Paris, mai $1898, \mathrm{n}^{\circ} 19^{3}$, sous le titre : le Repos dans le parc).

Recherche de composition pour l'Amusement champêtre du musée de Dresde, gravé par Champollion sous le titre de Partie champétre (K. Voermann, Catal. of the Royal Picture gallery of Dresden, $1905, \mathrm{n}^{\circ} 782$ et $\mathrm{pl}$. XII).

Cadre ancien, époque Louis XV, bois sculpté et doré. 


\section{PASTELS}

\section{CARRIERA}

(ROSALBA)

Venise, $1675+$ Venise, 1757 .

\section{0

\section{Portrait de l'artiste par elle-même.}

En buste, de trois-quarts à droite, l'artiste, déjà âgée, regarde le spectateur. Le visage, aux traits empâtés, est encadré d'un bonnet à ruche de dentelles, serré par des brides d'un rouge-orangé, nouées suus le menton. Le cou s'enfonce dans un corsage échancré, de couleur noirâtre, sous lequel s'aperçoit une garniture de dentelles. Fond gris, frotté de bleu par endroits.

Pastel.

Haut., 30 cent.; larg., 24 cent.

Repr. dans les Arts (1904), no 36, p. 2.

Probablement le pastel qui passa, sous le $n^{0} 1$, dans la vente de M. E. P... [Eugène Piot] (Paris, 3I mars 1856), composée d'œuvres de la Rosalba, rassemblées par Felicita Sartori, bien que Charles Blanc ait indiqué comme étant le portrait de la vente Piot, celui qui figura plus tard dans la vente du comte Pourtalès-Gorgier (Paris, $1865,11^{\circ} 330$ ), et dont la description ne s'applique pas au présent pastel ; mais J. Boilly, cité par A. Sensier (Journal de la Rosalba, Paris, 1865, pp. 477 et 540), indique, comme provenance au portrait Pourtalès, la vente Réville, - probablement l'une des deux ventes Révil (Paris, 1842 et 1845).

Cf. M. Tourneux, Collection de M. Jacques Doucet : pastels et dessins, dans les Arts (1904), $n \cdot 36, p \cdot 4$.

Cadre ancien, du commencement de l'époque Louis XVI, en bois sculpté et doré, à fronton, avec cartouche, et chutes de guirlandes fleuries. 


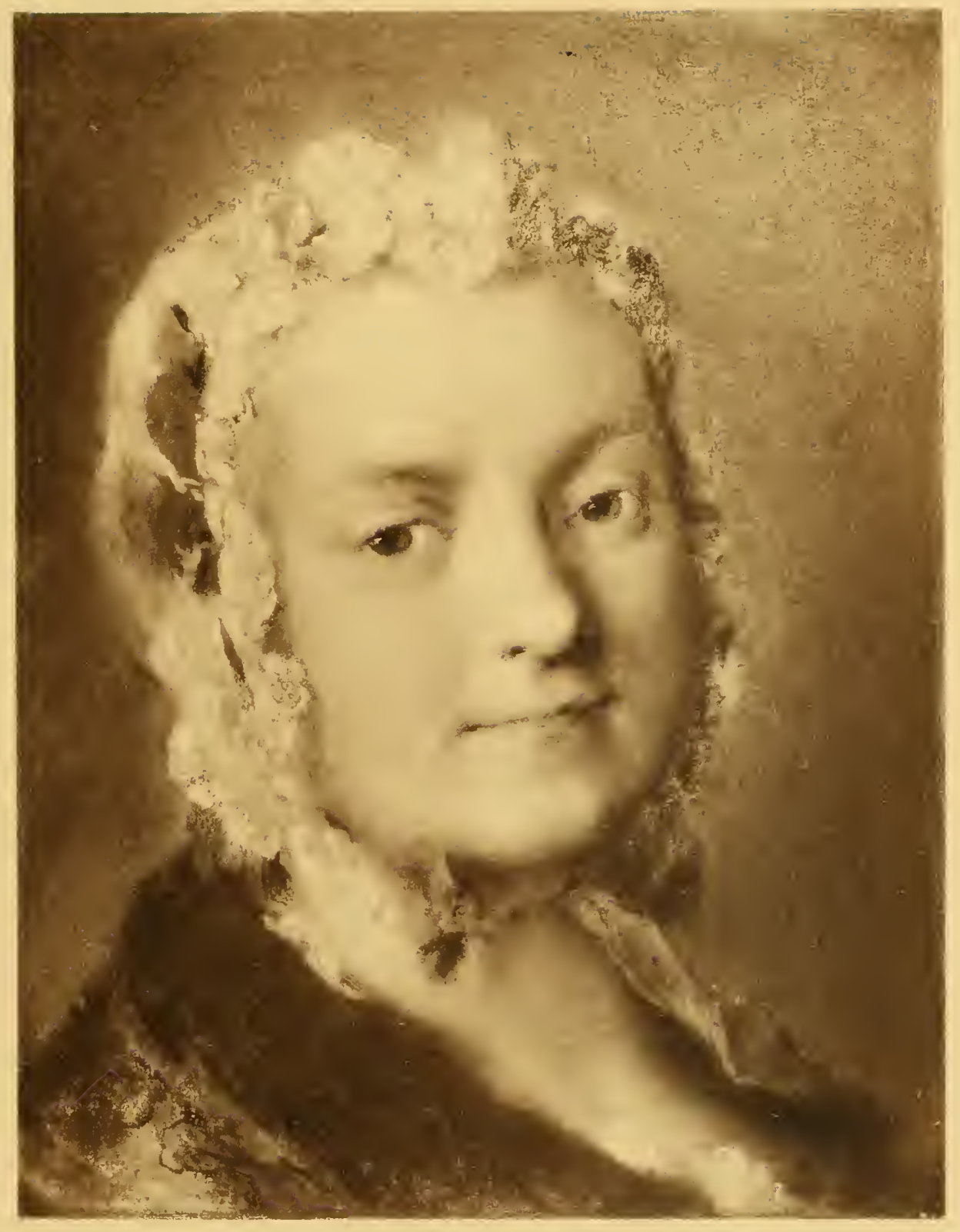

70 




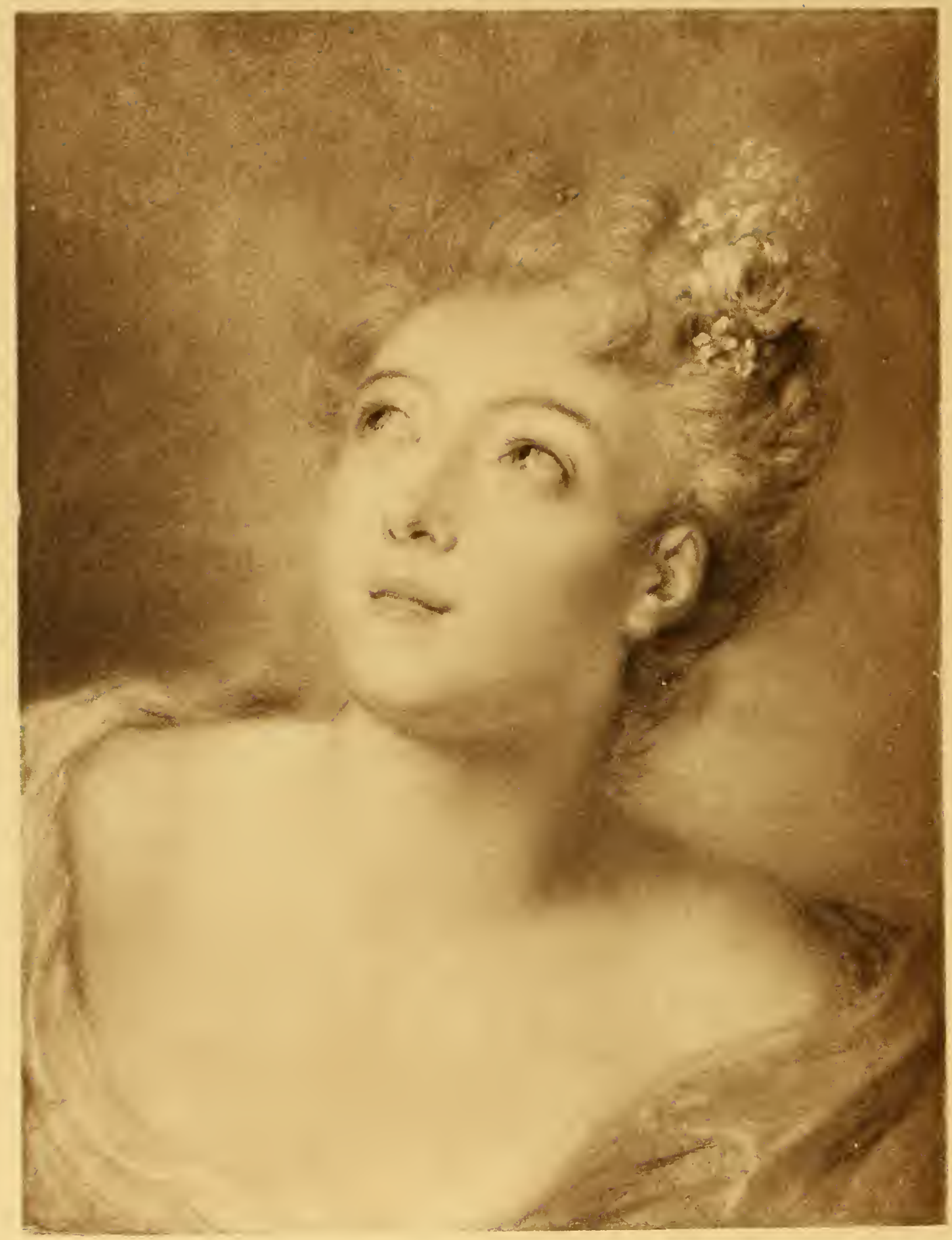




\section{CARRIERA}

( ROSALBA)

\section{1 \\ Tête d'étude.}

En buste, de trois-quarts à gauche, la tête levée, les yeux au ciel, la bouche entr'ouverte, un piquet de fleurs dans ses cheveux poudrés, la jeune fille a la gorge nue, sortant d'une fine chemisette blanche, que recouvre, sur l'épaule gauche, une draperie vieux rose.

Pastel.

Haut., 45 cent.; larg., 35 cent.

Repr. dans les Arts (1 904), no 36, p. 4.

Selon M. Tourneux, ce pourrait bien être la " très belle tête de femme, vue de troisquarts, les yeux élevés ", qui a passé en 1770 dans la vente La Live de Jully. Mais les dimensions de ce pastel, rappelées par A. Sensier (Journal, etc., op. cit., p. 534), soit 12 pouces de haut sur 10 pouces de large, sont trop sensiblement inférieures à celles du présent numéro pour permettre une identification absolue.

Cf. M. Tourneux, Collection de M.J. Doucet, etc, les Arts, op cit., p 4 .

Cadre ancien, d'époque Louis $\mathrm{XV}$, en bois sculpté et doré, à coquilles, torsades et fleurettes. 


\section{DUCREUX}

(JOSEPH)

Nancy, $1735+$ Paris, 1802 .

\section{2 \\ Portrait présumé de la fille de Sophie Arnould.}

De trois-quarts tournée vers la gauche et regardant en face, la tête de la jeune femme se détache sur le fond gris du papier. Un ruban bleu est passé dans les cheveux.

Pastel.

Ovale. Haut., 39 cent.; larg., 30 cent.

Collection de Mile Gendron, arrière-petite-fille du peintre.

Vente Ducreux (16-17 janvier 1865), no 91, sous cette désignation doublement inexacte : Sophie Arnould, par Latour.

Ce pastel représente peut-être la fille que Sophie Arnould avait eue de sa liaison avec le comte de Lauraguais, Alexandrine-Sophie, née le 7 mars 1767 , dont, suivant M. P. Dorbec, Ducreux peignit encore le portrait en 1798 (cf. P. Dorbec, Joseph Ducreux, dans la Gazette des Beaux-Arts [1 906], t. II, p. 215).

Cadre ancien, d'époque Louis XVI, en bois sculpté et doré, de forme ovale, à couronne de fleurs, nœud de ruban et guirlandes de feuillages. 


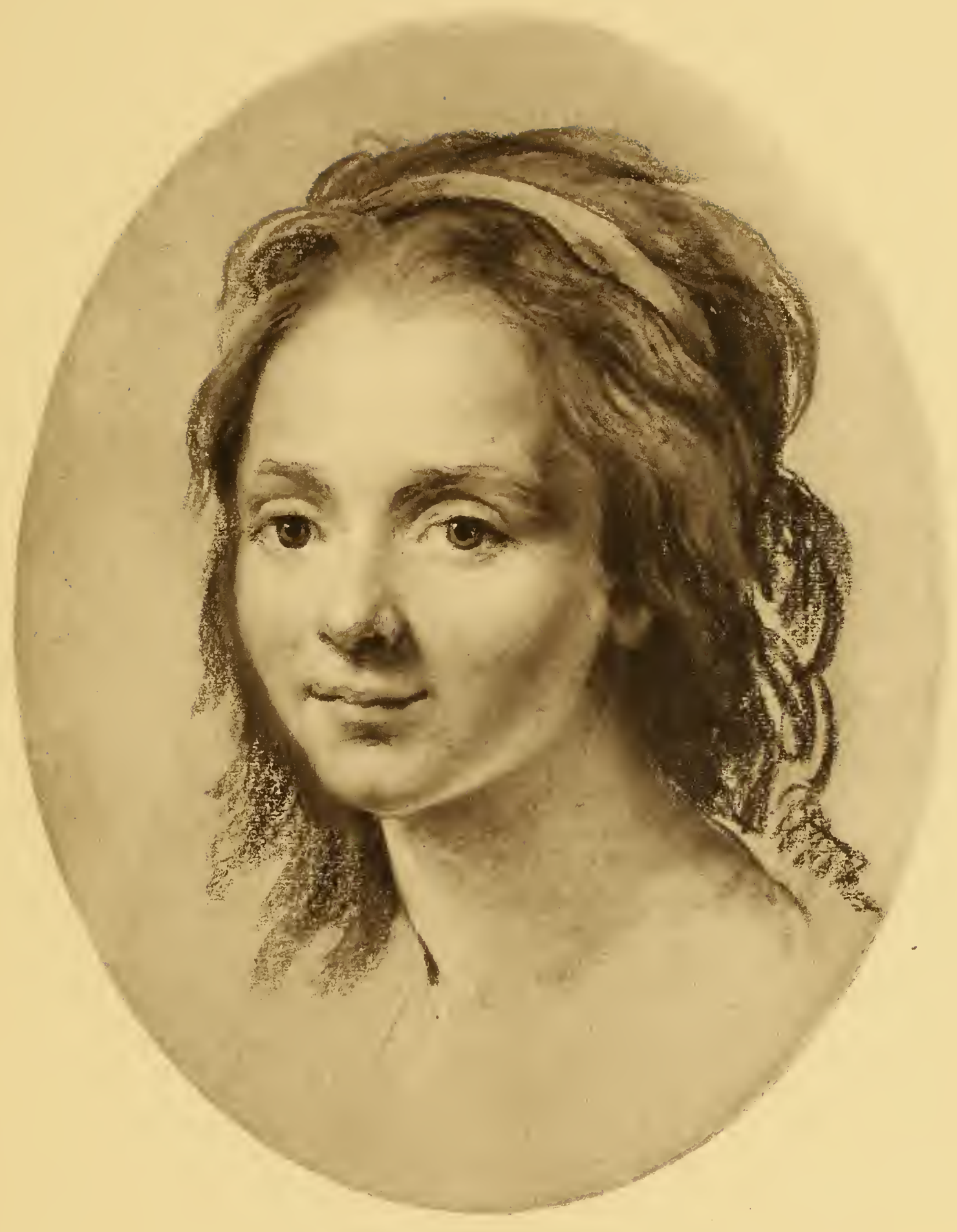

72 




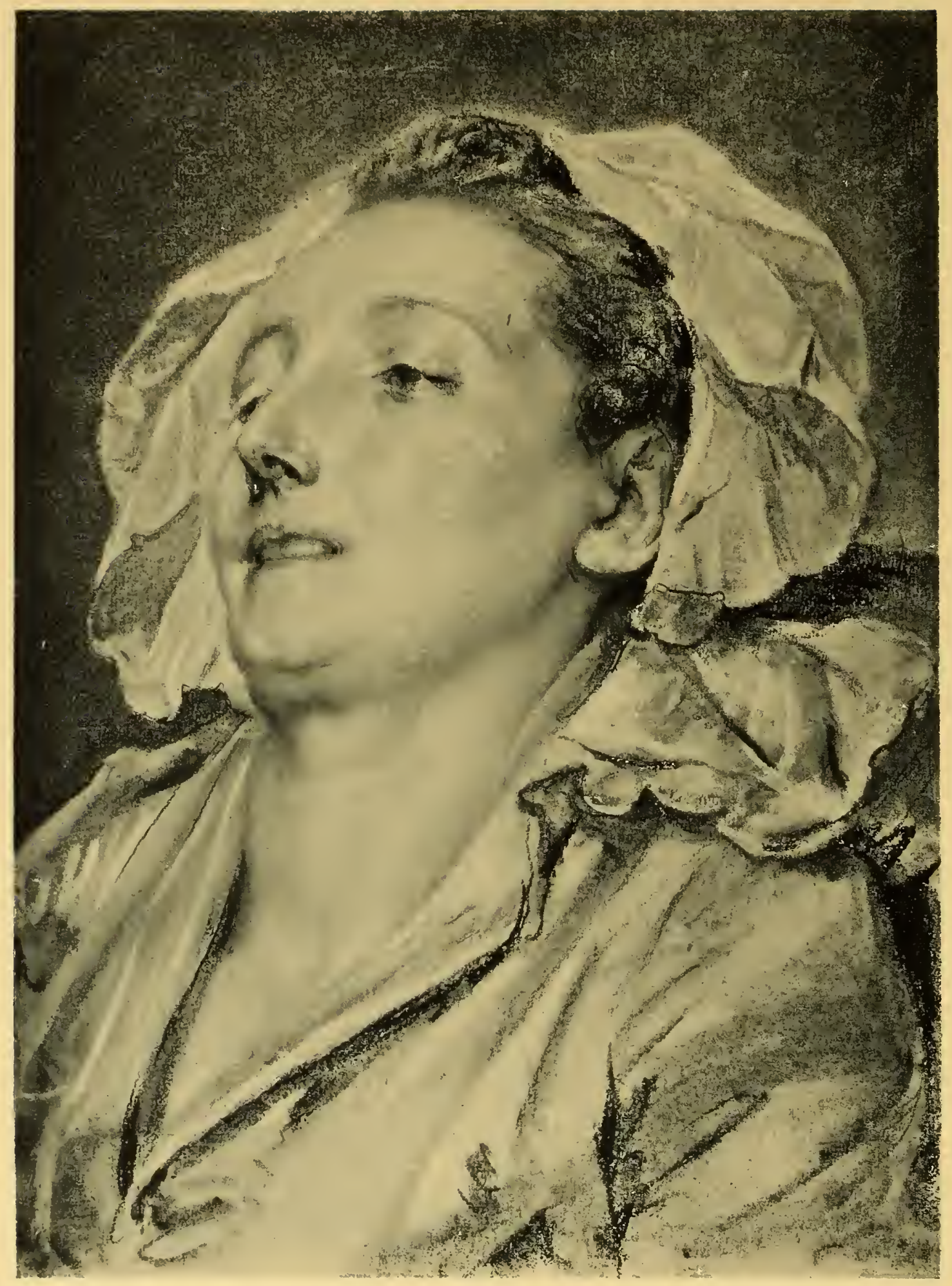




\title{
GR/EUZE
}

\author{
(JEAN-BAPTISTE)
}

Tournus, $1725+$ Paris, 1805 .

\section{3 \\ Tête d'étude pour "la Mère bien-aimée".}

De trois-quarts et regardant vers la gauche, la tête de la jeune femme est renversée en arrière. La bouche entr'ouverte laisse apercevoir les dents. Sur les cheveux bruns est posé une coiffe blanche. L'échancrure du vêtement découvre le creux de la gorge.

Pastel.

$$
\text { Haut., } 44 \text { cent.; larg., } 32 \text { cent. }
$$

Exp. de Cent Pastels (Paris, 1908), n० 20, Etude pour "l'Heureuse Mère ".

Repr. dans les Arts (1904), no 36, p. 27; - Cent Pastels, texte par RogerMilès, etc. (Paris, 1908.)

Peint en 176 o, le tableau célèbre de Greuze, la Mère bien-aimée, représentant Juseph de Laborde, sa femme, sa mère et ses enfants, fait partie aujourd'hui de la collection du marquis de Laborde (cat. J. Martin, no 169). Il n'a pas figuré au Salon de 1769 , quoique porté sous le no 152 du livret. Il fut prèté en 1860 , par la lamille de Laborde, à l'exposition du boulevard des Italiens (n 382). Gravé par Massard, etc., il est reproduit en héliogravure dans le livre de M. C. Mauclair, J.-B. Greuze (Paris, s. d. [1908], p. 79).

L'esquisse, exposée par Greuze en 1765 , a inspiré à Diderot un de ses passages les plus célèbres, qui s'applique parfaitement au présent pastel (Euvres, édit. Assézat [Paris, 1876$]$, t. X, p. 352).

Cf. Lady Dilke, French painters of the XViTitin century (London, 1899), pp. I32 et 137; - M. Tourneux, la Collection $J$. Doucet, etc., ies Arts, op. citu.,. 2+ ; - Cent Pastels, etc., op. cit., F. I3; J. Mlartin et C. Masson, OEuvre àe 3.-B. Greuze (Paris, Igo8), pp. 14 et 73 , cat. nos 169 et i 181.

Cadre ancien, d'époque Louis XVI, en bois sculpté et doré, orné de motifs : phénix, feuillage et accessoires, à la partie supérieure; tête de cheval, urne épanchant son onde ę feuillage, à la partie inférieure. 


\section{LA TOUR}

(MAURICE-QUENTIN DE)

Saint-Quentin, 1704 $\div$ Saint-Quentin, 1788 .

\section{4 \\ d. 120000 \\ Le Chevalier de Jars.}

Debout et vu presque jusqu'aux genoux, le corps tourné légèrement vers la droite, la tête de trois quarts et regardant à gauche, l'important personnage s'appuie du coude droit sur le dossier d'un siège canné. Portant la grande perruque à boucles tombant sur les épaules, il est vêtu d'un habit de velours gris violacé sur un gilet bleu. Cravate de linon, serrée au cou; jabot et manchettes de dentelles. De la main droite, il puise du tabac dans une boîte qu'il tient de la main gauche. $\mathrm{Au}$ fond, à gauche, une draperie d'un rouge foncé; à droite, une échappée d'un gris bleuté.

Pastel.

Haut., I m. ı̄ं larg., 85 cent.

Salon de 1740 : “115. Un Portrait jusqu'aux genoux, de M. de ${ }^{\star \star \star}$ qui prend du tabac ". - Exp. de Cent Pastels (Paris, 1908), n 36, Portrait d'Étienne Perrinet, sieur de Jars.

Repr. dans les Arts (1 g04), n³6, p. I 5.

De ce portrait, dont l'identification est établie par une note de Mariette, l'exposition de Cent Pastels contenait deux répliques : l'une, de plus petites dimensions (h. 0,$80 ; 1 ., 0,70 ; \mathrm{n}^{\circ} 33$, coll. de M. G. Dormeuil); l'autre, de plus grande taille au contraire (h. I m. $65 ; 1.1 \mathrm{~m} .35 ; \mathrm{n}^{\circ} 62$, coll. du marquis de Vogüé); celle-ci repr. dans Cent Pastels et dans la Reyue de l'Art, t. XXIV, p. 17.

Étienne Perrinet, sieur de Jars et de Boucart, né en 1670 , s'éleva d'une origine modeste aux plus hauts emplois. Directeur de la Compagnie des Indes pour'la régie des fermes générales en 1719 , il acquit, cette même année, une charge de fermiergénéral qu'il conserva jusqu'à sa mort ( 9 juillet s 762 ).

Cf. M. Tourneux, la Collection J. Doucet, etc., les Arts, op. cit., P. 14; - M. Tourneux, La Tour (Paris, 1 jot), pp. 39 et $40 ;-$ M. Tourneux, l'Exposition de Cent Pastels, Gazette des Beaux-Arts (1 go8), t. II, p. 9; - L. de Fourcaud, le Pastel et les Pasteliistes français au XVIII siecle, etc., Rivue de l'art ancien et moderne (1908;, t. XXIV, p. 22 ; - P.-A. Lemoisne, Expusition de Cent Pasteis, etc., less Aris (1 god), n' $\mathrm{n}^{\circ} 2, \mathrm{p} .20$.

Cadre ancien, d'époque Régence, en bois sculpté et doré, à coquilles, torsades, rinceaux et fleurs. 


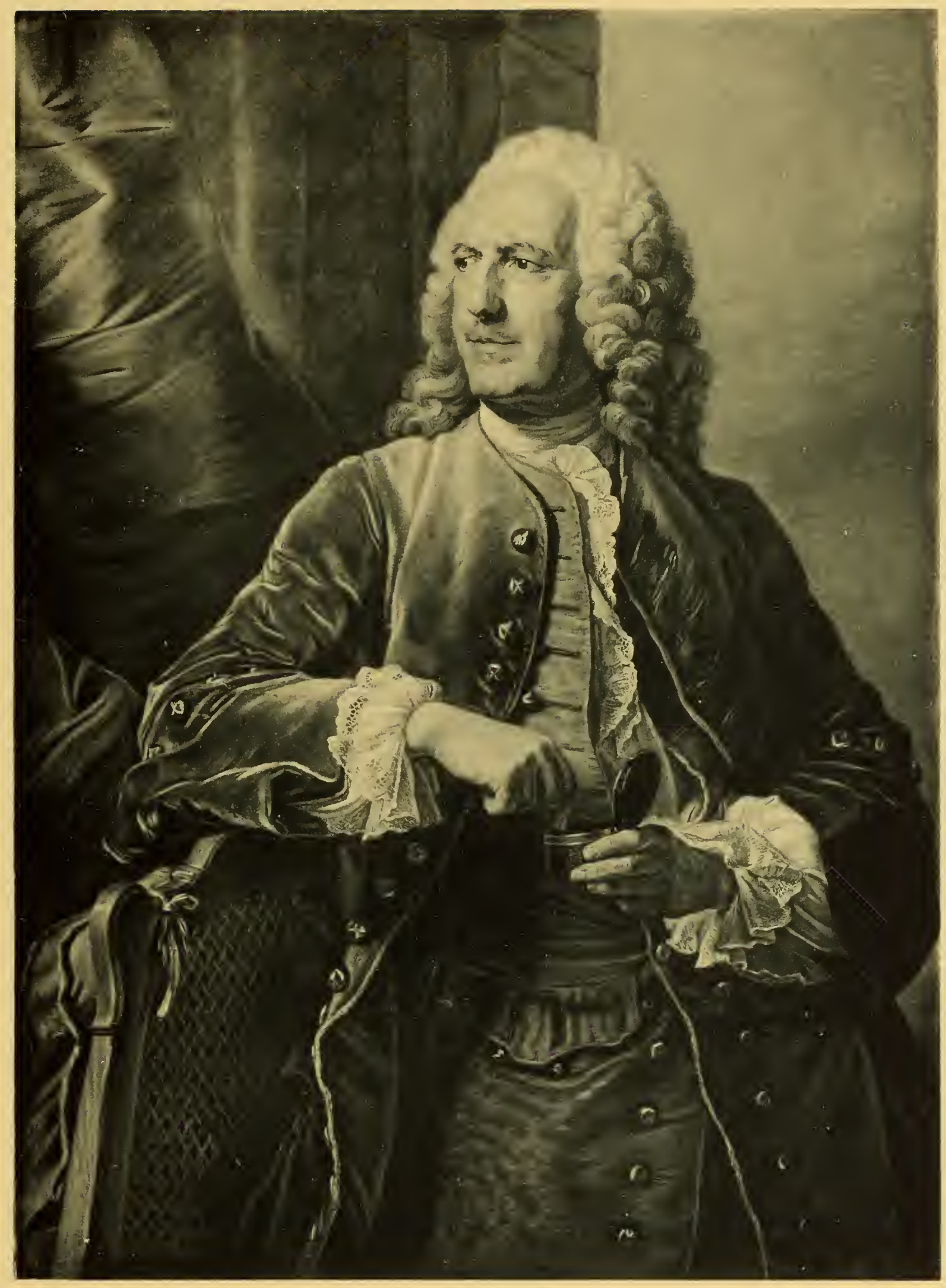






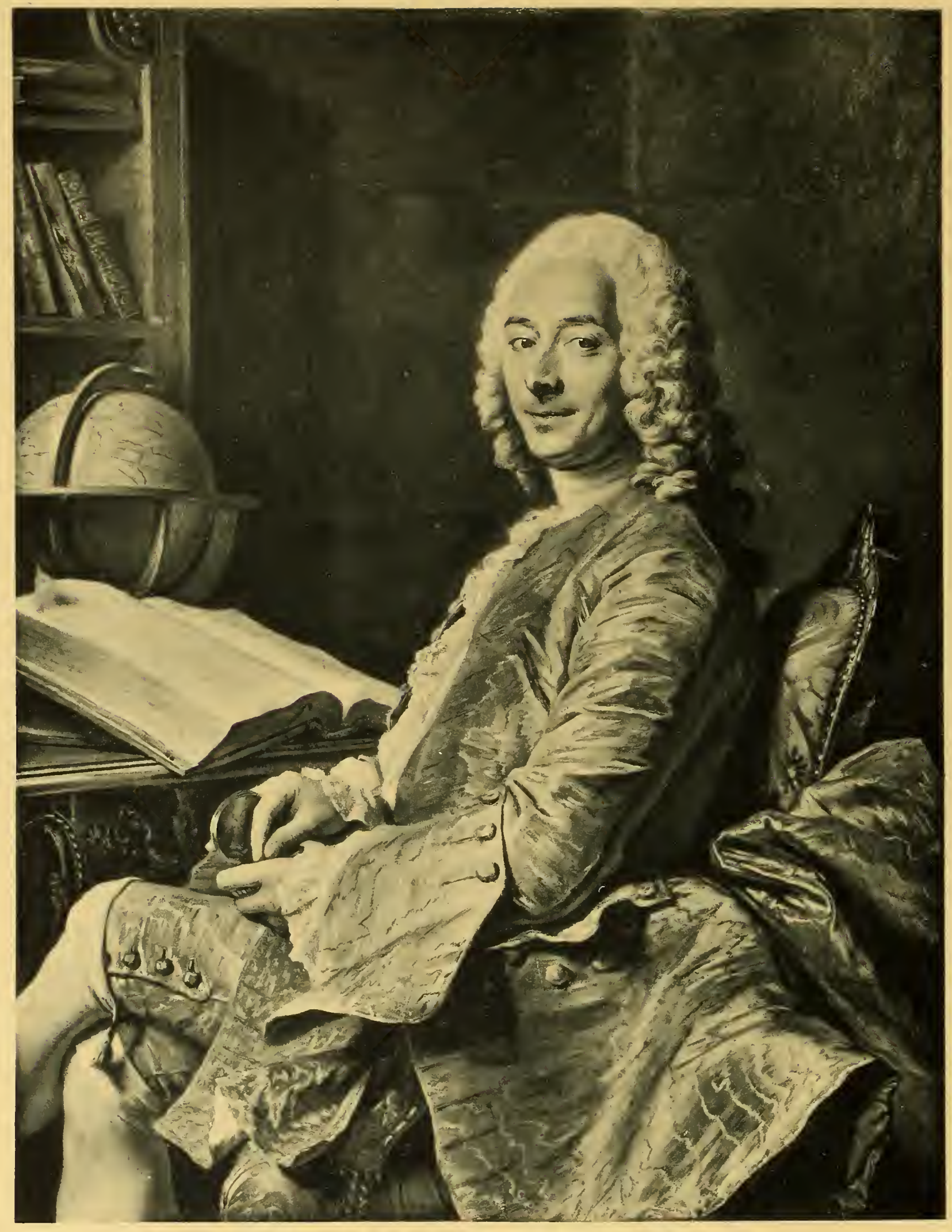




\section{LA TOUR}

(MAURICE-QUENTIN DE)

\subsection{0}

\section{Bon Henvide Po Phuschild Asis}

\section{5 \\ Duval de l'Épinoy.}

livre ouvert et d'une mappemonde, le corps de profil à gauche et vu jusqu'à mi-jambes, Duval de l'Épinoy tourne vers le spectateur son visage, aux traits fins, en souriant malicieusement. Il porte la perruque poudrée, dont les boucles tombent jusque sur les épaules. Le cou serré dans une cravate, il est vêtu d'un habit de moire grise, d'un gilet bleu et d'une culotte grise, que viennent recouvrir les bas blancs. Le jabot et les manchettes sont de dentelles. Les jambes croisées, il tient de la main gauche, posée sur la cuisse, une boîte à tabac dans laquelle puisent le pouce et l'index de l'autre main. Le fond, à droite, est d'un gris bleuté. A gauche, derrière la table, on aperçoit un casier de livres.

Pastel.

$$
\text { Haut., I m. 18; larg., } 90 \text { cent. }
$$

Saisi, comme bien d'émigré, - et signalé comme tel, le i 9 novembre I 793 , dans le procèsverbal de la Commission des monuments, - au domicile de Jean-Jacques Gallet de Mondragon, petit-fils de Duval de l'Épinoy, il passait à tort, en ces dernières années, pour le portrait de M. de Mondragon.

Vente du château de Beaumont-la-Ronce (Indre-et-Loire), rgo3

Salon de 1745 : " $167 . M^{* * *}$, amy de l'auteur, aussi en grand ". - Exp. de Cent Pastels (Paris, 1908), no 37, avec cette indication erronée : "A figuré au Salon de I740, sous le nom de M. de ${ }^{* *}$."

Gravé par Julie-G. Romain (pour la Gazette des Beaux-Arts, no du I er avril I90-1).

Repr. dans les Arts (1904), no 36, p. 5 ;-M. Tourneux, La Tour, etc., op. cit., p. 65 ; la Revue de l'Art (1908), t. XXIV, p. г 77 ; - les Arts (1908), no 82, p. 2 I; -Cent Pastels, etc., op. cit.

L'identification de ce portrait est établie par un passage de l'abbé Desfontaines, Jugement sur quelques ouvrages nouveaux, t. IX ( 1745$)$; par une note relevée par M. J. Guiffrey sur un exemplaire du livret du Salon de 1745 , ayant appartenu à Antoine Duchesne, prévôt des Bâtiments du Roi : "M. Duval, le roy des portraits de La Tour "; et par une autre note, celle-ci de Mariette, sur un autre exemplaire du même livret, avec cette appréciation : "C'est le triomphe de la peinture au pastel".

De Louis Duval de l'Épinoy, de l'Épinois ou de l'Épinay, on connaît peu de chose. Ecuyer, conseiller secrétaire du Roi, seigneur de la terre et du marquisat de Saint-Vrain, il maria, le 3 juin $: 75 \mathrm{I}$, sa fille Marie-Marguerite à François-Pierre de Delay de la Garde, et le 26 juin I 753 , sa seconde fille, Marie-Jeanne, épousait Jean-Jacques Gallet, écuyer, seigneur de Mondragon, conseiller d'État, etc., qui passait à tort, dans sa descendance, pour le modèle du présent portrait.

Cf. Mariette, Abecedario, t. IiI (Paris, 1856), p. 70; - Champfleury, La Tour (Paris, 1886), p. 23 ; - M. Tourneux, Études d'iconographie française, elc., Gajette des Beaux-Arts (1904), t. I, pp. 279 et suiv.; - M. Tourneux, La Tour, etc., op. cit., pp. 44 et 45 ; - M. Tourneux, la Colleciion J. Doucet, etc., les Arts, op. cit., p. 4 ; - M. Tourneux, l'Exposition de Cent Pastels, Gažette des Beaux-Arts (1go8), t. II, p. 9 ;-I. de Fourcaud, le Pastel, etc., Revue de l'Art (1908), t. XXIV, p. 223 ; - P.-A. Lemoisnc, Exposition, etc., les Arts (1908), n॰ S2, P. 20; - Cent Pastels, etc., op. cit., p. 27.

Cadre ancien, d'époque Louis XV, en bois sculpté et duré, à coquilles, rinceaux et torsades. 


\section{LA TOUR \\ (MAURICE-QUENTIN DE) \\ 76 \\ Le Maréchal de Belle-1sle.}

En buste, de trois-quarts à gauche, le maréchal, en perruque poudrée, nouée d'un ruban noir, tourne les yeux vers le spectateur. Il porte, sur la cuirasse, un habit bleu à broderies d'or, que traverse en sautoir un large ruban bleu maintenant la plaque du Saint-Esprit. A un ruban rouge tombant des épaules et formant collier, est suspendu l'insigne de la Toison d'or. Au cou, un ruban noir, couvrant la cravate, est noué sous le menton. Fond gris uni.

Pastel.

Haut., 60 cent. ; larg., 49 cent.

Provient de Thionville.

Salon de 1748: " 8 I. M. le Maréchal de Belleisle». - Exp. de Cent Pastels (Paris, 1908), n०40.

Gravé (la tête seule d'après La Tour) par Moitte, Mellini et Vangelisty.

Repr. dans les Arts (1 g04), n³6, p. 7 ; - la Revue de l'art (1908), t. XXIV, p. I 9 ; - les Arts ( 1908$), n^{\circ} 82$, p. 23 ; - Cent Pastels, etc., op. cit.

Charles-Louis-Auguste Fouquet, comte de Belle-Isle, duc de Gisors, pair et maréchal de France, était le petit-fils du surintendant Fouquet. Né à Villefranche en ı 684, mort en $176 \mathbf{r}$, il s'illustra à la fois comme homme de guerre et comme diplomate. Membre de l'Académie française ( 1749 ), il termina sa carrière comme ministre de la guerre ( 1758$)$.

Cf. E. ct I. de Goncourt, l'Art du XVIII siècle (Paris, 1883), t. I., pp. 228 et 287 ; - Lady Dilke, French fainters, etc., op. cit., p. $16+;-\mathrm{H}$. Lapauze, les Pastels de M.-Q. de La Tour à Saint-Quentin (Paris, 1899 ), p. 103; - M. Tourneux, la Collection J. Doucet, ctc., les Arts, op. cit., p. 14;-M. Tourneux, La Tour, etc., op. cit., p. $4^{6} ;-$ M. Tourneux, l'Exposition de Cent Pastels, Gazette des BeauxArts (1gos), t. II, p. 9; - L. de Fourcaud, le Pastel, etc., Revue de l'art, t. XXIV (1908), c. 120;-

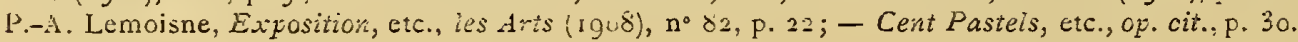

Cadre ancien, d'époque Louis XV, en bois sculpté et doré, à coquilles, rinceaux et fleurettes 


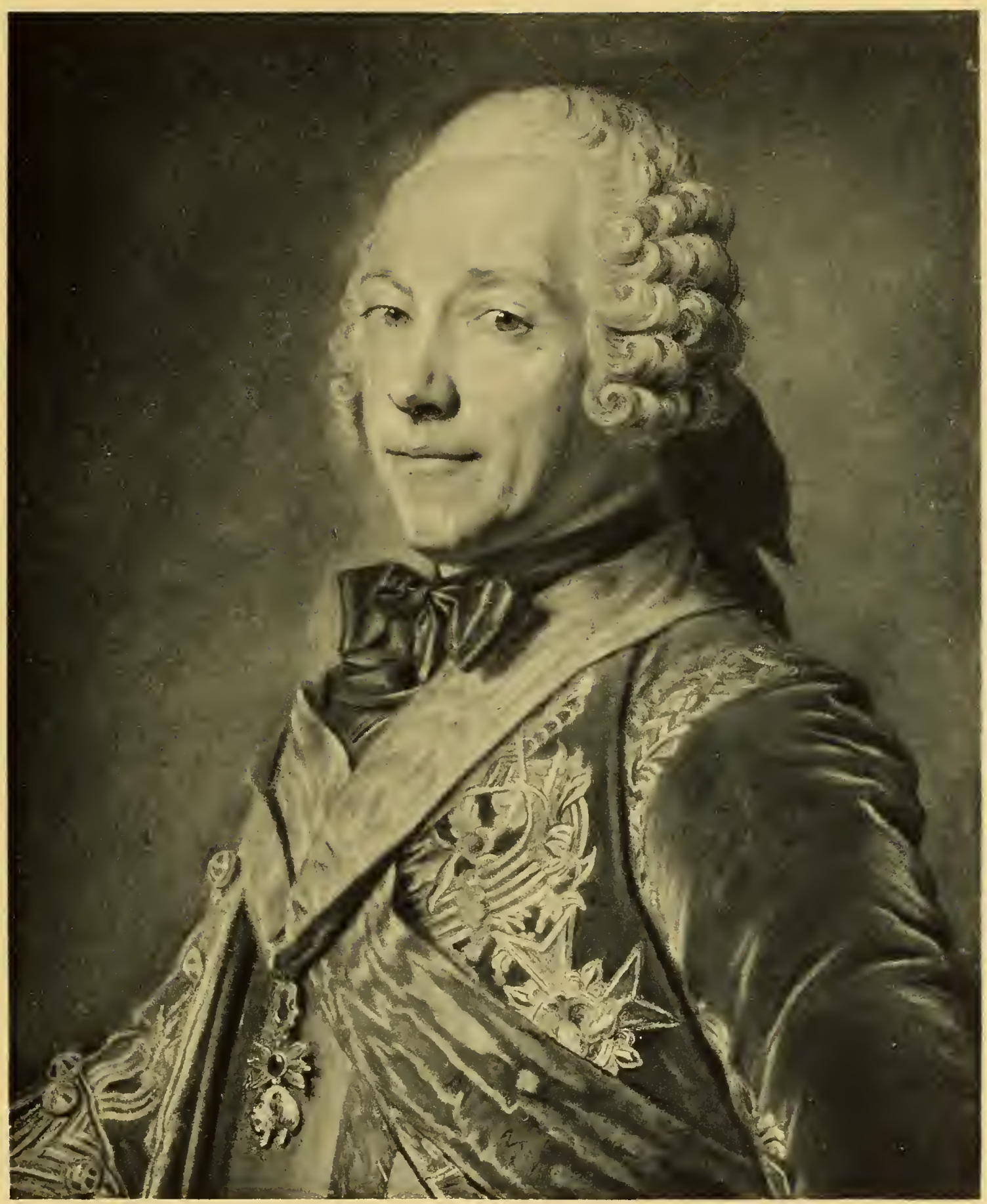






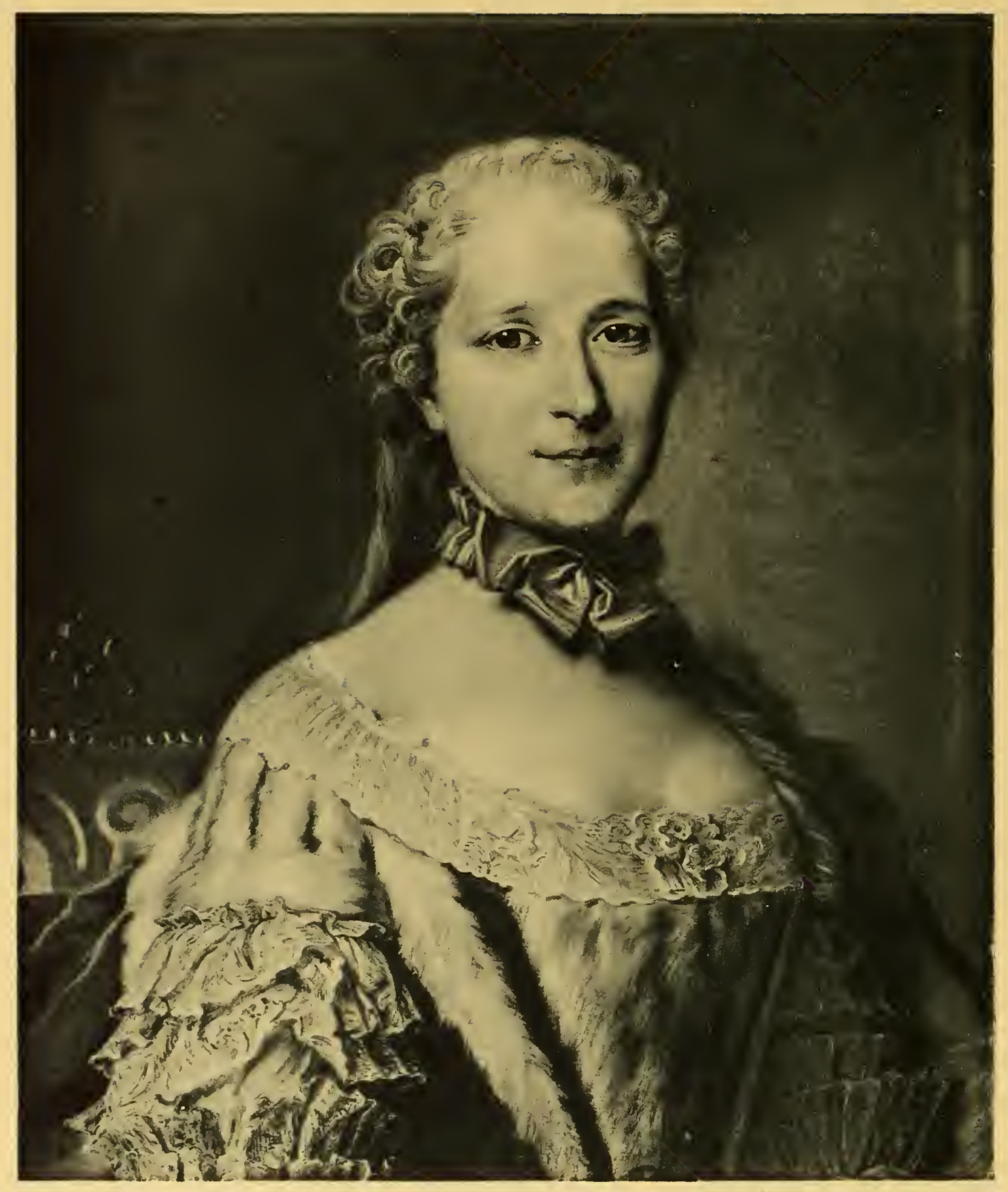




\section{LA TOUR}

(MAURICE.QUENTIN DE)

\section{7 \\ La Maréchale de Belle-1sle.}

En buste et de trois-quarts à droite, mais regardant en face, les cheveux poudrés et ondulés, elle est vêtue d'une robe bleue, décolletée, garnie de fourrure blanche et de dentelles. Un ruban bleu est noué autour du cou. Derrière le personnage, à gauche, le haut du dossier du siège sur lequel il est assis. Fond uni d'un gris bleuté.

Pastel.

$$
\text { Haut., } 59 \text { cent.; larg., } 50 \text { cent. }
$$

Provient de Thionville.

Repr. dans les Arts (1904), n³6, p. 8.

Le Maréchal duc de Belle-Isle épousa, le 21 mai 1711 , Henriette-Françoise de Durfort-Civrac, et en secondes noceș, le 15 octobre 1729 , Marie-Casimire-ThérèseGeneviève-Emmanuelle, fille de Louis-Marie, comte de Béthune, et d'Henriette d'Harcourt. Née le 4 septembre 1709 , la seconde Maréchale de Belle-Isle, dont nous avons ici le portrait, mourut le 3 mars 1755 , trois ans avant son fils unique, LouisMarie Fouquet, comte de Gisors.

Lady Dilke, French painters, etc., op. cit., p. I64;- H. Lapauze, les Pastels de M.-Q. de La Tour, etc., op. cit., p. Io3; - M. Tourneux, la Collection J. Doncet, etc., les Arts, op. cit., p. I4.

Cadre ancien, d'époque Louis XV, en bois sculpté et doré à coquilles, rinceaux et fleurettes. 


\section{LA TOUR \\ (MAURICE-QUENTIN DE)}

\section{8

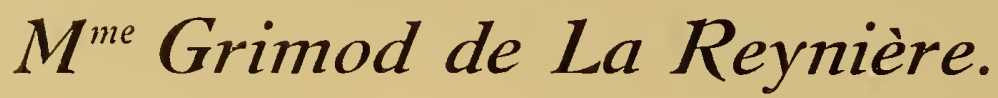

Assise et vue à mi-corps, de trois-quarts à gauche, elle regarde en face d'un air satisfait. Les cheveux sont poudrés et ondulés. Un ruban d'un bleu foncé enserre le cou. Elle est vêtue d'une robe de moire bleue décolletée. Le devant du corsage et les manches courtes sont garnis de dentelles. La main droite, jouant avec un éventail ouvert, est posée sur la gauche qui tient les cordons dorés d'un réticule d'étoffe brodée. Fond gris-bleu.

Pastel.

Haut., 79 cent.; larg., 63 cent.

Collection du Dr P. Véron (vente à Paris, 1858); - coll. Henri Didier (vente à Paris, $\rightarrow 6100 \%$ I 868 , no 158 ); - coll. de $M^{\text {me }}$ Denain (vente à Paris, 1893 , no 35 ).

Salon de 1751: "48. Plusieurs têtes au pastel sous le même No". Le détail de ces portraits est donné par le Mercure de France, par l'Abecedario de Mariette, et par l'abbé Le Blanc (Observations sur les ouvrages de Messieurs de l'Académie exposés au Salon du Louvre, I75I); - Exp. de tableaux de l'école française (Paris, 1860), n² 26; - Exp. des Portraits nationaux (Paris, 1878 ), n ${ }^{\circ} 56 \mathrm{I}$; - Exp. des Pastellistes français (Paris, 1885 ), $\mathrm{n}^{\circ} \mathbf{2 8}$; Exp. de Cent Pastels (Paris, 1908), no 35.

Repr. dans le cat. de la vente Denain (Paris, 1893); - Lady Dilke, French painters, etc., op. cit., p. 162; - les Arts (1904), n० 36, p. 9; - la Revue de l'art (1908), t. XXIV, p. I9; - Cent Pastels, etc., op. cit.

Le portrait de Grimod de La Reynière, qui fait pendant à celui-ci, a figuré également à l'exposition des Portraits nationaux (n० 560), - sous la désignation erronée d'AlexandreBalthazar-Laurent Grimod de La Reynière (1758-1837), l'écrivain gastronome, - ainsi qu'à la vente Denain (n०34; repr. au cat.).

Il ne s'agit ici, ni de la femme du gastronome, Adélaïde-Thérèse Feuchère $(1764-1837)$, comme l'indique par erreur le catalogue de l'exposition des Portraits nationaux; ni, comme on l'a également imprimé à tort, de Suzanne-Françoise de Jarente, qui épousa, le I er février I758, le fermier général l.aurent Grimod, sieur de La Reynière; mais, de Marie-Madeleine Mazade, née le 28 mai i 716 , morte le 23 février 1773 , troisième femme d'Antoine-Gaspard de L.a Reynière ( 1690 - I 756 ), le premier fermier général de ce nom, qu'elle épousa le 4 décembre 73 I .

Les difficultés auquelles donna lieu le règlement des portraits de $M$. et de $M^{\text {me }}$ de . La Reynière, par suite des exigences de La Tour, ont été racontées par Mariette dans un passage maintes fois reproduit de l'Abecedario (op. cit., p. 72 et suiv.).

Cf. Goncourt, l'Art du XVIII siecle, etc., op. cit., t. I, p. 240; - baron R. Portalis, Exposition des pastellistes français, Gazette des Becux-Arts (1885), t. I, p. 444;-Champfleury, La Tour, ctc.,op. cit., p. 26 ; - Lady Dilke, French painters, etc., op. cit., pp. :61 et $164 ;-$ H. Lapauze, les Pastels, etc., op. cit., Pp. 102 et 103 ; - N. Tournaux, La Tour, etc., op. cit., p. 51 ; - M. Tourneux, la Collection J. Doucet, elc., les Arts, op. cit., p. 6; - M. Tourneux, l'Exposition, etc., Gazette des Beaux-Arts (1908), 1. Il, p. 9; - L. de Foucaud, le Pastel, etc., Revue de l'Art (1908), t. XXIV, p. 224; - P.-A. Lcmoisne, Exposition, etc., les Arts (1908), n 82, p. 22 ; - Cent Pastels, etc., op. cit., p. 26.

Cadre ancien d'époque Louis XV, en bois sculpté et doré, à coquilles, rinceaux, torsades et fleurettes: 


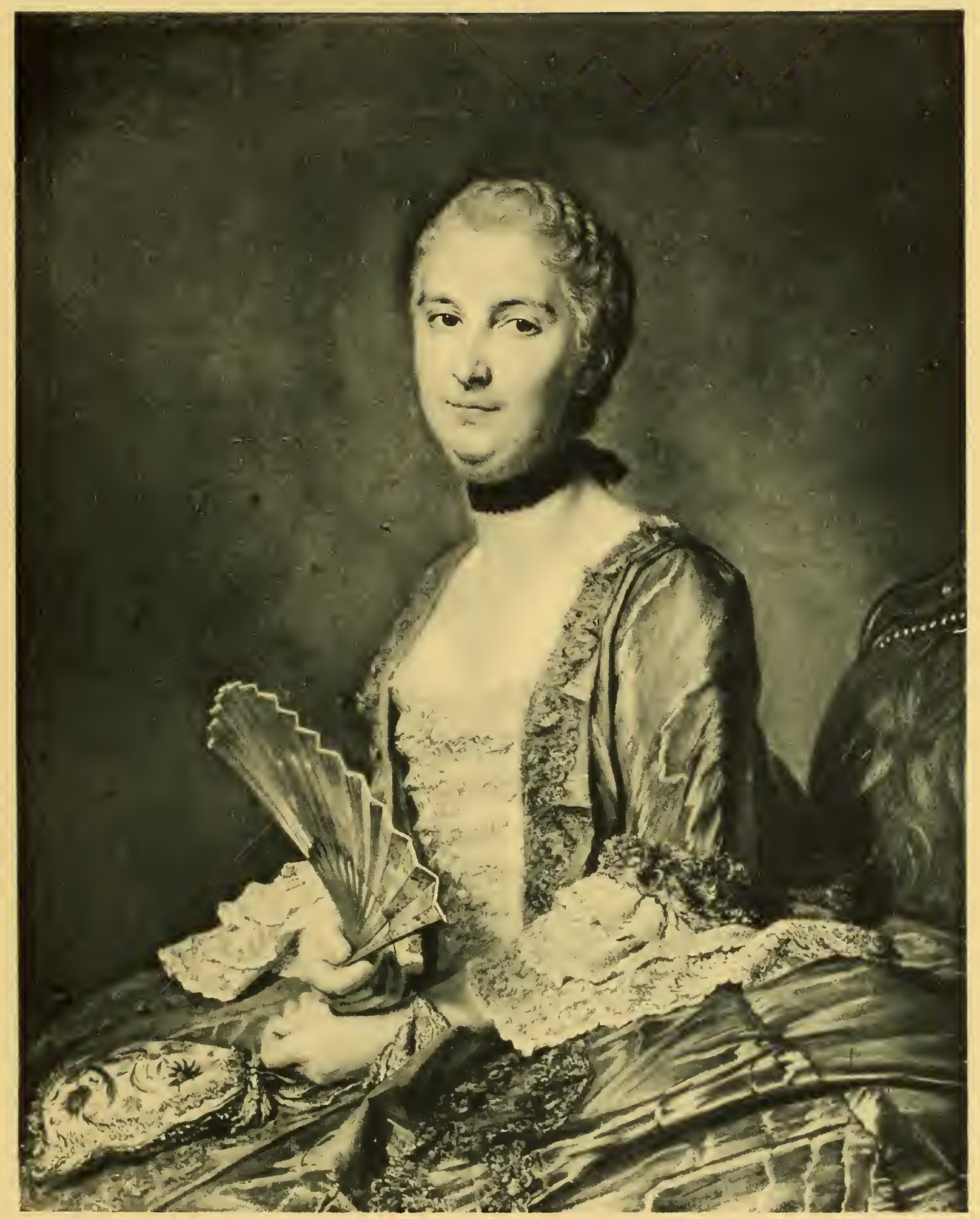






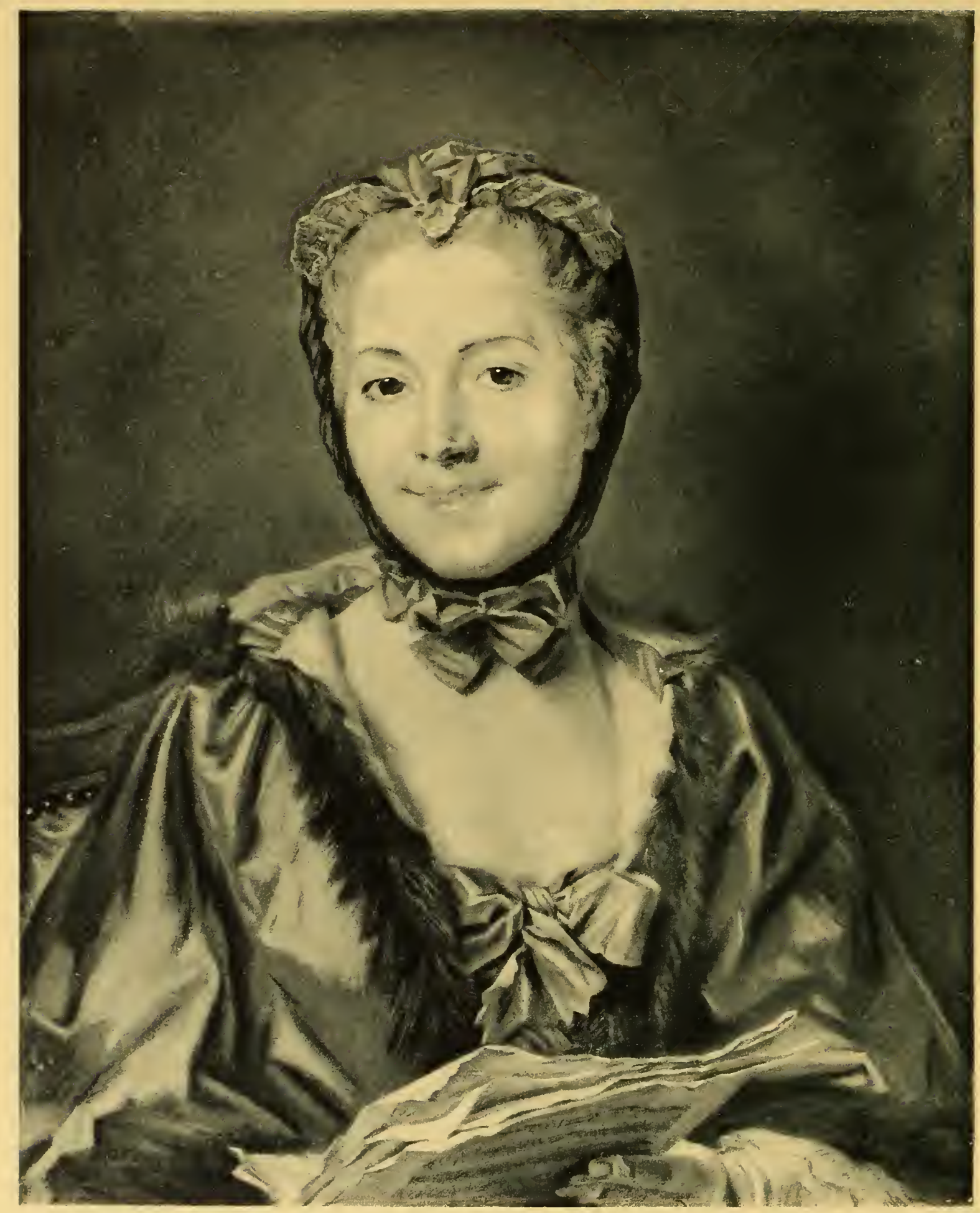




\section{LA TOUR}

(MAURICE-QUENTIN DE)

\section{0 79 \\ Marguerite Le Comte.}

En buste, presque de face, la tête légèrement à gauche, elle nous regarde en souriant. Sur les cheveux poudrés est posé un petit bonnet de dentelles, dont les brides noires sont nouées sous le menton. Au cou, un nœud de ruban bleu. La robe décolletée est bleue, à larges manches, bordée de fourrures avec nœud de ruban au corsage. La main gauche, ramenée devant la poitrine, tient ouvert un cahier de musique.

Pastel.

Haut., 67 cent. ; larg., 5 I cent.

Salon de 1753 : " 74. Le Portrait de Madame le Comte tenant un papier de musique»; - Exp. de Cent Pastels (Paris, 1908), nº $4 \mathrm{r}$.

Repr. dans les Arts (1904), no 36, p. 10 ; - la Revue de l'Art (1908), t. XXIV. p. $113 ;-$ Cent Pastels, etc., op. cit.

Née en 1719, femme d'un procureur au Châtelet, Marguerite Le Comte était l'amie de Watelet, l'artiste-écrivain, qui l'avait installée dans une habitation de plaisance au bord de la Seine, dite le Moulin-Joli, et auprès de qui elle avait son appartement au Louvre. Leur liaison, qui dura plus de trente ans, était admise par la meilleure compagnie, où ils étaient reçus, "ainsi que le mari de la dame, qui, chose assez bizarre, ne la quittait jamais " (Souvenirs de M" ${ }^{\text {me }}$ Vigée-Le Brun [Paris, s. d.], t. I, p. 103). Marguerite Le Comte fit avec Watelet le voyage d'Italie, où elle fut reçue triomphalement à Rome par les pensionnaires de l'Académie de France, en 1764. De son côté, Hubert Robert lui dédia une suite de dix pièces gravées, connue sous le nom de Soirées de Rome ( $1 ; 63)$. Précédemment, Saint-Non lui avait dédié une suite de six vues de la propriété du Moulin-Joli, d'après Le Prince (1755). Aimant et cultivant les arts, elle a laissé quelques eaux-fortes. Sur son portrait, gravé par Lempereur, d'après Watelet, elle est dite : des Académies de peinture et des belles-lettres de Rome, de Bologne et de Florence. Plus simplement au bas d'une de ses estampes, elle a écrit : la Maison de Marie Lecomte, meunière du Moulin-Joli, et c'est sous cette gracieuse dénomination que la jeune femme, accueillante aux écrivains et aux artistes, est le plus connue.

Cf. Abbé Le Blanc, Observations sur les ouvrages de MM. de l'Académie de peinture et de sculpture (1753); - Goncourt, l'Art du XVIII siècle, etc., op. cit., t. I, p. 23 I ; - H. Lapauze, les Pastels, etc., of. cit., p. 103 ; - M. Tourneux, la Collection J. Doucet, etc., les Arts, op. cit., p. I4; - M. Tourneux, La Tour, etc., op. cit., p. 52; - M. Tourneux, l'Exposition, etc., Gazette des Beaux-Arts (1908), t. II, p. 9 ; - L. de Fourcaud, le Pastel, etc., Revue de l'Art (1908), t. XXIV, p. 224; - P.-A. Lemoisne, Exposition, etc., les Arts (1go8), n 82, P. 24 ; - Cent Pastels, etc., op. cit., p. 3 r.

Cadre ancien, d'epoque Régence, en bois sculpté et doré, à coquilles et torsades. 


\section{LA TOUR \\ (MAURICE-QUENTIN DE) \\ 80 \\ Portrait d'un inconnu.}

En buste, le corps de trois-quarts à gauche, la tête légèrement à droite et regardant en face, il porte la petite perruque poudrée. Son habit gris bleu s'ouvre sur un gilet bleu à broderies d'or. Cravate serrée au cou ; chemise à jabot de dentelles. Fond gris, avec, à gauche, l'indication d'un tronc d'arbre.

Pastel.

Haut., 58 cent.; larg., 48 cent.

Repr. dans les Arts (1904), n³6, P. 12.

Cf. H. Lapauze, les Pastels, etc., of. cit., p. 103; - M. Tourneux, la Collection J. Doucet, etc., les Arts, op. cit., P. It.

Cadre ancien, d'époque Louis XV, en bois sculpté et doré, de forme mouvementée, à coquilles et torsades, avec motif d'ornement formant fronton. 


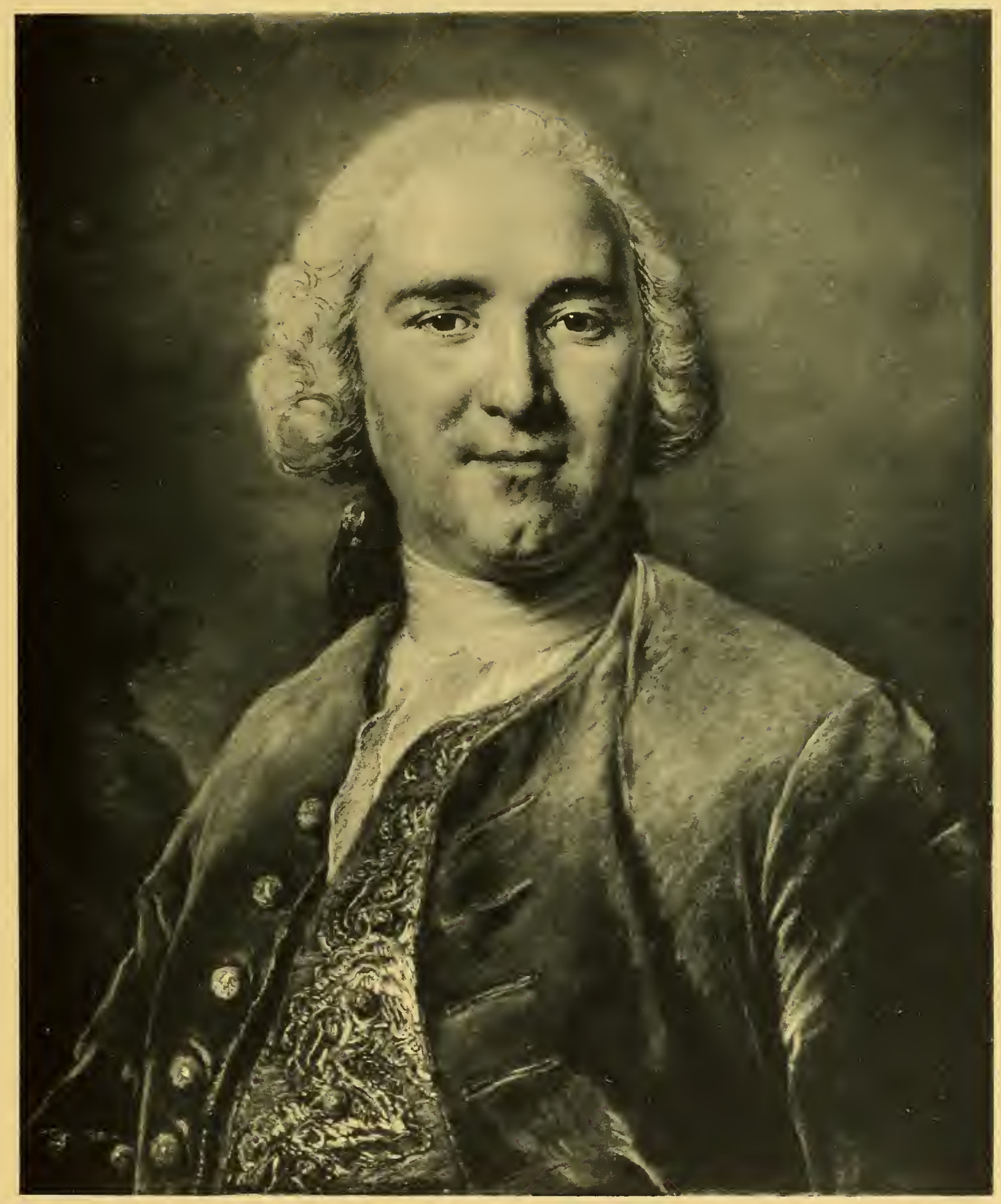






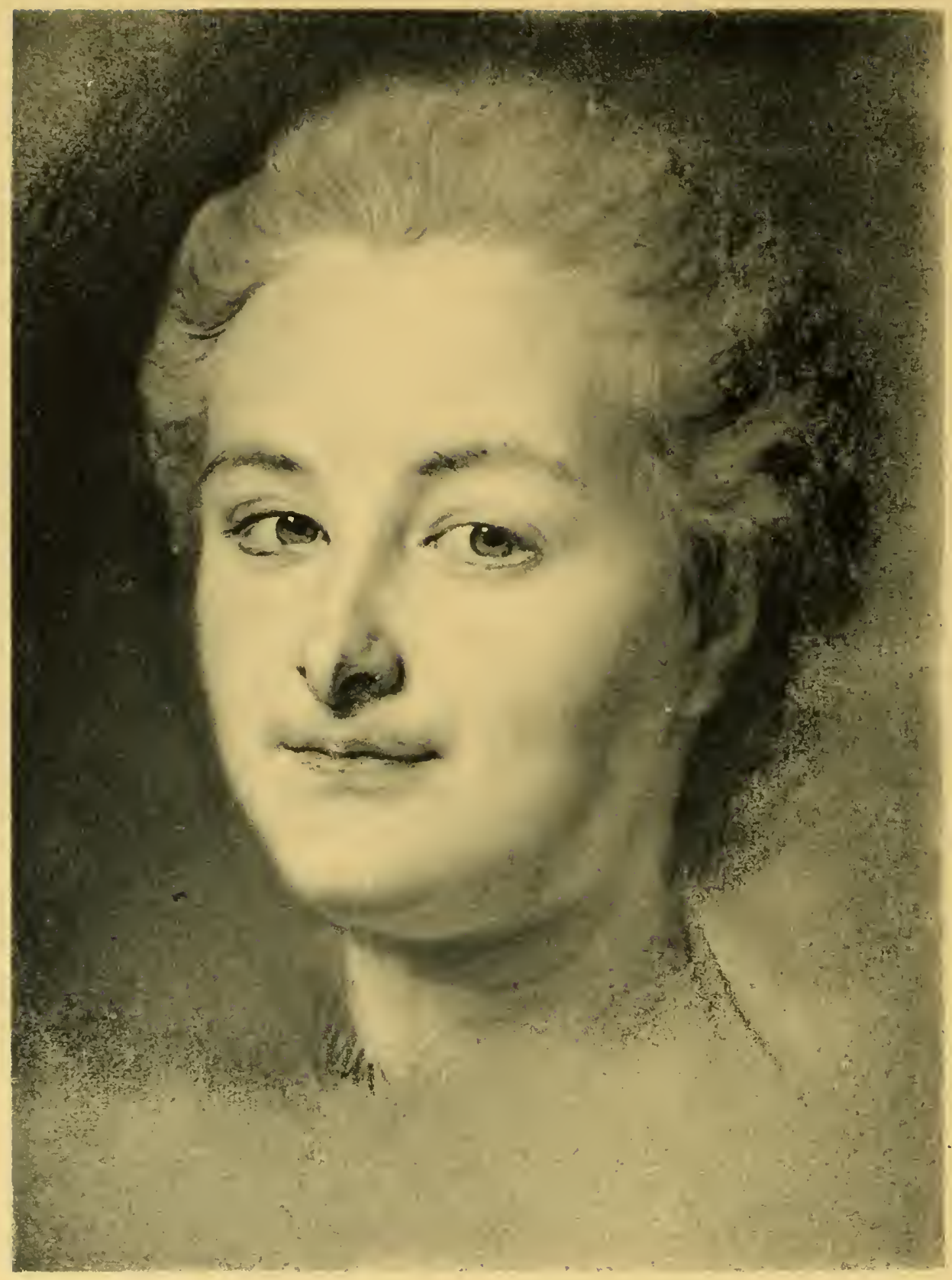

81 


\section{LA TOUR}

(MAURICE-QUENTIN DE)

\section{1}

43100 $\Phi$ ioures

\section{La Marquise de Rumilly. (Préparation.)}

Tête de trois-quarts à gauche, regardant en face. Cheveux relevés et poudrés. Fond gris.

Pastel.

Haut., 32 cent.; larg., 24 cent.

Au dos, sur le carton de l'encadrement, cette inscription, d'une écriture ancienne : $M^{\text {me }}$ la Marq. de Rumilly par Latour.

Vraisemblablement "la Marquise de Rumigny (sic), esquisse ", de la collection de l'architcte Claret (vente à Paris, décembrs $1850, n^{\circ} 157$ ).

Exp. de Cent Pastels (Paris, 1 go8), no 39.

Repr. dans A. Dayot, l'Image de la femme (Paris, 1899), pp. 177 et 213 ; - les Arts (1904), n³6, p. 11 ; - Cent Pastels, etc., op. cit.

La personnalité de la marquise de Rumilly demeure incertaine. Il s'agit peut-ètre de Françoise-Louise-Claude d'Auvillé, qui épousa, à Paris, le 10 janvier 1757 , ÉtienneCharles-Julien-Gauthier de Rumilly, sieur de la Motte et Molinous, qui fut officier des gardes'du Comte d'Artois, puis conseiller-sccrétaire du Roi à la grande chancellerie.

Cf. H. Lapauze, les Pastels, etc., op. cit., p. ı03; - A. Dayot, l'Image de la femme, etc., op. cit., p. 201 ; - M. Tourneux, la Collection J. Doucet, etc., les Arts, op. cit., p. r6; - M. Tourneux, l'Exposition, etc., Ga⿸丆ictte des Beaux-Arts (1908), t. II, p. 9; - P.-A. Lemoisne, Exposition, etc., les Arts (1908), $\mathrm{n}^{\circ} 82$, p. 26 ; - Cent Pastels, etc., op. cit., p. 29.

Cadre ancien, d'époque Louis XV, en bois sculpté et doré. 


\section{LA TOUR \\ (MAURICE-QUENTIN DE) \\ 82 \\ Portrait de jeune fille brune. (Préparation.)}

30000

Tête, vue de face, les yeux largement ouverts, regardant fixement le spectateur; les cheveux brun foncé, découvrant le front. Fond gris, frotté de bleu.

Pastel.

Haut., 37 cent. ; larg., 26 cent.

Exp. de Cent Pastels (Paris, 1908), n³8, Masque de jeune femme à cheveux noirs.

Repr. dans A. Dayot, l'Image de la femme, etc., op. cit., titre et p. 208 ; - les Arts (1904), no 36, p. 13; - Cent Pastels, etc., op. cit.

D'après M. Roger-Milès, ce serait très probablement le portrait d'une demoiselle La Chanterie, née en 1730 , et qui eut à l'occasion recours aux bons offices de La Tour pour désarmer la justice. Choriste à l'Opéra et fort jolie, elle eut des relations avec plusieurs hauts personnages de la cour de Louis XV. S'appelant en réalité Marie-Louise Chaumont, elle prit le nom de son père, vaguement écrivain, qui signait Guénon de la Chanterie.

Cf. H. Lapauze, les Pastels, etc., op. cit., p. Io3; $\rightarrow$ M. Tourneux, la Collection J. Doucet, etc., les Arts, op. cit., p. 16; - M. Tourneux, l'Exposition, etc., Gazette des Beaux-Arts (1908), t. II, p. 9; - P.-A. Lemoisne, Exposition, etc., les Arts (1908), no 82, p. 20 ; - Cent Pastels, etc., op. cit., p. 28 .

Cadre ancien, d'époque Louis XV, en bois sculpté et doré, à fronton ornementé. 


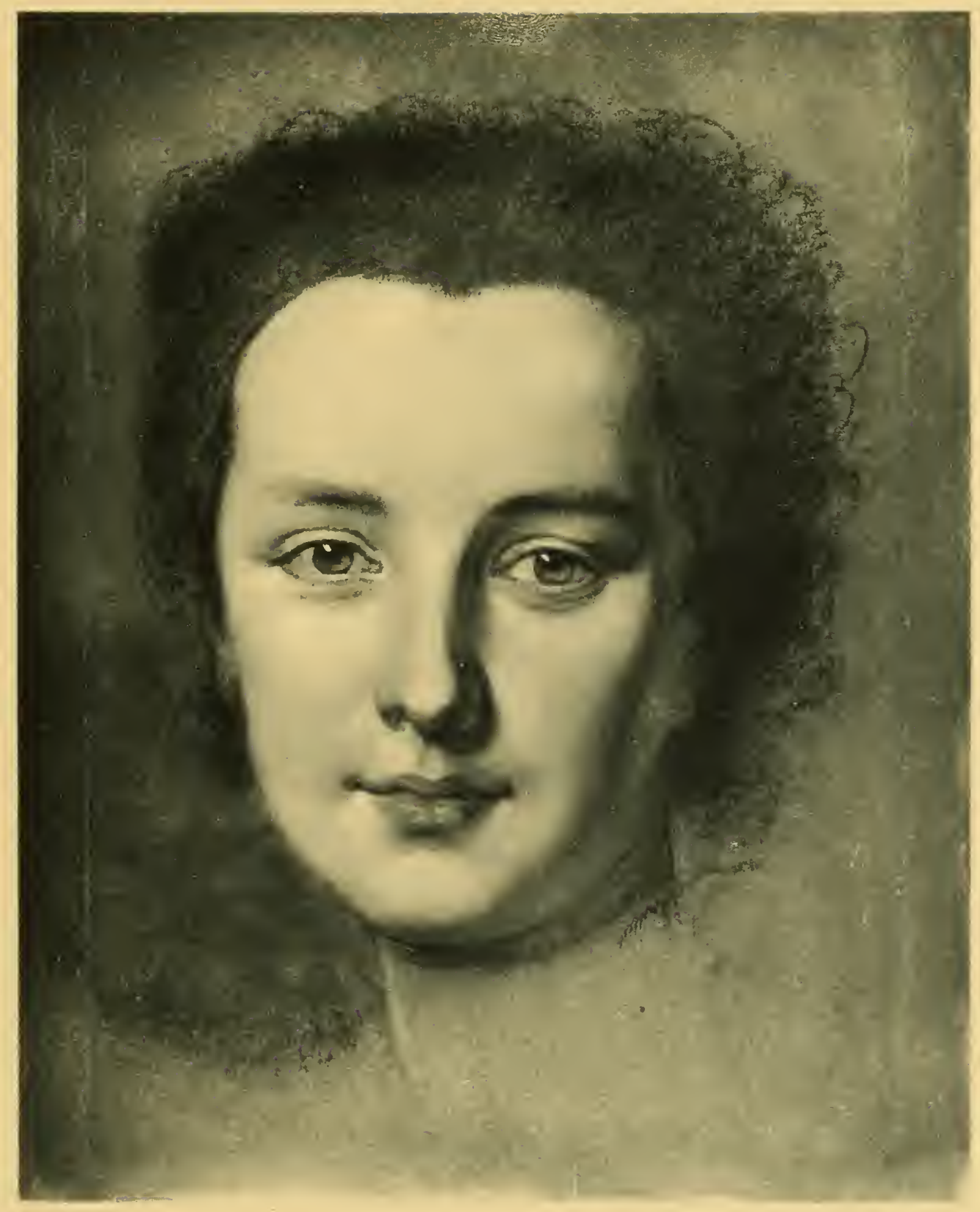

82 




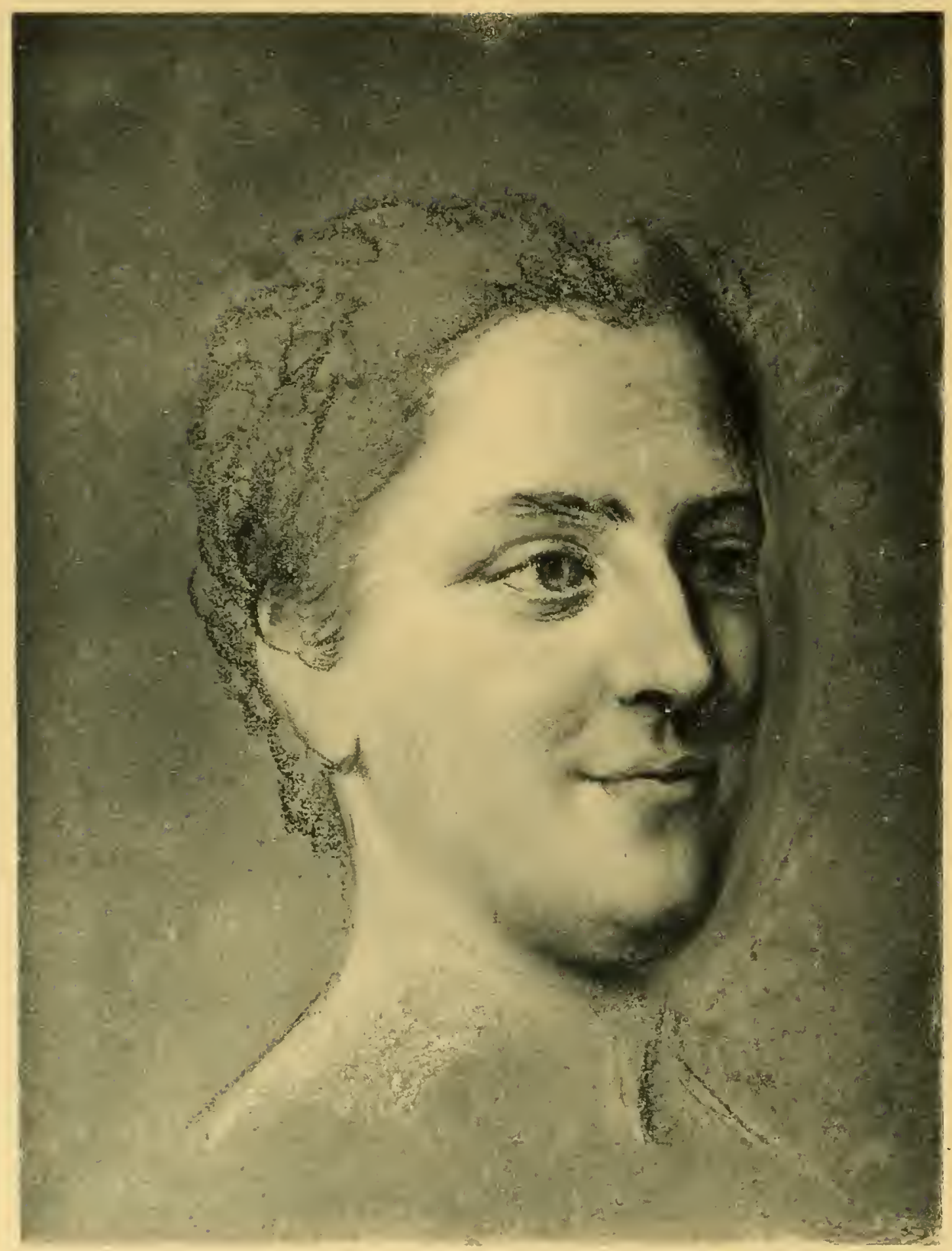

83 


\section{LA TOUR}

\section{Portrait de jeune femme. (Préparation.)}

Tête de trois-quarts et regardant à droite. Expression souriante. Cheveux relevés et ondulés, à peine indiqués. Fond gris du papier, frotté d'un peu de bleu à droite.

Pastel.

Haut., 32 cent.; larg., 24 cent.

Cadre ancien, d'époque Louis XV, en bois sculpté et doré, plat et uni, avec fronton à coquille, rinceaux et fleurettes. 


\section{LA TOUR \\ (MAURICE-QUENTIN DE) \\ 84 \\ Portrait présumé de d'Alembert. (Préparation.)}

Tête de trois-quarts et regardant à droite. Petite perruque. Cravate serrée au cou.

Pastel, papier gris.

Haut,, 28 cent.; larg., 23 cent.

Repr. dans les Arts (1904), no 36, p. 6.

Le portrait de d'Alembert, par La Tour, exposé au Salon de 1753; gravé par N.-F. Maviez, Massard, par Dagoty père (en coul.), par Hopwood, etc.; publié par A. Gasté (1 896 ), a été récemment donné au musée du Louvre par la famille de M. Danjon, professeur à la Faculté de droit de Caen. La " préparation " s'en trouve au musée de Saint-Quentin. (Cf. M. Tourneux, le Portrait a'e d'Alembert, etc., Revue de l'Art [1911 $]$, t. XXIX, p. 5 et suiv., avec les reproductions du portrait et de la "préparation $n$.)

Jean Le Rond d'Alembert, né à Paris le 16 novembre 1717 , mort le 29 octobre 1783 , s'illustra à la fois comme littérateur, philosophe et mathématicien. Membre de l'Académie des sciences (1741) et de l'Académie française (1754), il devint secrétaire perpétuel de cette dernière compagnie ( 1772 ). Avec son ami Diderot, il dirigea la publication de l'Encyclopédie (1751-1772), dont il écrivit le Discours préliminaire.

Cf. M. Tourncux, la Collection J. Doucet, etc., les Arts, op. cit., p. 16.

Cadre ancien, d'époque Louis XV, bois sculpté et doré, à fronton ornementé. 


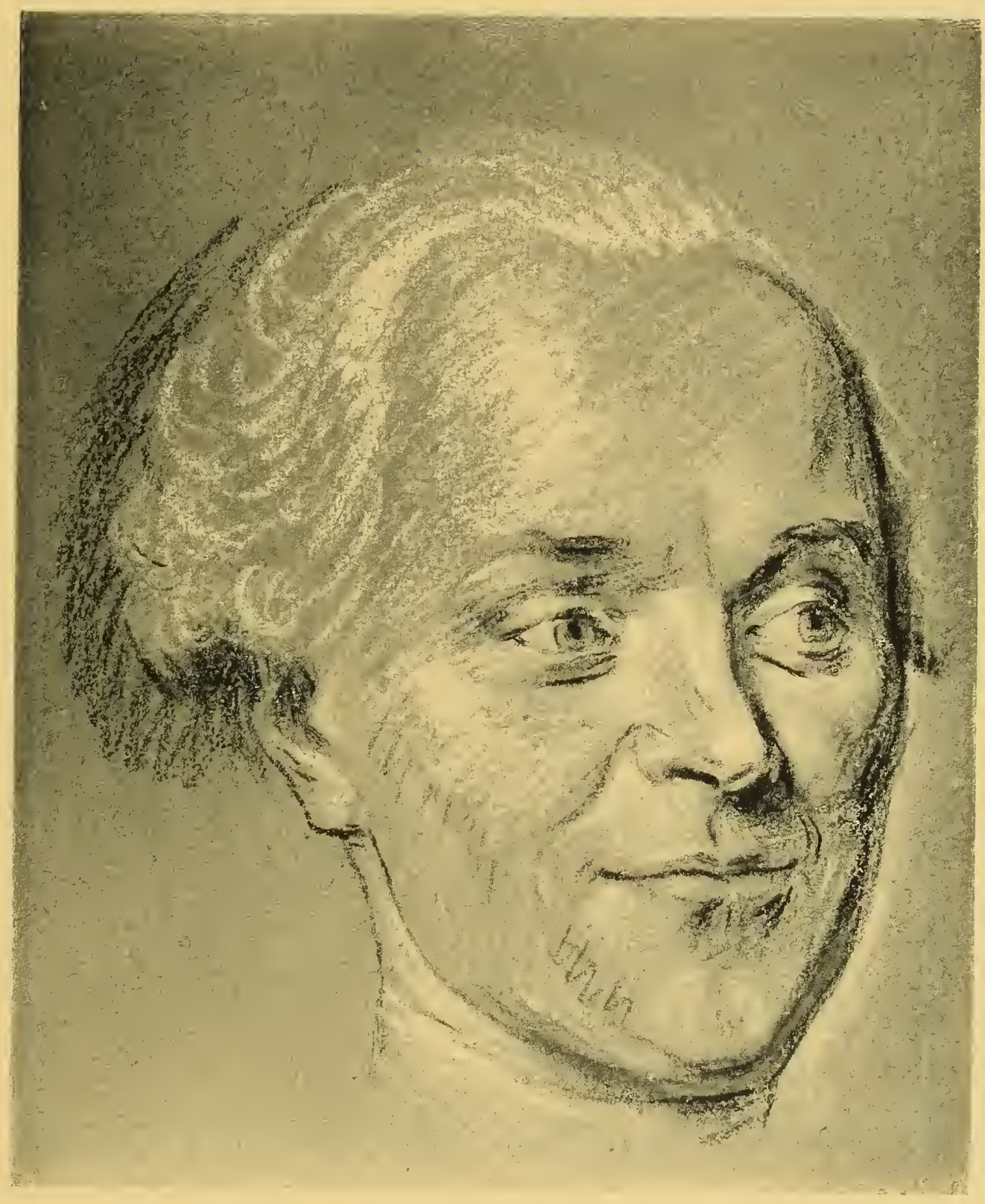

84 




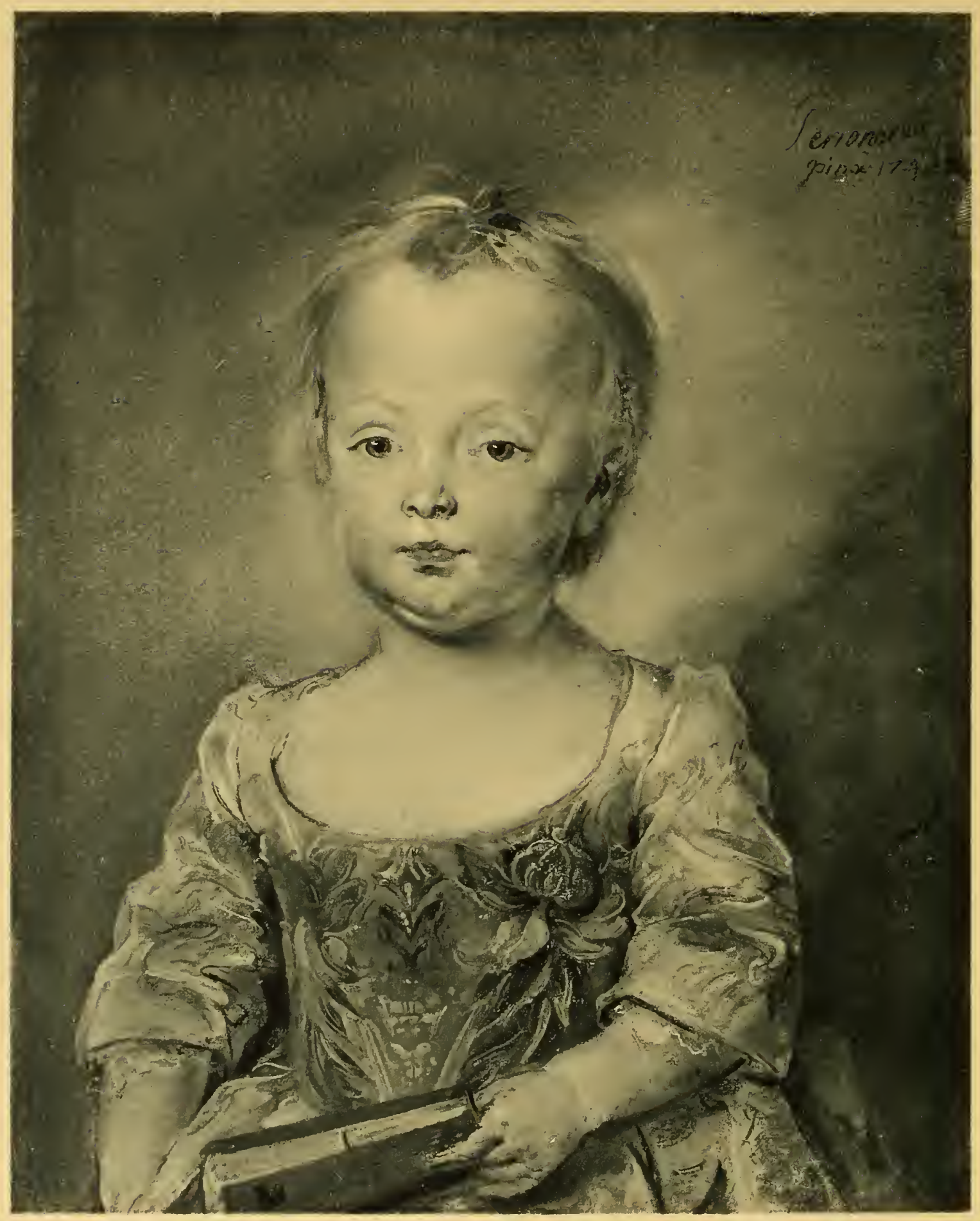




\title{
PERRONNEAU
}

\author{
(JEAN-BAPTISTE)
}

Paris, 17 I 5 - Amsterdam, 1783 .

\section{5 \\ Portrait d'enfant.}

$\mathrm{Vu}$ à mi-corps, très légèrement à gauche, les yeux bleus regardant en face, il est vêtu d'une robe à taille, décolletée et à manches courtes, de brocart blanc à broderies jaunes, bleues, roses et rouges, bordée de dentelles au corsage et aux manches. Dans la main gauche, il tient un jouet couvert en rouge. Le bras droit pend le long du corps. Fond gris bleu, ombré à droite dans la partie inférieure.

Signé en haut, à gauche : Perronneau pinx., 1744.

Pastel.

Haut., 5 I cent.; larg., 4 I cent.

Exp. de Cent Pastels (Paris 1908 ), n० 82 (indiqué par erreur comme daté de 1741).

Repr. dans les Arts (1904), n³6, p. 25; - la Revue de l'Art (1908), t. XXIV, p. 224 ; - Cent Pastels, etc., op. cit.; - L. Vaillat et P. Ratouis de Limay, J.-B. Perronneau (Paris, 1909), pl. 35; - Ch. Moreau-Vauthier, les Portraits de l'Enfant (Paris, s. d.), p. 241 .

Ce ne peut être, comme on l'a pensé un moment, le portrait du Jeune Écolier, frère de l'auteur, tenant un livre, exposé par Perronneau en 1746 ( $\mathrm{n}^{\circ}{ }_{1} 50$ ), puisque le livret annoté de ce Salon, signalé par M. J.-J. Guiffrey, indique cet ouvrage comme un tableau "en huile".

Cf. M. Tourneux, la Collection J. Doncet, etc., les Arts, op. cit., p. I6; - M. Tourneux, l'Exposition, etc., Gajette des Beaux-Arts (1908), t. 1I, p. 9; - L. de Fourcaud, le Pastel, etc., Revue de l'Art (1908), t. XXIV, pp. 229 et 292 ; - Cent Pastels, etc., op. cit., p. 68 ;-Bulletin de la Société de l'Art français (เgog), p. 59 ; - L. Vaillat et P. Ratouis de Limay, Perronneau, etc., op. cit., pp. 7, 8, 9, 85 et 142 , cat. $\mathrm{n}^{\circ} 3$; - Ch. Moreau-Vauthier, les Portraits de l'Enfant, etc., op. cit., p. 240.

Cadre ancien, d'époque Louis XVI, en bois sculpté et doré, avec nœud de ruban, formant fronton, guirlandes et chutes de fleurs et de rubans. 


\title{
PERRON NEA U
}

\author{
(JEAN-BAFTISTE)
}

\section{6 \\ Le Comte de Bastard.}

En buste, la tête levée, de trois quarts et regardant à gauche, il porte la haute perruque dite "de procureur », à larges boucles tombant sur les épaules. Il est vêtu d'un habit de velours gris noirâtre, sur un gilet gris foncé, qui s'ouvre sur un jabot de dentelles. Le cou est serré dans une cravate de linon blanc. Sous le bras gauche, on aperçoit une pointe du tricorne noir.

Signé, au-dessus de l'épaule gauche : Perronneau pinx. $110^{\text {bre }}{ }_{1747}$.

Pastel.

$$
\text { Haut., } 67 \text { cent.; larg., } 56 \text { cent. }
$$

Collection John W. Wilson (vente à Paris, $1881, \mathrm{n}^{\circ} 20$ ).

Exp. des Alsaciens-Lorrains (Paris, 1874$), n^{\circ} 964 ;-$ Exp. des Pastellistes français (Paris, 1885 ), $\mathrm{n}^{\circ} 72 ;-$ Exp. de Cent Pastels (Paris, 1908 ), no 79.

Gravé par Achille I. Gilbert (la gravure dans la Collection de M. John W. Wilson, exposée, etc. [Paris, 1873], p. 53; et dans le Catalogue des tableaux, etc., composant la galerie de M. John W. Wilson [Paris, 188 r], p. 22).

Repr. dans les Arts (1904), no 36, p. 17; - la Gazette des Beaux-Arts (1908), t. II, p. 1 ; ; - la Revue de l'art (1908), t. XXIV, p. 227 ; - Cent Pastels, etc., op. cit.; - L. Vaillat et P. Ratouis de Limay, J.-B. Perronneau, etc., op. cit., pl. 73.

Selon MM. L. Vaillat et P. Ratouis de Limay, ce serait probablement Dominique de Bastard, jurisconsulte français, né à Toulouse en 1683 , mort en 1777 . Doyen du Parlement de Toulouse, il devint membre du conseil du roi (1774).

Cf. J. Sermure, Exposition des Pastellistes français, dans l'Art (1885), L. Ior, p. 160; - M. Tourneux, J.-B. Perronneau (Paris, s. d.; tir. à part de Ia Gazette des Beaux-Arts, 1896), p. I5; - M. Tourneux, la Collection J. Doucet, etc., les Arts, op. cit., p. 16;-M. Tourneux, l'Exposition, etc., Gazette des Beaux-Arts (1908), t. II, p. 11; - L. de Fourcaud, le Pastel, etc., Revue de l'art (1908), t. XXIV, pp. 23o, 283, 284 et 292; - Cent Pastels, etc., op. cit., p. 65; - L. Vaillat et P. Ratouis de Limay, Perronteau, etc., op. cit., pp. 12,87 et 142 , cat. $\mathrm{n}^{\circ} 14$.

Cadre ancien, d'époque Régence, en bois sculpté et doré, à coquilles, rinceaux et fleurettes. 


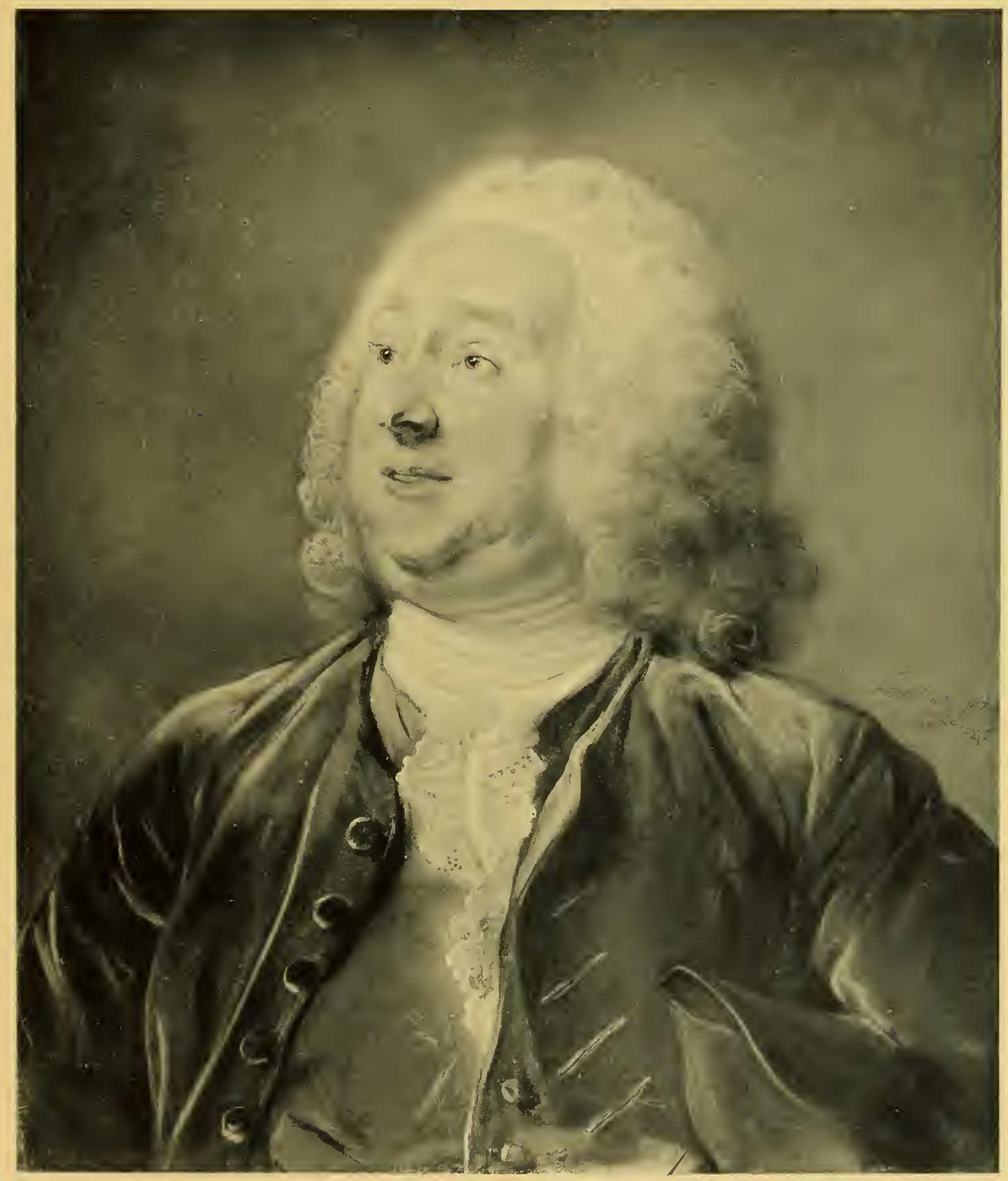






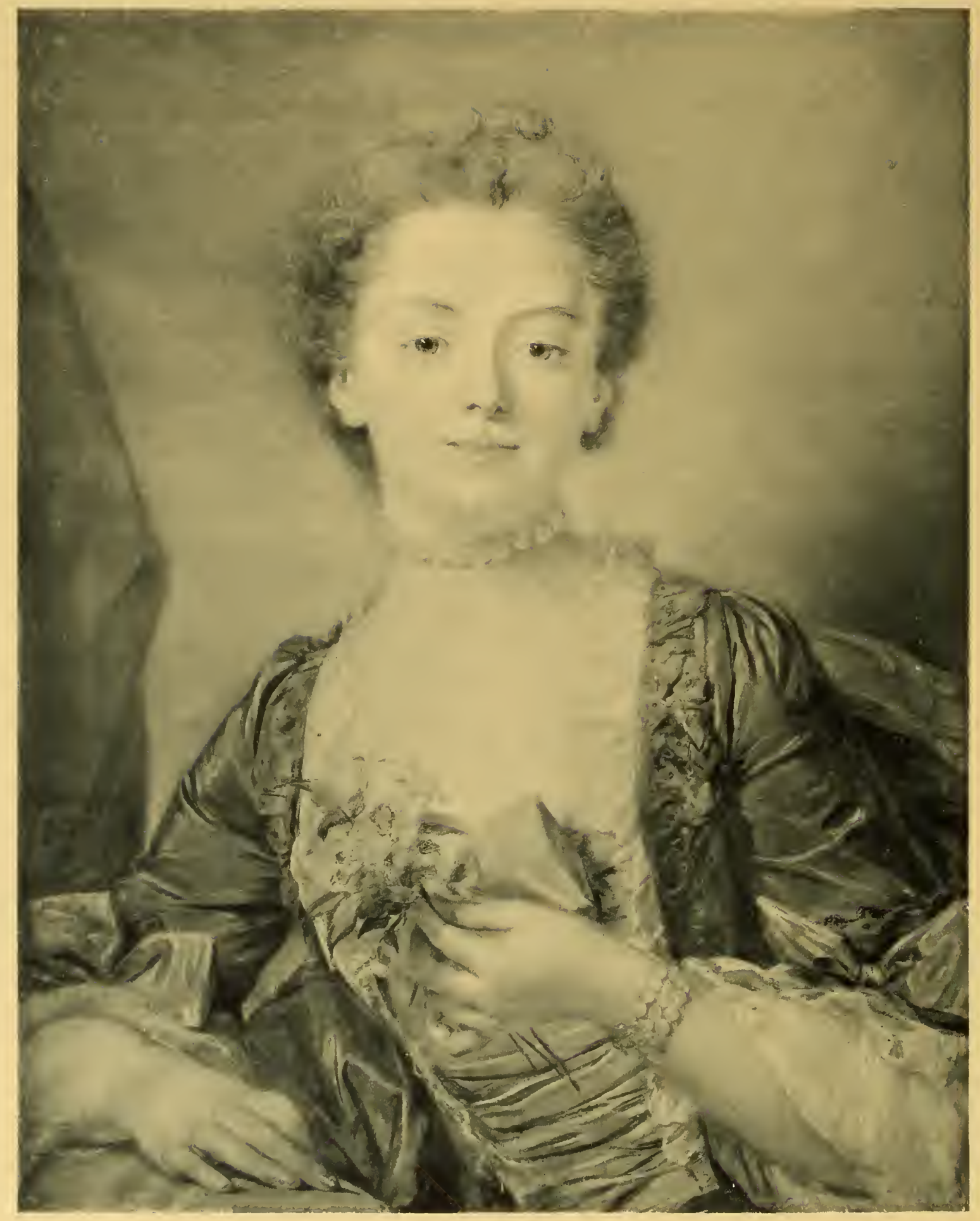

87 


\section{PERRONNEAU}

(JEAN-BAP'TISTE) \\ 87 \\ Portrait d'une jeune femme tenant un bouquet.}

Assise et vue à mi-corps, un peu penchée vers la gauche, elle tourne vers la droite sa tête coiffée de cheveux bruns, légèrement poudrés, et regarde en face. Le cou est orné d'un rang de perles. La robe décolletée, d'un gris-bleu, et les manches courtes sont bordées de fine batiste blanche plissée. Le corsage et les rubans sont bleus. De la main gauche, qu'elle ramène vers la poitrine, la jeune femme tient un petit bouquet de "barbeaux " ou bleuets. La main droite est posée à plat sur une table. Un bracelet de trois rangs de perles serre le poignet gauche. Fond gris clair, avec, à gauche, une draperie rouge.

Signé à gauche, au-dessus du bras droit : Perroneau, 1749.

Pastel.

Haut., 60 cent.; larg., 47 cent.

Salon de I750: " 134 . Madame ${ }^{\star \star \star}$, ayant un bouquet de barbeau "; - Exp. de Cent Pastels (Paris, 1908), n०8 $\mathrm{r}$.

Repr. dans les Maîtres du dessin (I901), 3e année ; - les Arts (I904), nº 36, p. 23 ; - la Revue de l'Art(1908), t. XXIV, p.231; - Cent Pastels, etc., op. cit.; - L. Vaillat et P. Ratouis de Limay, Perronneau, etc., op. cit., pl. 79.

Cf. M. Tourneux, Perronneau, etc., op. cit., p. I7; - M. Tourneux, la Collection J. Doucet, etc., les Arts, op. cit., p. I8; - M. Tourneux, l'Exposition, etc., Gazette des Beaux-Arts (19o8), t. II, p. 12 ; - L. de Fourcaud, le Pastel, etc., Revue de l'Art (1908), t. XXIV, p. 280 ; - P.-A. Lemoisne, Exposition, etc., les Arts ( 1908$), \mathrm{n}^{\circ} 82$, p. $30 ;-$ Cent Pastels, etc., op. cit., p. $67 ;-\mathrm{L}$. Vaillat et P. Ratouis de Limay, Perronneau, etc., op. cit., pp. 16, 91, 120 et 142 , cat. $\mathrm{n}^{\circ} 38$.

Cadre ancien, d'époque Louis XV, en bois sculpté et doré, de forme mouvementée, à coquilles, torsades et guirlandes de fleurs. 


\section{PERRONNEAU}

(JEAN-BAPTISTE)

\section{8}

\section{Jacques-Charles Dutillieu.}

En buste, il est aperçu dans un ovale formant lucarne. Portant la petite perruque poudrée, nouée par un ruban noir, il est vêtu d'un habit de velours rouge-orangé, sur un gilet de même couleur. A la cravate de linon blanc, serrant le cou, s'attache un jabot de dentelles. Sous le bras gauche on aperçoit la pointe du tricorne. Fond gris bleu.

Signé, près de l'épaule gauche : Perronneau.

Pastel.

Haut., 72 cent.; larg., 60 cent.

Par le Livre de raison de J.-C. Dutillieu, nous savons que ce portrait a été exécuté à Lyon en 1759 .

Ancienne collection Willemoy.

Exp. de Cent Pastels (Paris, 1908), n* 8o, Portrait de M. Dutilleul.

Repr. dans le Livre de raison de Jacques-Charles Dutillieu, publié et annoté par M. F. Bréghot du Lut (Lyon, 1886); - M. Tourneux, Perronneau, etc., op. cit., p. 32; - les Arts (1904), no 36, p. 21 ; - Cent Pastels, etc, op. cit, ; - L. Vaillat et P. Ratouis de Limay, Perronneau, etc., op. cit., pl. 69 .

Le portrait de Benoite Jacquin, femme de J.-C. Dutillieu, qui fait pendant à celui-ci (cat. Vaillat, $\left.\mathrm{n}^{0} 76\right)$, appartient à la collection de M. Léon Michel-Lévy. 11 a figuré à l'exposition de Cent Pastels (no 88) et est reproduit dans le livre de M. M. Tourneux sur Pcrronneau (p. 32), dans Cent Pastels, et dans le Perronneau de MM. Vaillat et P. Ratouis de Limay (pl. 6o).

Jacques-Charles Dutillieu, né à Paris en 1718 , mort à Lyon en $\mathbf{r}^{782}$, arait débuté par être peintre de fleurs. Ses envois à l'exposition de la place Dauphine lui avaient valu les encouragements d'Oudry. Il travailla mème pour la Cour ei pour la duchesse de Mazarin. Mais à la suite de la guerre de la Succession d'Autriche, ne trouvant plus à exercer son talent, il partit pour Lyon où il s'établit fabricant de soieries.

Cf. M. Tourneux, Perronneau, etc., op.cit.,pp. 3 I et 32 ; - Lady Dilke, French painters, etc., op. cit., pp. 164 (indiqué par erreur comme de La Tour) et 169 ; - M. Tourneux, la Collection J. Doucet, etc. les Arts, op. cit., p. 18 ; - M. Tourneux, l'Exposition, etc., Gazette des Beaux-Arts (1908), t. II, p. 12 ; - L. de Fourcaud, le Pastel, etc., Revue de l'Art (1908), t. XXIV, pp. 284, 287 et 292; - Cent Pastels, elc., op. cit., p. 66; - L. Vaillat et P. Ratouis de Limay, Perronneau, etc., op. cit., pp. 33, 97 et 142 , cat. $\mathrm{n}^{\circ} 75$.

Cadre ancien d'époque Louis XV, en bois sculpté et doré, à baguettes, avec coquilles et ornements dans les coins. 


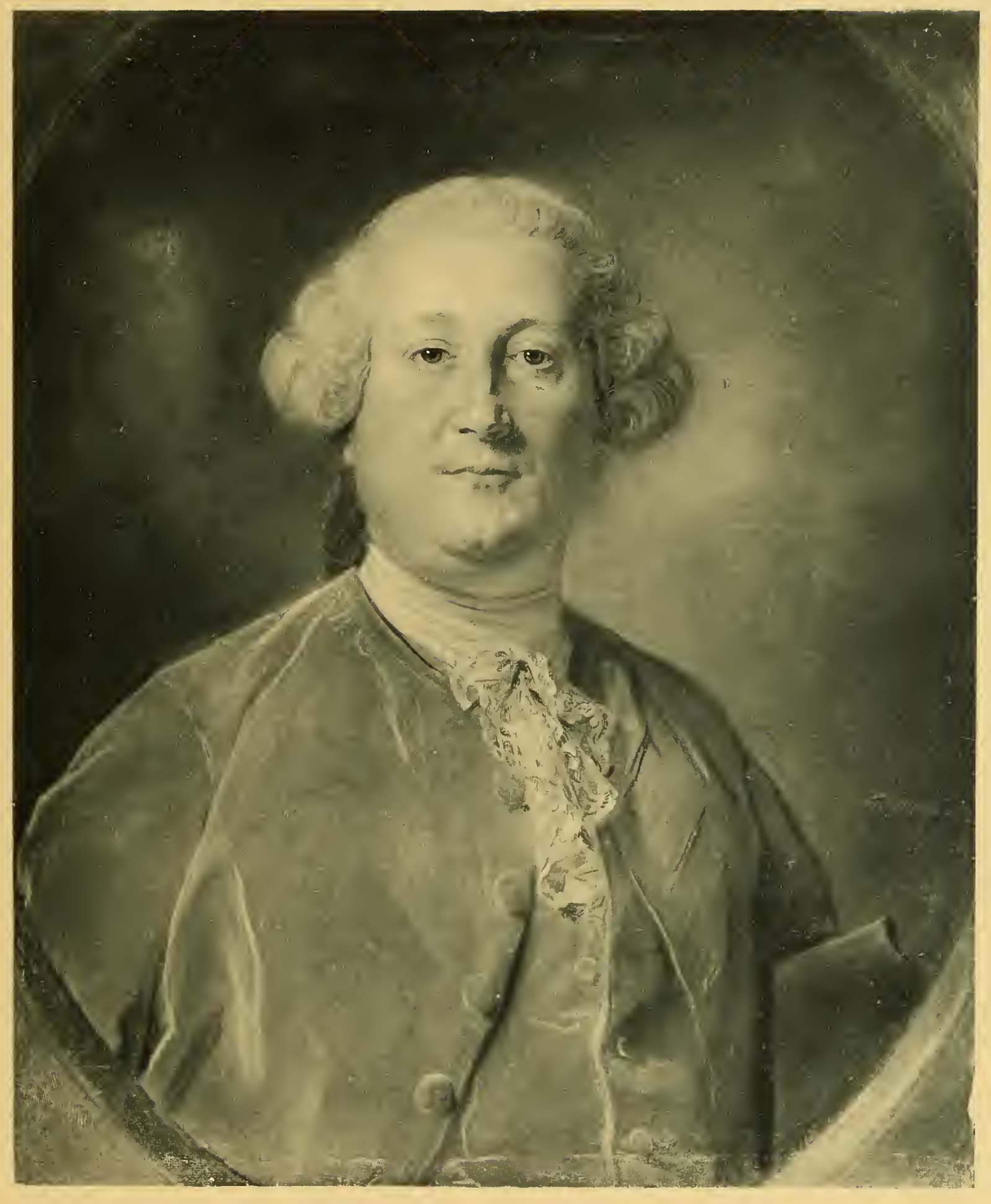






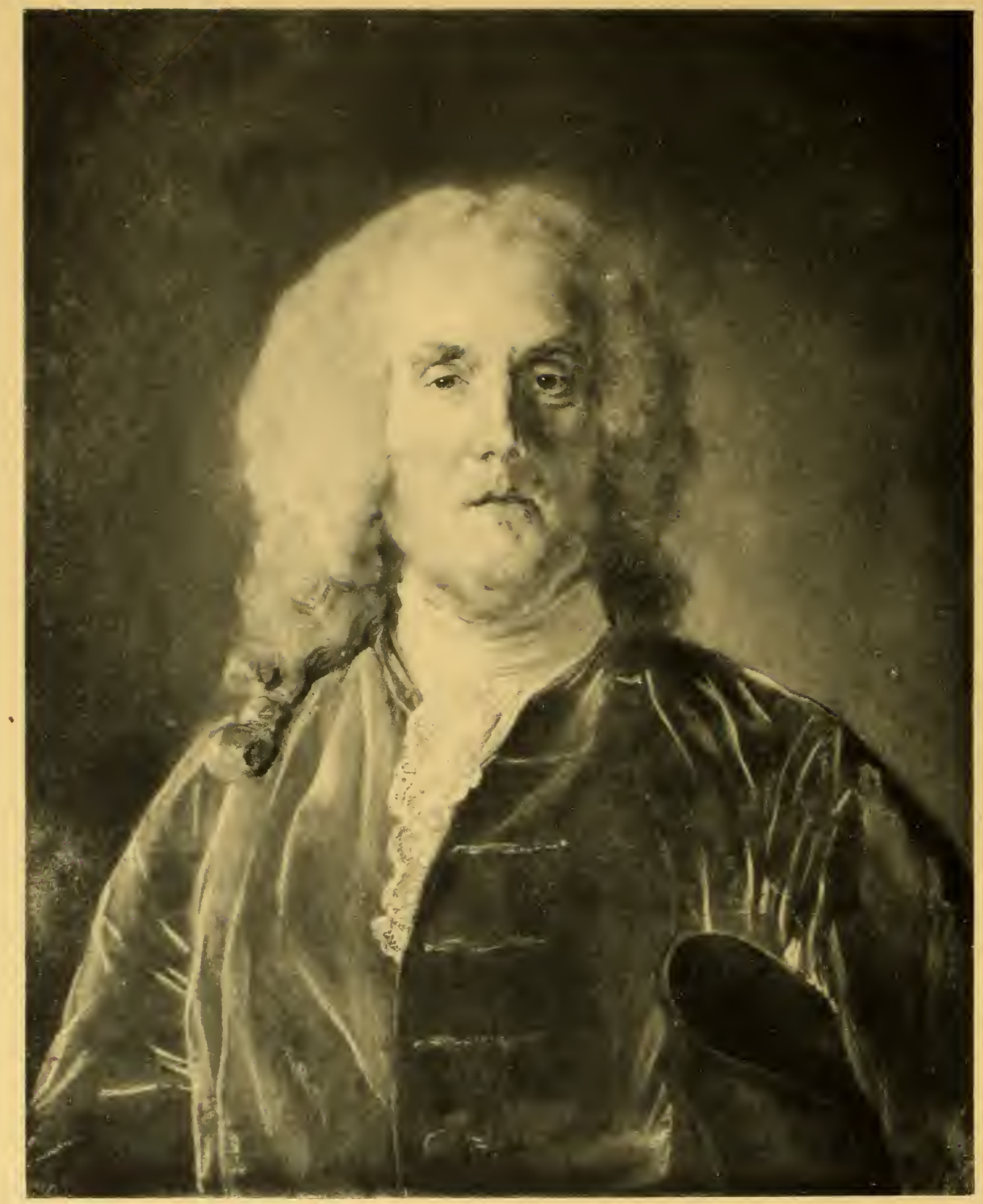

89 


\title{
PERRON NEAU
}

\author{
(JEAN-BAPTISTE)
}

\section{$8 \div 000$ \\ luife du nowve}

\section{9 \\ Abraham van Robais.}

En buste et vu de face, la longue perruque poudrée tombant sur les épaules, il est vêtu d'un habit de velours rouge. A la cravate_de linon blanc est attaché un jabot de dentelles. Sous le bras gauche, on aperçoit la pointe du tricorne. Fond gris jaunâtre.

Signé, en haut, à droite : Perronneau.

Pastel.

Haut., 73 cent.; larg., 59 cent.

Provient des environs de Montauban, de la famille Camp, alliée à Samuel van Robais, petit-fils d'Abraham van Robais.

Vraisemblablement le $n^{\circ} 62$ du Salon de 1773 : “M.V.R...", dont les dimensions, 27 pouces sur 22, concordent parfaitement avec celles du présent portrait.

Exp. de Cent Pastels (Paris, 1908), n० 78, Portrait de M. Van Rubai.

Repr. dans Lady Dilke, French painters, etc., op. cit., p. 168 (sous la désignation erronée de M. le Mas du Purssac); - les Arts (1904), $\mathrm{n}^{\circ}$ 36, p. 19 (même désignation); - la Revue de l'Art (1908), t. XXIV, p. 289 ; - Cent Pastels, etc., op. cit.; L. Vaillat et P. Ratouis de Limay, Perronneau, etc., op. cit., pl. 32.

Dans une lettre adressée d'Abbeville, le 2 janvier 1770 , à l'amateur orléanais Desfriches, Perronneau écrit : "J'ai profité de l'automne pour venir chez Monsieur Théophile Vanrobesse à Abbeville, faire le portrait de leur perre..... " Sur la demande du modèle, l'artiste en exécuta deux répliques, à peu près dans les mêmes dimensions (cat. Vaillat, $\mathrm{n}^{\text {os }}$ I 15 et I 16 ; coll. de Mme X... [Groult] et Henry Michel-Lévy).

Abraham van Robais, né le 25 mai 1698 , mort le 31 mai 1779 , cinquième fils d'Isaac van Robais, était fabricant de draps à Abbeville.

Cf. M. Tourneux, Perronneau, ctc., op. cit., p. 46; - Lady Dilke, French painters, etc., op. cit., p. 173; - M. Tourneux, la Collection J. Doucet, etc., les Arts, op. cit., p. 18 ; - M. Tourneux, l'Exposition, etc., Gazette des Beaux-Arts (1908), t. II, p. I2 ; - L. de Fourcaud, le Pastel, etc., Revue de l'Art (1908), t. XXIV, pp. 284, 288, 289 et 292 ; - Cent Pastels, etc., op. cit., p. 64; Bulletin de la Société de l'Art francais (1909), p. 58 ; - L. Vaillat et P. Ratouis de Limay, Perronneau, etc., op. cit., pp. 45, 102 et 142, cat. n० I 44 .

Cadre ancien, d'époque Régence, en bois sculpté et doré, à coquilles et ornements dans les coins. 


\section{PERRONNEAU}

(JEAN-BAPTISTE)

\section{0 \\ Portrait de femme.}

En buste, la tête de trois-quarts à gauche, elle regarde en face avec une expression souriante. Sur les cheveux bruns, légèrement poudrés, où sont piquées quelques fleurettes, est posé un fichu bleu dont une pointe retombe sur l'épaule droite. Au côté droit du corsage décolleté, de gaze transparente, s'attache une draperie bleue dont on voit flotter l'extrémité derrière l'épaule gauche.

Pastel.

Haut., 6 I cent.; larg., 49 cent.

Cadre ancien, d'époque Louis XV, en bois sculpté et doré, avec fronton ornementé. 


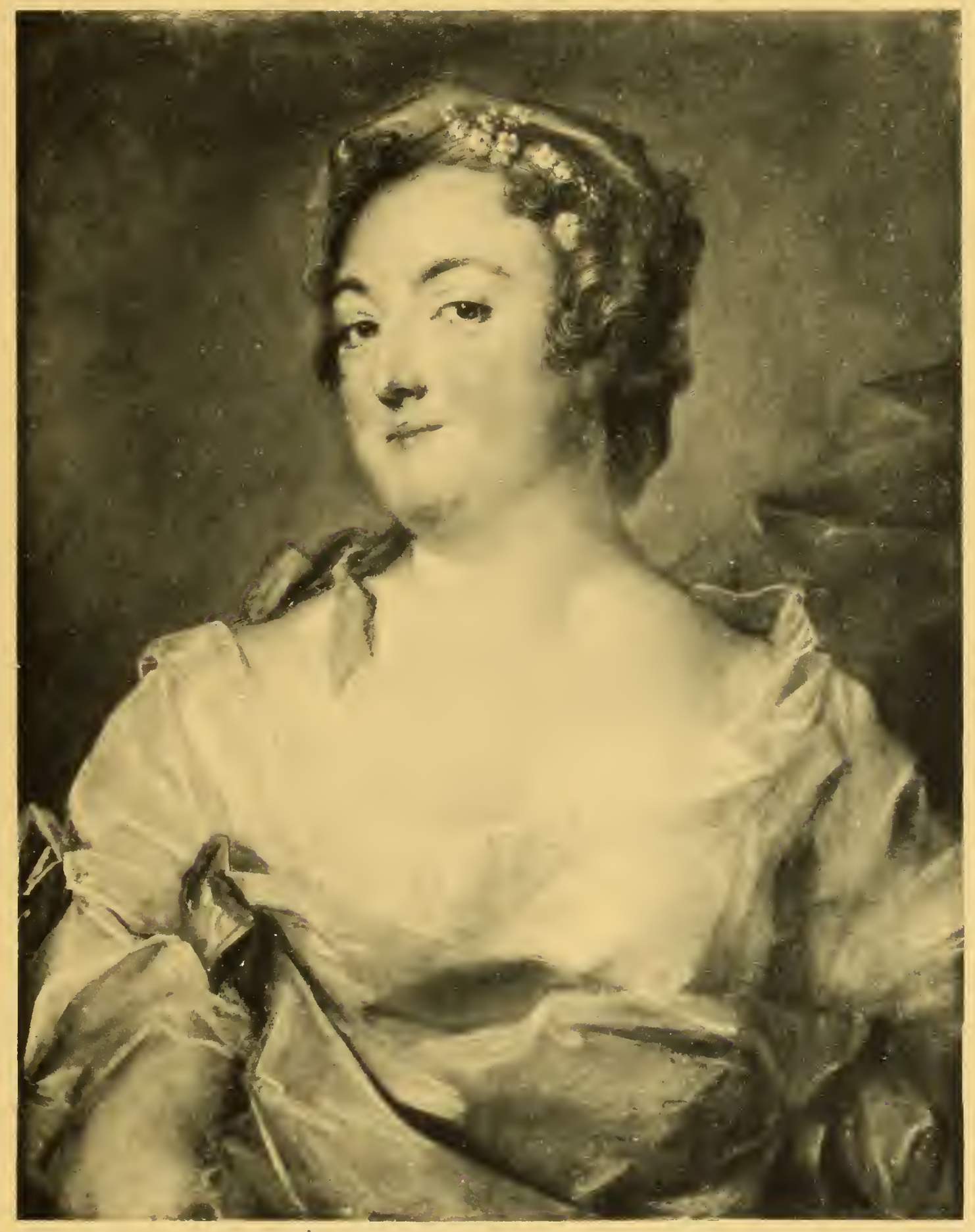






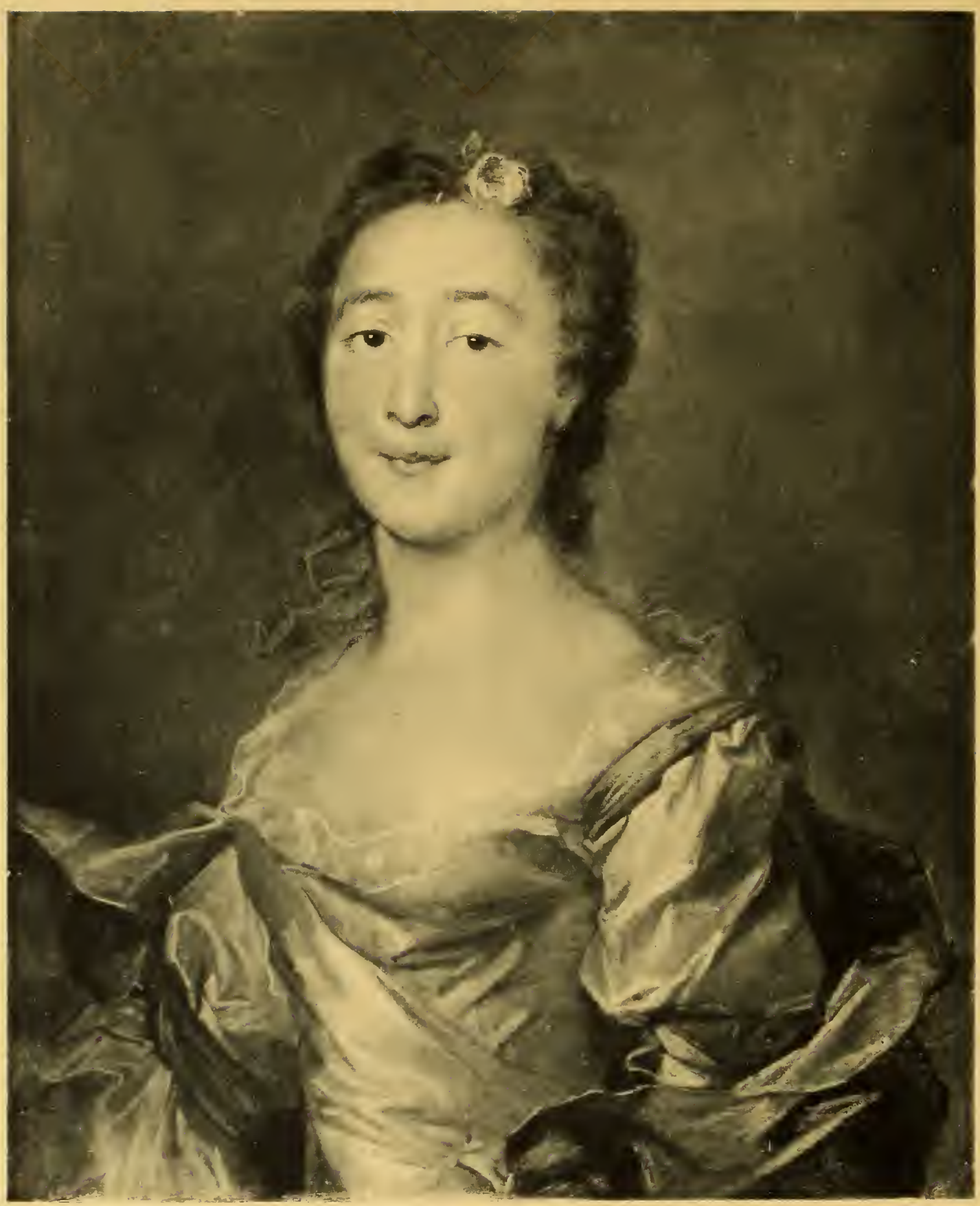

91 


\section{ÉCOLE FRANÇAISE \\ XVIII SIÈCLE \\ 91 \\ Portrait de femme.}

En buste, de trois-quarts à gauche, presque de face, les yeux fixés sur le spectateur, une rose piquée dans ses cheveux bruns, elle est vêtue d'une robe décolletée à fond jaune, avec manches garnies de rubans bleus. Une écharpe, passant derrière le dos, retombe sur les bras.

Pastel.

Haut., 73 cent.; larg., 63 cent.

Cadre ancien, d'époque Louis XV, en bois sculpté et doré, à baguettes, avec coquilles d'angles et un ornement formant fronton. 



